Bisserka Gaydarska, Marco Nebbia, John Chapman, Edward Caswell, Sophia Arbeiter, Eduard Ovchinnikov, Dmytro Gaskevych, Cătălin Lazăr, Theodor Ignat, Adrian Boyce, Amanda Dolan, Jason Newton, Dmytro Kiosak, Mykola Belenko, Oliver E. Craig, Harry K. Robson, Matthew von Tersch, Alexandre Lucquin, Zsuzsanna Tóth, Alice Choyke, David Orton, James Nottingham, Giselle Rainsford-Betts, Kim Hosking, Andrew Millard \& Galyna Pashkevych

\title{
5 The Finds
}

In this chapter, we present comparative analyses of artifacts and ecofacts from most of the Project excavations at Nebelivka (House A9, the Mega-structure, the Pit in Sondazh 1 and the test pits). The finds from the Ukrainian excavations of Houses B17 and B18, the 'industrial feature' and their respective pits are published elsewhere. All classes of finds were subject to the same taphonomic protocols before comparative analysis between the excavation units at Nebelivka and comparisons with other Trypillia sites and megasites. A team of pottery specialists considered alternatives to the Ryzhov pottery system, using the sherd rather than the whole vessel as the unit for 14 different comparative analyses. Dmytro Kiosak examined the small lithic assemblage, identifying a major decrease in lithic deposition after the large Early Trypillia samples. The special finds analysis considered the sample of almost 100 figurines, fired clay tokens and the only gold ornament known so far from the Trypillia group. David Orton and colleagues have written the first modern faunal report of a Trypillia assemblage, paying attention to inter-analyst variability and contextual variability. The small botanical assemblage, discussed by Galyna Pashkevych, was the result of the first water-sieving operation conducted on a Trypillia excavation and confirmed her views, counterfactual for megasites, on Trypillia arable farming as low in production and efficiency.

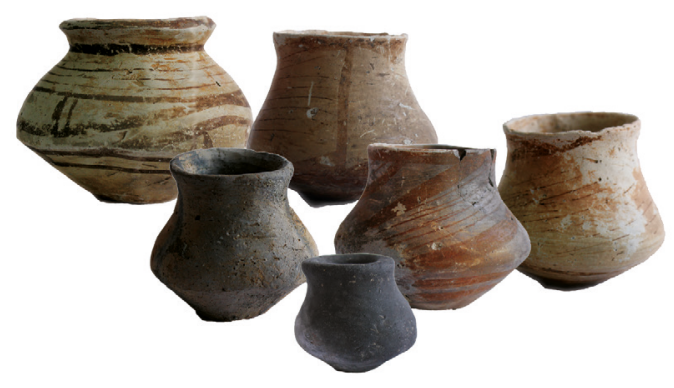




\section{Edward Caswell, Sophia Arbeiter, Eduard Ovchinnikov, Bisserka Gaydarska, Marco Nebbia \& John Chapman}

\subsection{Pottery}

\subsubsection{Introduction}

Pottery constitutes one of the three important classes of material finds in the Trypillia 'Big Other'. Cucuteni-Trypillia decorated pottery comprised both fine wares (painted in the Western part; incised in the East) and coarse wares (mostly incised and/ or impressed) (Tsvek 1996; Tsvek \& Rassamakin 2005). The shapes and decorative motifs of painted wares have been used to classify and date Trypillia phases, subphases and regional groups in a complex, interlocking typological scheme (Ryzhov 1993, 2012, 2012a). Pottery dominated the 'grave goods' (Chapman 2015) deposited in house-burning ceremonies, where the painted wares could easily be imagined as a prestige good in their own right. It could then be argued that the way that several households contributed pottery or, more frequently, decorated sherds to a houseburning ceremony was a kind of potlatch, in which fragments and whole vessels were placed in the house before burning and/or placed on top of the burnt mass of daub after the fire had died down.

The pottery component of the Cucuteni-Trypillia Big Other was indeed both generic and ambiguous - offering the potential for varied renderings of ceramic forms (Ryzhov 2012), while simultaneously providing the chance for varied readings of these forms (Tkachuk 2005). Part of their success was the combination of the individual and dividual identities that vessels embodied. A vessel was conjointly an individual object with specific meanings and a dividual part of a class of entities, its meaning negotiated in relation to the wider whole. Another key element of the Big Other was its reliance on ancestral values, materialized in long-term pottery traditions. Such ancestral values were nested in a communitarian manner, emphasizing the settlement over the Neighbourhood, the Neighbourhood over the household and the household over the person. Within such general parameters, we can begin to consider the pottery excavated at Nebelivka and its place in megasite pottery studies and the wider cultural context of Trypillia ceramic traditions.

\subsubsection{Sampling and Comparative Method}

The Project has developed three underlying premises for our pottery studies: (1) a pottery assemblage cannot be understood without first developing a model of pottery deposition for the context in question; (2) although the form and decoration of ceramics changed through time, time was NOT the reason for these changes - there were social, functional, technological and ritual reasons for such changes, which happened in a temporal setting which was itself initially neutral to change but on 
which people could draw for their own reasons; and (3) the best way of exploring these changes is the comparative method, using different classes of deposit to highlight differences. Here, we compare three assemblages from different Excavation Units - the largest Assembly House on the megasite (the 'Mega-structure'), a normal dwelling house (House A9) and the Sondazh 1 pit, as well as pottery from the test pits excavated into over 80 dwelling houses and Assembly Houses (for excavation reports, see sections in Chapter 4).

The Project has made a serious attempt to utilize the pottery typo-chronological system commonly in use in Trypillia site reports, as created by Sergei Ryzhov (1993, 2012).

An attempt at correlation of the different systems is made below (Table 5.1).

Table 5.1: Correlation of the numbered shape types used in the Ryzhov/Ovchinnikov and Nebelivka systems (see Fig. 5.1) (by B. Gaydarska).

\begin{tabular}{lll}
\hline $\begin{array}{l}\text { TYPES USED IN RYZHOV/ } \\
\text { OVCHINNIKOV SYSTEMS }\end{array}$ & $\begin{array}{l}\text { SUB-TYPES OF } \\
\text { OVCHINNIKOV SYSTEM }\end{array}$ & NEBELIVKA TYPES \\
\hline Miski & $\begin{array}{l}\text { Zrizano-konichni (1) } \\
\text { Napivsferichni (2) }\end{array}$ & $\begin{array}{l}\text { Everted-rim dish/plate } \\
\text { Rounded dish }\end{array}$ \\
& Zakriti (4) & Hole-mouth jar \\
Posudini Sferokonichni (5) & & Amphora \\
Posudini Bikonichni (6) & & Amphora \\
Gorshtiki (7) & & Necked bowl \\
Krateri (8) & & $\begin{array}{l}\text { Everted-rim dish/flaring-rim dish/ } \\
\text { necked dish }\end{array}$ \\
Kubki & Fali (9) & Flask/necked bowl/small amphora \\
Kubkopodibni (11) & One-handled amphora \\
Amfori (12) & & Amphora or storage-jar \\
Grushopodibni (13) & & Necked flask/amphora \\
Pokrishki (14) & & Hole-mouth jar (piriform) \\
Unikalni (15) & & Lid \\
Miniaturni (16) & & Rare types (high-handled dish/lugged \\
Binoklepodibni (17) & & $\begin{array}{l}\text { Mish/footed vessel) } \\
\text { Miniature vessels }\end{array}$ \\
\hline
\end{tabular}


Before further analysis, we should confront the problems of comparing the Ryzhov and Ovchinnikov systems (Ovchinnikov 2014), based upon whole vessels, with that used at Nebelivka, based upon the sherd as the unit of analysis. The weakness of the inclusive Nebelivka system is the presence of many necked forms and bases unattributable to any specific type. The solution has been to categorise rims into 'fine-necked', 'medium-necked' and 'thick-necked' and bases into 'fine bases', 'medium bases' and 'thick bases'. The Ryzhov/Ovchinnikov systems share four weaknesses: an over-reliance on amphorae types; a lack of differentiation of the 'kubka' type; a failure to distinguish 'dishes' from 'plates' in the 'miska' type; and a neglect of bowls (found in two types - 'miski' and 'gorshtiki'). Whatever the respective merits of the different systems, this makes it hard to compare the results of the Nebelivka typology with Ryzhov- or Ovchinnikov-based analyses from other sites.

The Ukrainian pottery specialist, Dr. Eduard Ovchinnikov, worked with us in the Nebelevka project and analyzed the assemblage from House A9 and the Megastructure (Ovchinnikov 2012, 2015). His approach is an alternative to Ryzhov's system, in which an initial division into fine painted wares, coarse wares and burnished wares formed the basis for a further sub-division into fabrics, based upon colour and temper (e.g., Ovchinnikov 2014). The next stage was the comparison of vessel shapes and decoration with wares and fabrics; the clearest shape typology is found in Ovchinnikov's study of the Kaniv group (Ovchinnikov 2014, p. 80 \& Rozdil 3 - here, Fig. 5.1). These stages fit well with the system used by the Project, based upon the Mont Beuvray system.

The 'Mont Beuvray system' is the product of decades of pottery research, leading to a standardized and highly effective system for recording pottery at the Late Iron Age defended urban complex of Mont Beuvray, Central France (Paunier et al. 1994; Barral \& Luginbühl 1995). The basis is a chronological system of shape types, each of which has been dated with reference to previous excavation contexts. The Fabric series and the decoration types are overlain on the dated vessel shapes. Since the starting-point of the Mont Beuvray system - dated shape types - was missing from Trypillia pottery research, we had to omit this stage for the Nebelivka assemblage, instead using the fabric types based upon colour as the framework for analysis.

In transposing this system to the Trypillia context, three key assumptions were made: (a) the basic unit of analysis is the sherd, with each sherd - no matter how small - having a 'voice'; (b) the ideal recording method is the 3-dimensional recording of each sherd on a GIS platform, although this was possible only for the Mega-structure; and (c) the same level of detail is recorded for each sherd. The basic variables recorded included Weight, Pot part, Fabric, Surface Colour (exterior and interior), Temper, Decorative Style and Motif(s), Wear traces and Burning. For rim and base sherds, the rim diameter and the proportion of rim surviving is recorded and the profile was drawn. Photographs were made of a high proportion of decorated sherds and significant undecorated sherds. This rigorous data collection stage required 
much training and post-excavation time, amounting to 250 person-days. The corpus of Nebelivka profile reconstructions and decorated pottery photographs is available in the Project Archive (DOI: https://doi.org/10.5284/1047599 Section 5 by excavation unit).
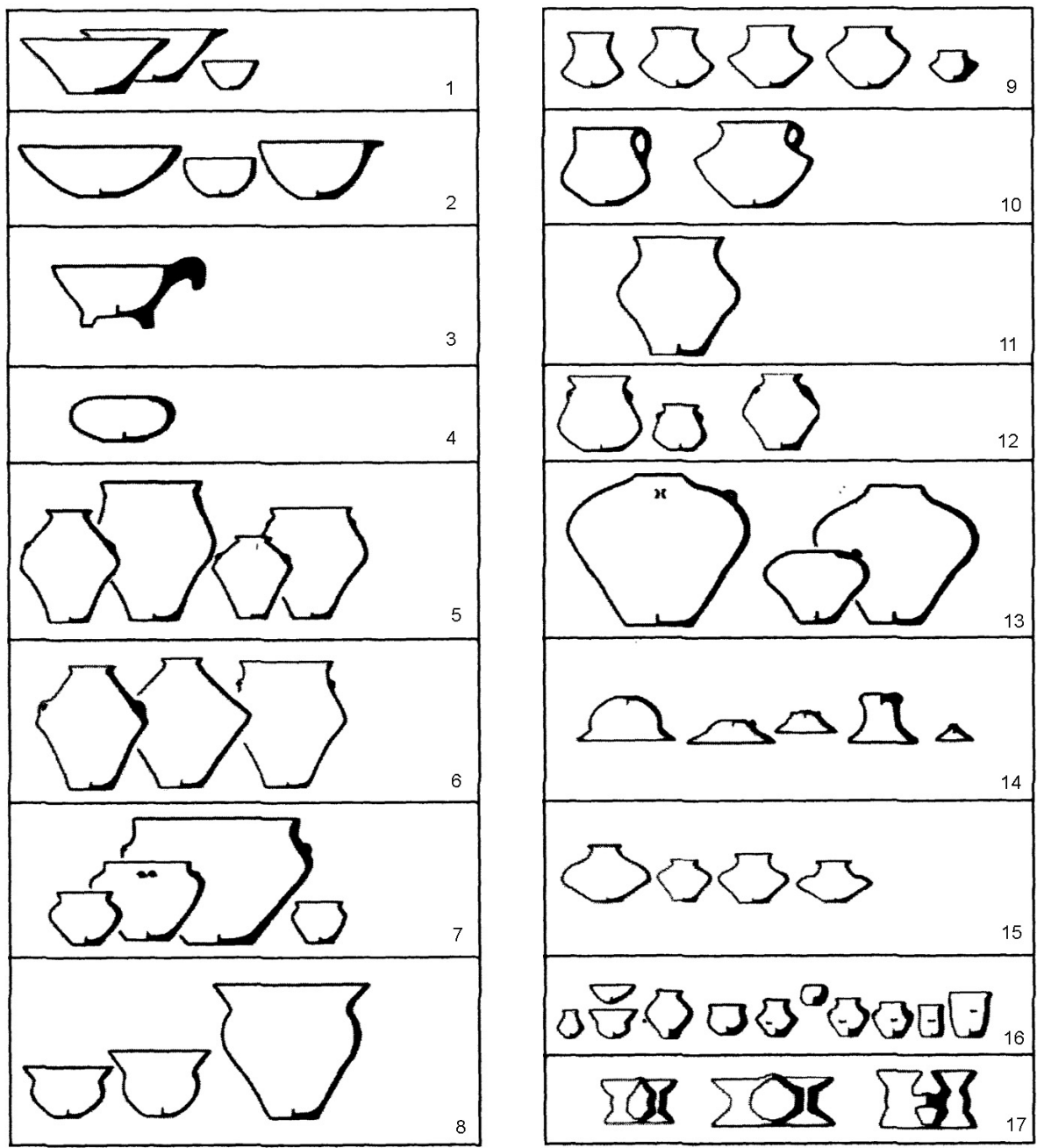

Figure 5.1: Pottery types used in the Ovchinnikov ceramic system (by Ovchinnikov 2014, 80; see our Table 5.1). 
Three of the four ceramic assemblages represented a different kind of feature - an Assembly House (the Mega-structure: see Section 4.5.1), dwelling house A9 (see Section 4.6.2) and the Pit in Sondazh 1 (see Section 4.5.3). Our initial expectation was that three pottery assemblages which were created in such different depositional conditions would have shown strong contrasts in many aspects of their basic characteristics. The fourth pottery 'assemblage' is a aggregation of all the pottery recovered from the 80+ test pits excavated in dwelling houses and Assembly Houses (see Section 4.5.2). The advantage of the test pit sample - the widespread distribution of the test pits across the megasite - is offset by the small fraction of any house excavated - generally no more than 3\%. This sample provides the ceramic equivalent of 'background noise' average values for ceramic deposition across the whole megasite. Comparisons of the three other assemblages with this average ceramic deposition will demonstrate the extent of their specificities.

It is also important to understand the effect of the placement within the house of a $2 \mathrm{~m} \times 1 \mathrm{~m}$ test pit on the size and character of its pottery sample (see above, p. 221). In this circumstance, the nul hypothesis is that the placement of the test pit has no effect on its pottery sample. A X2 test on sherd counts vs. test pit location (house corner zones, wall zones and the middle of the house) showed a p-value of 0.525458 , which is not significant at $0.01 \%$ - i.e., the Null hypothesis is confirmed. This result justifies comparison of test pit pottery samples with each other where informative.

\subsubsection{Taphonomy}

An essential component of the pottery study concerns the taphonomy of the four excavation units. In the architectural analysis, we alluded to the basic taphonomic residues studied by Schiffer (1976) and Kuna (2015) (see above, p. 53). Here, we integrate that discussion with taphonomic information from the pottery assemblages, starting with burnt houses, continuing with unburnt houses and Assembly Houses and concluding with pits.

\subsubsection{Burnt Houses in Test Pits}

We developed a standardised stratigraphic sequence of five contexts for all the test pits. While pre-house artifacts were found in some test pits, very few pre-house features were discovered (e.g., the small pit in Test Pit 15/1). The number of sherds found in Context 5 ranges from one (Test Pit 31/3) to 71 (Test Pit 24/4). In test pits with relatively high Context 5 sherd densities, a case could be made out for pre-house practices which may have influenced the building of a house at that place.

The question of whether pottery can be securely placed in Context 4 living floors or Context 3 destruction daub remains difficult to answer, since, even if sherds are 
found lying horizontally on a living floor, they may have fallen from a wall shelf into such a secondary position. We have allocated most sherds mixed in with destruction daub to Context 3.

Sherds lying on the top of the ploshchadka have usually been allocated to Context 3 to show the link between pottery deposition and the burning of the house. However, in a number of test pits, pottery has been found in Contexts 2 and 1, well above the top of the burnt clay mass, presumably through rodent activity (i.e., the formation of krotovini) or ploughing, despite the absence of ploughmarks in such small excavated areas.

The study of post-depositional impact on sherds showed that almost all vitrified sherds were found in the test pits (e.g., Fig. 5.2/6), together with the vast majority of eroded sherds (e.g., Fig. 5.2/3 \& 8), sherds with calcareous deposit ${ }^{73}$ (Fig. 5.2/4-5) and half of the sherds with secondary burning (Fig. 5.2/1-2). The variety of houses under investigation makes it difficult to draw general conclusions from such high rates of post-depositional change.

The exception to this sequence of five Contexts in a normal burnt house came in the Ukrainian-led excavation of burnt house A9. The finds were recorded with the usual Ukrainian system of location within a $2 \times 2 \mathrm{~m}$ grid, with no vertical differentiation between pre-house, living floor, destruction level and post-destruction material. This finds recording system meant that the House A9 assemblage represented an 'average' assemblage for all phases of the house's life cycle. This circumstance may explain some of the differences between the House A9 assemblage and the other finds assemblages. Given the extent of post-depositional effects on the test pit pottery, it is intriguing to note that not a single sherd from House A9 had been subject to postdepositional impacts such as burning, vitrification or calcareous deposition.

\subsubsection{Assembly Houses}

Assembly houses were normally characterised by the presence of an in situ platform, with very few finds (in contrast to unburnt houses) and no ploshchadka. This distinction was not found, however, in the largest assembly house in Nebelivka - the fully excavated Mega-structure, which combined destruction deposits usually typical of burnt houses in burnt areas and features more likely to be have been found in the open areas of Assembly Houses (see Chapter 4.5.1).

73 The surfaces of most of the excavated pottery from Nebelivka was covered in a calcareous crust, which was regularly removed during post-excavation processing with acetic acid. Whatever calcareous crust remained on the vessel after this cleaning meant that the sherd had suffered from stronger-than-usual soil processes. 


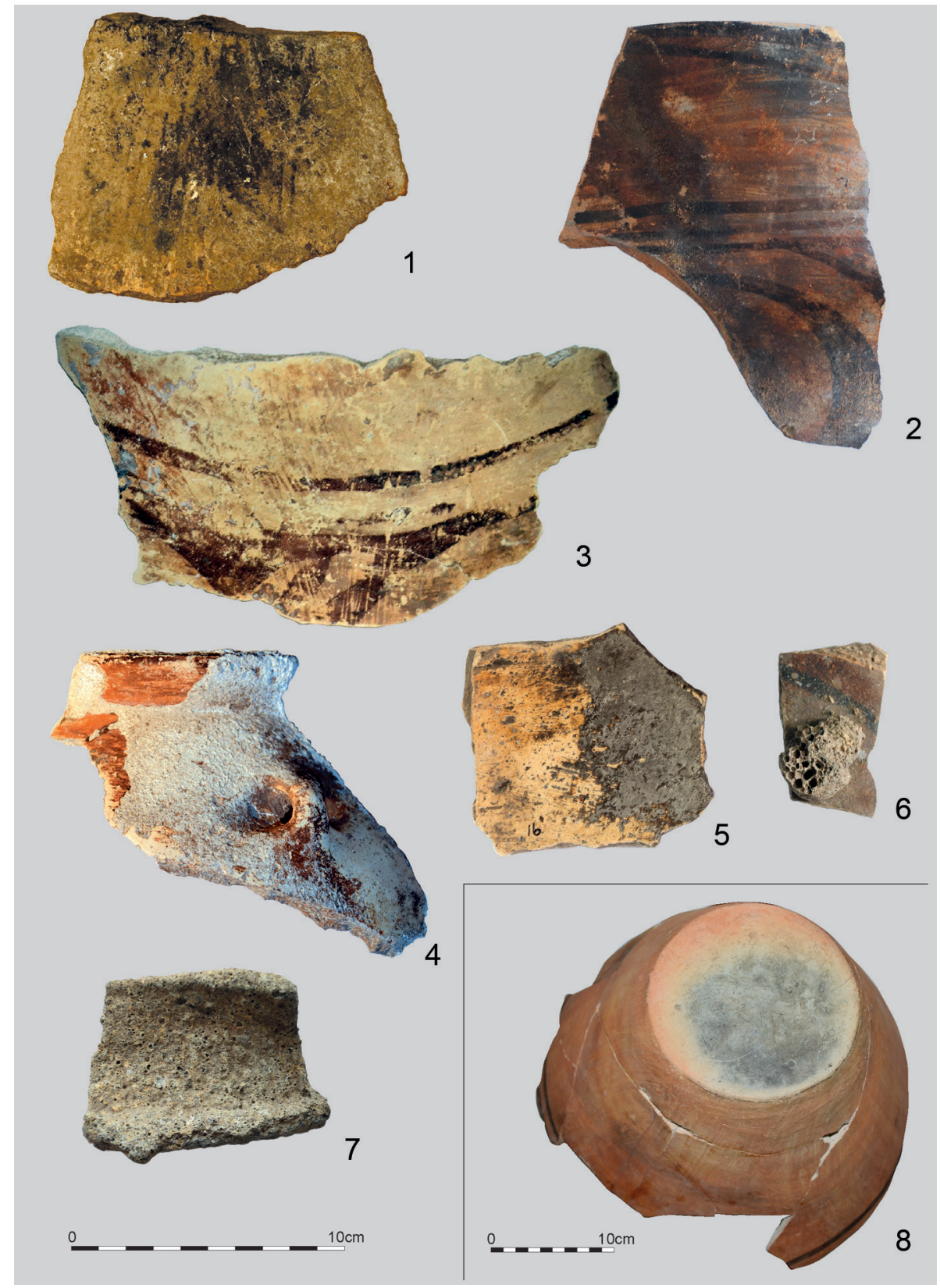

Figure 5.2: Taphonomy: (1) burnt sherd, Test Pit 20/1; (2) burnt sherd, Test Pit 33/1; (3) sherd with heavy wear, Test Pit 21/2; (4) sherd with heavy deposition, Test Pit 22/4; (5) sherd with moderate deposit, Test Pit 26/5; (6) vitrified sherd, Test Pit 24/3; (7) vitrified sherd, Mega-structure Context 208; (8) wear on base of sherd, Test Pit 1/3 (by K. Harding). 
The study of post-depositional impacts (Fig. 5.2) showed that vitrification has been observed on only one sherd deposited in the Mega-structure (Fig. 5.2/7), although many reconstructed vessels ${ }^{74}$ showed signs of burning.

By contrast, half of the sherds suffering from heavy erosion, all sherds with surface marbling effects and $12 \%$ of sherds with a calcareous deposit on their surface were deposited in the Mega-structure. The presence of heavily eroded sherds in the Megastructure only partially relates to deposition of sherds in open areas less susceptible to burning and more likely to suffer erosion; there are almost as many eroded sherds in walled areas. But they may equally support the conclusion of a temporal interval between the abandonment of the building and its burning, during which the sherds may have been left protected from the ensuing fire but exposed to erosive forces. Sherds with calcareous deposit are mainly concentrated in walled areas, suggesting local chemical processes.

\subsubsection{Pit, Sondazh 1}

The two main classes of deposit - the Episodes with finds concentrations and the intervening fill layers - were themselves grouped into five 'Stratigraphic Units' (henceforth 'SU's). One of the primary questions to be explored in the data analysis is the extent to which the SU assemblages differed from each other. The study of postdepositional impacts showed that one third of the sherds with burning were found in the Pit. The rarity of burnt layers in the Pit suggest that these sherds derived from burnt house residues but the absence of erosion on the Pit sherds indicates that the sherds had not been curated long before re-deposition (Kuna's 'tertiary refuse'). The occurrence of two-thirds of sherds with heavy calcareous crusting in the Pit suggests the action of specific local soil processes.

\subsubsection{Summary}

These taphonomic observations give us a clearer idea than before of how the four main pottery assemblages were formed. The following report will be divided into four sections: information on pottery production; the internal study of the four Nebelivka assemblages, focussing on their similarities and differences; a comparison of the Nebelivka assemblages with other recently excavated pottery assemblages from other megasites; and a more general comparison of the Nebelivka assemblage with Cucuteni-Trypillia pottery as a whole. The preliminary results of the internal Nebelivka analyses were presented to the Kirovograd International Conference (April 2015) and published as Caswell et al. (2016).

74 There are also many burnt animal bones deposited in the Mega-structure (see Orton, D. et al., below, pp. 405-406). 


\subsubsection{Pottery Production, Consumption, Refitting and Post-Depositional Evidence}

A total of 1,150 sherds (or $6 \%$ of the total sample) showed evidence pertaining to one or more of these processes (Table 5.2). The observations of post-depositional impacts on sherds have been included in the discussion on the taphonomy of the excavation units (see above). A X2 test showed that the distribution of 'taphonomically-affected' sherds was significantly different ( $p$-value $<0.01$ ) - in other words, there were differences in the distribution of these sherds in the various Excavation Units. The three most important contributions to this result were the absence of sherds with postdepositional damage in House A9, the high proportion of re-fitting sherds and sherds with production data in the Mega-structure, the high proportion of post-depositional damage in the test pits and the high proportion of sherds with information about form and/or decoration in the Pit in Sondazh 1.

Table 5.2: Distribution of 'interesting' sherds by excavation unit (by J. Chapman).

\begin{tabular}{llllll}
\hline & House A9 & Pit, Sondazh 1 & $\begin{array}{l}\text { Mega- } \\
\text { structure }\end{array}$ & Test Pits & Row Totals \\
\hline Making & 5 & 14 & 96 & 19 & 134 \\
Form/Decoration & 6 & 173 & 110 & 102 & 391 \\
Cases of re-fits & 9 & 22 & 124 & 50 & 205 \\
Post-depositional & 0 & 50 & 84 & 286 & 420 \\
Column Totals & 20 & 259 & 414 & 457 & 1150 \\
\hline
\end{tabular}

\subsubsection{Pottery Production}

A preliminary survey of clay sources in the Nebelivka micro-territory by N. Shevchenko succeeded in identifying four clay sources, all of which can be matched to the paste of Nebelivka ceramics (see above, Chapter 4.9). All of the inclusions used in this assemblage can be sourced locally, with grog from local pottery, chaff from the arable fields, shell temper from riverine molluscs (Fig. 5.3/7), grit from local river sands (Fig. 5.3/3), calcareous temper from local limestone outcrops and the rare mineral pyrites temper from granite outcrops. The vast majority of identifiable inclusions was found in coarse wares. The clay used for fine wares was standardised through purification and, if not already containing fine temper, the addition of very fine sand temper. The sources of fine ware pigments were more diverse, ranging from local ochres for yellow and red paint to manganese for black paint, once thought to be from Eastern Ukraine (Buzgar et al. 2010) but now more probably sourced from the Eastern Carpathians (Ellis 1984; Buzgar et al. 2013). 

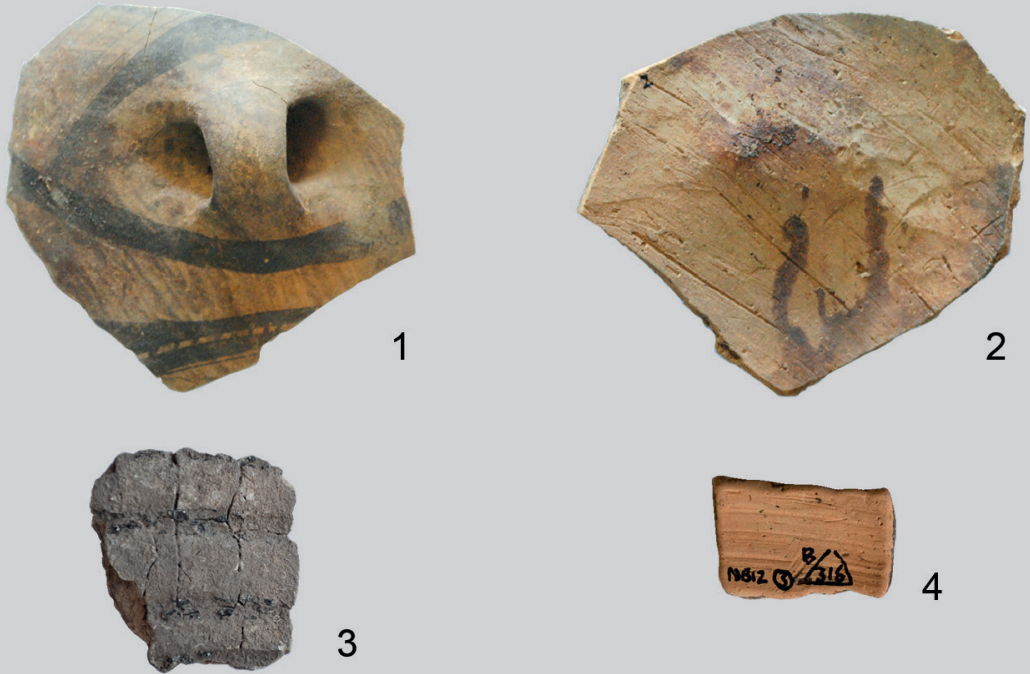

1

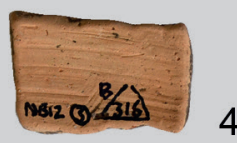

3
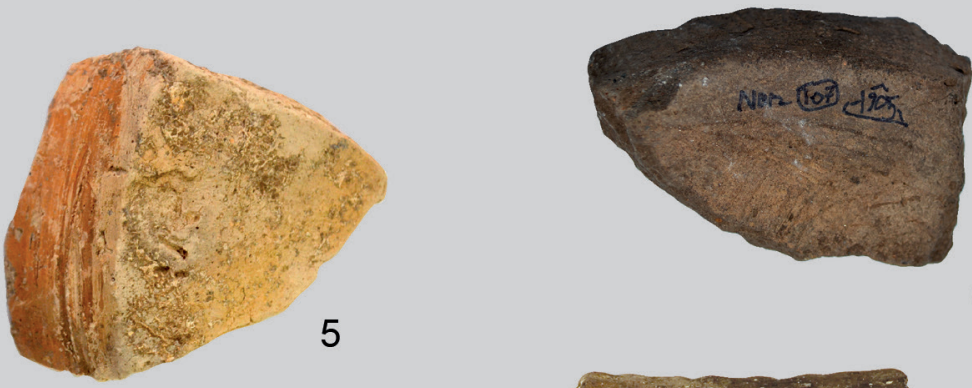

6

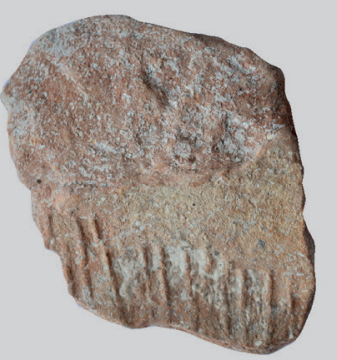

7
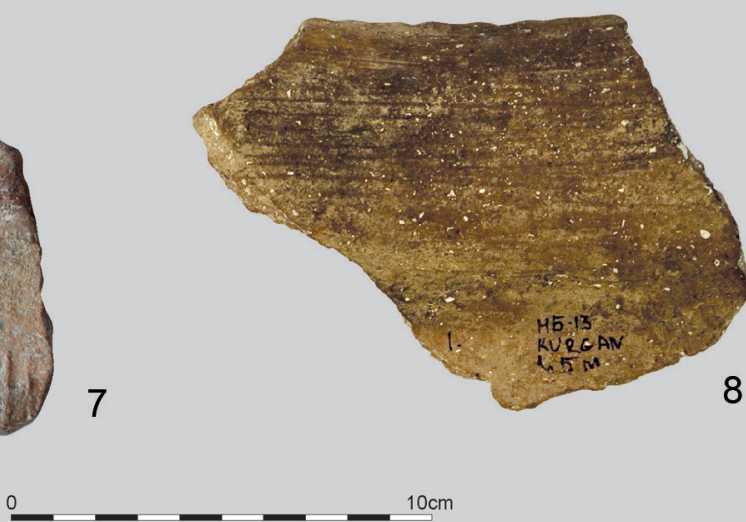

Figure 5.3: Pottery production: (1) handle pushed in, interior, Test Pit 24/3; (2) handle pushed in, exterior, with potting lines, Test Pit 24/3; (3) sherd with grit temper, Mega-structure Context 35; (4) sherd with possible wheel-marks, Mega-structure, TsT 8958, Context 3; (5) sherd with grooved decoration, House A9; (6) base with mat impression, Mega-structure TsT 1905, Context 151; (7) sherd with shell temper, Mega-structure Context 143; (8) sherd with interior potting lines, barrow (by K. Harding). 
Ever since Linda Ellis' (1984) ground-breaking study of Cucuteni-Trypillia pottery production, it has been recognised that a turntable has been used in the production of large, wheel-made storage-jars. However, signs of wheel-made forming have been rare in Trypillia assemblages ${ }^{75}$. Only one Nebelivka sherd shows signs of wheel-turning (Fig. 5.3/4). By contrast, 100 sherds show signs of forming through interior potting lines (Fig. 5.3/2 \& 8) while 18 sherds have exterior potting lines and a single sherd has both interior and exterior potting lines (Mega-structure SF 1987: DOI https://doi. org/10.5284/1047599 Section 5.1.2.2.1). Interior roughening through scratching and the removal of clay by grooving have each been found in one case. Finger-marks made by the potter to smooth the vessel wall have been found on four sherds, with one example of the pushing of the vessel wall in to allow the attachment of the handle (Fig. 5.3/1-2). In the absence of evidence for slab-construction, coil-building seems the most common shaping technique.

An important principle in the shaping of fine wares was the creation of vertical zones through the use of sharply defined necks, shoulders and carinations. An extension of this concept concerns the separate making of different parts of a vessel, such as handles, lugs, legs and lids, for later integration into the final shape. An even more refined technique involved the combination of the separately made parts of an amphora body and a sharply everted neck (Fig. 5.1). The most evolved integration concerns the binocular vessels, in which two separate vessels are connected with two hollow bands. In the context of the development of Late Neolithic East Coast Chinese pottery, Keightley (1987) links such multi-part manufacture to the conceptual leap of compartmentalisation, as well as a sense of geometric precision (cf. Chapman \& Gaydarska 2007, Chapter 2).

Apart from the widespread painting of fine ware vessels, channelling and scribble burnish were also rarely used on fine wares. Impressed, incised, grooved (Fig. 5.3/5) and plastic decoration were used on coarse wares. It can be shown from a single mat-impression on one base that mats were rarely used for the drying of coarse ware vessels prior to firing (Fig. 5.3/6).

The quality of Trypillia-Cucuteni fine wares has long been heralded as a sign of specialist potters, with very few firing mistakes in the vessels deposited on the megasite. While pottery kilns have been excavated at Taljanki and identified from geophysics at Majdanetske (Korvin-Piotrovskiy et al. 2016), there is still a debate over the function of the so-called 'industrial' feature excavated by the Ukrainian team in 2014 (Burdo \& Videiko 2016; cf. Chapman et al. 2016; see above, Chapter 4.7.4). The standard of both fine and coarse wares at Nebelivka was remarkably high, with only one case of a light-dark-light sandwich showing incomplete firing of a coarse ware sherd (Mega-structure SF153). The firing temperature of most fine wares must have

75 Cf. the traces of the use of a turntable at the Cucuteni AB site of Drăgăneşti - Valea Ungureanului (Palaguta 2007, 20 \& Fig. 26). 
exceeded the temperature of the house burning, since there were few cases of sherds whose surface colours had been changed by the house-fire.

\subsubsection{Sherd Refits}

The search for sherd refits is a traditional practice in Central and East European prehistory, with two principal motives - the establishment of chronological links and the reconstruction of complete vessel profiles. However, an alternative practice is the deliberate fragmentation of a vessel to deposit its constituent parts in two or more places (Chapman 2000; Chapman \& Gaydarska 2007, 2015). Here, the motive of multiple deposition of parts of the same pot was social - the creation or maintenance of social links between the depositors and the places of deposition. For this reason, it was felt important to search for sherd refits in the excavation units.

However, the size of the Nebelivka pottery assemblage and the space available for its post-excavation study made it impractical to conduct a full refitting study (cf. the warehouse necessary for the Kilverstone re-fitting operation: Garrow et al. 2005). Instead, sherd refits were sought in adjoining contexts, concentrating on the Megastructure. We are convinced that a wider refitting study would increase the number of refits and possibly the spatial scale of refitting practices. Even with this limited study, a total of 205 sherd re-fits was found, categorised in three ways (Fig. 5.4):

Type 1 sherds found in one context/findspot with no physical refits but considered to derive from the same vessel on the basis of form, fabric and decoration. Fifty-nine cases were found, in all the excavation units, with the number of refitting sherds ranging from two to 42. These examples are not considered to represent deliberate vessel fragmentation (Fig. 5.4/1).

Type 2 physically refitting sherds from the same context/findspot. Forty-eight cases were found, all but two in the Mega-structure (the two exceptions came from House A9). A large majority (75\%) featured two refitting sherds. These examples are not considered to represent deliberate vessel fragmentation (Fig. 5.4/2 \& 4).

Type 3 physically refitting sherds from different contexts/findspots. A total of 98 cases was found, many representing multiple refits of various sherds from the same vessel, especially in the Mega-structure. Sherd refits from different places were found in all excavation units. Almost all of the sherd refits were between fine ware sherds - this practice was confined to only $5 \%$ of coarse ware sherds. No remote refits were found between coarse ware sherds, which were restricted to same-vessel and same-context refits (Fig. 5.4/5). 


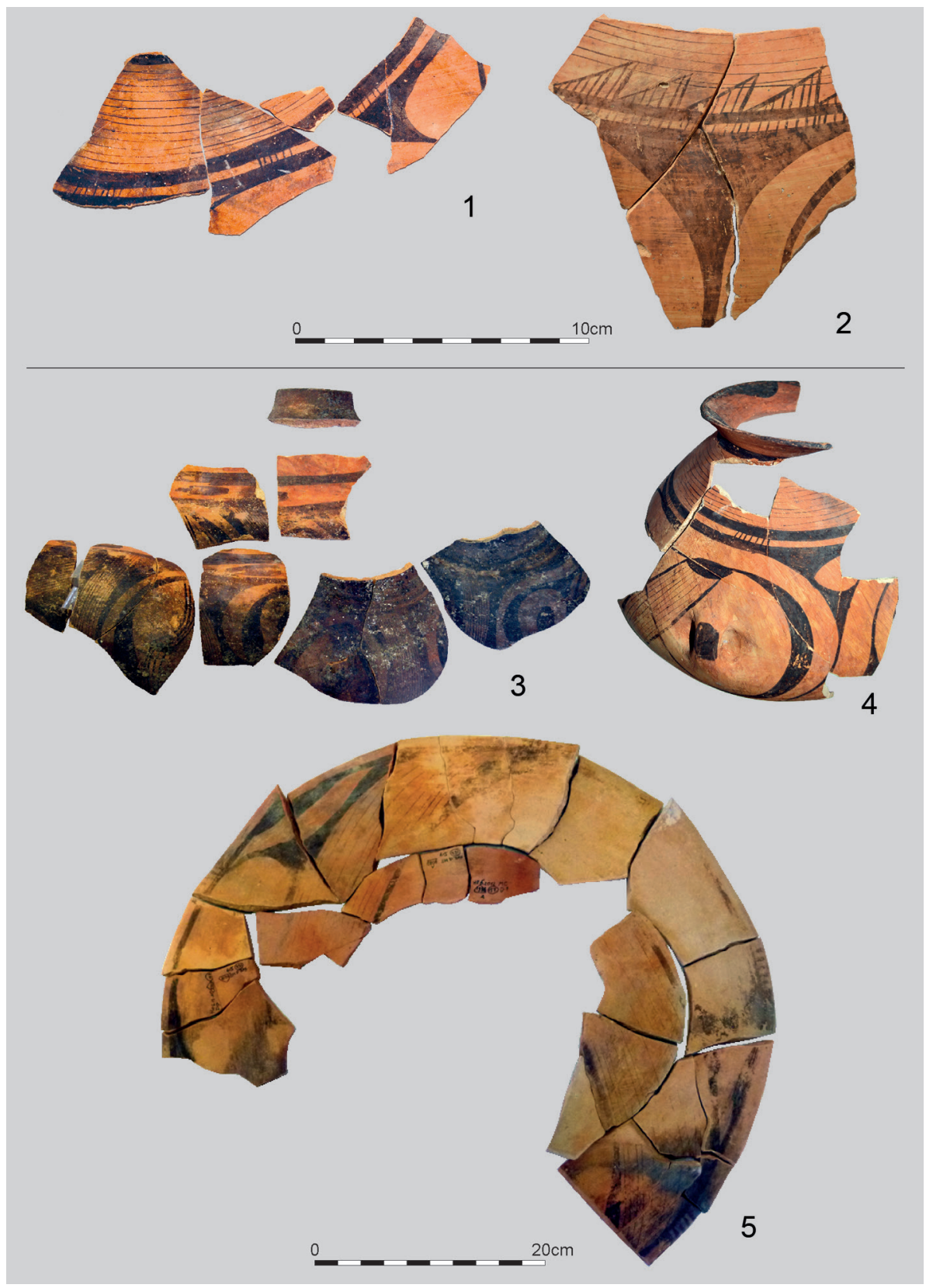

Figure 5.4: Sherd re-fits: (1) Type 1 re-fit, Test Pit 1/3; (2) Type 2 re-fit, Mega-structure Context 232; (3) Type 1 and 2 re-fits, Mega-structure Contexts 157 and 180; (4) Type 2 re-fit, Test Pit 1/3; (5) Type 3 re-fit, Mega-structure Contexts 157 and 4 (by K. Harding). 
These results show that deliberate fragmentation of vessels was a limited practice used to enchain ${ }^{76}$ different houses and different parts of the Mega-structure. The refits in different Stratigraphic Units of the Pit in Sondazh 1 also confirmed the practice of curation of sherds for later deposition, thus enchaining earlier to later depositional episodes.

\subsubsection{The Analysis of the Nebelivka Pottery Assemblages}

The multiple data sets recorded for the Nebelivka pottery inevitably led to a plethora of analyses, which are summarised below (Table 5.3). While the analysis was run using the largest possible sample, a sub-sample of the total ceramic assemblage was used in some cases. For example, GIS data was available for only the Mega-structure (Analysis 9), while estimates of the Minimum Number of Vessels (or 'MINV': Analysis 7) was feasible for clearly-defined contexts only (e.g., Episodes in the Pit, Sondazh 1). Each of the 13 analyses seeks to address questions which will be related to the broader question of the relationships between those using the ceramics and the way in which the ceramics have been deposited or discarded. The questions in the Table are not necessarily exclusive: other questions will be explored in the commentaries on the analyses.

\subsubsection{Sherd Numbers, Weights and Mean Sherd Size (Analysis 1)}

The total number, weight and mean weight of sherds in the studied part of the Nebelivka sample $^{77}$ amounted to 21,300 sherds, with a total weight of $504 \mathrm{~kg}$ and a mean weight of 23.7 g (Fig. 5.5). All four excavation units produced good pottery samples, with a minimum number of 3,500 sherds with a weight of $>80 \mathrm{~kg}$ in House A9. The main activity of sherd deposition in the Pit in Sondazh 1 occurred in Stratigraphic Units 3 and 4 , with the lowest deposition rates in SU 1 and increasing rates until a fall in SU 5. Equally, there was a decline with time in mean sherd weight, with the exception of a slight rise in SU 2, underlining a preferential deposition of large sherds at the base of the pit. The largest pottery sample in the Mega-structure came from the Destruction phase - 10 times more by number than on the living floor and three times more by weight. However, the highest mean sherd weight derived from the living floor - three times that of the Destruction phase. This shows a preferential deposit of large sherds

76 Enchainment is the process of creating social links between people and places through material means (Chapman 2000). It is a fundamental constitutive process of making relationships in the past and present (A. Jones 2012).

77 The excluded assemblages derived from Houses B17 and B18, the pits near B17 \& B18 and the industrial feature and its nearby pit. 
Table 5.3: Types of analyses of the Nebelivka pottery (by J. Chapman).

\begin{tabular}{|c|c|c|c|}
\hline No. & Analysis & Excavation Units & Question(s) addressed \\
\hline 1 & $\begin{array}{l}\text { Sherd Numbers and Weights, } \\
\text { with Mean Sherd Weight (incl. } \\
\text { cumulative frequencies of } \\
\text { weights) by all sherds, fine vs. } \\
\text { coarse wares and decorated } \\
\text { vs. undecorated sherds }\end{array}$ & $\begin{array}{l}\text { All samples; Quarters; Pit } \\
\text { Stratigraphic Units; Mega- } \\
\text { structure Phases }\end{array}$ & $\begin{array}{l}\text { What are the basic parameters of } \\
\text { the four assemblages and how do } \\
\text { they change through time? }\end{array}$ \\
\hline 2 & $\begin{array}{l}\text { Pot parts (rims, body sherds, } \\
\text { lugs/handles and bases) }\end{array}$ & $\begin{array}{l}\text { All samples; Quarters; Pit } \\
\text { Stratigraphic Units; Mega- } \\
\text { structure Phases }\end{array}$ & $\begin{array}{l}\text { Were there variations in space and } \\
\text { time in the deposition of different } \\
\text { vessel parts? }\end{array}$ \\
\hline 3 & Fabrics & $\begin{array}{l}\text { All samples; Quarters; Pit } \\
\text { Stratigraphic Units; Mega- } \\
\text { structure Phases }\end{array}$ & $\begin{array}{l}\text { To what extent can we recognize } \\
\text { distinctive Fabrics in time and } \\
\text { space? }\end{array}$ \\
\hline 4 & $\begin{array}{l}\text { Correlation between vessel } \\
\text { type \& fabric }\end{array}$ & $\begin{array}{l}\text { House A9, Pit Sondazh } 1 \\
\text { and Test Pits }\end{array}$ & $\begin{array}{l}\text { Were there variations in space and } \\
\text { time in the decoration of selected } \\
\text { pottery types and their fabrics? }\end{array}$ \\
\hline 5 & Vessel type & $\begin{array}{l}\text { All samples; Quarters; Pit } \\
\text { Stratigraphic Units; Mega- } \\
\text { structure Phases }\end{array}$ & $\begin{array}{l}\text { Were there variations in space and } \\
\text { time in the deposition of vessels } \\
\text { of various types? }\end{array}$ \\
\hline 6 & $\begin{array}{l}\text { General classes of vessel } \\
\text { (open vs. closed forms) }\end{array}$ & $\begin{array}{l}\text { All samples; Quarters; Pit } \\
\text { Stratigraphic Units; Mega- } \\
\text { structure Phases }\end{array}$ & $\begin{array}{l}\text { Were there variations in space and } \\
\text { time in the deposition of open and } \\
\text { closed classes of pottery? }\end{array}$ \\
\hline 7 & $\begin{array}{l}\text { Minimum Number of Vessel } \\
\text { (MINV) estimates }\end{array}$ & $\begin{array}{l}\text { Test Pits with sherd } \\
\text { samples of } 101 \text { or more }\end{array}$ & $\begin{array}{l}\text { Is it possible to define the MINV in } \\
\text { selected test pits? }\end{array}$ \\
\hline 8 & $\begin{array}{l}\text { Vessel sizes (in general and by } \\
\text { vessel type) }\end{array}$ & $\begin{array}{l}\text { All samples; Mega- } \\
\text { structure Phases }\end{array}$ & $\begin{array}{l}\text { Were there variations in space and } \\
\text { time in the deposition of vessels } \\
\text { of varying sizes? }\end{array}$ \\
\hline 9 & $\begin{array}{l}\text { GIS distribution of vessel types } \\
\text { by Phase and Area }\end{array}$ & Mega-structure & $\begin{array}{l}\text { Were there variations in the } \\
\text { distribution of vessel types in time } \\
\text { and space? }\end{array}$ \\
\hline 10 & $\begin{array}{l}\text { Variation in decorative style by } \\
\text { vessel type }\end{array}$ & Pit Sondazh 1 & $\begin{array}{l}\text { Was there variation through time } \\
\text { in the relationship between vessel } \\
\text { types and decorative style? }\end{array}$ \\
\hline 11 & $\begin{array}{l}\text { Presence/absence and } \\
\text { location of decorative motifs of } \\
\text { all decorative styles }\end{array}$ & $\begin{array}{l}\text { All samples; Quarters; Pit } \\
\text { Stratigraphic Units; Mega- } \\
\text { structure Phases }\end{array}$ & $\begin{array}{l}\text { Were there variations in space } \\
\text { and time in the deposition of } \\
\text { decorated sherds with varying } \\
\text { styles and motifs? }\end{array}$ \\
\hline 12 & $\begin{array}{l}\text { Distribution of combinations } \\
\text { of decorative motifs }(1,2,3 \text { or } \\
4 \text { motifs) }\end{array}$ & $\begin{array}{l}\text { All samples; Pit } \\
\text { Stratigraphic Units; Mega- } \\
\text { structure Phases }\end{array}$ & $\begin{array}{l}\text { Were there variations in space and } \\
\text { time in the number of motifs in } \\
\text { decorative combinations? }\end{array}$ \\
\hline 13 & $\begin{array}{l}\text { Distribution of decorative } \\
\text { motifs }\end{array}$ & Test Pit groups & $\begin{array}{l}\text { To what extent were sherds } \\
\text { with specific decorative motifs } \\
\text { deposited in different houses? }\end{array}$ \\
\hline
\end{tabular}



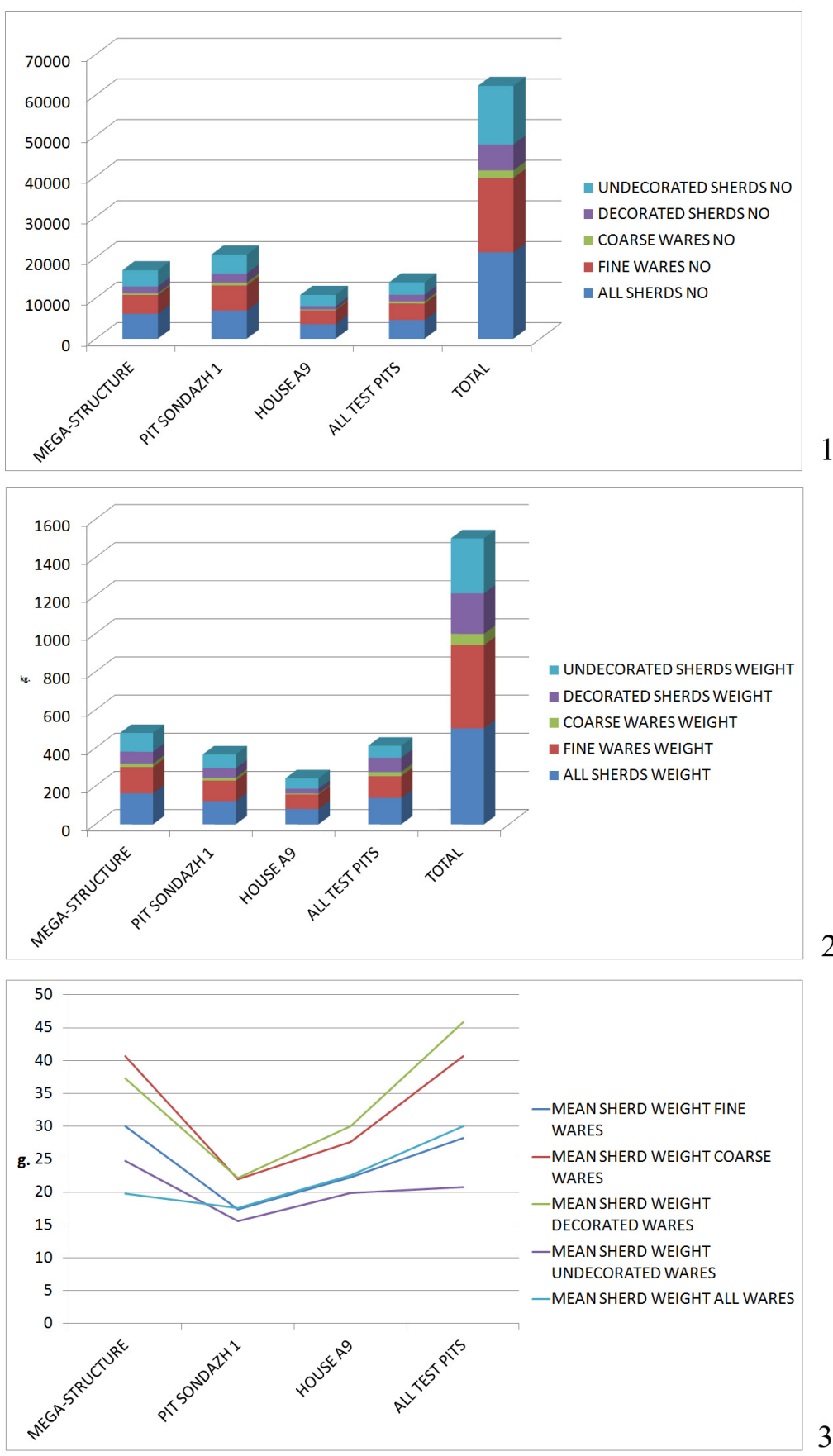

Figure 5.5: (1) number, (2) weight ( $\mathrm{kg}$ ) and (3) mean sherd weight (g) of pottery groups by Excavation Unit (by J. Chapman). 
on the living floor. A variety of sample sizes derived from different Test Pits, with larger samples from Quarters B, G and M and smaller groups from Quarters D-F and J (Fig. 5.6). This pattern was repeated at the level of the Neighbourhood, with large samples found in Neighbourhoods 13, 27, 59, 64-65, 75, 79, 104 and 124. The comparison of vessel sample size from test pits located in Zone 9 (the centre of the structure) showed similar variation at the level of the Test Pit (Fig. 5.7), while the only Neighbourhood with great internal variability was Neighbourhood 124, with samples of all sizes in the five different houses.

In a comparison of fine vs. coarse wares, the former predominated in all excavation units and all phases by number and weight (Fig. 5.5). The lowest proportion of deposited coarse ware sherds came from House A9 (4.5\% by number, $6 \%$ by weight), while other excavation units clustered around $10 \%$ by number, with more variation by weight. Higher mean sherd weights were recorded for coarse wares in each unit, with the highest in the Mega-structure and the test pits. Fine wares dominated all SUs in the Pit by number (always over 90\%) and by weight (82-90\%), with a decline over time of mean sherd weights for both fine and coarse wares, with the exception of larger fine ware sherds in SU 2. Most Quarters showed a similar pattern, except in Quarter M, where $25 \%$ of all sherds were coarse wares. The dominance of fine wares over coarse wares in all phases of the Mega-structure was total ( $>96 \%$ by number, $>94 \%$ by weight).

In a comparison of decorated vs. undecorated sherds, the latter was dominant in all excavation units, with $\sim 30 \%$ of decorated sherds by number/ $\sim 2 \%$ by weight (Fig. 5.5). Decorated sherds ranged from $23.5 \%$ in House A9 to $35 \%$ in the test pits by number, whereas the range by weight was $31 \%$ in House A9 to $55 \%$ in the test pits. Higher mean sherd weights were recorded for decorated sherds in each unit, with the highest in the Mega-structure, most of the Quarters and the test pits. The decorated undecorated sherd ratio varied by depth in the Pit, Sondazh 1, with unusually more decorated sherds in SU 1 and almost as many in SUs 3 (by number \& weight) and 4 (by weight). Larger decorated than undecorated sherds were typical for all SUs, with both showing a decline in mean sherd weight with time (except for SU 2). The living floor has the highest proportion of decorated sherds of all Mega-structure units (40\% by number; $55 \%$ by weight, with the highest mean sherd weight), in contrast to the small, generally undecorated sherds placed on the destruction daub.

A comparison of all these data shows that House A9 and the test pit data lie at opposite ends of the spectrum, with the Mega-structure and the Pit in intermediate positions. House A9 shows the lowest decorated sherd proportion, the lowest ratio of coarse ware sherds and a lower mean sherd weight; by contrast, the test pits show the highest proportion of decorated sherds, and coarse wares and a higher mean sherd weight. There is a strong diachronic trend in the Pit, with largest sherds at the base, decreasing with time, except for SU 2, in which a peak in sherd size and numbers shows a different depositional practice from the usual trend. The Megastructure phases show equally strong depositional contrasts, with fewer but larger, 


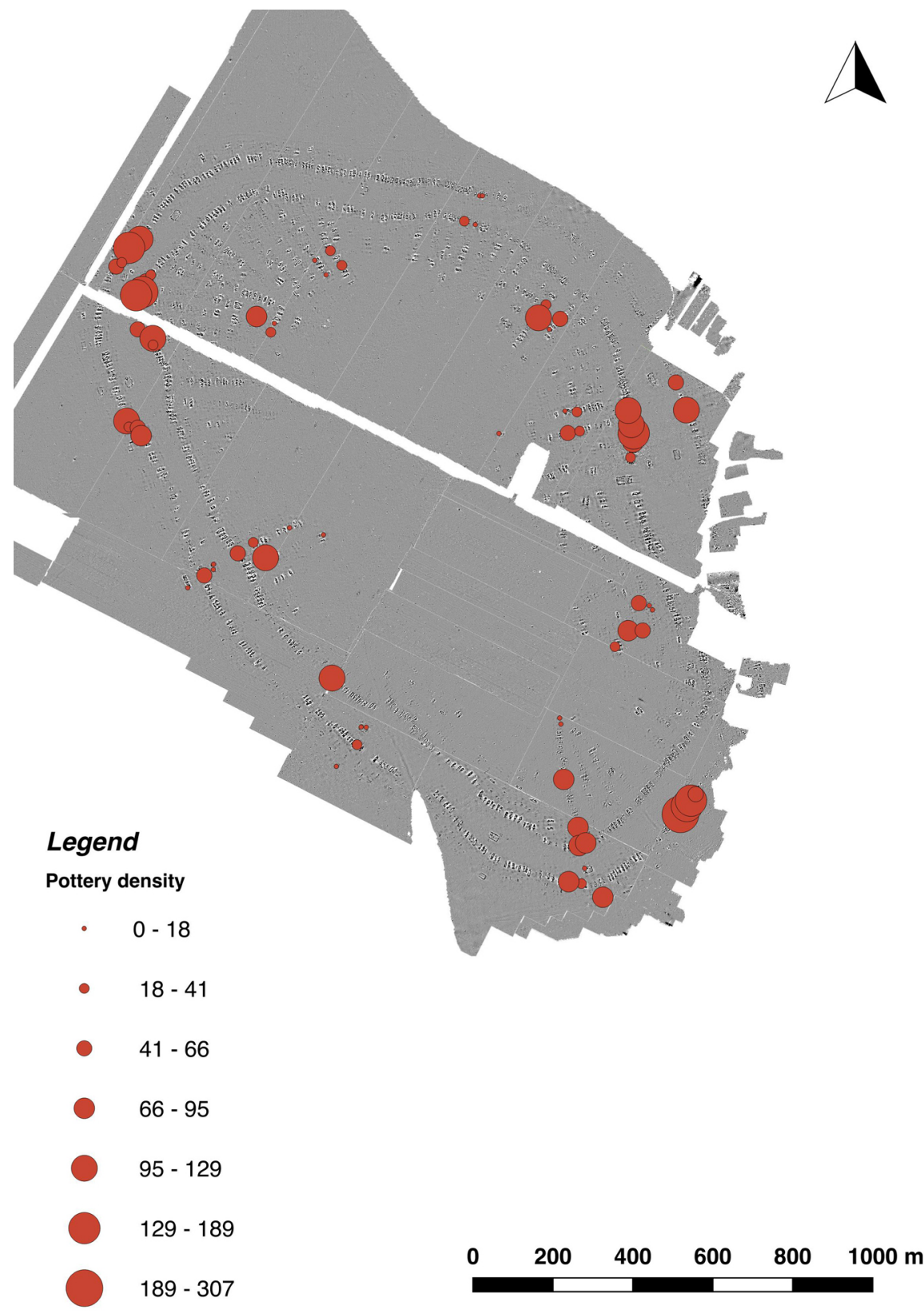

Figure 5.6: Density of pottery samples by weight (g), Test Pits (by M. Nebbia). 


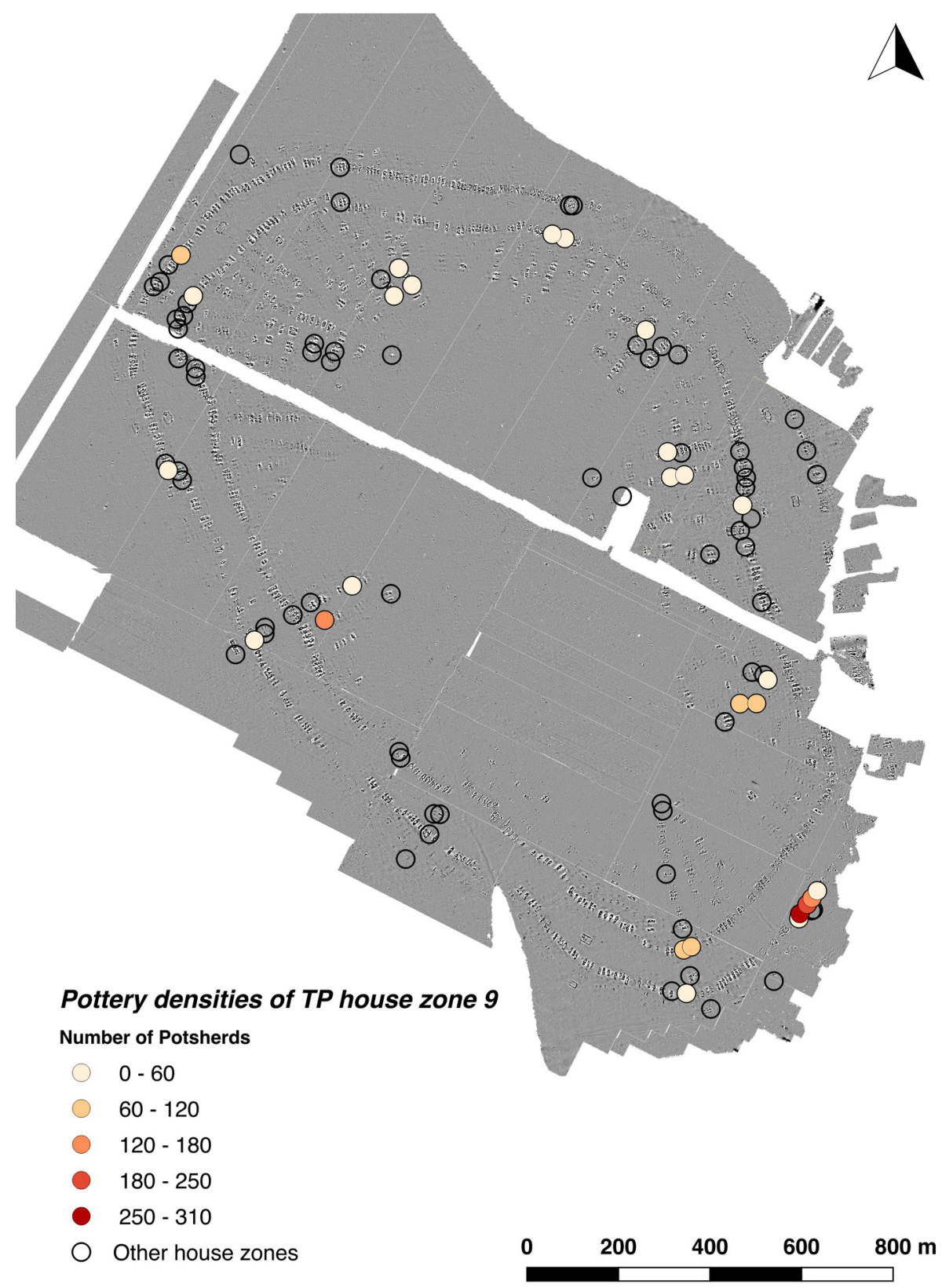

Figure 5.7: Density of pottery samples from Test Pits placed in the centre of burnt houses (Zone 9) (by M. Nebbia). 
and more often decorated, sherds on the living floor, more sherds but less decorated in the Destruction phase and many small, mostly decorated sherds placed on the ploshchadka. These data frame an ongoing discussion of how many, and what type of, sherds were placed in different parts of the megasite and how these cumulatively strategic choices were built up of a large number of small-scale tactical depositional decisions.

\subsubsection{Pot parts (Analysis 2)}

The comparison of the percentages of rims, body sherds, handles \& lugs and bases in all excavation units except one shows, in every case, a clear predominance of body sherds (>80\%). Rims are usually at $11-12 \%$, while the range of bases stands at $4-7 \%$. The sole exception - SU 2 in the Pit - showed unusual values of sherd numbers and weights: here again, the lowest body sherd representation, at $77 \%$, is matched by the highest proportion of rim sherds - at $19 \%$ - of any excavation unit. With this one exception, these consistent results show minimal difference in the representation of body parts in each excavation unit.

\subsubsection{Fabrics (Analysis 3)}

In the Mont Beuvray system of pottery analysis, pottery fabrics play an important role. Their creation stems from an integration of surface colour and types of ware (including temper). Equally, at Nebelivka, it has proved possible to combine the coding for surface colour and fine vs. coarse ware to produce a series of 18 fabrics, in which seven colours were used to make both fine and coarse wares, three colours were confined to fine wares and one colour was restricted to coarse wares (Fig. 5.8). The series of Nebelivka fabrics is as follows (Table 5.4).

There is a distinct pattern of fabric preference (Fig. 5.9/1-4), with three of the excavation units showing a clear to strong preference for Fabric B (red-grey fine ware) with a second choice of Fabric A (pink fine ware). This was also found in the pottery of most Quarters, but other Fabrics proved the most popular in four Quarters - Fabrics I, K and Q. The fourth unit - House A9 - has very few Fabric B sherds, though Fabric $\mathrm{A}$ is the second choice at $23 \%$. Here, the predominant Fabric is C (red fine ware), with two other Fabrics - E (light brown fine ware) and O (kaolin white fine ware) - of lesser significance but not found to be important in any of the other excavation units. The distinctive profile of Fabric preference in House A9 shows the significance of the Nebelivka fabrics in the underpinning of household identity, while preferences for fabrics different from the norm may also have contributed to the identity of people living in different Quarters. 

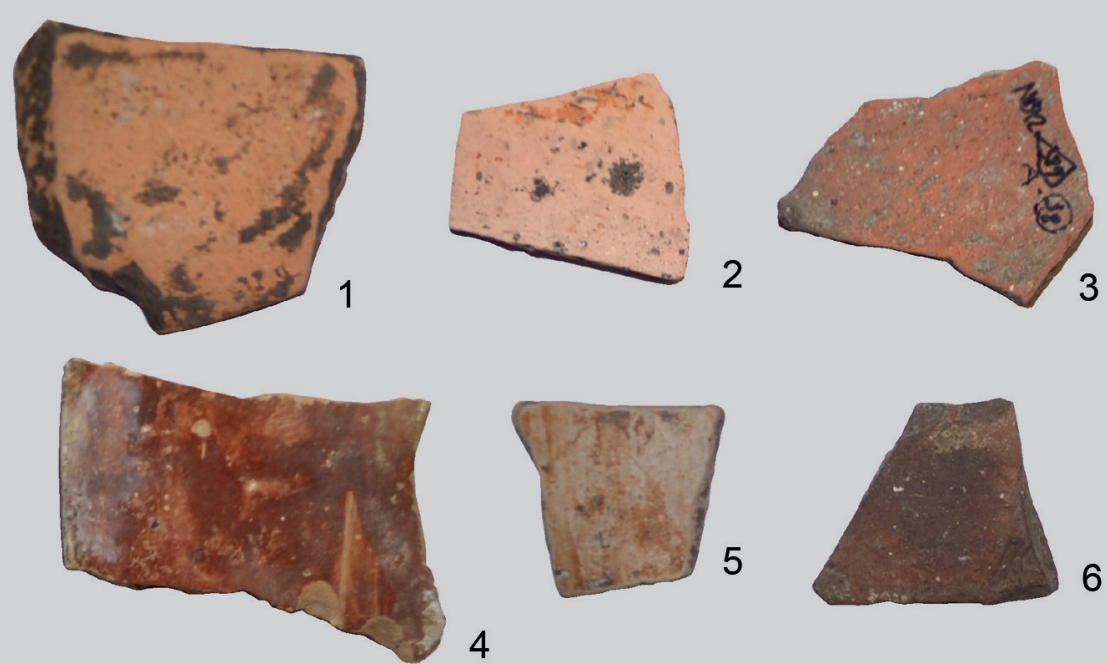

4
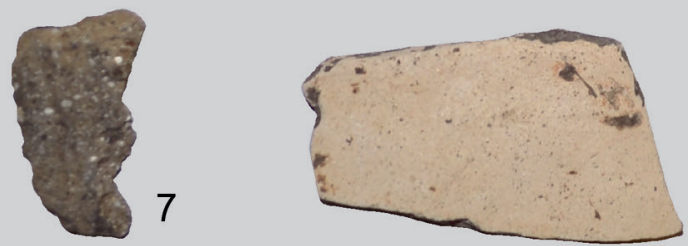

8

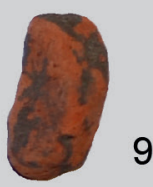

9
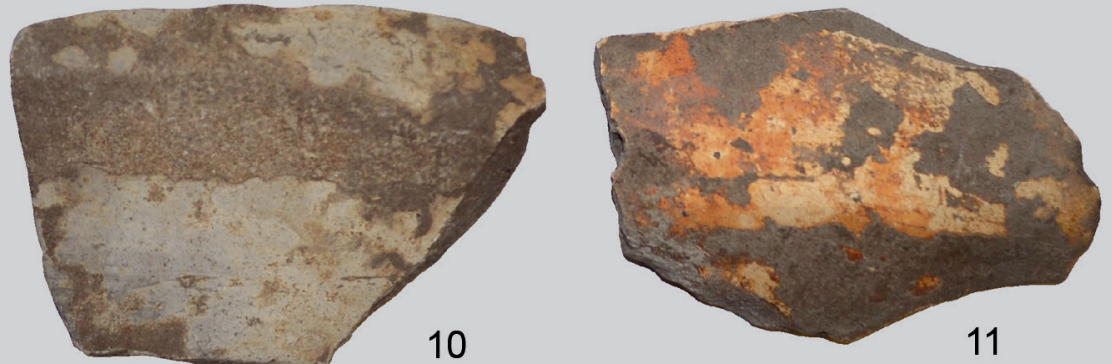

$10 \mathrm{~cm}$

Figure 5.8: Fabric colours: (1) Fabric C; (2) Fabric A; (3) Fabric B; (4) Fabrics I-J; (5) Fabrics E-F; (6) Fabrics G-H; (7) Fabric D; (8) Fabrics O-P; (9) Fabrics K-L; (10) Fabrics M-N; (11) Fabrics Q-R (by K. Harding). 
Table 5.4: Nebelivka pottery fabrics (see Fig. 5.8) (by J. Chapman).

\begin{tabular}{lll}
\hline Fabric & Designation & Surface Colour \\
\hline A & Pink Fine Ware & 2 \\
B & Red-Grey Fine Ware with sand temper & 3 \\
C & Red Fine Ware & 1 \\
D & Grey Coarse Ware with shell temper & 9 \\
E & Light Brown Fine Ware & 5 \\
F & Light Brown Coarse Ware & 5 \\
G & Dark Grey Fine Ware & 6 \\
H & Dark Grey Coarse Ware with shell temper & 6 \\
I & Dark Brown Fine Ware & 4 \\
J & Dark Brown Coarse Ware & 4 \\
K & Dark Red Fine Ware & 8 \\
L & Dark Red Coarse Ware & 8 \\
M & Grey-Brown Fine Ware & 7 \\
N & Grey-Brown Coarse Ware & 7 \\
O & Kaolin White Fine Ware & 10 \\
P & Kaolin White Coarse Ware & 10 \\
Q & Orange Fine Ware & 11 \\
R & Orange Coarse Ware & 11 \\
\hline
\end{tabular}

There is only minor change through the Stratigraphic Units of the Pit in Sondazh 1. All SUs are dominated by Fabric B (red-grey fine ware) but without a diachronic trend. The only trend with time is in the greater importance of Fabric A (pink fine ware), with the exception of SU 2.

The number of Fabrics selected at above the 10\% threshold is broadly similar across the excavation units, with the highest number $(n=10)$ found in the sample drawn from the widest spatial range - the test pits. Only two Fabrics (A and C) are found at above the $10 \%$ threshold in all units, while four coarse ware Fabrics ( $\mathrm{L}$ - dark Red; N - grey-brown; P - kaolin white; and $\mathrm{R}$ - orange) never cross this threshold. Fabric H (dark grey coarse ware) is found only in the Pit, Sondazh 1, while Fabric M (grey-brown fine ware) occurs above the threshold only in House A9. The identity of those contributing vessels or sherds to house or pit deposition is reproduced in the combinations of the Fabrics. The difference in the numbers of fabrics selected by Quarter shows a difference in various parts of the megasite, with the utilisation of most fabrics in the Eastern area, medium numbers in the Western area and the lowest fabric numbers in the Northern area.

The fabric preferences of specific houses within three Quarters - B, G and M can be compared with the overall Quarter statistic. While the four houses in Quarter 
B and the three houses in Quarter M show broadly similar fabric preferences, there was far more variability in the four houses of Quarter $G$, with the most popular fabric different in three of the houses (Fig. 5.9/5-8). This selection of different clay sources, perhaps through time, suggests the formation of different identities, perhaps related to different groups of visitors dwelling in different Quarters.

\subsubsection{Fabrics vs. Form (Analysis 4)}

There are four forms found with sufficient frequency to make comparisons between excavation units in respect of their fabric preferences: bowls, carinated forms or amphorae, dishes and plates.

In House A9, 11 fabrics were chosen to make these vessel forms (Fig. 5.10/1-4). Five fabrics dominated the four forms - Fabrics A (pink fine ware), D (grey coarse ware), G (dark grey fine ware), I (dark brown fine ware) and $\mathrm{K}$ (dark red fine ware). While the dishes and plates shared exactly the same fabric preferences (Fabric D > K > I), the bowls and carinated shapes showed variations between Fabrics A and D for the carinated, $\mathrm{K}$ and $\mathrm{C}$ for the bowls.

In the Pit in Sondazh 1, there was far less variability in choice of fabrics, with all vessel forms dominated by Fabric B (the red-grey fine wares varied between 50\% and $67 \%$ of all sherds). This was not a fabric that was at all prominent in House A9. In contrast to House A9, the secondary preferences for dishes and plates were Fabrics A (pink fine ware) and $\mathrm{K}$ (dark red fine ware), while the secondary preferences for bowls and amphorae (Fabrics A, G and I) also differed from those in House A9. The general conclusion is that selection of fabrics for deposition in House A9 and the Pit was based upon contrasting principles which contributed to the formation of local identities.

\subsubsection{Vessel Form (Analysis 5) ${ }^{\mathbf{7 8}}$}

It has already been explained why the form of the Nebelivka vessels has been studied by an alternative system to the Ryzhov system commonly used in Trypillia ceramic research (see above, pp. 266-268). The more detailed typology is based upon eight types, which include a broad category of 'necked form' for small rims and a 'Rare' category which includes such types as hole-mouth rims, binocular vessels and storage jars (Fig. 5.11). The more general typology recognises open types (dishes and plates) and closed types (bowls, amphorae and flasks), as well as an 'Other' category (necked forms, miniature vessels and bases). The abundance of otherwise unclassifiable bases in all excavation units - a total of $30 \%$ of all sherds - is managed through presenting two versions of both typologies by the inclusion and exclusion of bases from the statistics (Figs. 5.10/5-8 \& 5.11/1).

78 See https://doi.org/10.5284/1047599 Sections 5.1.2.4; 5.2.1.2.4; 5.4.2.4; 5.3 for individual Test Pits. 

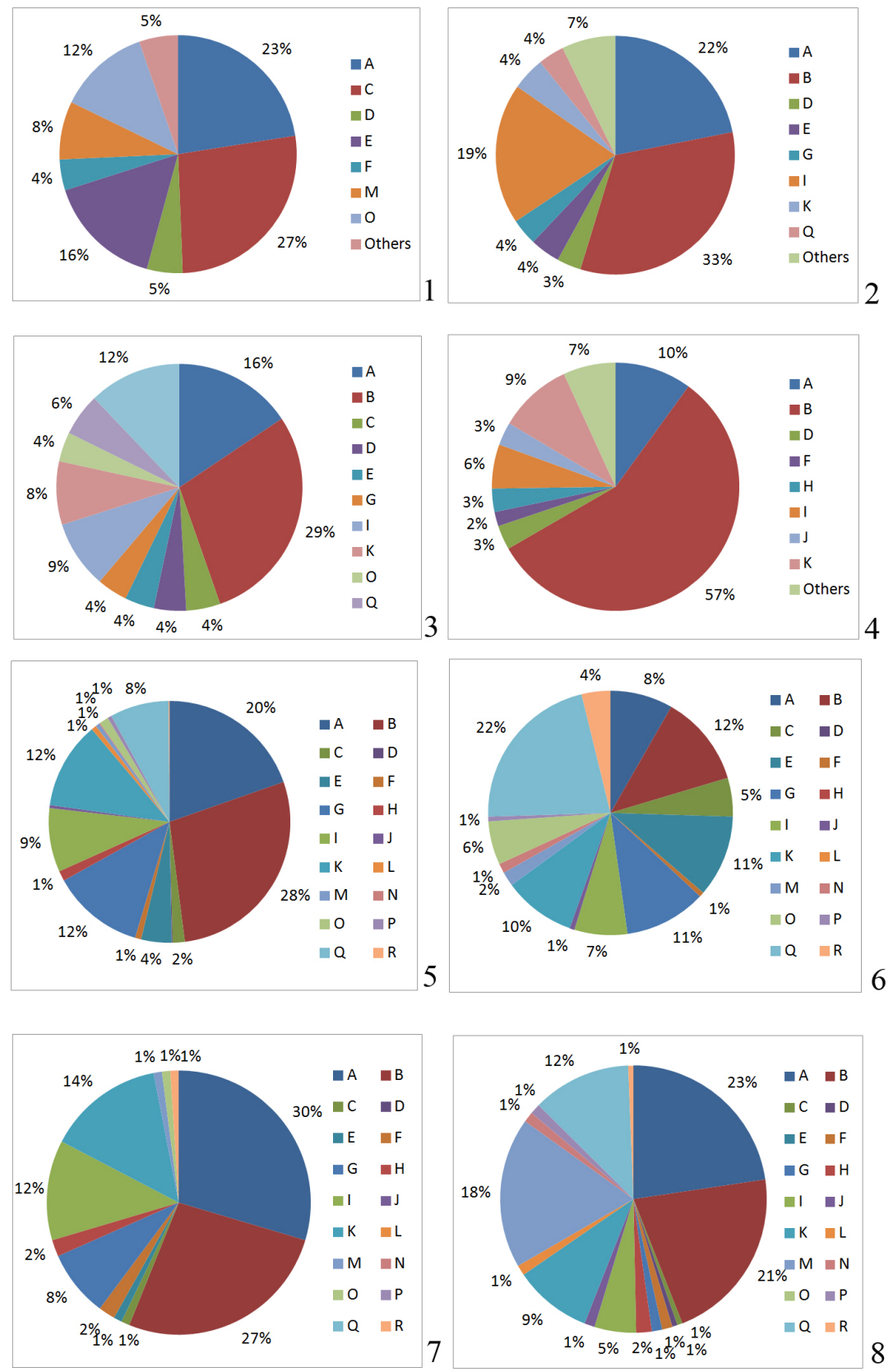

Figure 5.9: Fabric distribution for (1) House A9; (2) Mega-structure; (3) Test Pits; and (4) Pit, Sondazh 1; Fabric by sherd number for (5) Quarter G; (6) Test Pit 24/3; (7) Test Pit 25/1; and (8) Test Pit 25/2 (by J. Chapman). 

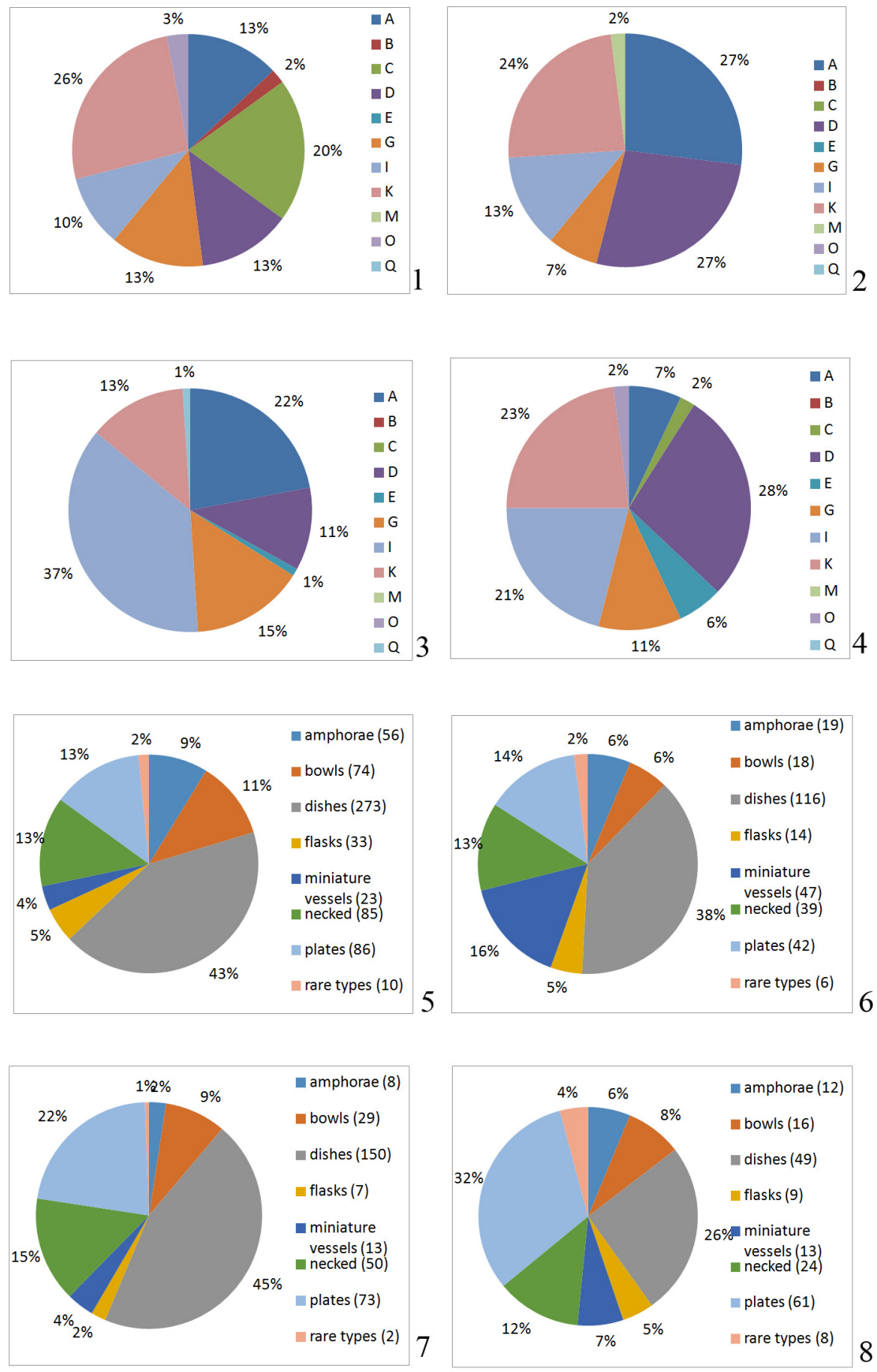

Figure 5.10: Surface colour vs. vessel form for (1) bowls; (2) carinated vessels; (3) plates; and (4) dishes, House A9; distribution of rim types without Bases for (5) Pit, Sondazh 1; (6) Test Pits; (7) Mega-structure; (8) House A9 (by J. Chapman). 

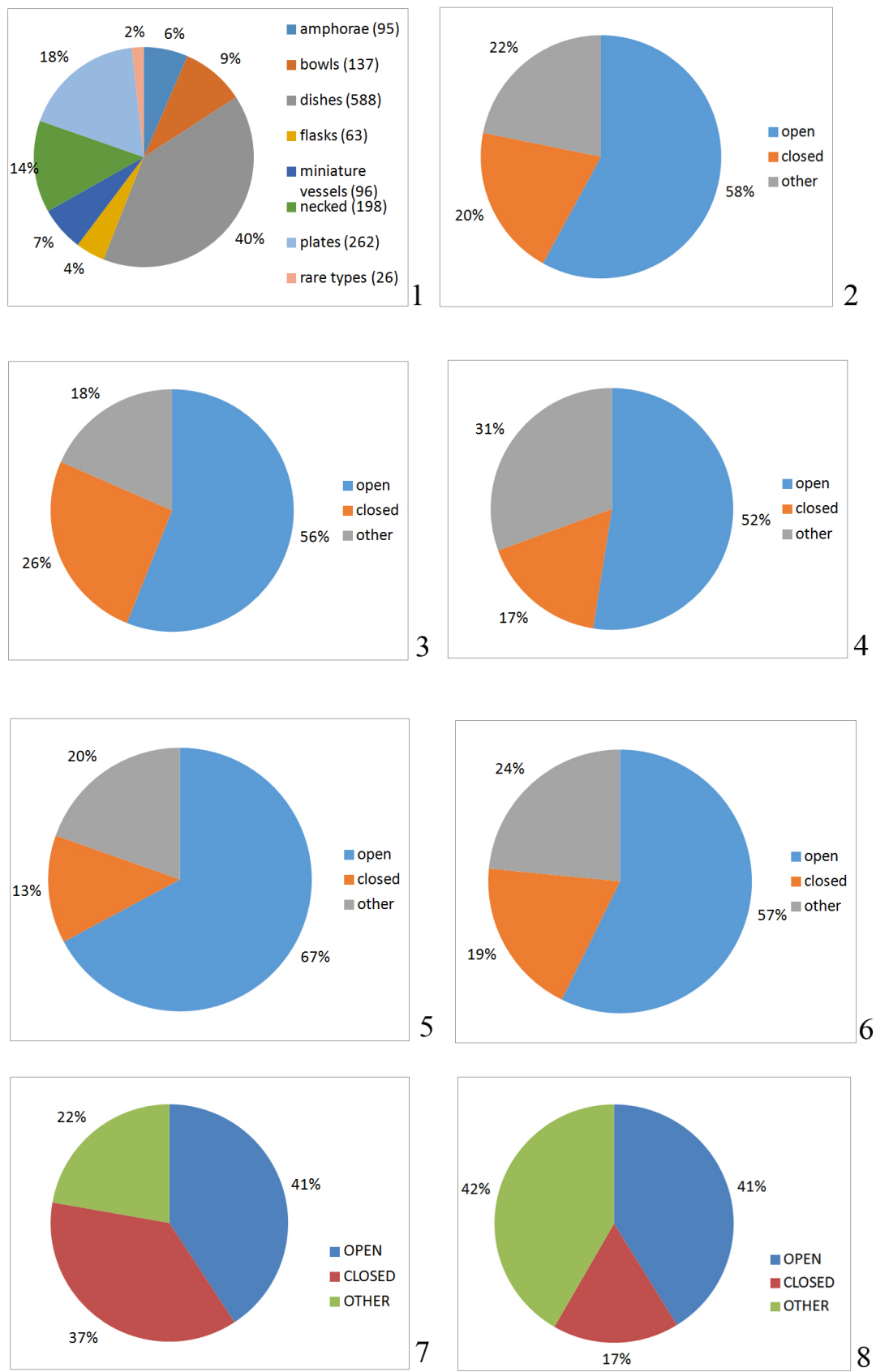

Figure 5.11: (1) distribution of shape types, all Units; distribution of open \& closed categories without Bases: (2) all Units; (3) Pit, Sondazh 1; (4) Test Pits; (5) Mega-structure; (6) House A9; (7) Pit, Sondazh 1 SU2; and (8) Pit, Sondazh 1 SU 4 (by J. Chapman). 
Inclusion of bases in the detailed typology has a variable impact on the results, especially for House A9, where $56 \%$ of the sherds were bases, but rather less for the other units, with $25 \%$ of bases or less. The over-representation of bases in House A9 emphasises that these house assemblages cannot be considered as 'living assemblages' (Schiffer's 'primary refuse'). Dishes were the most common form overall (at 28\%) and also in three units, at 32-34\%, with far fewer in House A9 (11\%). Plates were represented in a similar range (10-16\%) in all units. The distribution of necked forms followed that of dishes - a similar range in three units (10-11\%) but far fewer in House A9.

Removing bases from the distribution shows that, while all eight types were found in each unit, dishes now became the most frequent form at $40 \%$, with plates at $18 \%$ and necked forms at 14\% (Fig. 5.11/1). All other types were found at frequencies of lower than $10 \%$, with the Rare type least common at $2 \%$. In all units except House A9, dishes were found more frequently than plates - by a factor of three in the Pit and a factor of two in the Mega-structure and the test pits. Necked forms were found in one vessel in eight or nine across the site, while there was a special concentration of miniature vessels in the test pits. The same pattern of a preference for dishes and plates over amphorae, bowls and flasks was found in all Quarters. An unusual occurrence was the concentration of 14 miniature vessels in five houses in Quarter $\mathrm{H}$ - perhaps related to the special contents of miniature vessels as suggested by lipid analysis of the Mega-structure group of small pots (see below, Chapter 5.2.3.4).

\subsubsection{Comparisons Between Open and Closed Forms (Analysis 6)}

The general typology excluding bases shows a strong preference for open over closed forms (Fig. 5.11/2), with the highest in certain Quarters (from 75\% in Quarter $\mathrm{H}$ to $90 \%$ in Quarter N) and a preference for open forms in the Mega-structure $(67 \%)$ (Fig. 5.11/5). Closed forms peak in the Pit at $24 \%$, while the lowest total occurs in the Mega-structure (12\%). The peak of 'Other' forms occurs in the test pits (Fig. 5.11/4). Inclusion of bases in the general typology biases the results towards the 'Other' category, which peaks at 75\% in House A9 with its high number of bases. As in the typology without bases, the highest proportion of open forms occurs in some Quarters and then the Mega-structure, the lowest in the test pits.

There are major variations in the open: closed ratios in the different Stratigraphic Units of the Pit, with open forms usually dominant and increasing with time. The often variant values in SU 2 are found in the unusually high frequency of closed forms - 15-22\% higher than in other SUs (Fig. 5.11/7-8). By contrast, there is a strong preference for open forms in all Phases of the Mega-structure (range: 60-70\%). The use of large plates for communal eating of collectively prepared food is a particular sign of the Mega-structure, which suggests that feasting was an important practice in this building (Fig. 5.14/2). The general preference for plates and dishes is particularly characteristic of the Nebelivka assemblage. What is interesting is the 
overall rarity of storage vessels of any kinds, although the so-called 'pithos' form is known from the podium in the Mega-structure. Given the coverage of all parts of the house in $80+$ test pits, it may be expected that some storage facilities and/or vessels would have been discovered - but only two cases have been identified - in Test Pits $22 / 1$ and 22/3, both placed near the end-wall of the house. The null hypothesis is as unsatisfactory as it is currently untestable - that communal storage facilities and large numbers of storage vessels were located in parts of the megasite that have not yet been investigated.

\subsubsection{Estimation of the Minimum Number of Vessels (MINV) (Analysis 7)}

In addition to MINV estimates for the assemblage of each excavation unit, MINV estimates have been made for more detailed components of two of the excavation units - the test pits and the depositional episodes in the Pit in Sondazh 1. However, the depositional context of these two units is strongly contrasting. The test pit samples derive from a small (2-4\%) part of the house, usually from the destruction of the house. The episodes in the Pit represent concentrations of deposited sherds in more or less continuous depositional action, when more sherds than usual were gathered from other contexts of primary or secondary deposition and then thrown into, or placed in, the Pit to produce an 'episode' of deposition. The sherd clusters were usually found as a complete unit in one zone of the Pit, rarely covering more than $1 \mathrm{~m} \times 1 \mathrm{~m}$ in area.

A total of 73 Test Pit assemblages was studied for MINV estimates. The mean MINV was 5.2, with a standard deviation of 4.8. Sixteen Test Pits with samples of 101 or more sherds were selected for more detailed MINV estimates. The question of sherd refits complicates such estimates in two cases. In Test Pit 28/2, 76 refitting sherds (total weight $-0.975 \mathrm{~kg}$.) yielded a single decorated amphora, while, in Test Pit 25/1, two complete dishes were reconstructed from 51 sherds (total weight $-0.449 \mathrm{~kg}$.) Otherwise, the mean number of sherds per vessel ranged from seven (Test Pit 23/2) to 29 (Test Pit 1/2) and the MINV from five (Test Pit 15/1) to 15 (Test Pit 23/2) vessels, with no statistical relationship between the two values. The number of types in the vessel groups ranged from one to seven types, with two-thirds of groups dominated by dishes and with plates, miniature vessels and amphorae also occasionally most frequent. Considering that the test pits represented no more than $2-4 \%$ of complete house floors, it is remarkable that such high MINV frequencies have been recovered. But it is also important to note that almost all of the vessels were recovered as fragments - often quite small fragments - of the vessels. This reinforces the case for the deposition of not only complete vessels but also sherds in the death assemblages of houses at Nebelivka. 

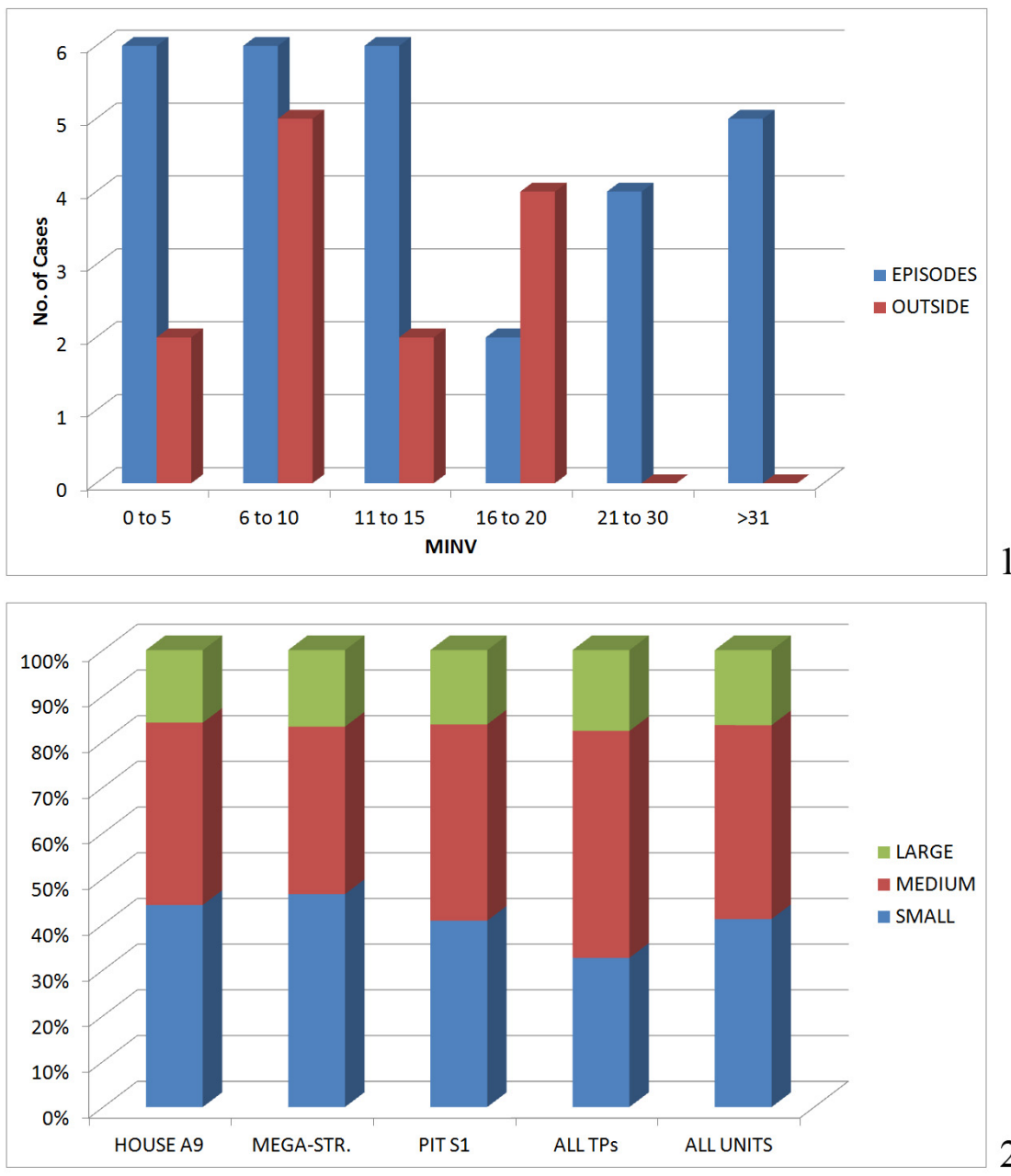

Figure 5.12: (1) Minimum Number of Vessel estimates for Episodes and deposits outside Episodes, Pit, Sondazh 1; (2) Vessel sizes by excavation unit (by J. Chapman).

A total of 29 episodes of deposition in the Pit can be used for MINV estimates. ${ }^{79} \mathrm{~A}$ poor fit was found between the number of sherds in an Episode and the MINV, indicating preferential deposition of rims in some Episodes and body sherds in others. There was an even wider range of vessels than in the test pit MINVs - from body sherds only in Episode 19 to an estimated total of 43 vessels in Episode 12 (Fig. 5.12/1). By

79 Photographs of the Pit 1 Episodes, with a full list, can be found in https://doi.org/10.5284/1047599 Sections 5.4.2.1 \& 5.4.4.3. 
any standards, this latter was a major depositional event - an important ceremony bringing together several households or an entire Neighbourhood - while other Episodes were clearly smaller-scale and more intimate in nature.

Ten of the Episodes comprised an estimated 20 or more vessels, prompting the question 'was there a standard ceramic group for deposition in Episodes'? The variability in these 10 Episodes (Fig. 5.12/1) shows that the answer is 'no' but the regular deposition of between four to six of the six commonest types shows a polythetic pattern of discard. This regularity was reinforced by the preference for dishes in nine out of the 10 Episodes with large samples; bowls predominated in the only exception (Episode 8). This suggests that the same practice of depositing dishes used for personal or small group consumption was used in both units. A second regularity was the practice of depositing two to four plates in each of the larger Episodes, suggesting that collective preparation and consumption of food was also important before deposition in Episodic mode.

The range of sherd numbers in the Episodes makes an interesting comparison with sherd numbers for deposition outside the Episodes, whether spatially or temporally. Sherds deposited in Episodes comprised three times the number of sherds placed outside the Episodes. The mean number of sherds placed in Episodes exceeded the mean for sherds placed outside Episodes (152 cf. 90 sherds), with each type of deposit showing wide variance in sherd numbers (within Episodes: 2-394 sherds; outside Episodes: 4-184 sherds). Such variability in sherd deposition supports the notion that deposition within and outside Episodes were essentially similar practices but with a more concentrated, perhaps formalised mode of discard in the Episodes. This conclusion finds further support from the MINVs estimated for deposition outside the Episodes (Fig. 5.12/1), with values of up to 20 vessels in two areas, and the finding of a similar spread of vessel types in these pot groups.

\subsubsection{Vessel Size (Analysis 8)}

Given the rarity of complete vessels, the proxy measure used for vessel size is the rim radius, which has been divided into three size classes: small $(2.5-7.5 \mathrm{~cm})$, medium $(8-15 \mathrm{~cm})$ and large $(15.5 \mathrm{~cm}$ and above). The complete sample of rim sherds shows a size distribution of $35 \%$ small vessels, $40 \%$ medium-sized vessels and $25 \%$ large vessels (Fig. 5.12/2). ${ }^{80}$ Three of the excavation units show similar profiles to the whole sample; it is only in the test pit data that we found a small variation, with rather more mediumsized vessels and fewer small vessels than usual. This overall similarity in size profiles suggests that all of the assemblages under study derived from the same general pool of vessels produced for generalised rather than specialised household utilization.

80 Illustrations of pottery by size (e.g., for the Mega-structure) can be found in https://doi. org/10.5284/1047599 Section 5.1.2.4; see finds from other Excavation Units in Section 5. 


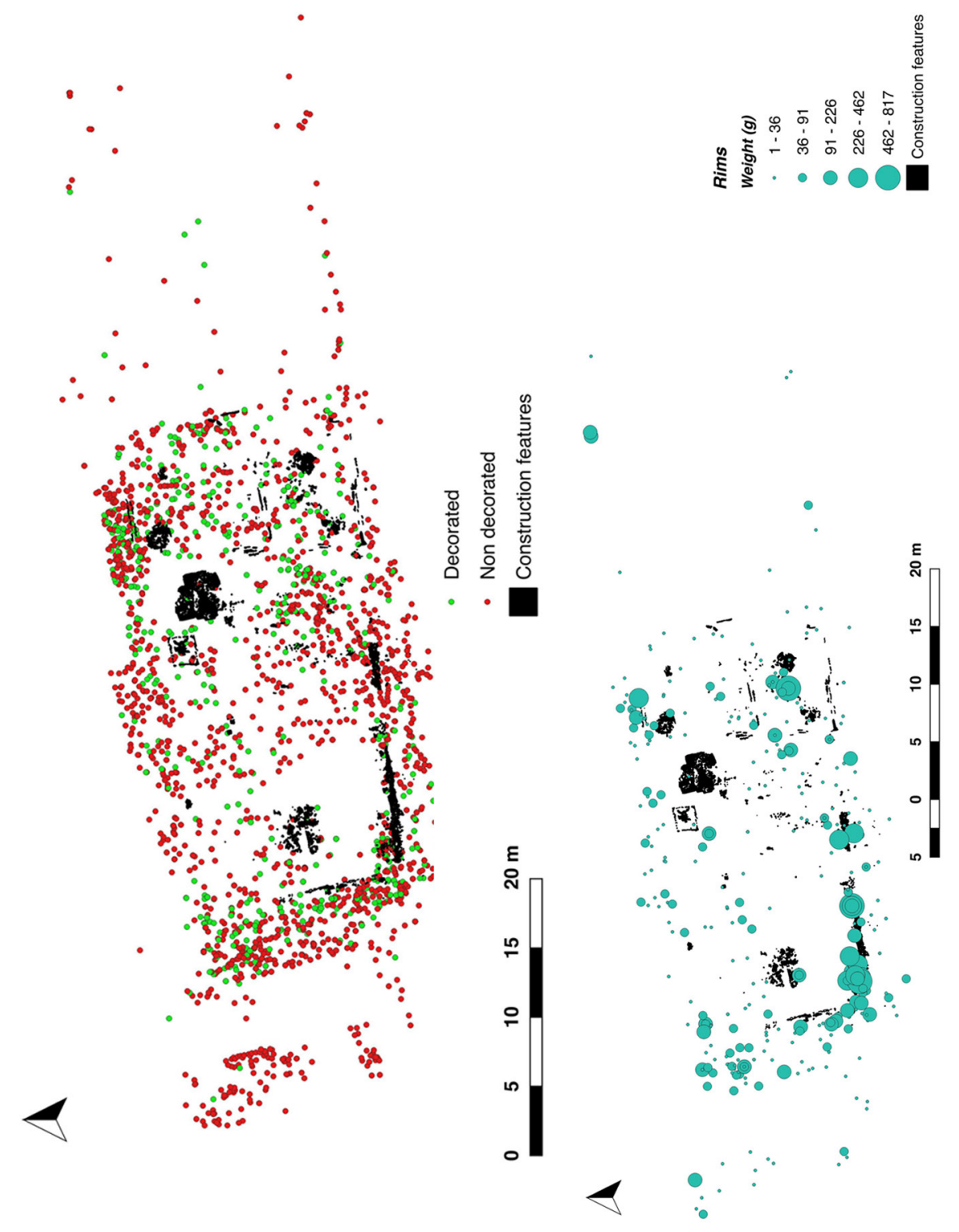

Figure 5.13: Upper: distribution of decorated vs. undecorated sherds; lower: distribution of rims by weight, Mega-structure (by M. Nebbia). 


\subsubsection{Distribution of Vessel Types in the Mega-Structure (Analysis 9)}

The Total Station recording of sherds from the Mega-structure allows a GIS-based distribution of pottery types and decorative styles (for decoration, see below, p. 299ff). Six types of distribution can be recognised (Fig. 5.14):

a) all-over heavy scatter, found for body sherds, painted fine wares and all vessels with decoration (Fig. 5.13 upper);

b) all-over medium scatter, found for rim sherds (Fig. 5.13 lower);

c) medium scatter in most areas, found for sherds with impressed decoration (Fig. 5.14/1);

d) all-over thin scatter, found for bases, handles \& lugs, coarse wares, plates, necked bowls, dishes, necked dishes (Fig. 5.14/2), fine and medium necked forms;

e) specific clusters or areas, found for bowls (Fig. 5.14/3) and one cluster of miniature vessels; and

f) singletons, found for complete vessels, amphorae and other miniature vessels.

Given that the all-over heavy scatters merge sherd deposits from all Phases, the Phase distributions give more precision to the spatial analysis. Unless not recognised and excavated, signs of pre-Mega-structure activity were limited to activity under the place where the podium would be built. The ten or more sherd clusters placed on the living floor, mostly in the North-East rooms or near the walls (Fig. 5.14/4), suggest depositional events or episodes involving a wide range of social groups whether households, Neighbourhoods or even Quarters - all contributing the sign of their identities to what was the largest Assembly House at Nebelivka. Equally, the six or more sherd clusters found in the open central area or outside to the West of the Mega-structure betoken similar episodes, even though we cannot date them precisely. What the sherds discarded during the Destruction phase underlines is the massive collective scale of deposition in many different episodes by many different social units - amounting to over 2,500 sherds and almost $60 \mathrm{~kg}$ of ceramic. This was, in many ways, the defining collective depositional process of the Mega-structure, created by contributions from occupants all over the megasite at the time of the Mega-structure's burning. These vessels or sherds could not have been placed on the Mega-structure living floor, since they would have been discovered in a Living Floor context! This means that this large number of vessels and sherds were left in places from which they fell (e.g., shelves, hooks, wall niches) with walls and ceilings to form the destruction deposit.

The distributions of the individual pottery types present us with an interesting absence - the lack of any functionally coherent pottery groups. By contrast, we find overall thin scatters for the majority of types, including the most common types the dishes and plates. This means that we are not looking at a collection of 'living assemblages' sensu Schiffer (1976) but, instead, a long series of collective depositions placed according to a Nebelivkan logic of quotidian practice which was certainly related to collective consumption and probably feasting. 

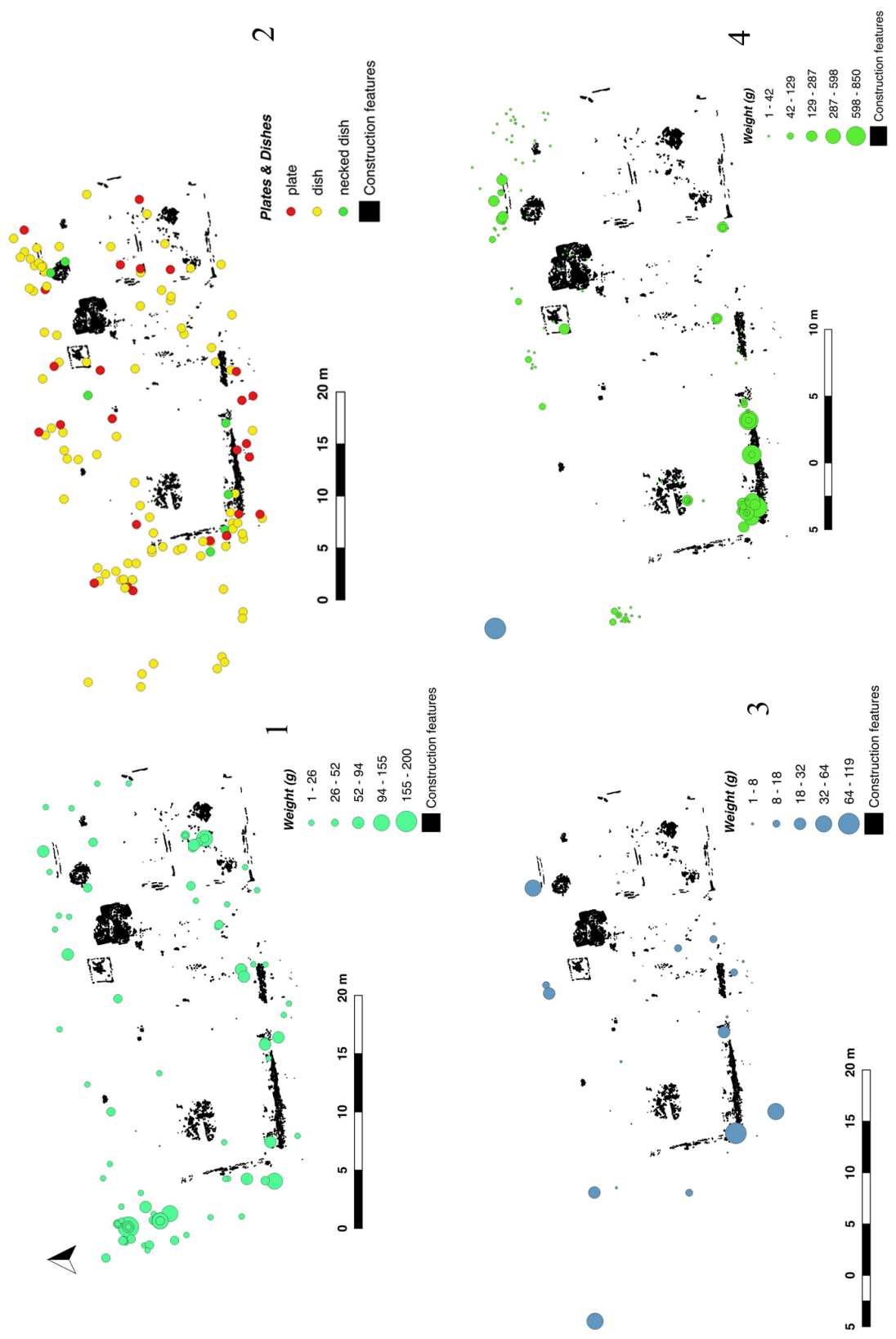

Figure 5.14: Distribution of (1) impressed sherds by weight; (2) plates, dishes and necked dishes; (3) bowls by weight; (4) pottery found on Living Floor (Phase 2) by weight, Mega-structure (by M. Nebbia). 


\subsubsection{Decorative Style by Vessel Type (Analysis 10)}

This analysis considers the relationship of the vessel form derived from the detailed typology to decorative style, using the Pit assemblage in Sondazh 1. This analysis shows strong trends in this relationship, suggesting well-developed rules governing the decoration of vessels. Plates are the only type to which no impressed, incised or grooved decoration is applied, with all decoration being painted. There is a major component of painted decoration in the amphorae, dishes and flasks, although a small proportion of non-painted motifs is found on these forms as well. Impressed motifs are almost as common on necked forms as are painted motifs, while the only type with more impressed than painted decoration is the bowl.

\subsubsection{Distribution and Placement of Decorative Motifs by Excavation Unit (Analysis 11)}

The typology of the decorative motifs at Nebelivka is based upon an extension to the test pits and House A9 of the research of Ms. Sophia Arbeiter, who created a detailed typology of the motifs found in the Mega-structure and the Pit in Sondazh 1 (Arbeiter n.d.; Caswell et al. 2016). The unit of analysis - the individual motif - was selected because of the small size of most sherds.

A total of 169 decorative motifs was defined in three overall groups: 41 nonpainted motifs, 72 motifs painted on vessel exteriors and 56 motifs painted on vessel interiors (Figs. 5.15-5.18). The non-painted motifs and the exterior painted motifs were used more frequently than the interior painted motifs. A comparison of the excavation units where decorative motifs occurred shows the greatest variation in use of interior painted motifs, ranging from $34 \%$ of all motifs in the test pits to $60 \%$ in both the Mega-structure and the Pit, Sondazh 1.

Non-painted motifs ranged from $51 \%$ of all possible motifs in the test pits to $72 \%$ in House A9, while the narrowest variation in use occurred with exterior painted motifs - a range of $62-72 \%$ across all excavation units. There are three trends in the developing choice of motifs in the Stratigraphic Units in the Pit. An increase in nonpainted motifs with time was matched by a decline in exterior painted motifs, with a greater choice of interior painted motifs in the middle part of the Pit. These results indicate that the choice of decorative motifs made a contribution to the identity of local groups at Nebelivka. 

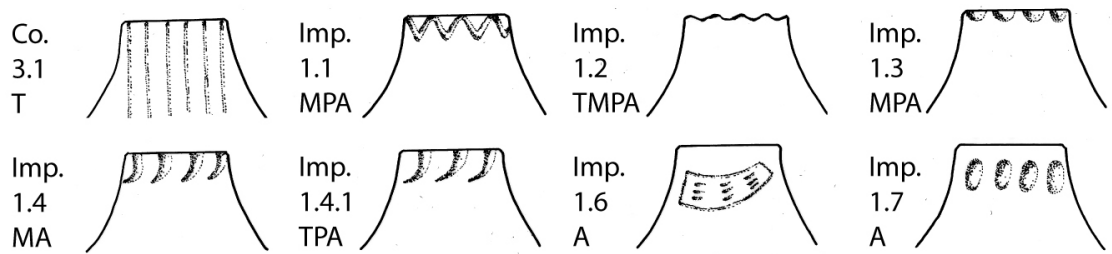

Imp.
2.3
TMPA

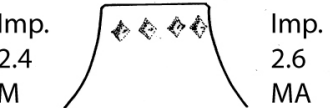
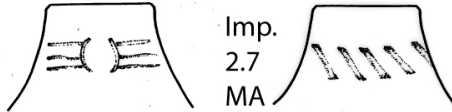

Imp.

2.8

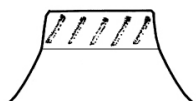

Imp.

TMPA

Imp.
3.2
TMPA

$\left.\begin{array}{l}\text { Imp. } \\ 3.3 \\ \text { TMP }\end{array}\right) .9000000$

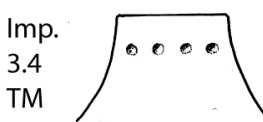

Imp.
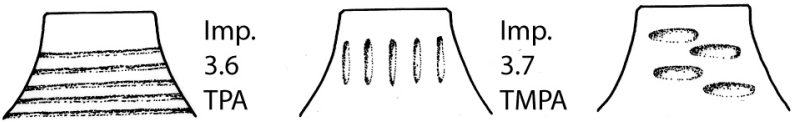

Imp.
3.9
PA
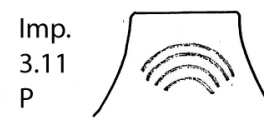

Imp. Pai.
$3.4 / 3.2$
$M$

000 Imp. Pla.

12. 3.1

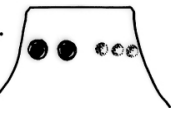
Imp.Pla.
3.2
$\mathrm{TPA}$
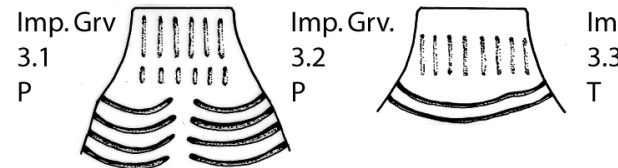

mp.Grv. 1111111
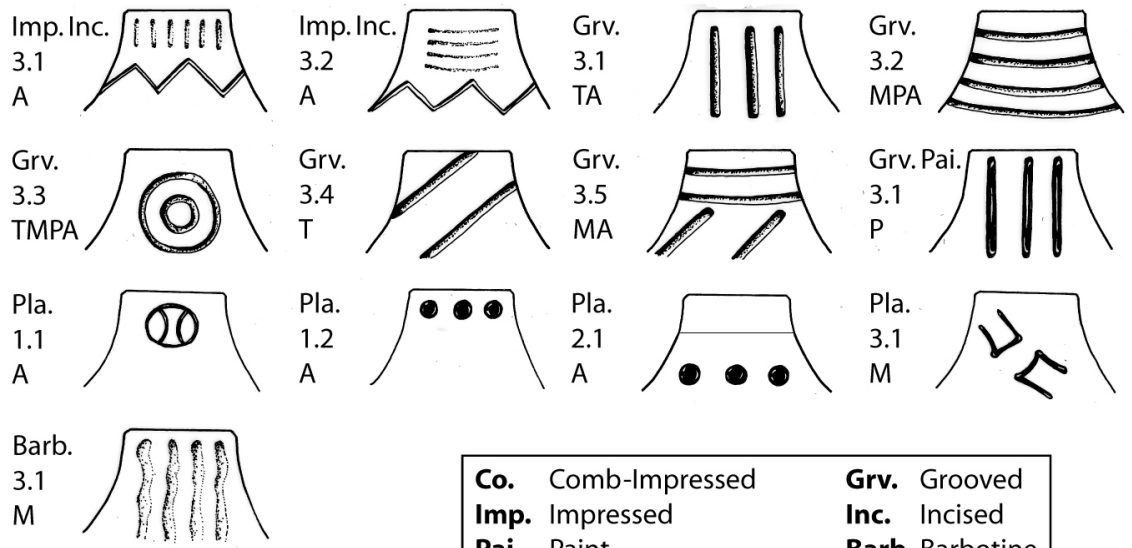

Co. Comb-Impressed Imp. Impressed

Pai. Paint

Pla. Plastic
Grv. Grooved

Inc. Incised

Barb. Barbotine

Figure 5.15: Coarse ware decorative motifs. Numbers (e.g., 3.1) refer to Motif Numbers. Key: $T$ - Test Pits; M - Mega-structure; P - Pit, Sondazh 1; A - House A9 (L. Woodard). 

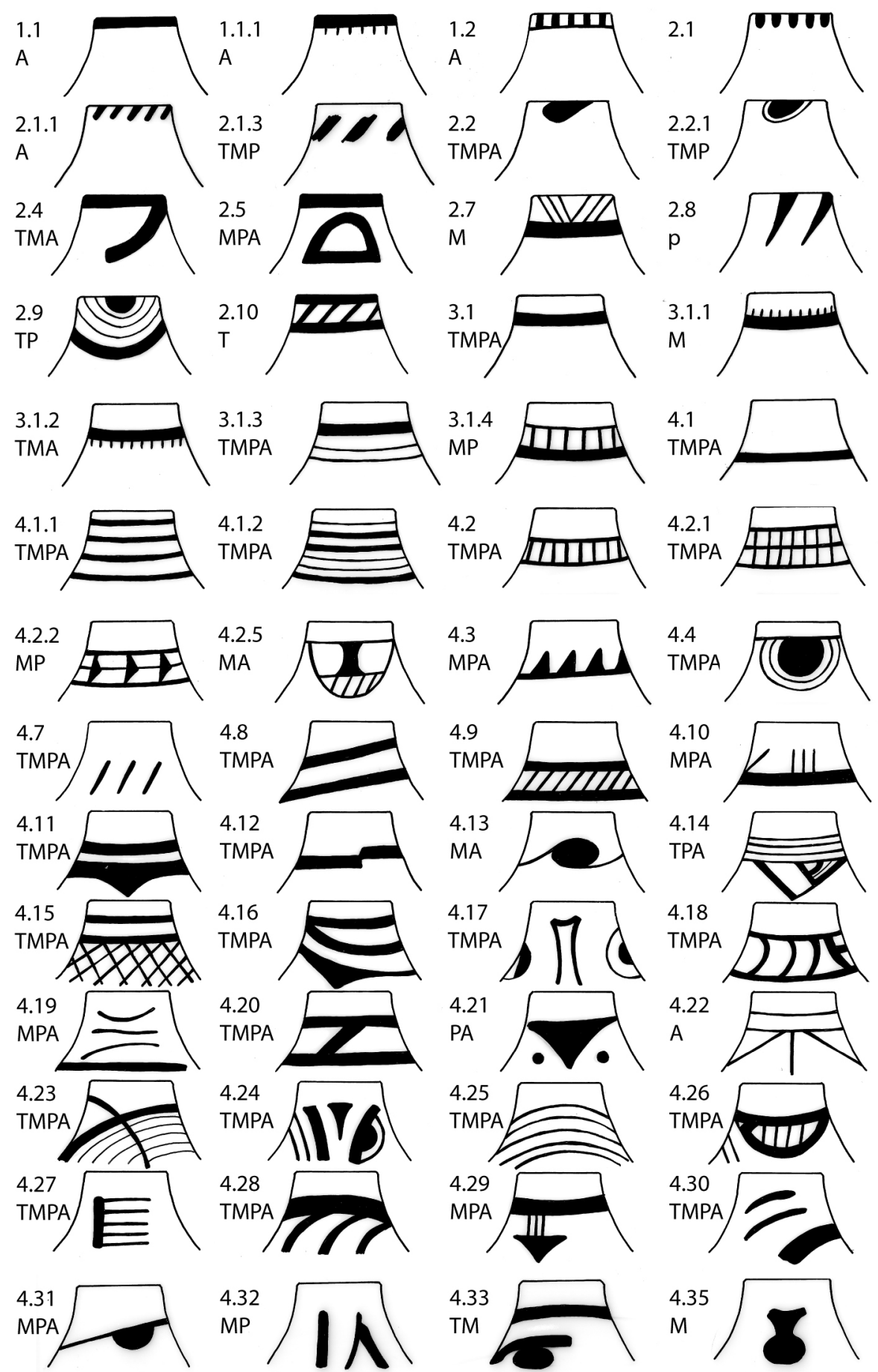

Figure 5.16: Fine ware exterior painted motifs (by L. Woodard). 

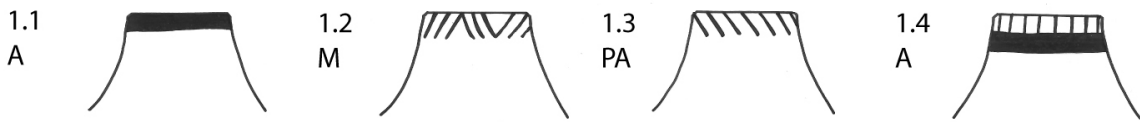

1.5
MPA
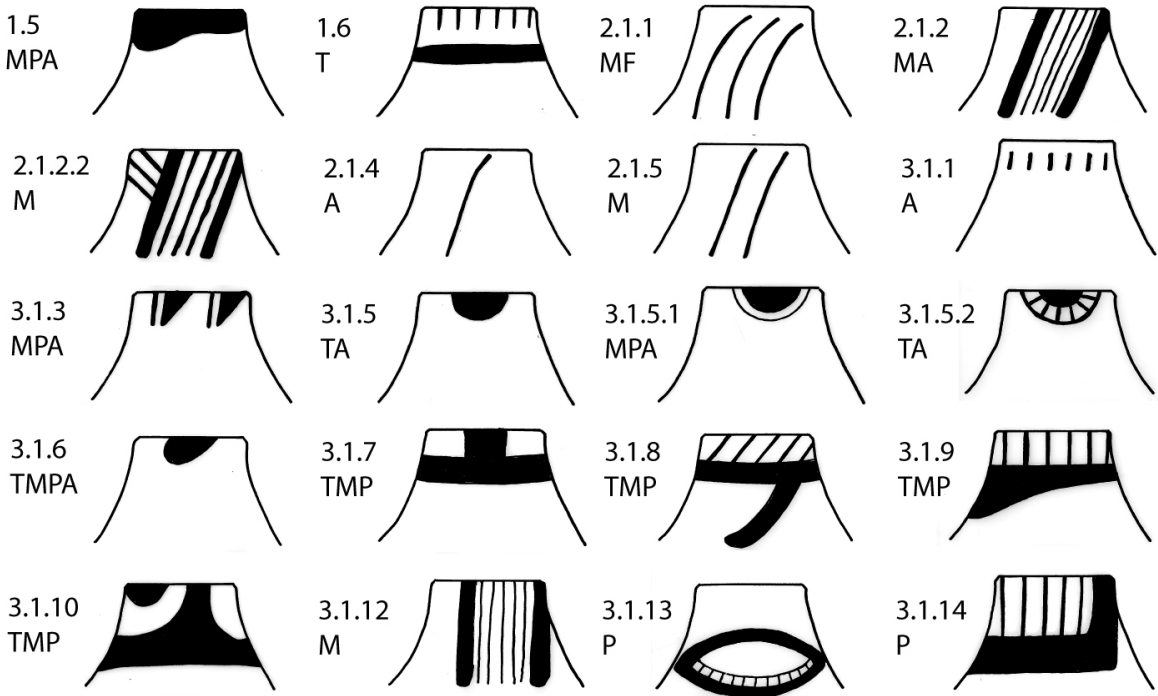

3.1 .16

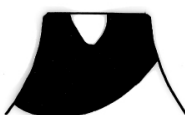

3.1 .17

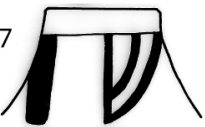

3.2 .1
TMPA
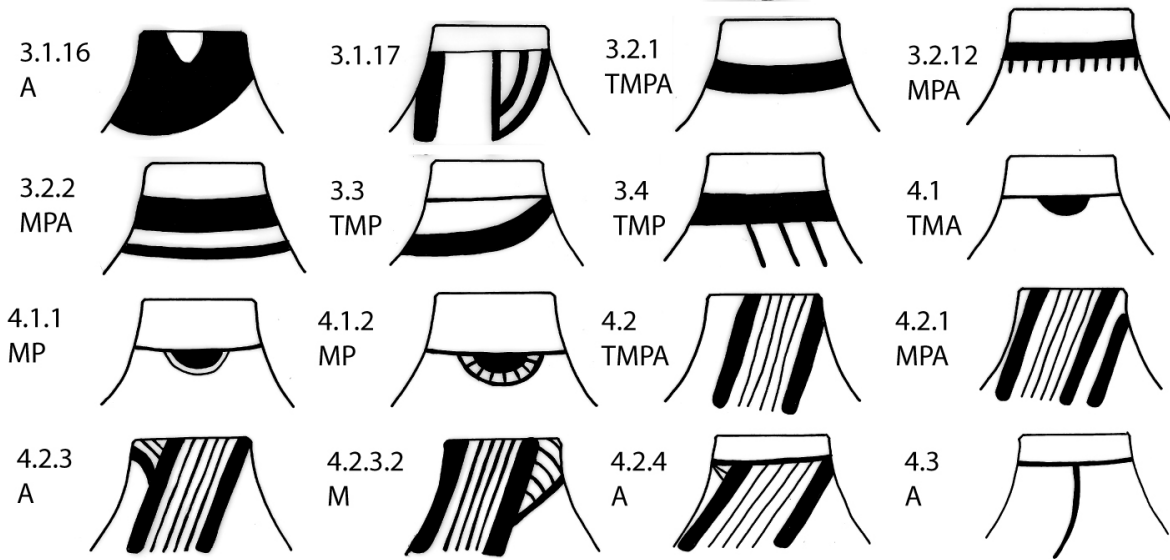

A

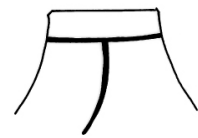

4.4
TMPA

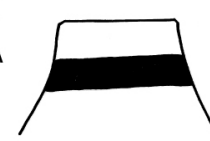

4.5

A

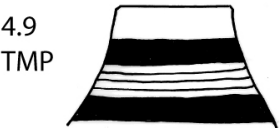

4.10

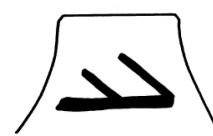

4.7
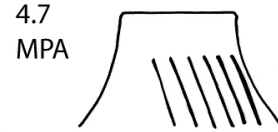

4.8 MPA

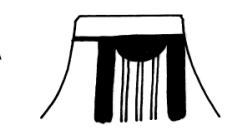

M

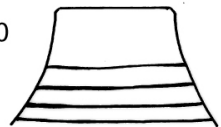

4.12

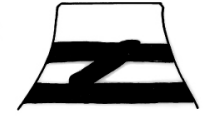

4.13

MP

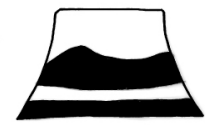

Figure 5.17: Fine ware interior painted motifs (by L. Woodard). 

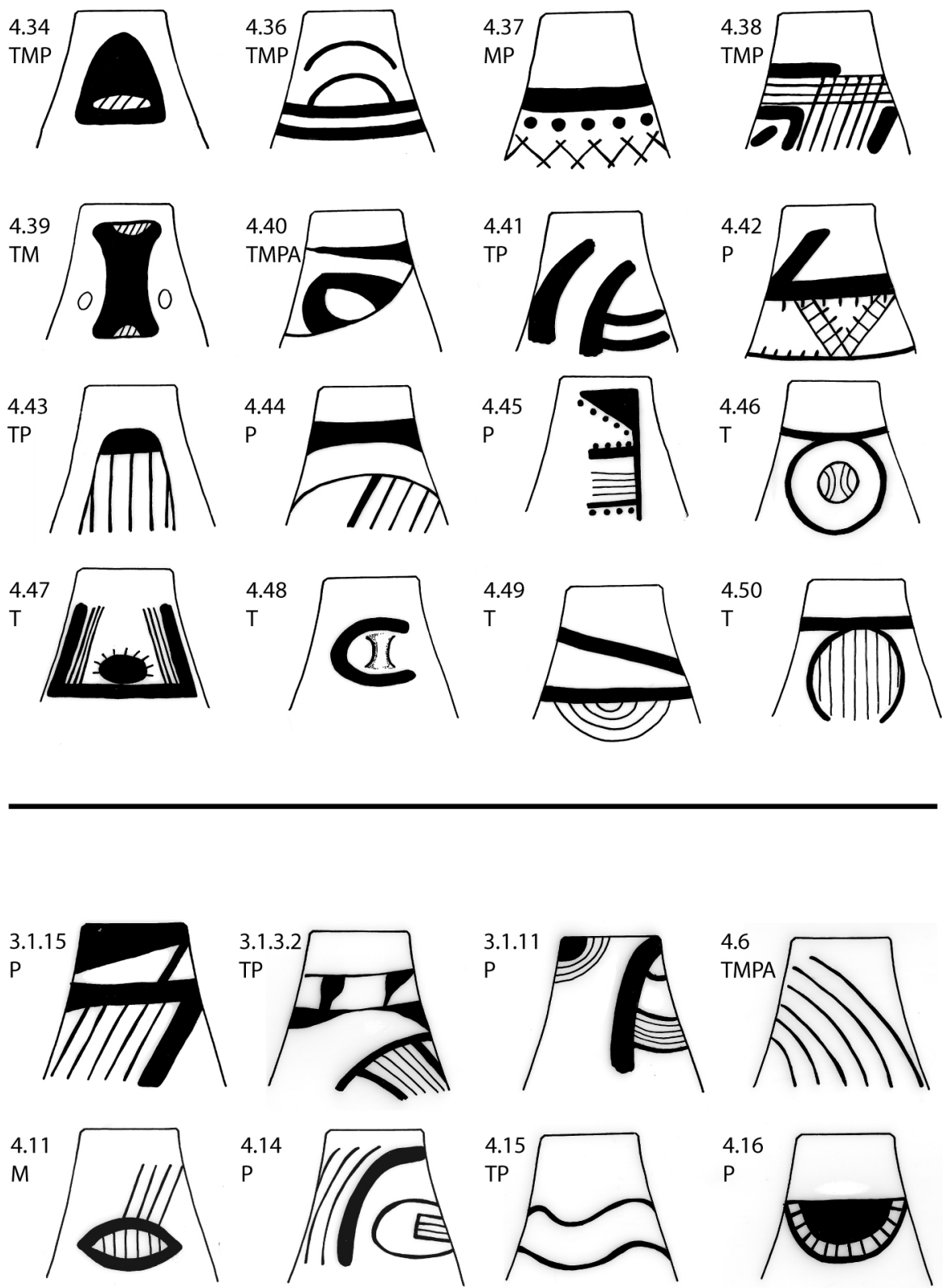

Figure 5.18: Fine ware exterior (rows 1-4) and interior (rows 5-6) painted motifs (by L. Woodard). 
A more nuanced picture emerges from the analysis of Quarters, where the samples are much smaller than in the full excavation units. There, differences are observed in the selection of non-painted motifs, interior painted motifs and exterior-and-interior painted motifs in different parts of the megasite. Non-painted motifs show consistently moderate values except in Quarters C and F. Interior painted motifs were absent in the Northern part (Quarters G and H), infrequent in the South-East area (Quarters $\mathrm{L}$ and $\mathrm{N}$ ) and most frequent in the Eastern and North-Eastern parts (Quarters B, C and F). Exterior-and-interior motifs were not found at all in the Northern and NorthEastern areas but used most frequently in the South-Eastern area (Quarters L and N). These differences in motif placement show that people living in different parts of the megasite - perhaps also in different decades - were making choices as much at the Quarter level as at the household and Neighbourhood level.

\subsubsection{Decorative Motif Combinations (Analysis 12)}

In view of the overall mean sherd weight of $23.7 \mathrm{~g}$ for the Nebelivka assemblage, it is perhaps not surprising that there is but one motif on $75 \%$ of all decorated sherds. The incidence of sherds with one motif only rises to $96 \%$ of painted sherds. Most of the non-painted motifs and those sherds with combined motifs on the exterior and interior surfaces were deposited in House A9, while exterior and interior painted motifs were preferentially placed in the Mega-structure.

The frequency of decorated sherds with multiple motifs decreases as the number of motifs increase. All decorational locations displayed combinations of both two and three motifs but four-motif combinations were found only on non-painted motifs and exterior painted sherds. Two-motif combinations showed a varied distribution in excavation units, with non-painted motifs equally represented in House A9 and the Mega-structure, exterior painted motifs most frequent in the Pit, exterior-and-interior painting most often in House A9 and interior painting evenly spread. These patterns reinforce the previous conclusion of identity-formation through choice of decorated sherds for final deposition. These performances are especially striking in the burning of House A9 and the Mega-structure, but the multiplicity of smaller performances in pit deposition should not be overlooked.

\subsubsection{Motif Linkage (Analysis 13)}

One of the most detailed analyses of decorative motifs concerns the distribution of sherds with specific motifs in the $80+$ test pits. From a total of 169 motifs, only 22 were found in three or more test pits. Eighteen cases comprised exterior painted motifs, with only one interior painted motif and three non-painted (impressed) motifs. The rarity of interior motifs is curious in the light of the high frequency of open forms in the test pits. Most of the 22 motifs were found in between three and seven Test Pits, while only three motifs linked more than 10 Test Pits (see below, Fig. 5.19). 
Two more detailed plots of motif linkage have been prepared: the four most popular motifs across the entire megasite (Fig. 5.19) and all 11 motifs in the seven test pits excavated in Quarter B (Fig. 5.20). The four most popular motifs were found as follows: Impressed Motif 3.1 (12 test pits) and Exterior Painted Motifs 4.8 (25 test pits), 4.1.2 (15 test pits) and 4.16 (10 test pits) (Fig. 5.19). It should be noted, however, that two of these motifs were relatively simple and had possibly been included in many motif combinations. Only one widespread motif (4.16) was more complex, with inclusion in many combinations unlikely.

The distribution patterns of these four motifs show complex relations across the megasite, first related to the overall presence of motifs, then to single motifs, then to motif combinations and fourthly to zonal variations (Table 5.5).

Table 5.5: Location of single motifs and motif combinations (Figs. 5.15-5.18) by zone, megasite (by J. Chapman).

\begin{tabular}{lllll}
\hline MOTIFS & EAST SIDE & NORTH SIDE & WEST SIDE & SOUTH SIDE \\
\hline $\begin{array}{l}\text { PRESENCE (SOLO OR IN } \\
\text { COMBINATION) }\end{array}$ & 11 Test Pits & 14 Test Pits & 7 Test Pits & 9 Test Pits \\
3.1 & OC/IRS & OC/IC/IRS & OC & IC/IRS \\
4.8 & OC/IC/IRS & OC/IC/IRS & OC/IC/IRS & OC/IC/IRS \\
4.1 & OC/IC/IRS & IC/IRS & OC/IC & OC/IC \\
4.16 & IC/IRS & OC/IC/IRS & - & OC/IC/IRS
\end{tabular}

\section{SOLE MOTIFS}

$\begin{array}{lllll}3.1 & \text { OC } & \text { IRS } & - & \text { IC/IRS } \\ 4.8 & \text { OC/IRS } & \text { IC } & \text { IC/IRS } & \text { OC } \\ 4.1 & \text { OC/IRS } & - & \text { IC } & \text { OC } \\ 4.16 & - & \text { IC } & - & -\end{array}$

COMBINATIONS

\begin{tabular}{lllll}
$3.1+4.8$ & - & - & OC & - \\
$3.1+4.1$ & OC/IRS & - & - & - \\
$3.1+4.8+4.1$ & - & IC & - & IC \\
$3.1+4.8+4.16$ & - & OC & - & OC \\
$4.8+4.1$ & IC & IRS & OC & - \\
$4.8+4.16$ & IC/IRS & IRS & - & OC/IRS \\
$4.8+4.1+4.16$ & IRS & IRS & - & - \\
$4.1+4.16$ & IC & - & - & - \\
\hline
\end{tabular}

Key: OC - Outer Circuit; IC - Inner Circuit; IRS - Inner Radial Streets 
We begin with the overall distribution of single motifs, whether found on their own or in combination. Some motifs, such as 4.8, occurred widely in every zone of all four sides of the megasite, while others occurred in most sides of the megasite but in different zones (e.g., Motif 4.1, found in all zones on the East side but absent from the Inner Radial Streets on the West and South sides and from the Outer Circuit on the North side). Very few motifs were absent from all zones of one side of the megasite, as was the case with Motif 4.16, missing from the West side completely.

A different picture derives from those test pits where only one motif of the four was found. With such motifs, the coverage is much more patchy, with no examples of a solo motif found in all zones of a megasite side. Most solo motifs were deposited in only one zone, with only Motif 4.8 found in each zone of every side. Motif 4.16 continues to show the narrowest distribution, found as a solo motif only in the Inner Circuit of the South side.

Motif combinations also show a varied linkage pattern, with some combinations occurring in only one zone (e.g., Motifs $3.1+4.8$ in the Outer Circuit on the North side only; Motifs $4.1+4.16$ in the Inner Circuit on the South side only), most others found in more than one zone on more than one side and not a single combination found on all sides.

Another way of understanding these motif linkages is to consider motifs from houses in the same Neighbourhood. Of the eight Neighbourhoods with two or more motifs represented, not a single Neighbourhood has two houses with identical motif combinations. The opposite case - two houses with mutually exclusive motifs was found in Neighbourhood 45, while two Neighbourhoods opposite each other in the Outer and Inner Circuits (Neighbourhoods 75 and 76) shared similar motif combinations. Otherwise, difference dominated the Neighbourhood patterning, with the suggestion of the primacy of household identity in all cases.

A more spatially intuitive way to understand these complex linkages is the examination of each side in turn. This will lead to a more spatially nuanced story for each side (e.g., 'West side story'). The West side story has a negative character - the absence of Motif 4.16 is the only absence from all zones of a side in the entire mapped corpus. This suggests that people making painted wares with this complex motif had a distant relationship to all of the seven test-pitted houses on the West side. But other motifs (especially Motif 4.8) linked the West side to all other sides, even though few motif combinations occurred on the West side and, when found, only in the Outer Circuit.

The main differentiating elements of the North side story were that it was the only side with Motif 3.1 in all zones and the only side in which Motif 4.16 appeared solo. In contrast to the West side, this side reveals many motif combinations, as well as the deposition of Motifs 3.1, 4.8 and 4.26 in all zones. The general picture is one of greater integration through motif linkage than on the West side. 


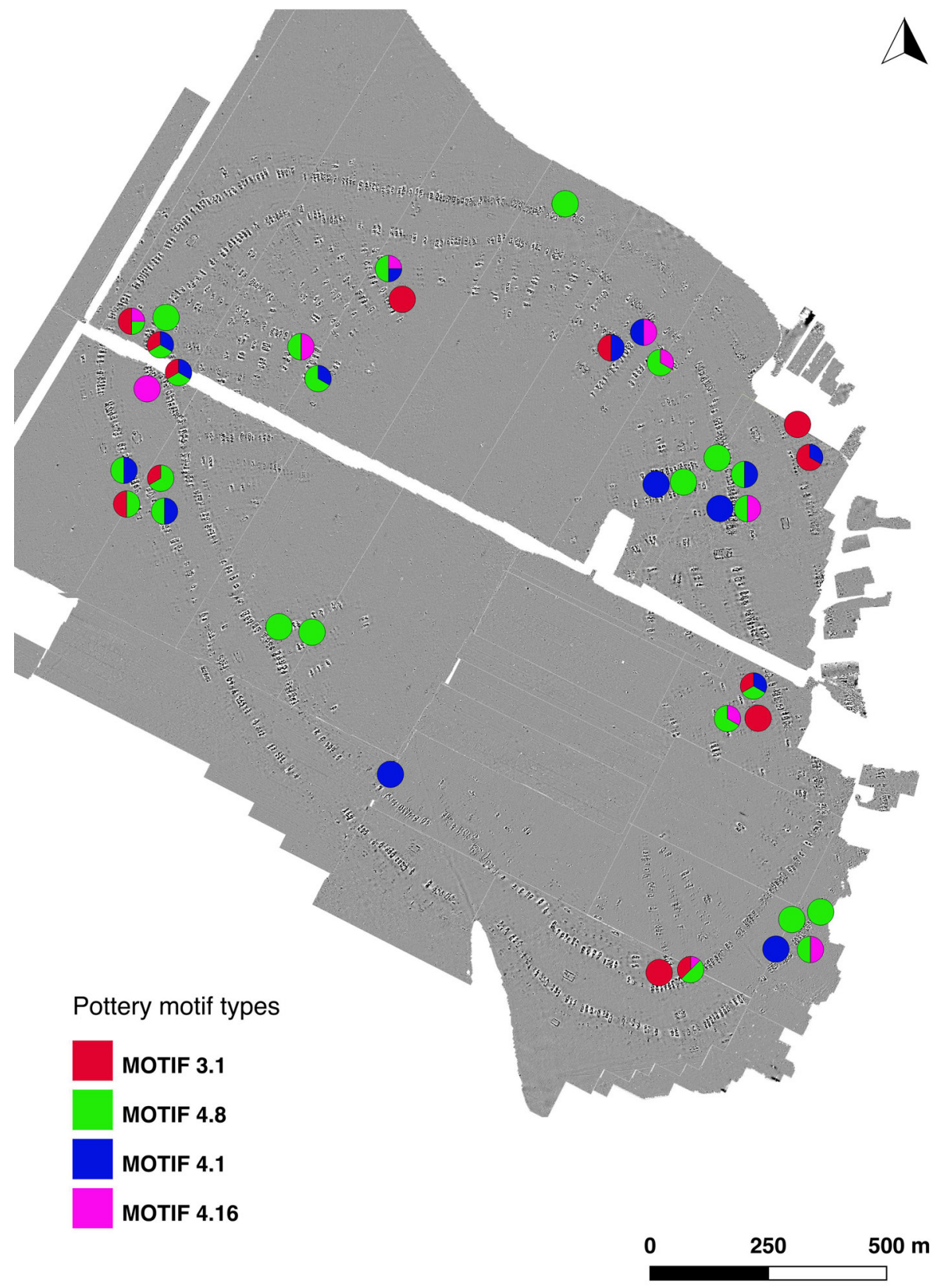

Figure 5.19: Motif linkage plans for four most common motifs, megasite (by M. Nebbia). 
The East side motif distribution shares the high frequency of motif combinations with the North side, although this side has the fewest combinations in the Outer Circuit. Motifs 4.8 and 4.1 were found in all zones of this side, as were they as solo Motifs. These data suggest lower integration than in the North side but more than the West side.

The final story - the South side - shows more similarities to the West side than the other sides, with few motif combinations and those found mostly in the Inner Radial Streets. Motifs 4.8 and 4.26 were deposited in all zones on this side, but especially in the Outer Circuit and the Inner Radial Streets. These data show a picture of moderate integration through motif linkage.

To summarise these complex patterns of motif linkage, potters created designs on vessels which were used and ultimately deposited as complete, or often broken before deposition, in the house where they were made or in other houses. The closest links between houses can be recovered by solo motif distributions, while the opposite trend - the absence of a motif from an entire side - attests to minimal relationships with other households. Between these extremes lies the vast majority of motifs, which demonstrate links between household at various scales - in the same Neighbourhood, in the same zone or on the same side. The motif linkage data shines a light on the real complexity of inter-household relations on a site as large and complex as Nebelivka. Further research on these distributions would undoubtedly provide most interesting results.

The distribution of all 11 motifs in the seven Quarter B test pits (one in the Outer Circuit, four in the Inner Circuit and two in the Inner Radial Streets) shows remarkable diversity, whether at the individual test pit level, the Neighbourhood level, within and between zones. No two test pits shared the same range of motifs; for example, all four houses in Neighbourhood 13 showed different motif combinations. The only test pit in the Outer Circuit was the only place in the entire Quarter containing Motif 13.1. This variability continued in the Inner Radial Streets, where each house had different motifs, but there are more similarities in the Inner Circuit (Motif 4.8 found in three out of four test pits; Motifs 4.15 and 13.2 found in two out of four test pits). When comparing motifs across zones, only two of the 11 motifs were found in each zone (Motifs 4.15 and 4.23), while two more motifs were found in two of three zones (Motif 4.17 in both Outer and Inner Circuits; Motif 4.26 in the Inner Radial Streets and the Inner Circuit). This complex distribution suggests a basic differentiation at the household level, with multiple but highly variable links between households in the Quarter. If most of the pottery deposited in burnt houses consisted of placed deposits, this overlapping motif linkage suggests that people from other houses were making offerings to an about-tobe-burnt house by sharing their favourite motifs. In this sense, motif linkage tells us something about communal practices and house-burning rituals. 


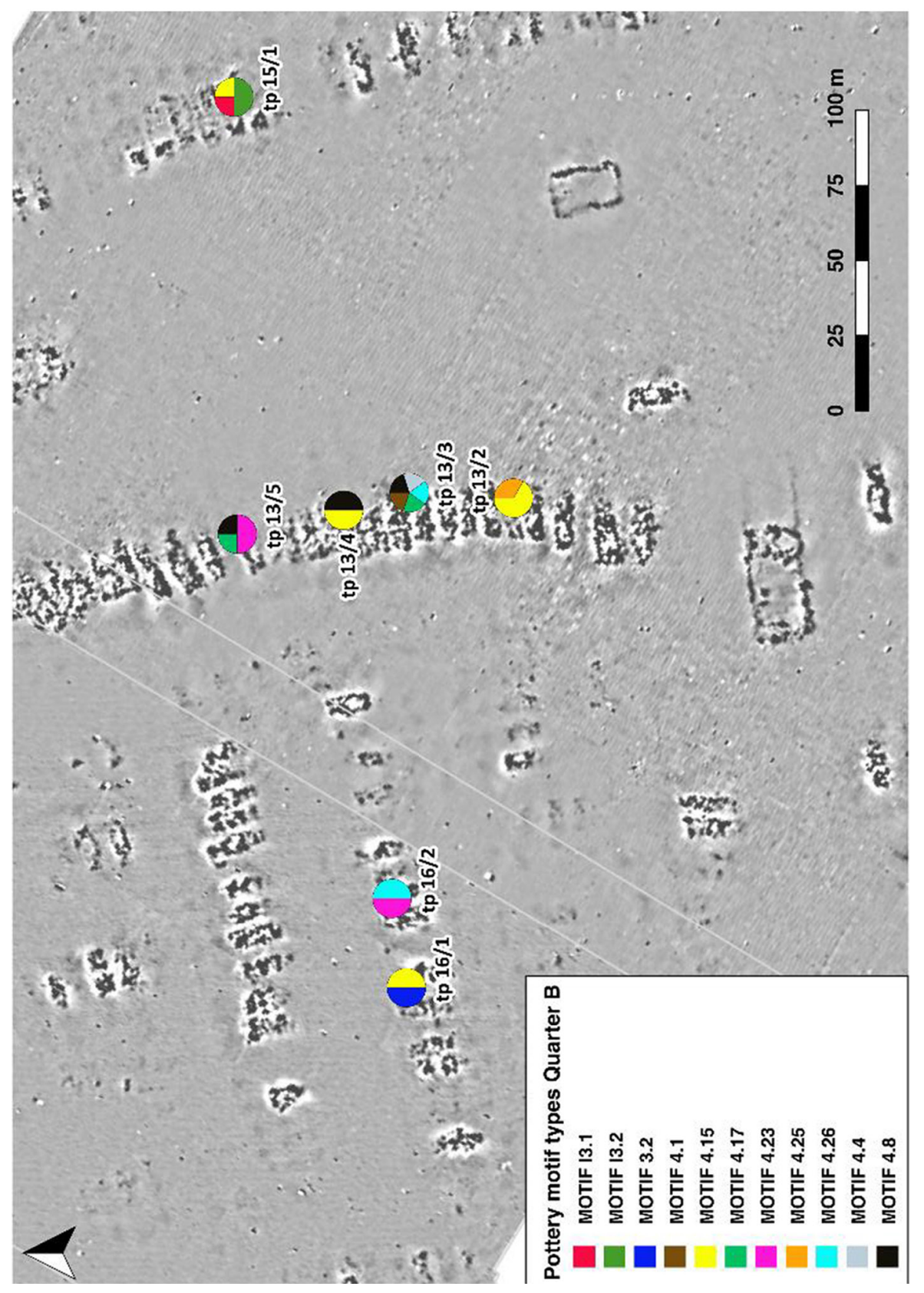

Figure 5.20: Motif linkage plan, Quarter B, megasite (by M. Nebbia). 


\subsubsection{Discussion of the Pottery Analyses}

The key aspect of the Trypillia ceramic Big Other is that, within an overall similarity of technology, form and decoration, there remains the possibility for local difference. This enabled local communities and households to adhere to the general principles of the Big Other without denying themselves the potential for varying practices best suited to the social milieu and the point of time in the overall megasite sequence in which they found themselves. The starting point of the discussion will, therefore, be the multiple similarities between the pottery assemblages from the four excavation units at Nebelivka, before we turn to the equally numerous differences.

The first overall similarity concerns the similarity in the fabric profiles at Nebelivka. While there is certainly variation in the less frequent parts of the profile (see below, p. 313), the most popular Fabrics showed similar frequencies in three of the four units. This implies a basic strategy of clay and temper procurement from the Nebelivka micro-region and similar practices in clay preparation. Similarities can also be seen in the shapes and sizes of the discarded vessels. Although the frequencies of use to which the vessel types were put did indeed vary, the same range of shape types can be seen in every excavation unit. This indicates that the basis for vessel use was indeed widely shared, whether the ubiquity of bowls and necked forms for food preparation, the plates and dishes for larger- and smaller-scale consumption and the ubiquitous rarity of the deposition of storage jars. In terms of vessel size, the balance between small, medium-sized and large vessels, despite one minor variation in the test pits, shows the discard of a generalised assemblage in all excavation units, with rare indications of specialisation in form (one example might be the set of 21 miniature vessels that probably fell off a shelf in the Mega-structure, a second the concentration of miniature vessels in houses in Quarter H). This suggests that those depositing the vessels and sherds were making those selections from a stable, enduring pool of vessels created through similar production in many parts of the site. Another similarity concerns the use of the same decorative styles in all parts of the site. The predominance of the painted style in comparison with impressed, incised, grooved and plastic styles can be regarded the hallmark of Trypillia pottery. But it is important that decoration is regarded as a mainstay of the pottery Big Other, even though variations in decorative motifs, and in the placement of motifs, may characterise the different parts of the megasite. A further similarity concerns the shared rules for the application of certain decorative styles to specific vessel forms. The Trypillia practice, which lies somewhere between the principle of mutually exclusive categorisation and more flexible, cross-cutting categorisation (Keightley 1987; Chapman \& Gaydarska 2007, Chapter 2), is widely shared across the megasite. The last two similarities concern the choice of the nature and size of the pot part to be deposited. The distribution of pot parts is remarkably similar in all excavation units, showing a cumulative convergence of depositional practices across the megasite. This convergence extends to sherd sizes as plotted on almost identical cumulative frequency graphs. We can envisage similar fragmentation techniques applied to the 
full range of vessel forms, which in turn led to the similarities in potpart distributions. Thus, in important stages of the life of many Nebelivka vessels, there was convergence towards the similarities which were vital to the continued working of the Big Other at the local level, played out in month after month, year after year and generation after generation in the maintenance of a pottery tradition. The people using vessels engaged with a broadly similar range of statements about how a pot should be as those who made the vessels - thereby forming a stable material world throughout the megasite sequence. In the Neighbourhoods and Quarters of Nebelivka, household members were most likely to have used the pottery and then deposited or discarded the vessels in their own house or another household (cf. Wengrow 2001).

However, the other side of the Big Other was the local variability which was possible without posing a threat to the global concepts. This variability was more often the greater or lesser preference for a particular ceramic trait rather than its presence or absence. More nuanced than a presence/absence dichotomy, this graded variability is a tacit reinforcement of the ceramic Big Other and can be seen in many of the analyses of the Nebelivka pottery. An important question was whether the Nebelivka residents were making identities more through the use of cross-cutting variability (e.g., the tensions between household, Neighbourhood and Quarter identities) or with polar opposites (e.g., male-female, first settler-latecomer; cf. Chapman \& Gaydarska 2007, Chapter 2). To explore this question, we turn to the results for each excavation unit.

The test pit sample is the megasite sample in which temporality - mediated by the social - could have had the strongest effect on individual test pit pottery; after all, the difference in the date of dwelling in these houses may have been as much as five generations, or 200 years. Although the Project has been unable to produce a detailed inner chronology for Nebelivka, we should be aware that mediated temporal factors may have been significant in ceramic differences between test pits.

The test pit sample shows depositional practices more focussed on decorated sherds than the other units; the decorated sherds in the Test Pits are larger than in the Pit and House A9 but the same size as sherds from the Mega-structure. Counterfactually, the test pit decorated sherds made use of the lowest proportion of interior painted and non-painted motifs of all units, although the high number of non-painted ware two-motif combinations was matched only by the Mega-structure. The distribution of decorative motifs found in three or more test pits showed an even spread with one motif (4.8), a preponderance in the Northern half in two cases (Motifs 3.1 and 4.1) and a predominance in the North-Eastern half in the remaining motif (4.16). These distributions of common motifs underlined the links between all parts of the megasite but also suggested stronger linkage in the Northern part.

The distribution of test pit fabrics differed from all other units except the destruction phase of the Mega-structure in a preference for two fabrics and an even distribution of many other fabrics. This distribution is consistent with the diversity of test pits in the total sample. The vessel size profile in the test pits differs from the other three similar profiles, with fewer small and more medium-sized vessels. The 
only distinguishing feature of vessel form in the test pits is the high concentration of miniature vessels - another point of resemblance to the Mega-structure. However, the predominance of dishes in the test pit MINV series showed a tendency towards the deposition of food preparation ceramics. In summary, the test pit sample showed the kind of diversity that was expected from the combination of many small house samples but with an added emphasis on those decorated sherds marking local identities. Despite the tendency for the deposition of food preparation ceramics, the test pit sample showed closest links to that of the Mega-structure.

The analysis of all the test pit pottery found in a specific Quarter led to questions being asked of the pottery at a different spatial scale - intermediate between the megasite as a whole and the individual test pits. Differences between these smaller ceramic assemblages can be seen at three spatial scales: parts of the megasite, the Quarter itself and houses within some Quarters. Area differences were observed in the choice of motif placement in three out of the four general decorative categories - nonpainted motifs, interior painted motifs and exterior-and-interior painted motifs. They were also found in variations in the number of fabrics used in a Quarter.

There are several cases where most Quarters conform to a pattern, with one or two exceptions. One of the most striking cases is the preference for open rather than closed vessel forms in most Quarters. However, in Quarter G, the lowest ratio of dishes to plates in all the Quarters characterised a pottery assembly with the greatest degree of inter-household fabric variation. One interpretation of these observations is that communal feasting was particularly important as a way of integrating people from a wider-than-usual range of small sites in the Nebelivka catchment.

The variety of household choices made for vessel fabrics in the four houses in Quarter G contrasts with the relatively homogenous household choices in Quarters B and M. This may be a sign of different clay source preferences, different constituents of the households in a given Quarter (more variable in Quarter G, less variable in the other Quarters) and may also involve different dates of dwelling. Bayesian modelling of dates for houses within each Quarter suggest few chronological differences but, in Quarter G, Test pit 25/3 post-dates all other samples excepting that from 25/1 which itself predates most other samples. Equally, in Quarter E, Test Pit 20/1 is earlier than Test Pit 20/3 and 35/1. In general, we are still finding it hard to make progress with fine-grained dating of houses, Neighbourhoods and Quarters at Nebelivka (see Section 4.8).

The Mega-structure sample showed similarities and contrasts both within the various Phases and also with the other units. There was strongly preferential deposition of large, decorated sherds on the living floor before the burning of the Mega-structure, a far greater number of sherds occurring in the destruction phase and a large number of small, undecorated sherds found after the burning of the structure. The preference for decoration was emphasised by the highest number of combinations of both interior and exterior painted motifs and the common use of non-painted motifs, as in House A9. There was a shared preference for three Fabrics 
in all phases but the choice of many Fabrics in sherds deposited in the destruction phase suggests a diversity of contributors to the burning event - supposedly from other Neighbourhoods and even Quarters as well as local households. The emphasis on communal consumption - perhaps feasting - is shown in the Mega-structure sample by the highest proportion of open forms in any unit. In summary, the Megastructure sample shows a greater tendency towards communal consumption and large decorated sherd deposition than in any other unit - both choices related to the performance of burning the Mega-structure. There are no greater similarities with any of the three other samples - just traits overlapping with each unit.

The House A9 sample shows a wider range of differences from all of the other three samples but, even here, the differences are graded rather than absolute. Thus, the House A9 sample is the only sample where plates outnumbered dishes - a contrast emphasized in the use of more different Fabrics for each form than in the Pit and in the variations in choice of secondary Fabrics too. This assemblage shows the highest proportion of non-painted ware motifs chosen than in any other unit yet, counterfactually, combines this with the lowest proportion of coarse wares deposited. The choice of a different Fabric profile from the other units and the lowest proportion of decorated sherds of all units serves to underline the differences between the House A9 sample and the other three units. It would be interesting to see if other complete house assemblages (such as House B17) showed such differences - as if to emphasise their individual identities in contradistinction to the other units. The strong preference for plates shows a tendency for deposition related to communal consumption on the occasion of burning the house. The dispersed deposition of vessels and sherds across mostly Room 1 shows that the material was carefully and deliberately placed before the burning of the house, so as to reproduce extant inter-household relations (see below, p. 326).

Finally, the assemblage from the Pit in Sondazh 1 showed diachronic trends in its stratigraphic units (SUs) that were more significant than similarities and differences with other units. The earliest deposit (SU 1) included the largest fine and coarse ware sherds and even more decorated than undecorated sherds - a most unusual event in all samples. Although this initial deposit lacked special animal deposits (cf. at Majdanetske: Müller \& Videiko 2016, pp. 79 \& 86), the special emphasis on large and decorated sherds marks this out as an important communal event. Whatever happened next, in the SU 2 deposits, marked a contrast not only to SU1 but also with the later SUs. SU 2 reversed the diachronic trend towards smaller fine and coarse ware sherds and the increased use of Fabric A (pink fine ware). The choice of the highest proportion of closed forms in the entire Pit - itself selecting more closed forms than any other unit - shows that Pit deposits and especially the SU 2 deposits were hardly the result of feasting or communal consumption but rather of smaller-scale food preparation and consumption ceramics. This conclusion is borne out by the far higher ratio than usual of dishes to plates. The preference for Fabric B (red-grey fine ware) is comparable to other units but the preference for closed forms distinguishes the Pit 
from all other units. This suggests that, after an initial depositional event emphasising large and decorated sherds, the materials deposited in the Pit derived from domestic food preparation events, presumably from different adjacent houses. Nonetheless, we should not forget that parts of over 40 vessels were deposited in some of the Pit Episodes, suggesting large-scale deposition by several households not necessarily matched by communal consumption.

The consideration of the pottery samples from the four different samples allows us to answer the question posed above: was the use of cross-cutting variability more important than polar opposites in the construction of megasite identities? The clear preference for graded differences rather than presence/absence variation indicates that a relational strategy was preferred, with the slow build-up of the remains of depositional events creating and maintaining the identities that related persons to all of their nested social contexts - households, Neighbourhoods, Quarters and ultimately the megasite itself. In the next section, we shall compare pottery developments at other Trypillia sites and, in a more detailed consideration, seek to identify whether or not similar strategies of pottery discard were utilised at the neighbouring megasites of Taljanki and Majdanetske.

\subsubsection{Comparisons with Other Trypillia Pottery Assemblages}

The vast majority of Trypillia pottery studies ${ }^{81}$ is concerned with the typo-chronology of the assemblage in question (e.g., Ryzhov 2012a) - an issue which we feel is better addressed through AMS dating (see Chapter 4.7). No other site studies include a complete suite of the Nebelivka pottery analyses - indeed some analyses are not found in any other report (analyses 2, 8, 11 and 12), making inter-site comparisons somewhat limited. Ovchinnikov's (2014) report on the Kaniv group considers the relationships between fabric and form, and form and decorative style, in a qualitative way. His shape typology (2014, p. 80, here Fig. 5.1) is used in preference to the Ryzhov system but Ovchinnikov does not focus on house or pit assemblages. Indeed, the number of reports with pottery presented as a series of 'house assemblages' or 'pit assemblages' is even smaller; in this comparison, we shall focus on the best example - the megasite of Taljanki (see annual reports) - together with the more limited recent UkrainianGerman excavations at Majdanetske (Müller et al. 2017). Additionally, in an excellent example of scholarly analysis, the study of Trypillia painted signs by T. M. Tkachuk (2005) provides house-by-house comparisons for each type of sign.

81 We do not consider all 'pottery studies' to be site 'pottery reports'; the latter should include as a minimum a general consideration of the total assemblage(s) and the presentation of some form of pottery catalogue. 
Sherd numbers, weights and Minimum Numbers of Vessel (MINV) estimates are provided for the earlier Taljanki excavations (up to 2008). A total of 60,000 sherds was recovered from 39 complete house excavations plus other investigations, an unstated proportion reconstructed to 800 whole vessels or complete profiles (Ryzhov 2008, p. 134). A total of 23 reconstructed vessels came from House 32, and 56 vessels from House 33, from a combined sample of 776 sherds out of a total of 3,390 sherds in the two houses. Likewise, in the earlier Majdanetske excavations (1984-9), over 100,000 sherds, reconstructed to 2,000 vessels, came from 25 houses and 15 pits (Shmaglij \& Videiko 2001-2, p. 89). The excavators estimate that between 1,000 and 5,000 sherds came from any single house, meaning that household living assemblages comprised between 20 and 130 vessels per house. This may be compared with the excavation of a claimed two-storey house - House 44 - at Majdanetske, where 1,735 sherds weighing $61.5 \mathrm{~kg}$ were found, estimated to derive from a total of 37 vessels. Irrespective of the fact that a set of 130 vessels in one house would hardly leave any space for the inhabitants to walk around the house, let alone work, have sex, rest or sleep, many of the Majdanetske house totals far exceed the ethnographic data on household pottery assemblages, with mean and S.D. of $25 \pm 27$ vessels in coeval use per house (Varien \& Mills 1997).

The only direct parallel to the Majdanetske data from Nebelivka showed 3,500 sherds from House A9, with a weight of over $80 \mathrm{~kg}$ and a MINV (minimum number of vessels) of 192 (excluding bases). This indicates that, although smaller than the number of sherds estimated per house at Majdanetske, the House A9 assemblage exceeded the sherd weight of Majdanetske House 44 by $30 \%$ and far exceeded the MINV of any Majdanetske house. These data confirm that House A9 was a 'death assemblage' (an assemblage of vessels or sherds placed in a house before it was burnt: pace Schiffer 1976, 'secondary refuse') rather than a living house assemblage (Schiffer's 'primary refuse'). For comparison, the Nebelivka Mega-structure statistics show a total of 6,162 sherds, weighing $163 \mathrm{~kg}$, estimated to derive from a MINV estimate of 332 (excluding bases). As with House A9, the increase in estimated MINV in the Mega-structure is far greater than the increase in sherd number and weight at Majdanetske.

It is possible to compare the MINVs from the $2 \times 1 \mathrm{~m}$ test pits at Majdanetske 2013 and Nebelivka (2013-14). In the nine test pits at the former, MINV estimates ranged from zero to 13 , with a mean and S.D. of $4.3 \pm 4.1$ vessels, while the mean and S.D. at 73 test pits at Nebelivka was slightly higher, at $5.2 \pm 4.8$, with a range of zero to 23 vessels.

While there were no systematic statistics on pottery discard from the older excavations at Majdanetske, two pits excavated in 2013 showed contrasting results. In Pit 50 (up to $1.2 \mathrm{~m}$ in depth), 809 sherds weighing $20 \mathrm{~kg}$ were estimated to derive from 39 vessels. There was considerable variation in pottery density in this pit, with highest levels reaching $3.5 \mathrm{~kg} / \mathrm{m}^{3}$, as well as large quantities of daub $(581 \mathrm{~kg})$. In the deeper Pit 60 (1.5m in depth), far fewer sherds were found - 451, weighing 10kg and derived from an estimated 24 vessels - but they were accompanied by far more daub (1,332kg.) than in Pit 50. By comparison, the much larger Nebelivka Pit (3.5m in depth) 
in Sondazh 1 contained 6,948 sherds, weighing 122kg, with an estimated MINV of 640 vessels (excluding bases) but with far less daub. We have some way to go before understanding the pits on megasites in terms of their widely varying functions and contents. However, a common feature was large-scale special deposition ${ }^{82}$, implying inter-household performances - whether the 640 vessels in the Nebelivka Pit (Sondazh 1) or the more than one tonne of daub in Majdanetske Pit 60, aptly described as the burial of a house (Müller et al. 2017).

There are few available statistics on the quantities of fine ware vs. coarse ware, or decorated vs. undecorated sherds, per site and, even more so, excavation unit. The Nebelivka pattern is very clear (over $88 \%$ fine wares; $~ 30 \%$ (by number) or $\sim 40 \%$ (by weight) of decorated wares by excavation unit). This is replicated in the recent excavations at Taljanki (houses 32-33, 40-47), where fine wares remained above $90 \%$ by number, with exceptions in a few houses in the earlier excavations (e.g., House 2, with $83 \%$ fine wares). No data on fine wares or decorated wares are currently available from Majdanetske.

While the analysis of vessel fabrics is presented as a description of visual studies at Majdanetske and Taljanki, there is technological support for the three fabric types found in the Kaniv group (Shevchenko, pp. 76-79, 92-94 \& 96-97; in Ovchinnikov 2014). Fabric I predominates in the Kaniv sites (70-90\% by number) and comprises a naturally sandy clay with occasional additions of crushed sherd, organic temper, haematite or limestone, fired to a range of orange hues in an oxidising atmosphere. The mixing of ferruginous clay with kaolinite produced a brick-red surface colour, rare in the Kaniv group but more common in the Nebelivska group. Fabric II comprised the so-called 'Cucuteni C' coarse wares - a greasy clay with shell or occasional organic temper, fired in a reducing atmosphere to produce grey hues but with uneven firing often giving variegated colours. Fabric III was a medium fabric, with no added temper, fired in a reducing atmosphere to produce contrasting colours on the interior (browns and red-browns) and exterior (dark brown). We can identify general similarities to the Kaniv fabrics in the Nebelivka assemblage, with Nebelivka Fabrics B and C closest to Kaniv Fabric I, the Nebelivka kaolinite Fabric O matching Kaniv kaolinite clay and Nebelivka Fabric H matching the Kaniv Fabric II. At Nebelivka, the combined frequency of Fabrics B and C ranges from $27 \%$ to $60 \%$, with Fabric O (kaolinite) varying from $3 \%$ to $12 \%$ and Fabric $\mathrm{H}$ (coarse wares) up to $10 \%$. What is rare at Nebelivka is the frequency of crushed sherd temper added mostly to kaolinite in the Kaniv sites.

There is no parallel for our analysis of the fabrics of four vessel forms - bowls, amphorae, dishes and plates at any other site. The closest conjoint analysis of vessel shapes and fabrics was conducted for the various stages of the Kaniv group(Ovchinnikov 2014, pp. 143-5, 149). In the BII phase, Fabric II vessel shapes are restricted to necked

82 Large-scale depositional events are also implied by the often large numbers of figurines and the intense but thin animal bone scatters found in pits. 
bowls and it is only in late CI that dishes are also made in this Fabric. Similarly with Fabric III, the limited repertoire of flaring-rim dishes and lids in Phase BII is broadened in Phase CI with the addition of dishes, flasks and necked bowls. By contrast, there is considerable continuity in the Fabric I forms throughout the group, with additions of biconical amphorae in stage 3 and the narrowing of the repertoire in stages 4 and 5. Since Nebelivka has been dated to Phase BII only, the comparison can be only with Kaniv stage 1 . The impression is that there is a much more variable relationship between vessel form and fabric at Nebelivka than in the Kaniv sites.

In the following comparative section, we have used the Nebelivka equivalent of the Ryzhov/Ovchinnikov system (see Fig. 5.1 and Table 5.1). The comparison of the recently excavated Majdanetske units (House 44, Pits 50 and 60) with 10 recently excavated Taljanki houses shows the variability of pottery deposited in 'burnt house assemblages' (Fig. 5.21/1). While amphorae predominate in all three Majdanetske units, they are the commonest form in only two of the 10 Taljanki houses, which show a far higher proportion of dishes and plates in seven houses. The under-representation of bowls in the Ryzhov system is reflected in their rarity at Taljanki compared to their frequency in the Majdanetske units. Flasks ('kubki') show a variable presence in both megasites. The Nebelivka units strongly contrast with the Majdanetske and Taljanki groups, with far fewer flasks and amphorae, many more bowls and a similar frequency of dishes and plates to that of Taljanki but far more than at Majdanetske. These variations betoken differences in daily practices between the three sites which prompt a debate about the similarities in depositional strategies existing between the three sites.

A ceramic indicator for intra- or inter-site differences in practice is the ratio of open to closed vessels. It is interesting to note a much higher ratio of open forms in the 10 Taljanki houses in comparison with the three Majdanetske units (Fig. 5.21/2). The pattern at Nebelivka is closer to that of Taljanki, with over $50 \%$ of open forms in all units; the Nebelivka Pit (Sondazh 1) has substantially more open forms than either of the Majdanetske Pits 50 and 60. To the extent that these figures conceal an emphasis on plates rather than dishes, the Nebelivka and Taljanki deposition suggests removal and re-deposition of vessels or sherds from contexts of collective rather than individual consumption to a far greater degree than occurred at Majdanetske, despite the possible interpretation of feasting for Pit 50 (Müller et al. 2017, p. 56).

The GIS-based distribution of vessels in house units has but recently developed in Trypillian archaeology, whether at Nebelivka (2009, 2012) or Majdanetske (2014). The only published analysis from Majdanetske - House 44 - is complicated by the debate over a one- or two-storey house (see above, Chapter 4.1) and missing information ${ }^{83}$. The interpretation of a non-overlapping distribution of what has been claimed to be an upper-floor and a ground-floor distribution does, in fact, make good sense as a

83 Unfortunately, looters destroyed ca. one-third of the house surface (Müller et al. 2017, p. 34). 

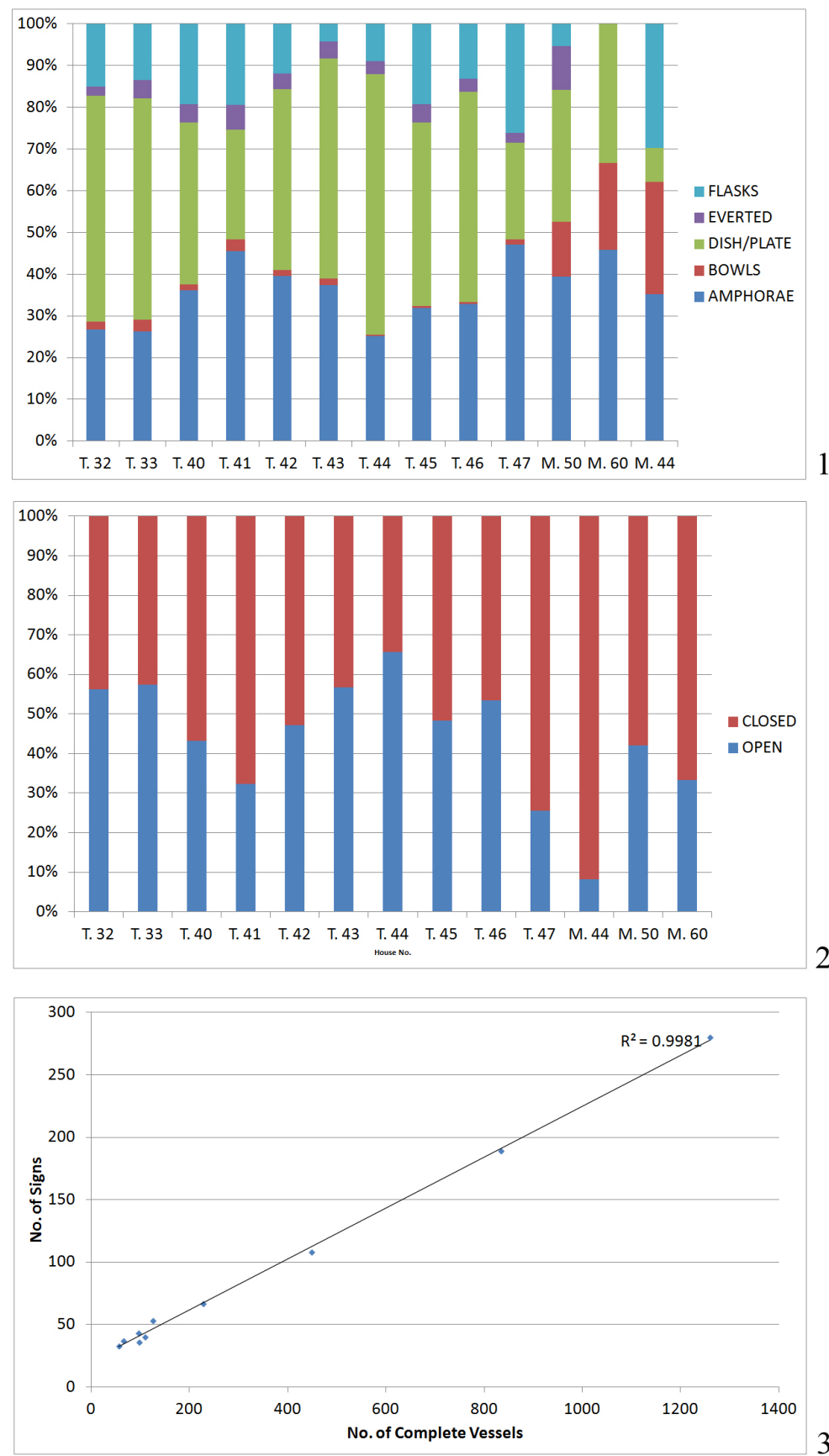

Figure 5.21: (1) Composition of burnt house assemblages by vessel shape; (2) ratio of open: closed vessels; Taljanki (T) and Majdanetske (M); (3) regression analysis of painted signs vs. sample size, Bug-Dnieper Interfluve sites, based upon Tkachuk 2005 (by J. Chapman). 
complementary distribution on a single-storey house. The main pottery cluster of flasks, small amphorae, fine ware and storage vessels lay between the platform (aka 'altar') and the hearth, with dishes placed on the podium or in a corner, complementing the cluster of storage vessels in the centre. The sum total comprises one large, or a series of small, depositional events in which people from House 44 and from other houses placed vessels or sherds before the burning of House 44.

By comparison, the one-storey House A9 pottery distributions showed a strikingly dispersed group of vessels and sherds, with not a single grid square containing more than one pottery cluster (Fig. 5.25 lower). Since we maintain that the House A9 assemblage of a minimum number of 192 vessels is far too large to represent a 'living assemblage' (primary refuse pace Schiffer 1976), this finding suggests placement of different types of vessel in different parts of the house before burning, as a staged 'event' which may have mimicked daily household practices but which, equally, may have conveyed another message about the way that pottery was used or the relations between occupants and visitors who contributed offerings.

Many contrasts were observed in these distributions, the most general of which was the paucity of sherd clusters in in the Southern room (only two small clusters of bowls and three small clusters of impressed sherds) as compared to the six large clusters in various parts of the larger Northern room and the four large sherd clusters placed outside the house away from the three pits (Grid Squares E10, V1, V4 and ZH 3) - bowls, coarse wares and sherds with impressed decoration (Fig. 5.23 \& 5.24 upper). More detailed contrasts include the placing of clusters of fine ware sherds near the East wall (Fig. 5.22 upper) with coarse ware clusters near the West wall (Fig. 5.23 upper); painted sherd clusters along the Southern part of the East wall (Fig. 5.22 lower) with impressed sherds in the North-East corner (Fig. 5.23 lower); bowls West of the Northern room platform (Fig. 5.24 upper) compared to dishes North of the platform (Fig. 5.24 lower); and bowls and dishes inside the house (Fig. 5.24) as contrasted with plates deposited outside the house (Fig. 5.25 upper). None of these clusters was exclusive in the sense that all bowls were found in the large and small clusters but they nonetheless indicate places of concentrated deposition, often of 10 or more vessels. These clusters can hardly be accidental, nor do they consist of functionally coherent assemblages - they simply represent concentrations of specific vessels linked to particular food preparation or consumption practices. It is interesting, therefore, that vessels of individual or small-group consumption were deposited in different places within the house, while the plates used in communal consumption were placed outside the house. This last contrast suggests a difference in the location of the two styles of consumption - larger-scale outside the house and smaller-scale inside the house.

The pottery distributions in the Nebelivka Mega-structure equally demonstrated the lack of any functionally coherent pottery groups, instead showing overall thin scatters for the majority of types. We interpret these distributions as a long series of collective depositions related to collective consumption and probably feasting. 

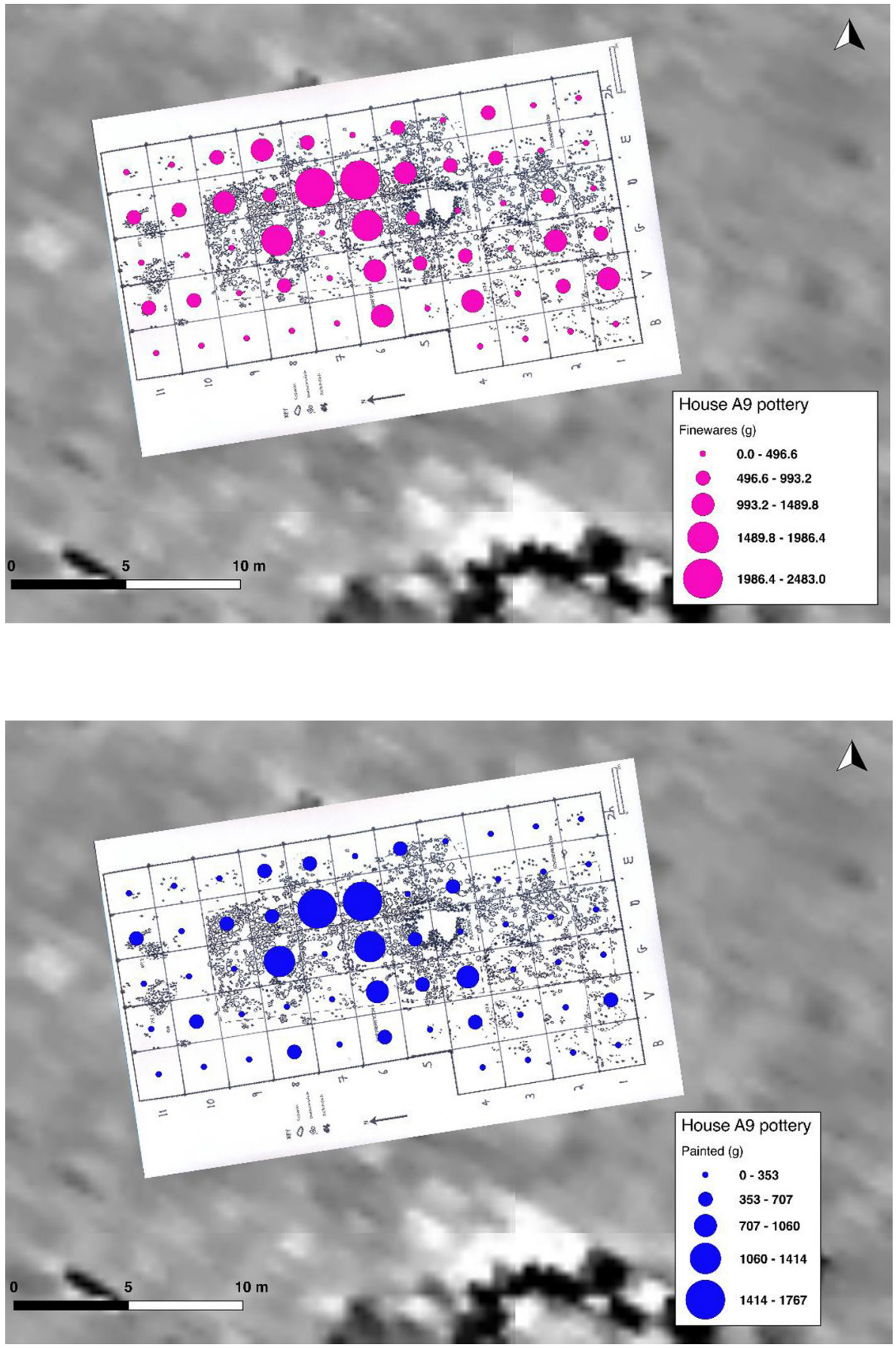

Figure 5.22: Distribution of (upper) fine wares; (lower) painted wares, House A9 (by M. Nebbia). 

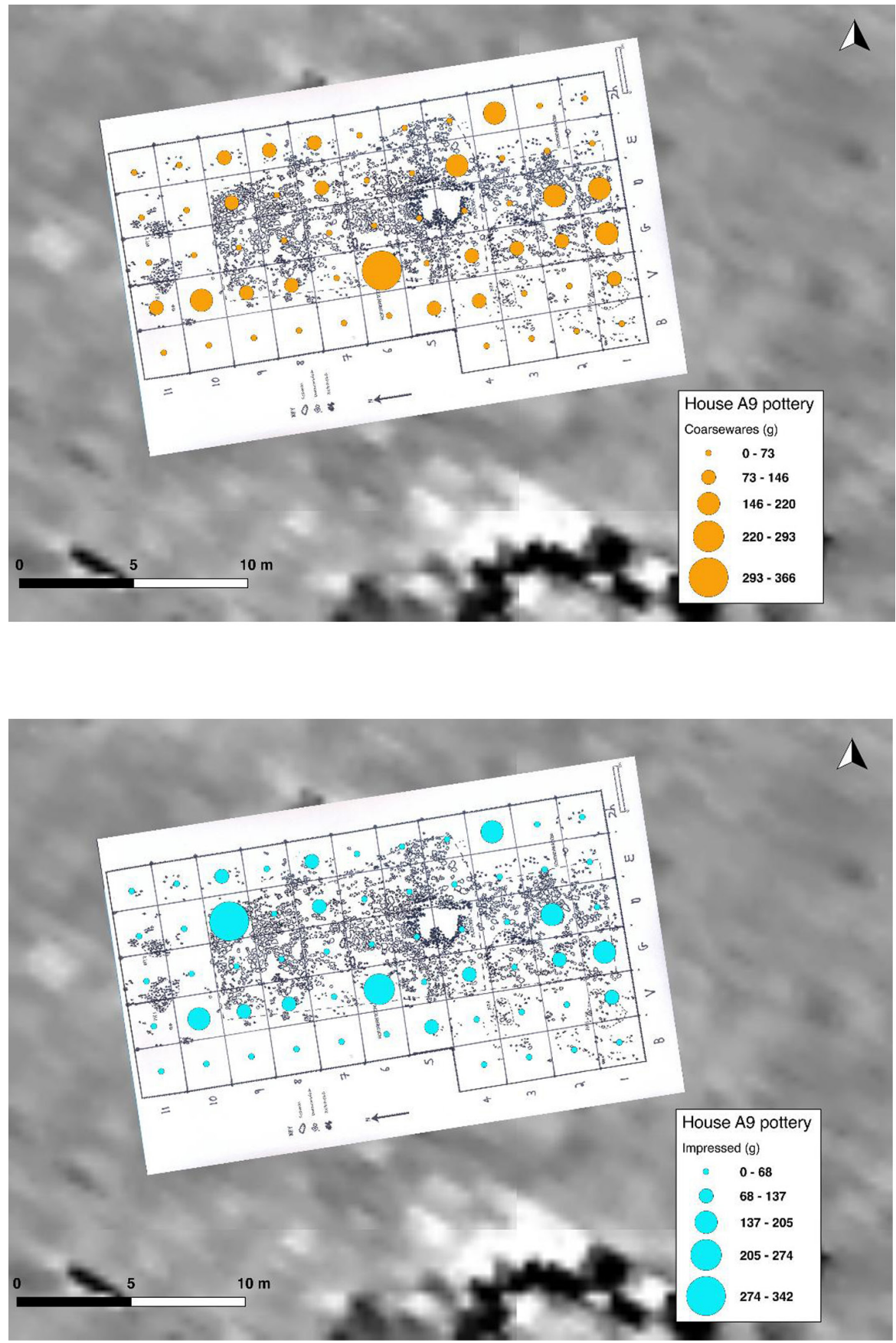

Figure 5.23: Distribution of (upper) coarse wares; (lower) sherds with impressed decoration, House A9 (by M. Nebbia). 

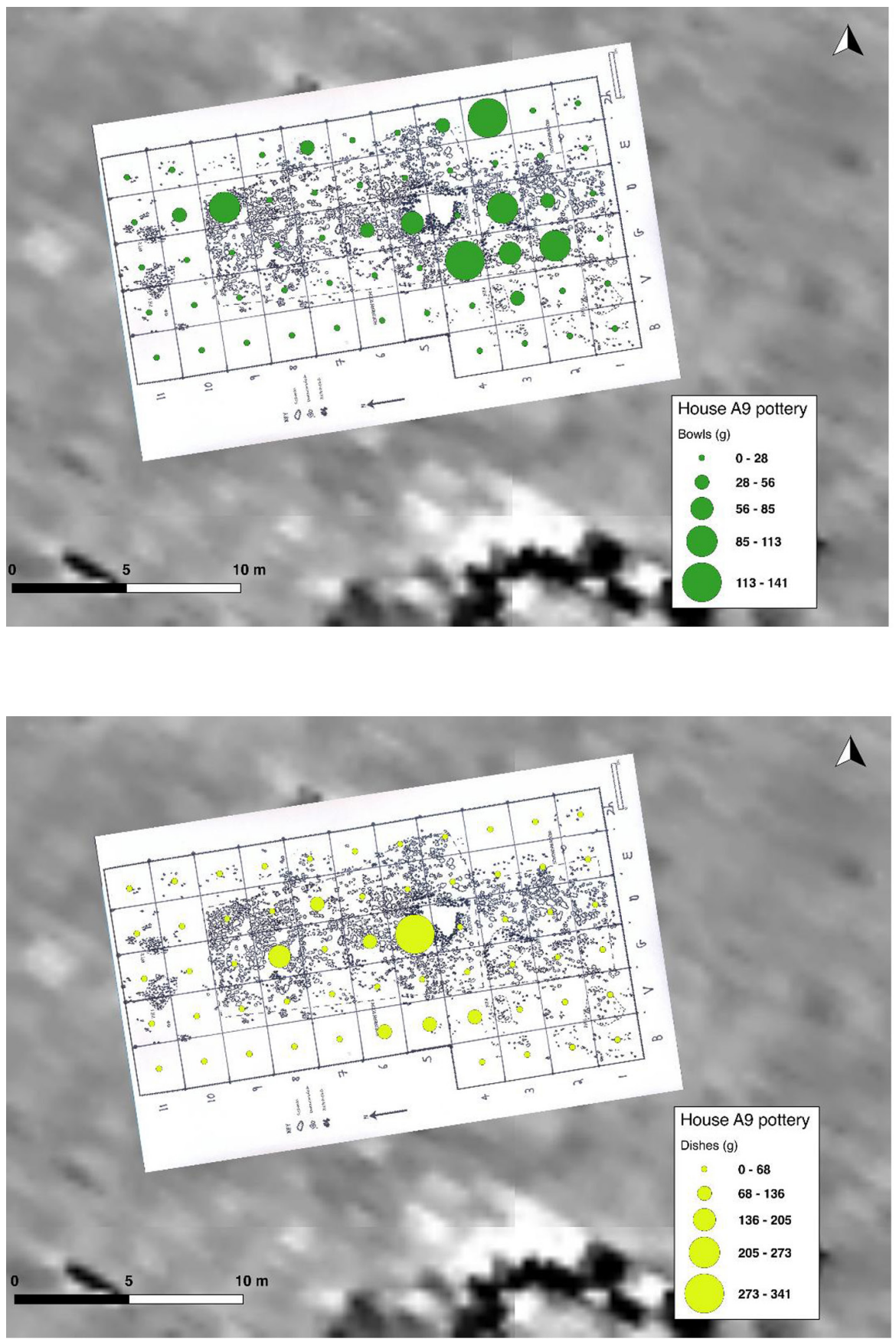

Figure 5.24: Distribution of (upper) bowls; (lower) dishes, House A9 (by M. Nebbia). 

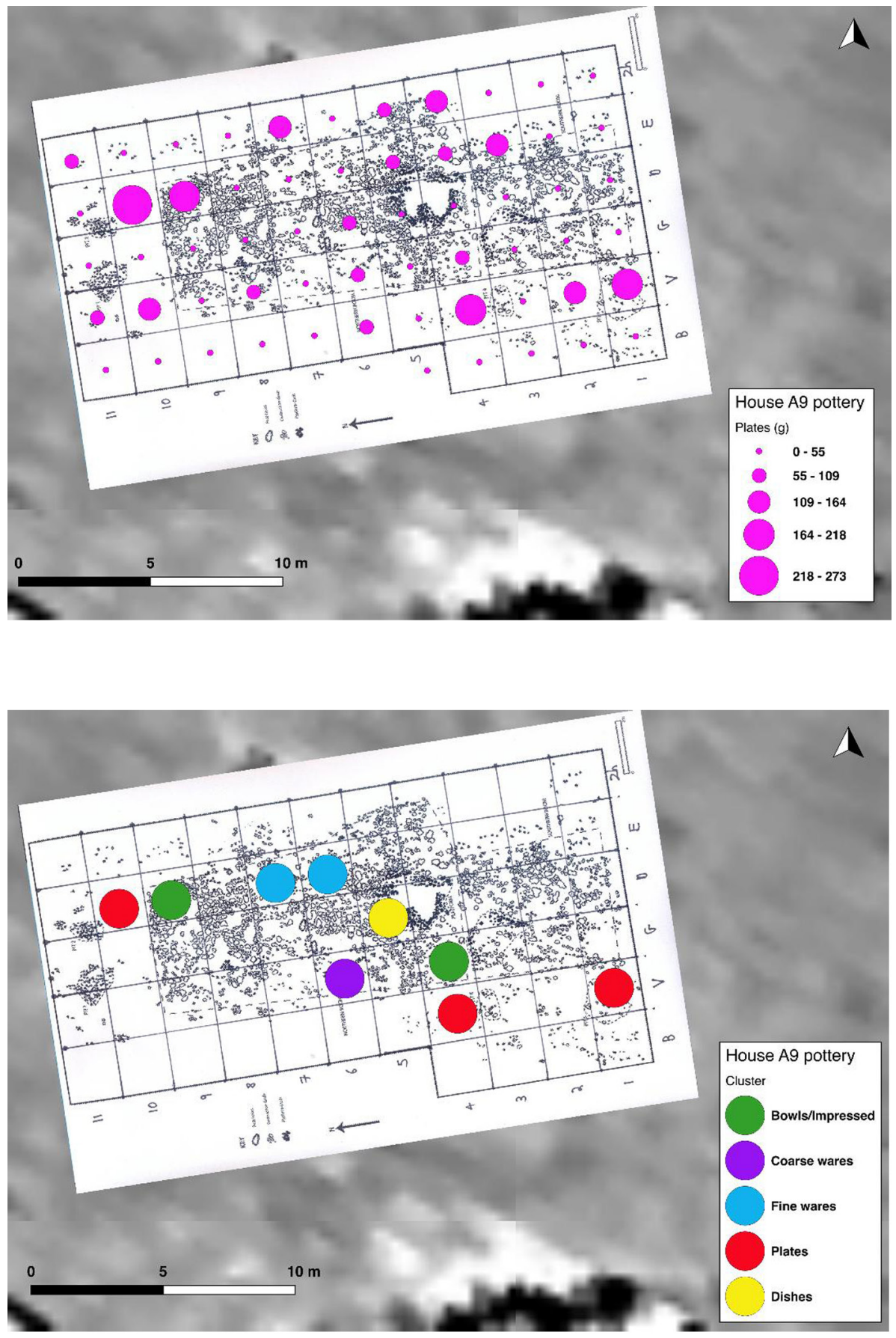

Figure 5.25: Distribution of (upper) plates; (lower) summary diagram, House A9 (by M. Nebbia). 
The relationship between vessel forms and decorative styles has been explored for the Kaniv group (Ovchinnikov 2014, pp. 143-5, 149). Similar rules of the mixture of decorative styles are found in the Kaniv and the Nebelivka assemblages, with both impressed and painted styles on flasks, necked bowls, everted-rim dishes and amphorae. We cannot compare the Nebelivka finding of the exclusive use of painted motifs on plates or the preference for impressed decoration over painting on bowls, since neither of these types is distinguished in the Kaniv group.

The intra-site distribution of decorative motifs has not been attempted for any other megasite but there is a comparable analysis from Majdanetske for painted signs which Tkachuk (2005) considers to form part of the Trypillia sign-system or sacred pictographic script ${ }^{84}$. Tkachuk has studied the painted signs and sign-combinations for 10 sites in the Southern Bug-Dnieper Interfluve in Phases BII and CI. It is interesting to note that a regression analysis of the number of painted signs vs. the total number of complete vessels from each site showed a very close fit (Fig. 5.21/3). This shows that the variability in the number of signs is not related to differences in site size or hierarchical rank but, rather, to sample size.

The only sites where Tkachuk compares the deposition of vessels with signs in individual houses are Taljanki (Tkachuk 2005, Vol. II, pp. 153-178) and Majdanetske (Vol. II, pp. 126-152 \& Ris. 18). At the latter, comparison of the sign assemblages from 18 fully excavated houses built in parallel in a circuit over 120m (Shmaglij \& Videiko 2001-2, Ris. 13) shows that almost all houses were linked to at least a dozen other houses in a complex, dense network of interaction (2005, p. 152). However, if the spatial analysis is limited to signs deposited in a minimum of six houses up to the maximum of 18, three different patterns are revealed (Fig. 5.26/1): (a) little engagement in the network in several houses in the Western and Central groups; (b) a number of links within the Eastern group and between the Eastern and Central groups; and (c) the highest number of links between the Western and the Eastern groups. Five houses in particular showed preferential links between each other, indicating targeted deposition of these significant vessels and, in turn, the probable differentiation of ritual deposition in these houses.

A second analysis made possible by Tkachuk's systematic database of signs by site is a comparison of signs from the Southern Bug-Dnieper Interfluve (SBD) sites with the 128 painted motifs from Nebelivka. A total of 20 painted motifs (or 15\% of the total) can be compared with Tkachuk's signs - six motifs with close parallels, two with both close and general parallels and 12 motifs with a general similarity (Fig. 5.26/2).

84 Cf. Hudson \& Milisauskas' (2017) characterisation of the Trypillia sign system as 'a series of signs that are syntactically structured by a linguistic or cultural grammar and housed in the group's mental lexicon'. 

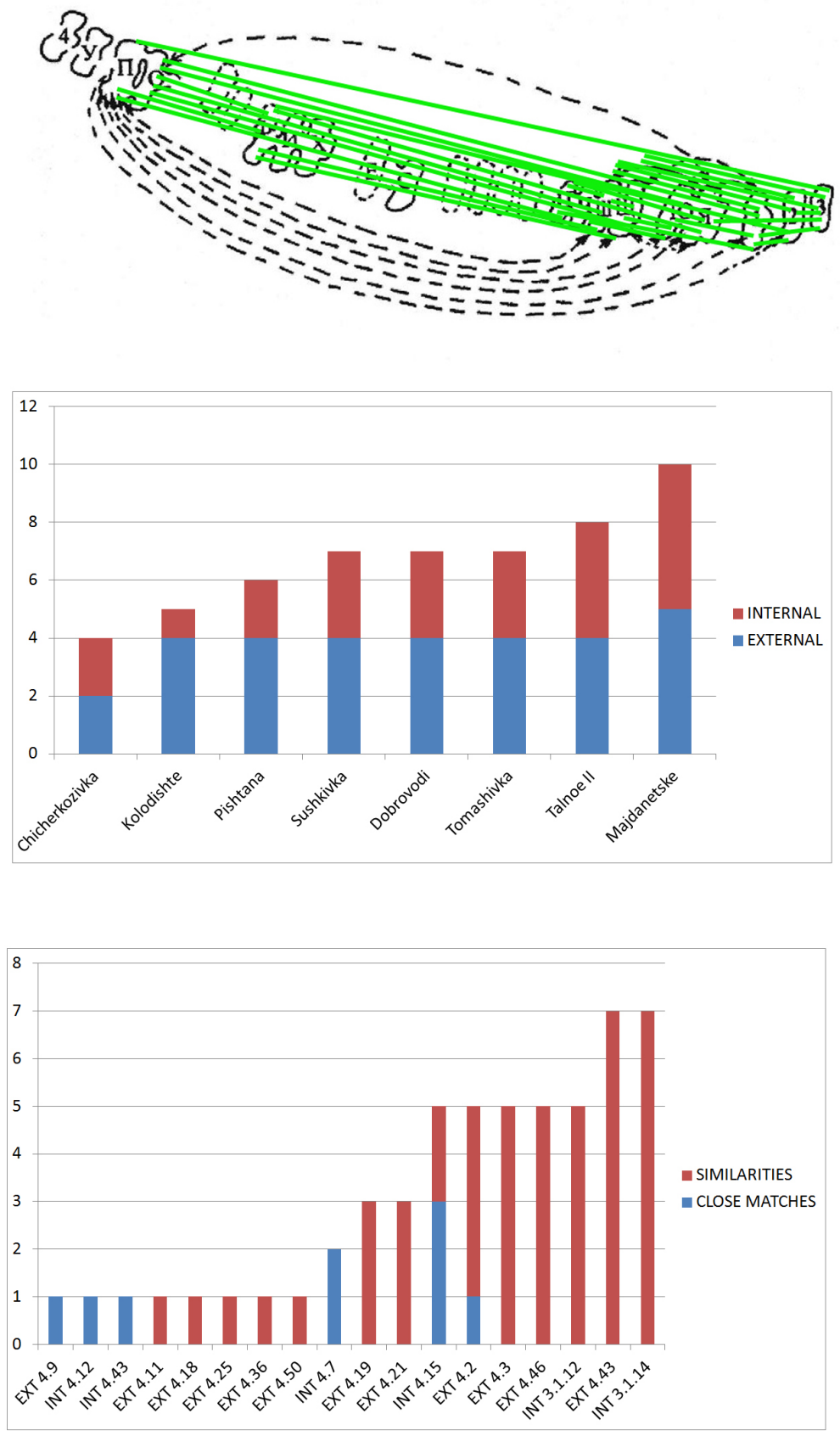

Figure 5.26: (1) distribution of painted signs shared between houses, Majdanetske; (2) comparison of Nebelivka painted motifs with painted signs on other Trypillia sites; (3) comparison of painted signs on Bug-Dnieper Interfluve sites (by J. Chapman, based upon information in T. Tkachuk 2005). 
While over half of the Nebelivka motifs were found at one to three SBD sites, two motifs with close similarities to the painted signs - although among the simplest were found on all of the SBD sites in the study. The eight sites varied in the number of signs comparable to the Nebelivka motifs, with the three largest totals coming from the three closest sites - Volodymyrivka, Taljanki and Majdanetske (Fig. 5.26/3). This suggests that the painted sign-system was reinforcing the long-term network linkage in the SBD, thereby contributing to the stability of the Big Other.

In summary, the comparison of pottery analyses conducted at Nebelivka with other Trypillia sites shows patchy results, with four key points:

1. Inter-site similarities between Nebelivka, the Taljanki and Majdanetske megasites and the Kaniv group sites emphasise the way that all of these sites readily conform to the overall canons of the Trypillia ceramic Big Other, whether in vessel forms, fabrics, fine ware preference, decorative styles and their relationship to vessel forms and engagement with the Trypillia sign-system.

2. The inter-site differences between these sites can be subsumed within the inherent regional variability of the Trypillia Big Other, which is expected to offer the possibilities of such differences between sites especially as they occurred at an intra-site level (e.g., the more variable relationship between vessel form and fabric at Nebelivka in comparison to the Kaniv group).

3. Variations in the number of vessels comprising the burnt house assemblages at the megasites show that, while some smaller assemblages may have been selected from living assemblages, the larger groups (e.g., Nebelivka House A9) show contributions from more than one household - perhaps several active houses in the Neighbourhood.

4. Variations in the ratio of open to closed vessels in megasite burnt house assemblages suggest that the vessels were collected from different kinds of discard deposits, in turn indicating variability in the disposal of the ceramic remains of daily practices such as cooking and feasting.

Bisserka Gaydarska, John Chapman, Marco Nebbia, Dmytro Gaskevych, Cătălin Lazăr, Theodor Ignat, Adrian Boyce, Amanda Dolan, Jason Newton, Oliver E. Craig, Harry K. Robson, Matthew von Tersch \& Alexandre Lucquin

\subsection{Special Finds}

We have divided the Special Finds from the excavations at Nebelivka into eight categories on the basis of material and type: (1) fired clay figurines; (2) fired clay tokens (aka 'counters'); (3) the group of miniature vessels from the Mega-structure; (4) the other miniature vessels; (5) chipped stone; (6) ground stone; (7) bone tools; and (8) other Special Finds (which include other fired clay finds, unusual vessels and a single gold hair ornament). The detailed, fully illustrated catalogue of these finds is 
available by excavation unit elsewhere (see https://doi.org/10.5284/1047599 Section 5). In this section, in addition to the specialist reports on the Special Finds, which include comparisons with other megasites and the wider context, we contribute a synthesis of the overall significance of the Special Finds at Nebelivka - in particular, what makes them 'Special'.

\section{Bisserka Gaydarska, John Chapman \& Marco Nebbia}

\subsubsection{Figurines}

Figurines have already been cited as one of the three cornerstones of the Trypillia Big Other (see above, p. 37) - the vital long-term framework for daily practice in this vast time-space network. It is therefore important to see how the Nebelivka people and potentially visitors to the megasite used figurines in their depositional practices.

The sample of images from the Nebelivka fieldwork comprises a total of 143 fragments (Table 5.6). This total means that, following Terna's (2017) metric, the mean number of figurines per $100 \mathrm{~m}^{2}$ of excavation amounts to 5.0 - matching the mean number for smaller Trypillia sites rather than the mean of 4.0 for megasites (Gaydarska 2019).

We were able to make a typological, contextual and fragmentation study of 74 images, comprising 78 fragments, with two additional possible figurines. Descriptions of each image are available in the ADS Archive (https://doi.org/10.5284/1047599 Section 5).

Table 5.6: Image fragment count by excavation unit (studied images in BOLD) (by J. Chapman).

\begin{tabular}{|c|c|c|c|c|c|c|c|c|c|c|}
\hline $\begin{array}{l}\text { MEGA- } \\
\text { STR. }\end{array}$ & $\begin{array}{l}\text { H. } \\
\text { A9 }\end{array}$ & $\begin{array}{l}\text { H. } \\
\text { B17 }\end{array}$ & $\begin{array}{l}\text { H. } \\
\text { B18 }\end{array}$ & $\begin{array}{l}\text { PIT NEAR } \\
\text { B17 } \\
\end{array}$ & $\begin{array}{l}\text { PIT NEAR } \\
\text { B18 } \\
\end{array}$ & OVEN & $\begin{array}{l}\text { PIT NEAR } \\
\text { OVEN }\end{array}$ & PIT S1 & $\begin{array}{l}\text { TEST } \\
\text { PITS } \\
\end{array}$ & SURFACE \\
\hline 23 & 20 & 4 & 2 & 17 & 4 & 1 & 29 & 25 & 10 & 8 \\
\hline
\end{tabular}

\subsubsection{Making}

In accordance with local pottery-making, the images have been made in three fabrics: fine wares of oxidising colours with painted decoration on a well-smoothed surface (6 fragments); a rare dark burnished ware (2 fragments); and the commonest fabric - a variety of oxidising colours in medium fine ware, from yellow to dark brown. The heavy organic temper discussed for many Cucuteni-Trypillia images (Monah 1997, p. 219) was absent at Nebelivka. Otherwise, the clays used for the images were comparable to those used for pottery (see Section 5.1.3). 


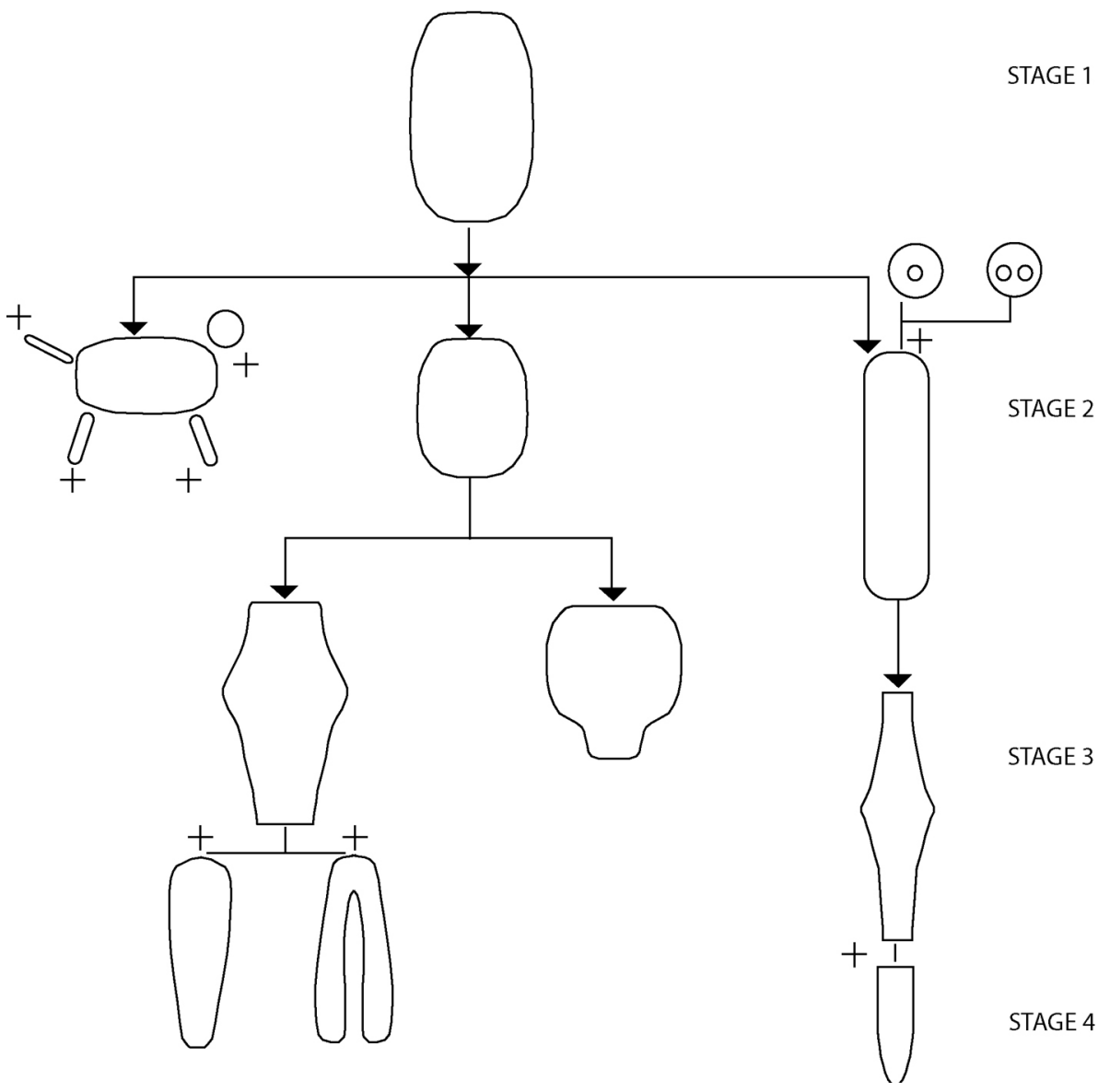

Figure 5.27: Alternative pathways to making Trypillia figurines (by L. Woodard).

\subsubsection{Types}

The images have been made into three forms from the same initial oval lump of clay: (a) broad shapes (termed 'statuettes': Monah 1997, p. 220); (b) thin, cylindrical shapes (termed 'figurines': 1997, p. 220); and (c) zoomorphs. A simple, 4- or 5-stage châine opératoire was used to make all three types, with choices of the form of the arms and the legs made at successive stages (Fig. 5.27). A single statuette was modelled in a seated position (Pit, Sondazh 1: SF 67). The few statuettes with preserved bases were made to be free-standing, while the figurines were pointed, to be inserted into a soft matrix (e.g., sand or a foodstuff) or simply lying down. Each of the three types was deposited in broadly similar proportions in all of the main excavation units studied here, with the exception of the absence of zoomorphs in the Mega-structure. The decoration of statuettes and zoomorphs was rare at Nebelivka (Figs. 5.28 \& 5.29/2): six statuettes with painted decoration in dark on light paint, and a single example of 
a domestic sheep with incised fleece (Fig. 5.31 upper). The publication of some of the otherwise unstudied images showed that the faces of two statuettes were modelled in a realistic manner (Burdo 2015, Ris. 2/1 \& 2/3).

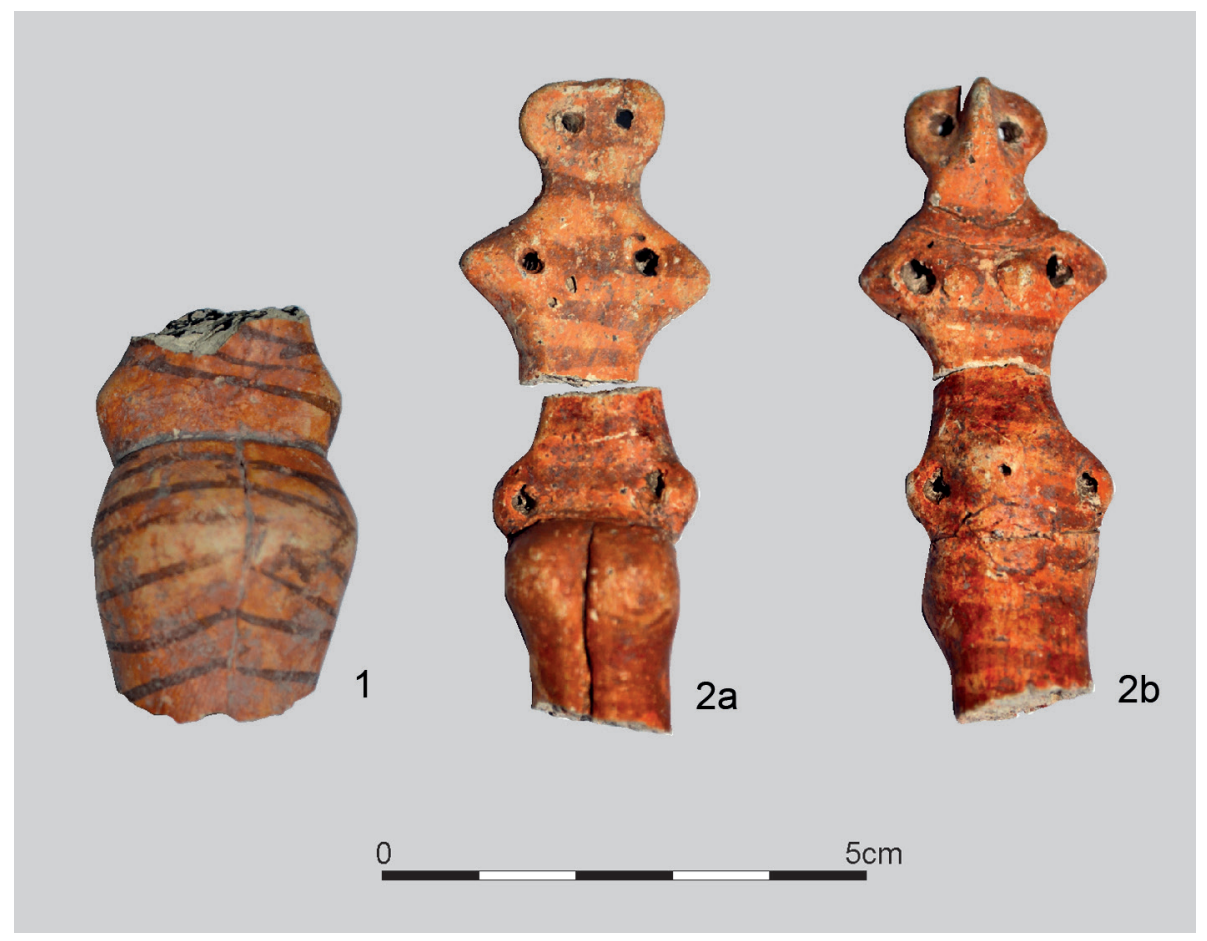

Figure 5.28: Decorated anthropomorphic figurines from Pit, Sondazh 1: (1) SF 23 and (2) SF $28+43$ : (a) back, (b) front, Nebelivka (by K. Harding).

\subsubsection{Gender}

There is a complex relationship between sex and gender, with the former more inherent and the latter more performed. Gender was a primary characteristic of Cucuteni-Trypillia images. The maker could choose whether or not to depict gender and in which way (the addition of a tiny clay penis; applied pellet breasts; the incision of a pubic triangle). Subsequently, a gendered image could lose its gender through fragmentation, with the gendered part removed somewhere else and the non-gendered part deposited. There is thus an important difference between a deliberately non-gendered image and an image that has lost its gender information. Almost half of the Nebelivka images were deliberately non-gendered, with a quarter given female characteristics and very few rendered male (Figs. 5.29/1 \& 5.30/5). The others - just under 25\% - presented no remaining gender information. The majority of images with gender characteristics had lost their heads and/ or feet - exactly those parts of the body that normally did not bear gender information. 


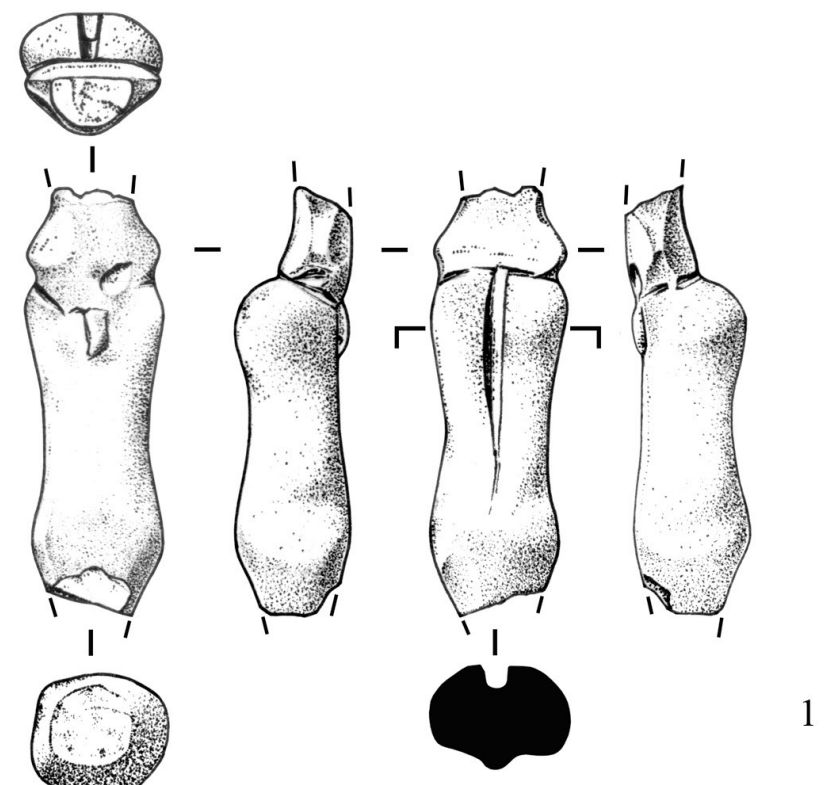

لسلسلسلسلسلسلسلسا

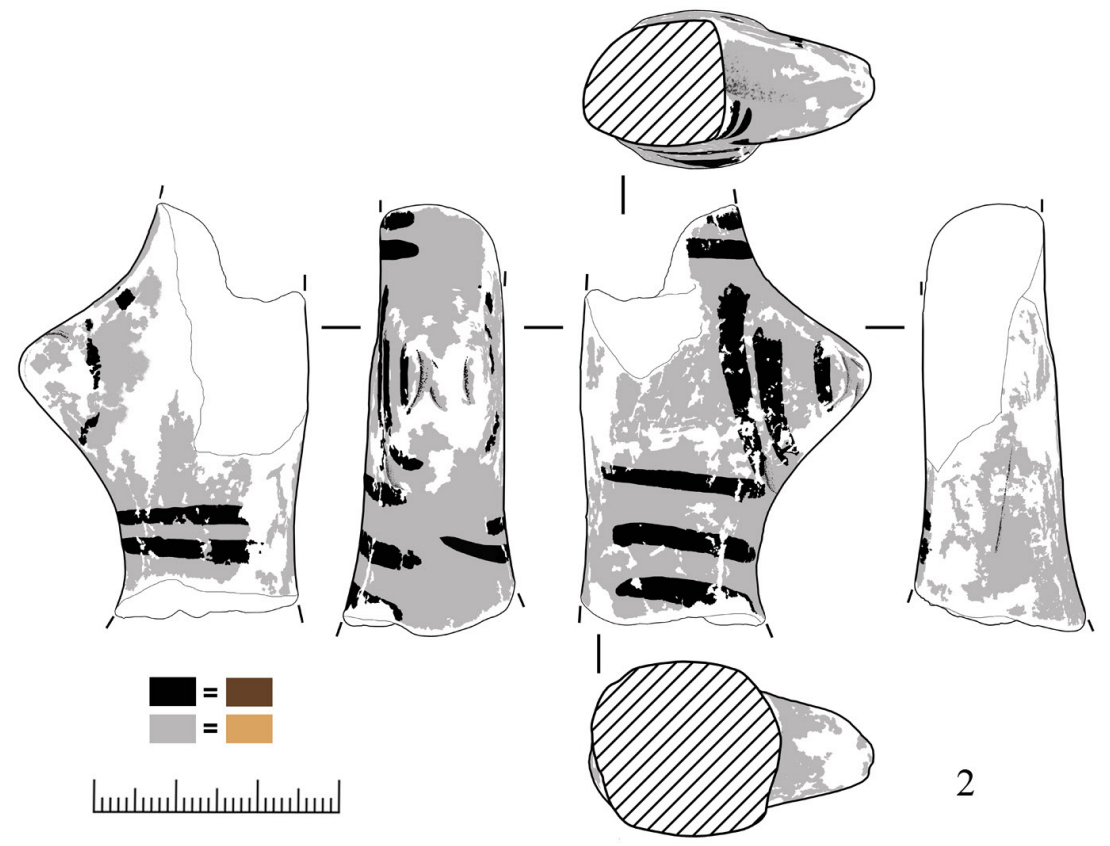

Figure 5.29: Anthropomorphic figurines: (1) male, SF 3230; (2) non-gendered, Grid F12; Megastructure, Nebelivka (by V. Pankowski). 


\subsubsection{Fragmentation}

It cannot be coincidental that no examples of complete images have yet been found at Nebelivka. The body parts were classified according to the system which we developed for the Late Copper Age figurine assemblage at tell Dolnoslav (Chapman \& Gaydarska 2007, Chapter 6). Twelve different body parts were found at Nebelivka heads, torsos, bottoms, legs and feet, and combinations of the basic five parts (Fig. 5.30/1-4). The greatest variety of body parts was found in the Pit in Sondazh 1 - 11/12 parts, with the least $(n=3)$ found in the Test Pit sample. Torso-to-leg fragments were outnumbered by other types of fragments in the Test Pits (Fig. 5.46). Although sample size undoubtedly affects this statistic, the sample size of House A9 was almost the same as in the Pit but with the deposition of half as many body parts. This may mean that a wider range of people or households contributed to the deposition of images in the Pit or that different body parts were placed in different Pit episodes. The preferred body part in all units except the Test Pits was the torso-to-leg fragment (or 'TL'). In all units, there was a deficit of heads - indeed only six heads were found in the sample of 74 individuals (viz., 8\%; cf. 10\% of heads in the Dolnoslav sample: Chapman \& Gaydarska 2007, Table 6.2). This statistic provides strong support for the notion that the images were fragmented before their deposition. Two further arguments derive from the four cases of two re-fitting fragments from the same image. There was a single example of two fragments from the same statuette deposited in different stratigraphic units in the Pit Sondazh 1 (No. 28 in SU 4, No. 43 in SU 5) (Fig 5.28/2). This indicates that the statuette was broken, with one part deposited while another part was curated for an unknown period of time before itself being deposited. A second re-fitting example depicts a very unusual break of a statuette into a front part and a back part (Mega-structure Grid Square F11) - a fracture that would have been impossible to achieve by accident. In general, the Nebelivka fragmentation data support the notion of deliberate fragmentation before deposition, with some evidence for curation of fragments and much evidence for removal of body parts (especially heads) to an as yet unidentified place or places.

\subsubsection{Context of Deposition}

In their study of the Majdanetske images, Shmaglij \& Videiko (2001-2) noted the preferential deposition of images in pits rather than houses - a finding confirmed by the more recent work at Nebelivka (Burdo \& Videiko 2016). However, variable deposition rates have been found at completely excavated Nebelivka houses - 22 in House A9 and only four in House B17. Only one Assembly House has been excavated the Mega-structure - but, perhaps surprisingly, it contained no more images than House A9. The finding of only one image in each of 10 Test Pits and none in the remaining 78 shows that the strategy of test-pitting is not the best way to increase the figurine sample! 

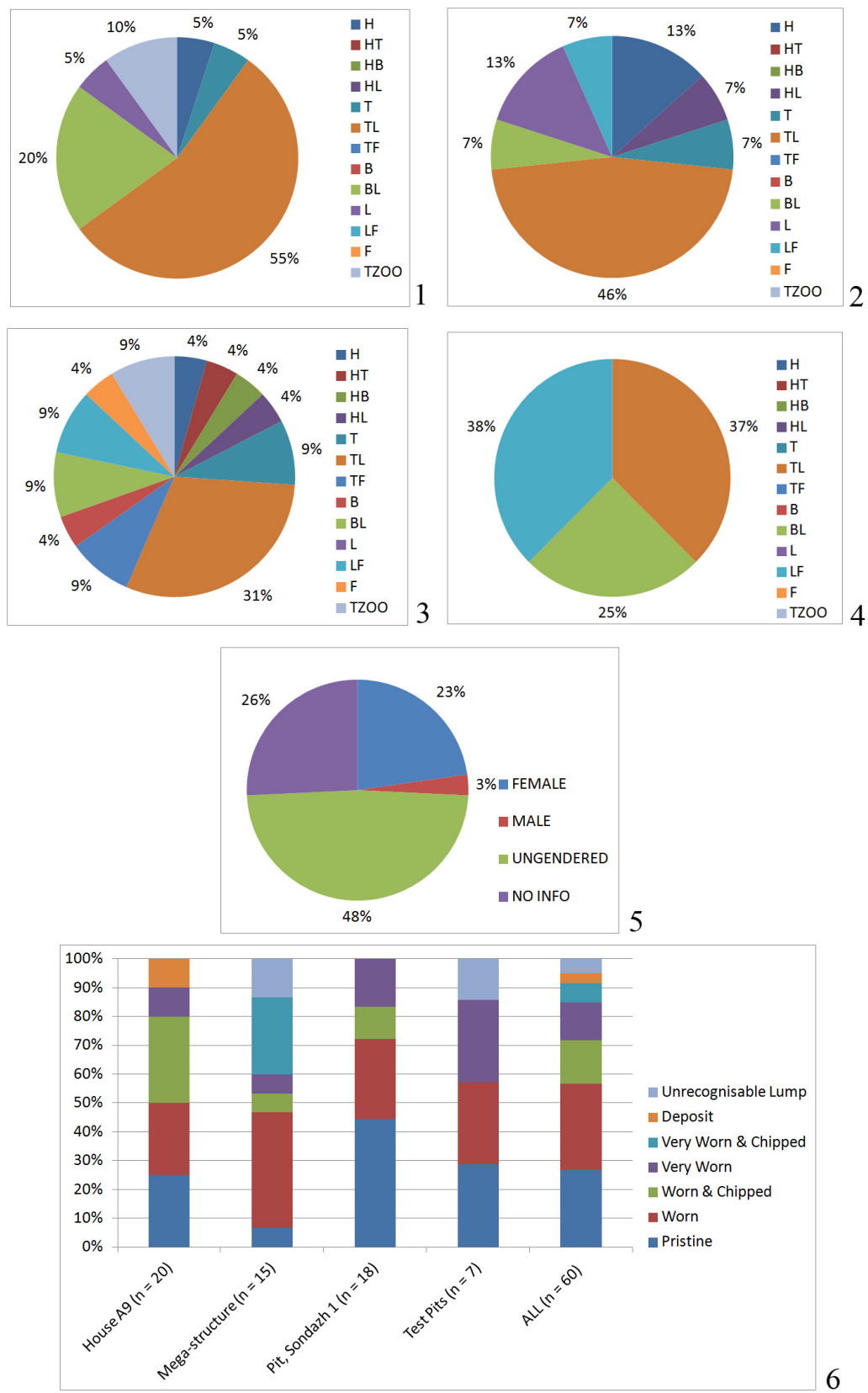

Figure 5.30: Figurine body parts by excavation unit: (1) House A9; (2) Mega-structure; (3) Pit, Sondazh 1; and (4) Test Pits; Key to figurine parts: $\mathrm{H}$ - head; HT - head-torso; HB - head-buttock; HL - head-leg; T - torso; TL - torso-leg; TF - torso-foot; B - buttock; BL - buttock-leg; L - leg; LF leg-foot; $\mathrm{F}$ - foot; TZOO - torso of zoomorph. (5) gender characteristics of figurines; (6) condition of figurines by excavation unit (by J. Chapman). 
In terms of more detailed distributions, the Mega-structure images derived mostly from the destruction Phase 3, with a preference for deposition near the outer walls, with two Phase 2 images found near Platform 89. The marked absence of a concentration of images suggests episodic deposition and/or the lack of clear rules for deposition. Deposition in the Pit in Sondazh 1 consisted mainly of 'episodes', in which pottery and images were placed in shallow re-cut scoops. Because the fill of the scoops was the same soil as the matrix, it was difficult to be sure of the outlines of all the scoops (see Fig. 4.53) but it is highly probable that all the figurines were discarded in episodic deposition. The vast majority was discarded where there were most episodes - in the middle Stratigraphic Units (SUs 3 and 4) - with only two deposited in the lowest SU.

\subsubsection{Condition}

The condition of the Nebelivka images varied from a pristine surface with no erosion or wear to small, highly degraded fragments termed 'unrecognisable fired clay lumps'. The overall pattern was the worse the surface wear, the fewer the images (Fig. 5.30/6). The only excavation unit with all stages of wear was the Mega-structure, where $92 \%$ of the images were worn; fewer images were worn in the other excavation units (mean $=70 \%$ ). The variable wear in the Mega-structure may have resulted from differing firing conditions in the Assembly House burning as well as varying lengths of time that the images were curated before deposition. The general conclusion from the analysis of image condition was that curation of whole and fragmentary images was a widespread practice at Nebelivka.

\subsubsection{Comparisons with Other Assemblages}

The images of the Cucuteni-Trypillia group have been well studied for many decades (Pogoševa 1985; Monah 1997, 2016; Burdo 2008). These general studies show that, in stylistic terms, the Nebelivka images resemble the Phase BII figurines from other sites such as Volodymyrivka (Passek 1949), Kolomiishchina II (Pogoševa 1985) and Voroshilivka (Gusev 1995). All three types identified at Nebelivka are also well known from the nearby Phase CI megasites of Taljanki and Majdanetske, where long-running excavations have recovered many figurines. At the latter, 340 figurines were found in the excavation of 25 houses and 15 pits from 1986-1991 (Shmaglij \& Videiko 2001-2). Close parallels are often found, such as the incised fleece on caprines at Nebelivka (Test Pit 16/ 1: here Fig. 5.31 upper) and Taljanki House 44 (Kruts et al. 2010). 


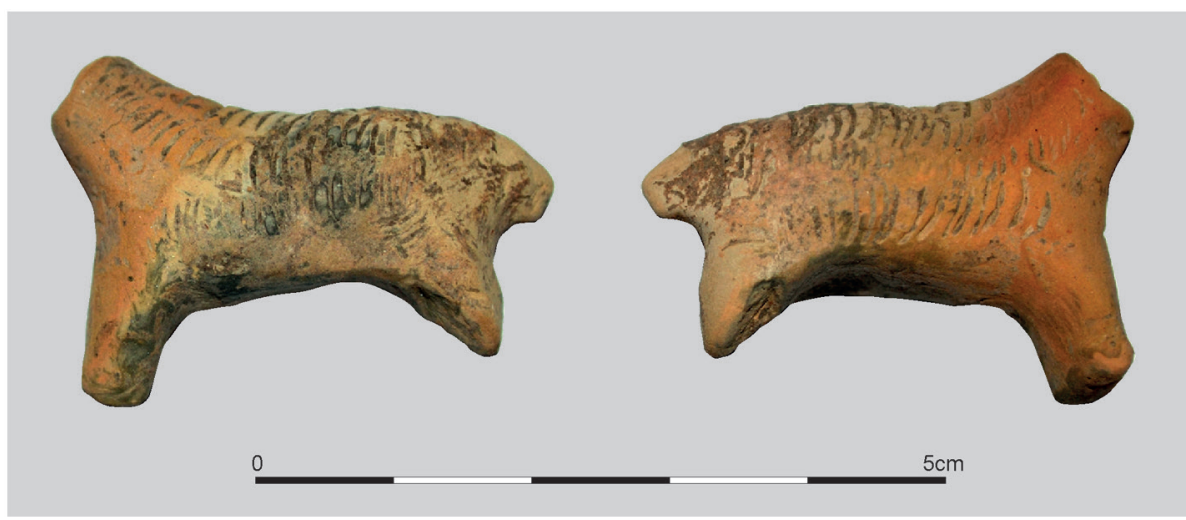

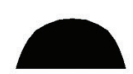

1

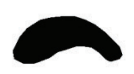

2

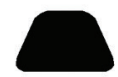

3

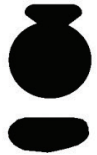

4

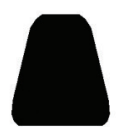

5

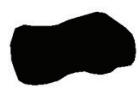

6

Figure 5.31: Upper: zoomomorphic figurine, Test Pit 16/1; lower: types of fired clay tokens (upper by K. Harding; lower by L. Woodard).

To put the Nebelivka sample into long-term context, Gaydarska (2019) has extended Therna's (2017) data on figurine density by size of excavated area to show that the site density of figurines stabilises in Phase B and declines in Phase C, with no increase in figurine density in larger sites (e.g., megasites). The same is true of realistic figurines. We interpret this as a sign of stability in the Trypillia Big Other irrespective of major changes in site agglomeration (Phases BII-CI) or population dispersion (Phase CII). The continuity in aggregate figurine use between smaller sites and megasites is perhaps surprising and requires an explanation (see Chapter 6).

With reference to the density of figurine discard in houses and pits on the three megasites, the picture is more complicated than a simple preference for higher figurine discard in pits. The average number of images deposited in or near 20 houses at Taljanki and two from Majdanetske (2013 excavations) is fewer than three ${ }^{85}$. However, in exceptional houses such as Majdanetske House $\Pi$, a total of 40 images was found in what was presumably the house of a ritual leader or a centre of communal ritual. Whether the 20 images discarded in Nebelivka House A9 can be similarly interpreted remains an open question. A similar variability of figurine discard is found in pits.

85 The mean and standard deviation is $2.7 \pm 1.4$. 
While no images at all were found in the 2013 excavations of three pits at Majdanetske (Müller et al. 2017), large numbers of both anthropomorphic images and zoomorphs were placed in the pits near House E (Shmaglij \& Videiko 2001-2). It is clearly no longer acceptable to assume that figurine discard in pits is always greater than house discard, though this was often the case (cf. the deposition at the Cucuteni A-B site of Traian: Bem 2007).

The overwhelming majority of images at both Majdanetske and Taljanki was discarded as fragments, echoing the Nebelivka practices. However, there was one example of breakage followed by deposition of fragments from the same image in two different contexts. Fragments from the same realistic head were found in pits under adjacent Houses $\Pi$ and Y at Majdanetske (Shmaglij \& Videiko 2001-2, Fig. 49/6). This example of enchainment through images is particularly interesting because it targets 'places-to-be' - areas marked out by the digging of a pit prior to house construction. Comparable inter-context re-fittings are found in Taljanki for other types of Special Finds.

\subsubsection{Summary}

The Nebelivka images consisted of zoomorphs, statuettes and figurines (terminology following Monah 1997), distributed in all the main excavation units. They represented one part of the Trypillia Big Other but their low frequency conforms to the overall paucity of figurines on other megasites. The images had been made with simple operational chains from clays visually similar to those used for pottery-making and with few attempts at decoration. All the images were fragmentary, with limited re-fitting evidence and fragmentation evidence indicating deliberate breakage - a conclusion amply supported by the high number of missing body parts - especially heads - from completely excavated units. In addition to being broken, over 2/3rds of images in all excavated units were worn, rising to $92 \%$ in the Mega-structure. The varied wear was caused by a combination of differing firing conditions in house fires and the length of time the images were curated before deposition. Many of the ceremonies involving images also included deliberate fragmentation and/or curation. The repeated practice of fragmentation indicates that the large numbers of missing parts enchained the houses and pits to other places, where the missing parts were discarded. Trypillia figurines reflexively contributed to the Big Other in two ways: as part of significant ceremonies (Burdo 2008) at the household, Neighbourhood and possibly even the Quarter level and also through a quotidian role in the enchainment of houses to each other and possibly to other places further away. 


\section{Bisserka Gaydarska, John Chapman \& Marco Nebbia 5.2.2 Tokens (Counters)}

The small fired clay objects found occasionally on Trypillia sites have been termed 'tokens' or 'counters' in the Nebelivka field reports (see https://doi.org/10.5284/1047599 Section 5). Their defining characteristics are their small size (rarely more than $3 \mathrm{~cm}$ in diameter and $2 \mathrm{~cm}$ in height), their lack of decoration on the flat surface (with a few exceptions), the absence of a handle and their expedient manufacture. In the standard summary of fired clay stamp seals (or 'pintaderas') in the Balkan Neolithic and Copper Age, Makkay $(1984,2005)$ publishes a small number of undecorated conical fired clay objects ${ }^{86}$ without distinguishing them from the often elaborately decorated and much more frequent pintaderas. There is therefore a minimal overlap between pintaderas and tokens, which have been interpreted as children's toys, gaming pieces or economic aids for counting (Shatilo 2015).

The term 'token' in the Near East is more appropriate for stylistic comparison with the Trypillia objects. Plain tokens are first known from the 8th millennium BC, coeval with the development of domesticated plants and animals at sites such as Mureybit (Schmandt-Besserat 2010, p. 27). Schmandt-Besserat (2010, p. 32) suggests that these early tokens related to 'casual daily life items' which were not especially standardised in shape or size. Tokens first became much more differentiated, and subsequently more standardised, in the Uruk period, with the growth of administrative practices on urban sites (2010, pp. 28-32).

A total of 31 counters has been found at Nebelivka, the vast majority being deposited in the Mega-structure, one found in each of five houses in test pits and a single example in the Pit in Sondazh 1. The tokens in the Mega-structure were concentrated in the East rooms and the West area, with occasional examples deposited near the Southern and Northern walls and in the unrooved central part but with a cluster placed outside the Mega-structure to the West (Fig. 5.48 upper).

The crumbly nature of most of the tokens shows that these objects were formed from a single lump of red or brown clay and fired at a lower temperature than the images and a much lower temperature than the painted pottery. When well-preserved, the flat surface of the tokens is either round or oval. There is considerable variation in the shape of the cross-section, with six broad types in evidence (Fig. 5.31 lower \& Table 5.7).

86 The Cucuteni-Trypillia tokens include four from Luka Vrublevetskaya (Makkay 1984: No. 127) and eight from Frumuşica (Makkay 1984, Nos. 68-75); others derived from Copper Age sites such as Sultana, Ruse and Ezerovo as well as Late Neolithic Turdaş (Makkay 1984, Nos. 255-262) and Liubcova (Makkay 2005, No. 72), while there is even an Early Neolithic Körös example (Makkay 1984, No. 99). 
Table 5.7: Frequency of token types, Nebelivka (see Fig. 5.31 lower).

\begin{tabular}{lllllll}
\hline Type & $\mathbf{1}$ & $\mathbf{2}$ & $\mathbf{3}$ & $\mathbf{4}$ & $\mathbf{5}$ & $\mathbf{6}$ \\
\hline Form & domed & $\begin{array}{l}\text { sub - } \\
\text { rectangular }\end{array}$ & $\begin{array}{l}\text { irregular } \\
\text { domed }\end{array}$ & $\begin{array}{l}\text { nicked } \\
\text { rounded }\end{array}$ & trapezoidal & irregular \\
Frequency & 9 & 5 & 7 & 1 & 4 & 5 \\
\hline
\end{tabular}

There was decoration on the flat surface of only three of the tokens: one Type 3 token with ribbed decoration and one Type 1 and one Type 2 tokens with incised ridges. No parallels for these motifs were found in Makkay's pintadera catalogues. However, the poor preservation of the tokens, contingent upon their low firing, means that some decorational information may not have survived the destruction of the Mega-structure or the houses. Indeed, only just over half the tokens were found complete, with the edges of ten tokens (or 32\%) eroded and seven tokens (or 23\%) preserved in a fragmentary state. The possibility of enchainment through differential deposition of token fragments is lowered because of the poor preservation of the objects.

The comparison of the Nebelivka tokens with those from Majdanetske is based upon a rather minimal publication from the latter (Shmaglij \& Videiko 2001-2, Ris. 52). If Figure 52 represents the full range of formal variation, then even greater variation in shape was seen in a smaller assemblage - seven basic types with variations (presence or absence of vertical perforation). The cross-sections of several of the Majdanetske tokens closely matched those from Nebelivka. Since no Assembly House was excavated in the 1986-91 campaigns at Majdanetske, these tokens would have been deposited in pits or houses.

In summary, the poor quality of the clay, the low firing temperature and the crumbly surface appearance of most of the Nebelivka tokens indicates expedient production, making it improbable that these objects were used in a ritual or administrative role in a complex society. The variability of the tokens' shapes is at odds with the standardisation of tokens used in early urban contexts at Ur (SchmandtBesserat 2010). However, the key concentration of $80 \%$ of the tokens in the Megastructure is suggestive of a more formal role for tokens than simply children's toys; the most likely use was as gaming pieces made for ceremonial games or divination in Assembly Houses (Shatilo 2015). Two fragments of a possible gaming board have also been discovered in the Mega-structure (see below, p. 378). 
John Chapman, Bisserka Gaydarska, Dmytro Gaskevych, Cătălin Lazăr, Theodor Ignat, Adrian Boyce, Amanda Dolan, Jason Newton, Oliver E. Craig, Harry K. Robson, Matthew von Tersch \& Alexandre Lucquin

\subsubsection{The Group of Miniature Vessels from the Mega-Structure}

Miniature vessels have been part of the Nebelivka story ever since Shmaglij's first test pits there in 1981 (Shmaglij \& Videiko 1992). In the current Project, a total of 84 such vessels has been found, some in each excavation unit. The largest group derives from the Mega-structure $(n=33)$ mainly because of the find of a group of 21 miniature vessels in a destruction context (https://doi.org/10.5284/1047599 Section 5.1.2).

Theirs is a story of two parts - the exterior and the interior. It was only when the calcareous crust was removed from these vessels that the true significance of their exterior was revealed. Six vessels were decorated in a graphite-based wash, while graphite-painted motifs were found on three vessels and possibly a fourth. Although this is the first time when graphite-painted decoration has been found on Trypillia pottery, it is not the first use of graphite in pottery production in the prehistory of the Ukraine. The following summaries of the specialist reports explore the early use of graphite, the stylistic parallels of the Nebelivka graphite-painted vessels with East Balkan fine wares and preliminary characterisation studies.

\section{Dmytro Gaskevych}

\subsubsection{Graphite in the Production of Pottery in the Ukrainian Para-Neolithic ${ }^{87}$}

The use of graphite as an admixture in a ceramic paste of Neolithic pottery is the subject of current research (cf. Gaskevych 2017). While there are several graphite sources in Ukraine large enough for industrial use (e.g., one of the largest deposits of graphite in Europe in the Hayvoron district of Kirovograd County), there are over 300 small sources of graphite in the Ukrainian Granite massif, so much analytical work remains to be done (for a start, see below, Section 5.2.3.3). There are five main clusters of sites with pottery in which graphite has been mixed with the clay (Fig. 5.32): the Dnister group, the Southern Buh group, the Middle Dnipro group, the Dnipro Rapids group and the Azov Sea group. Of particular interest is the Southern Buh group, which lies closest to Nebelivka and also close to many early Trypillia sites (Hayvoron, Sabatynivka II, Hrebenniukiv Yar, Hrenivka, etc.).

87 The term 'para-Neolithic' refers to the fact that the overall rarity of remains of domesticated species - whether plants or animals - in these sites. Kotova (2003, Chapter 1) refers to such sites as 'Neolithic'. 


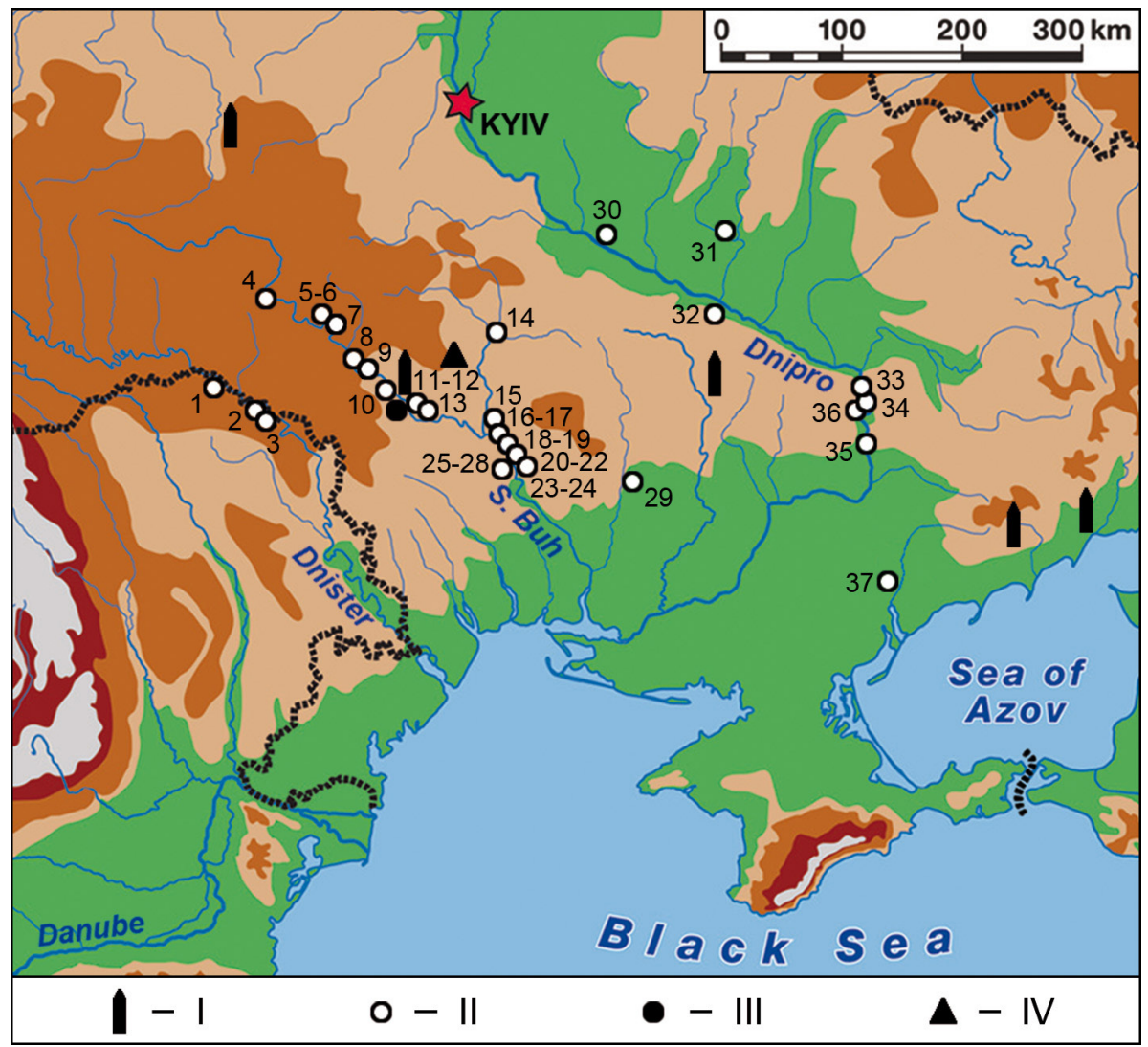

Figure 5.32: Map of Ukrainian para-Neolithic sites with graphite-tempered pottery: Symbols: I present-day industrial source of graphite; II - para-Neolithic site; III - LBK site of Kamiane-Zavallia; IV - Trypillia culture site of Nebelivka; Buh-Dnister culture: 1-Tătărăuca Nouă XV, 2-Soroka I (level 1a), 3-Soroka V, 4-Pechera I, 5-Samchyntsi I, 6-Samchyntsi II, 7-Shymanovske II, 8-Bazkiv Ostriv, 9-Shumyliv-Cherniatka, 10-Hayvoron-Polizhok, 11-Zavallia, 12-Zhakchyk, 13-Melnychna Krucha, 14-Dobrianka 3, 15-Mykolyna Broiaka, 16-Kompaniiska Skelia, 17-Hrushivskyi Ostriv, 18-Semenivka, 19-Ustia Korabelnoi, 20-Puhach 1, 21-Puhach 2, 22-Klepana Balka, 23-Tashlyk 2, 24-Tashlyk 3, 25-Gard, 26-Gard 3, 27-Gard 4, 28-Lidyna Balka, 29-Novorozanivka; Kyiv-Cherkasy culture: 30-Buzky I, 31-Lysychyi Horb, 32-Uspenka 2; Surskyi culture: 33-Strilcha Skelia, 34Kizlevyi V, 35-Vovchok; Azov-Dnipro culture: 36-Mykilske 2; Surskyi or Azov-Dnipro culture: 37Kamiana Mohyla 1 (by D. Gaskevych). 
The Southern Buh group in turn comprises three site clusters, which differed in the frequency of use of a graphite admixture and its abundance in the ceramic paste.

The first cluster, lying within $20 \mathrm{~km}$ of the main Hayvoron source, includes several sites of the Buh-Dnister culture (BDC) and the LBK site of Kamyane-Zavallia (Kiosak 2017). The quantity of pottery with graphite is relatively small, but the concentration of graphite in the clay is medium to high.

A cluster of sites to the North of the source includes several BDC sites on the Southern Buh River and the BDC site of Dobrianka 3 on the Tikych River. Vessels with a graphite admixture are rare. The concentration of graphite in its paste is low to medium.

The third cluster to the South of the source includes BDC sites on the River Southern Buh and its left tributaries (Mykolyna Broiaka on the Chornyi Tashlyk River and Novorozanivka on the Inhul River). The amount of pottery with graphite and its typological diversity are the largest in the Southern Buh area. The concentration of graphite varies, but it is often very high. The surface of such vessels glitters like silver or lead.

Nowadays, there are 69 published dates obtained from 20 BDC sites. Fifty-two of the dates correspond to a wide range between 6500 and $4700 \mathrm{BC}$ and can be related to the East European para-Neolithic. The overwhelming majority of them were measured on samples of bone and antler from sites of the Southern Buh River region at the Kyiv radiocarbon laboratory in 1998-2005. The study of archaeological contexts from which the samples of these dates come showed that none of them is related to a feature. Most of the dated sites are characterized by the absence of a clear stratigraphic position of the para-Neolithic materials, as well as by possible non-homogeneity of cultural layers (Gaskevych 2014). While the absolute chronology of the BDC graphite pottery is currently uncertain, some typological characteristics and methods of decoration indicate its contemporaneity with the LBK. This is also evidenced by "imports" of LBK pottery from the sites of Bazkiv Ostriv and Gard, as well as one vessel from the site of Bazkiv Ostriv made of paste with graphite and decorated with a very rare example of brown painting of probable Middle Danube origin (Gaskevych 2017a).

It seems that a chronological gap between the latest para-Neolithic pottery which contained graphite in its paste and the discovery of graphite-painting at Nebelivka is filled by some of the latest Trypillia A pottery synchronous with Cucuteni A sites to the West. Thus, Zbenovich (1989, pp. 90 and 93) mentions "a few small fragments of fine vessels with graphitized surface” from sites such as Sabatynivka II, Luka-Vrublivetska and Hrenivka. Tovkailo (2005, pp. 34-35) has also written about his discovery of rather numerous pottery with graphite admixture at the same Early Trypillian phase on the multi-layered sites of Puhach 1, Puhach 2, Gard, Gard 3 and Gard 4 in the steppe zone of the Buh River catchment. However, there remains the likelihood that graphite painting in the Trypillia group was related to exchange relations with the East Balkan Copper Age communities. 


\section{Cătălin Lazăr \& Theodor Ignat}

\subsubsection{Graphite Painted Ware Analogies in the East Balkans}

Pottery painted with graphite to make silver designs represented a technological innovation for the Neolithic communities of the Balkans. The first evidence of the use of this new technique dates from the end of the 6th millennium BC in Eastern Macedonia and South-West Bulgaria, where graphite was a component in the slip used to cover the pots (Aslanis 1989; Bailey 2000; Leshtakov 2005). The emergence of graphite-decorated pottery in the 5th millennium BC is closely related to the development of gold and copper metallurgy (Bailey 2000), with diffusion of that decorative technique from South to North to coincide with the supply route of this kind of raw material (Leshtakov 2005). During the East Balkan Early Copper Age (ca. 5000-4600 cal. BC), graphite decoration is found on the vessels of the Maritsa, Sava, Gradeshnica, Polyanitsa and Final Boian communities (Bojadjiev et al. 1993; Bailey 2000; Voinea 2005; Leshtakov 2005). Many authors claim a substantial increase (even described as an explosion) in the usage of graphite-decorated pottery in the second half of the 5th millennium BC (Bojadjiev et al. 1993; Bailey 2000; Voinea 2005; Leshtakov 2005; Dănilă 2014), which has led to the term 'the East Balkan graphite pottery complex’ (Tasić, N. 1989; Petrescu-Dâmbovița 2001; Voinea 2005) (here Fig. 5.33). However, this assertion is only partially correct, since graphitedecorated pottery, although specific for the Kodzhadermen-Gumelniţa-Karanovo VI (KGK) and Krivodol-Sălcuţa-Bubanj Hum (KSB) communities, represented a reduced percentage of the total ceramic assemblages in other coeval groups. Thus, the analysis performed on a series of well-published ceramic assemblages indicates that graphitedecorated pottery represented a proportion between $2 \%$ and $15 \%{ }^{88}$. By comparison, ceramics decorated with graphite were very common in the KGK VI group (Todorova \& Matsanova 2000; Petrova 2007, 2011; Popova, M. 2012; Popova, M. and Kostov 2017). On the other hand, in Romania, we note that there are tell settlements of the KGK VI group with only a few fragments of graphite-painted sherds ${ }^{89}$ and conversely (graphite-decorated vessels occur mostly on large tells). Sometimes the graphitepainted pots were associated only with a particular building ${ }^{90}$. For KSB communities, the graphite-decorated pottery is more rare, ranging from 1\% and 3\% (Pătroi 2011).

\footnotetext{
88 The percentage of graphite-painted wares - Lîga = 2\% (Randsborg and Merkyte 2005); Pietrele = 2.9\% (Toderaș et al. 2009); Hârșova = 5\% (Voinea 2005); Căscioarele = 5.9\% (Voinea 2005); Vinitsa = 15\% (Popova, M. 2012); Sultana-Malu Roșu = 14.9\%.

89 e.g., Bucșani, Carcaliu, Măriuța, Șeinoiu and Vitănești (Bem 2001; Parnic and Chiriac 2001; Șimon and Parnic 2001; Andreescu et al. 2003; Burens et al. 2010).

90 e.g., Pietrele - Central House, and Sultana-Malu Roșu - House no. 2 (Andreescu and Lazăr 2008; Reingruber 2012).
} 


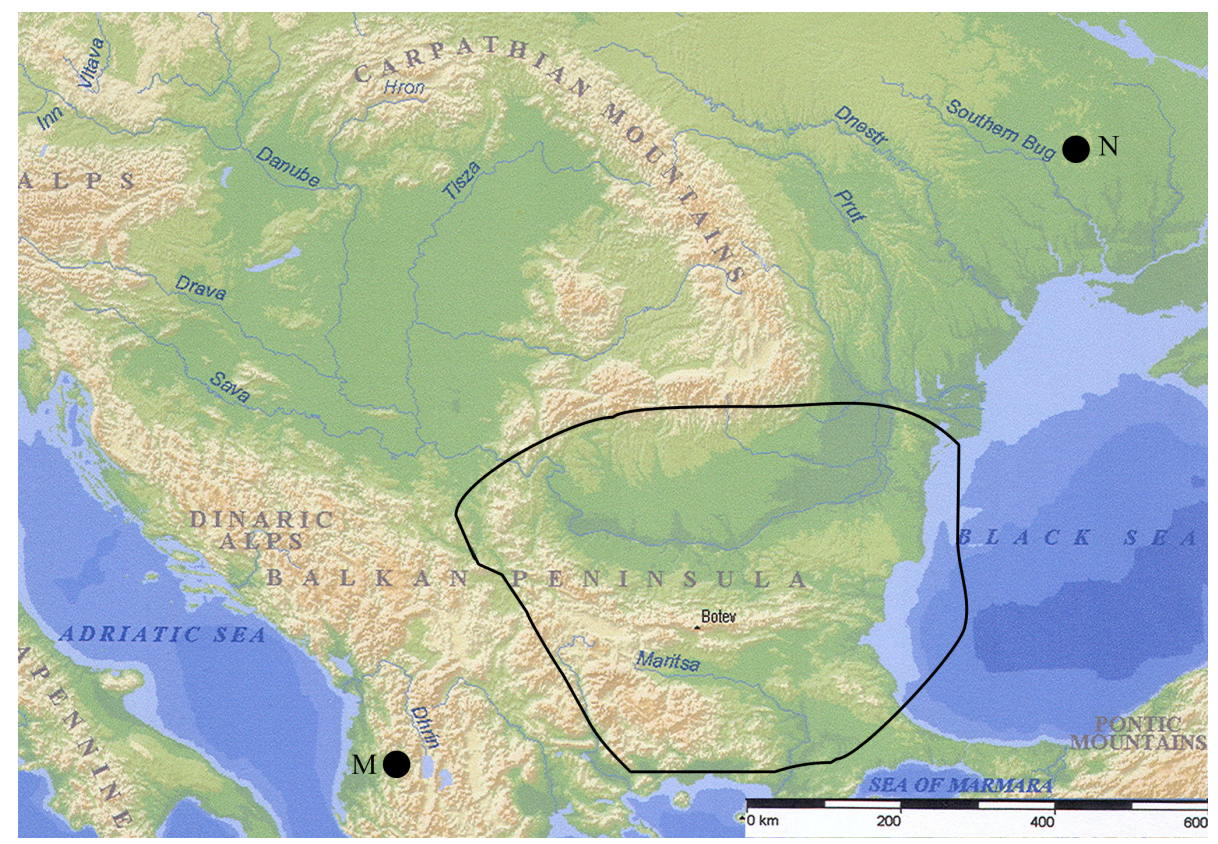

Figure 5.33: Map of East Balkan graphite painted ware complex: M: Maliq; N: Nebelivka (by B. Gaydarska).

The analysis of graphite decoration motifs from the KGK VI group reveals an evolution through time, with a shift from simple and rectilinear geometric motifs at the beginning to more complex and curvilinear ones in the middle and final stages. Positive-negative ornamentation is characteristic for all three phases, while strictly negative ornamentation only occurs at the end of the second phase. Elements and motifs with chronological value are relatively few but enough to offer some dating possibilities. The round compositions, depicting elements and motifs structured in one or four levels are relatively rare at the beginning of the KGK VI group and are more common towards its end (Voinea 2005; Petrova 2011).

It is generally considered that graphite-decorated pottery decreases or even almost disappears in the last phase of KGK VI (Leshtakov 2005; Voinea 2005). Although we are not denying this assumption, the findings at the Sultana-Malu Roșu tell settlement shows that, in the Gumelnița B1 phase, there is an increase in the percentage of the painted pottery in general and graphite painting in particular $(23.5 \%$ in B1 levels versus $7.1 \%$ in A2 levels). Also, the pottery assemblages at Pietrele (Toderas, et al. 2009), and Gumelnița (Dumitrescu and Marinescu-Bîlcu 2001) present numerous examples of graphite-painted vessels in the final levels of those tell settlements.

The complete miniature vessel painted with graphite from Nebelivka has a typical shape for Cucuteni-Trypillia ceramics. Even the motifs painted on the vessel body 
are specific to these communities. There are no specific parallels with the graphitedecorated pottery from KGK VI and KSB communities. By contrast, the rim sherd (Fig. 5.34/1) comes from a typical shape for the 5th millennium BC in the Balkans - a dish with internally-thickened rim with many analogies in the settlements of the KGK VI and KSB communities (Fig. 5.34/4) ${ }^{91}$. Furthermore, the decoration of the internallythickened rim, with oblique parallel lines in graphite, represent a specific decorative motif for KGK VI and KSB communities (Fig. 5.34/2-3) ${ }^{92}$. There are no known parallels in the KGK VI and KSB repertoire for the decoration of house daub with a graphite wash.

Contacts and exchanges between KGK VI and Cucuteni-Trypillia communities are well documented for the 5th millennium BC (Palaguta 2007, Fig. 96). Thus, in many Gumelniţa settlements North of the Danube, discoveries of imported Cucuteni-Trypillia vessels were made ${ }^{93}$ (Voinea 2005). Also, the mixed group Stoicani-Aldeni (BolgradAldeni II) in the contact area between the KGK VI and Cucuteni-Trypillia groups in Romania, Moldova and Ukraine proves the coexistence of both communities, as supported by the mutual transfer of material culture elements including pot shapes and decorative motifs. All this proves a long history of exchange and interaction between these communities and, in this context, the discovery of the graphitedecorated pottery from Nebelivka should not surprise us. If the complete miniature vessel painted with graphite represents a local product, specific to Cucuteni-Trypillia communities, only the decoration technique was adopted - a sign of knowledge transfer. However, the rim sherd was part of a dish which was most probably an imported vessel from the latest communities of the KGK VI group. The dating of Nebelivka to 3970-3770 BC is not an impediment, because many KGK communities survived into the early centuries of the 4th millennium BC according to radiocarbon data available for the final levels of tell settlements such as Sultana-Malu Roșu ${ }^{94}$.

91 e.g., Azmak, Devetashkata Peshtera, Galabovo, Gumelnița, Kozareva Mogila, Krivodol, Lîga, Ostrovul Corbului, Pietrele, Sadievo, Sălcuța, Sultana-Malu Roșu, Tangâru, Varna, Vinitsa and Yunatsite (Todorova \& Matsanova 2000; Dumitrescu \& Marinescu-Bîlcu 2001; Randsborg \& Merkyte 2005; Voinea 2005; Petrova 2007, 2011; Andreescu \& Lazăr 2008; Toderaș et al. 2009; Pătroi 2011; Georgieva 2012; Popova 2012; Reingruber 2012; Popova \& Kostov 2017).

92 e.g., Gumelniţa - here, Fig. 1, Pietrele - here, Fig. 2, Tangâru - here, Fig. 3, Kozareva Mogila here, Fig. 4, Devetashkata Peshtera - here, Fig. 5 (Dumitrescu 1925; Voinea 2005; Hansen et al. 2007; Georgieva 2012; Popova \& Kostov 2017).

93 e.g., Brăiliţa, Căscioarele, Gumelniţa, Hârşova and Vidra.

94 As shown by the $14 \mathrm{C}$ date of $5140 \pm 35$ BP (4039-3804 cal BC) (Poz-52551) (Lazăr et al. 2018); 5230 \pm 50 BP (4174-3961 cal BC) (Poz-52542); and $5250 \pm 40$ BP (4230-3973 cal BC) (Poz-52550) (Lazăr et al. 2016). 


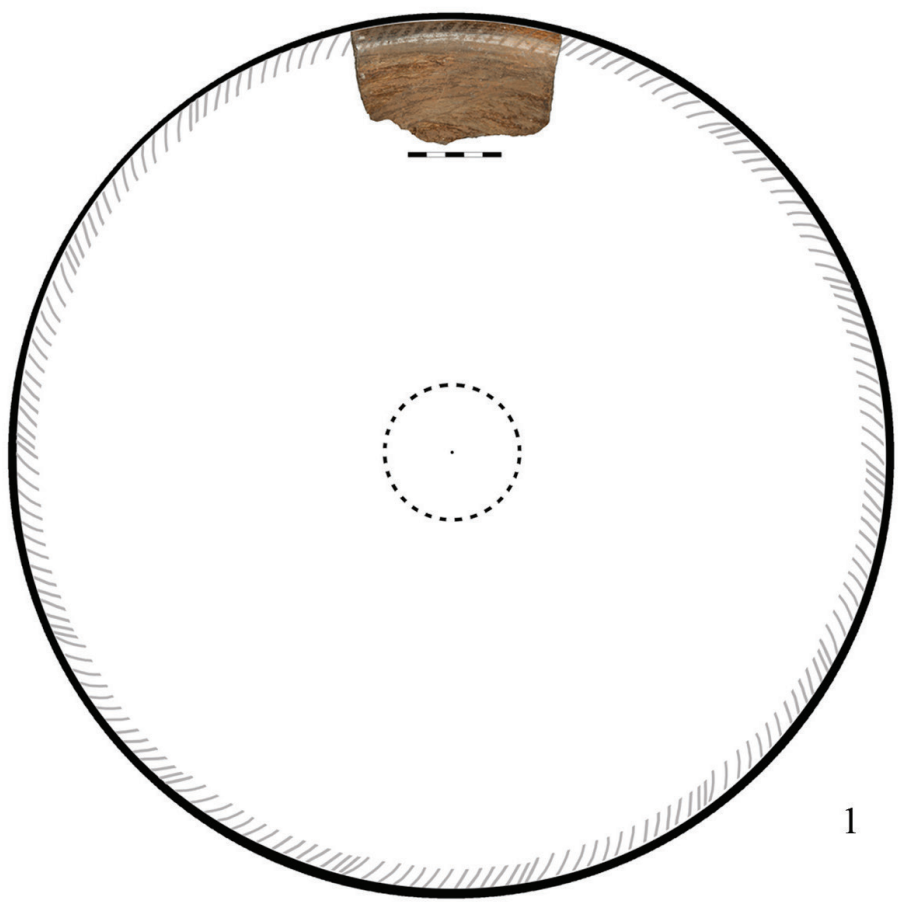

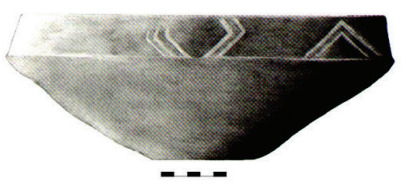

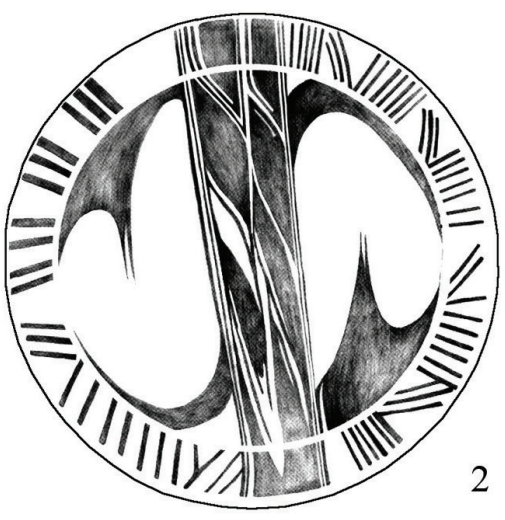

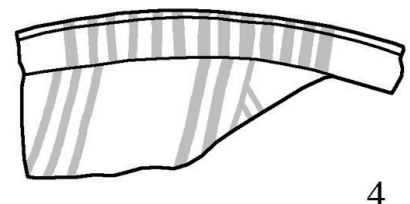

Figure 5.34: Graphite painted analogies for the Nebelivka internally thickened rim dish (1): (2) Pietrele (after Hansen et al. 2007); (3) Tangâru (after Voinea 2005); and (4) tell Gumelniţa (after Dumitrescu 1925) (by T. Ignat \& C. Lazăr). 


\section{Adrian Boyce, Amanda Dolan \& Jason Newton}

\subsubsection{Sourcing the Nebelivka Graphite}

There has, as yet, been no study of the effects of firing graphite in pottery on the chemical composition of the graphite itself. Thus, if isotopically heavier carbon in graphite paint was a result of isotopic fractionation during firing, with the lighter ${ }^{12} \mathrm{C}$ being driven off to a greater extent, this would leave the residue enriched in the heavier isotope, making it difficult to match the object graphite to the graphite source. Further research is necessary on the chemical transformations of graphite in the process of production.

Moreover, since there has been no comprehensive study of the graphite sources in Ukraine and the East Balkans, there is currently no database for the characteristics of graphite from different sources. What we know is that there are several major sources of graphite and over 300 small sources in the Ukrainian Granite Shield alone (Gaskevych 2017). For the East Balkans, while only one graphite source is known from Southern Romania (near the town of Targovishte), multiple sources have been identified in Bulgaria (Leshtakov 2004, 2005). As yet, the graphite from these sources has not yet been analysed for comparison with prehistoric graphite decoration. This means that the present study can contribute only a relative differentiation of the chemical constituents of graphite which, although precise, cannot be positively linked to existing sources.

The analysis of the graphite in six Nebelivka objects, as well as two samples of graphite from modern graphite mines in the Ukraine and two standards, was undertaken in the East Kilbride Lab. Each sample was analysed by two carbon isotopic techniques - closed tube combustion with dual source isotope ratio mass spectrometry and an on-line elemental analyser in continuous flow with an IRMS. The comparison between the two techniques delivered reproducible results in all but one sample, for which there was a ready explanation (too little material was loaded into the tube for analysis).

The results (Table 5.8) provide four valuable preliminary results: (1) there is a good differentiation between the two graphite sources from Kirovograd County; (2) there is a good differentiation between the graphite in the dish with an internally-thickened rim (ITR dish) and the remaining objects from Nebelivka, which form a convincing cluster; (3) the two contrasting values for the graphite from the ITR dish are too low for a derivation from either of the two Kirovograd County sources. However, the ITR dish results may be the product of changes in the graphite during firing (see above); and (4) the Nebelivka cluster of values is not closely matched with either of the two sources. 
Table 5.8: Results of the Carbon isotopic analyses of graphite (by A. Boyce).

\begin{tabular}{llll}
\hline Sample & $\begin{array}{l}\text { Closed Tube } \\
\left(\delta^{13} C_{\text {V-PDB }} \%\right)\end{array}$ & $\begin{array}{l}\text { Continuous MS } \\
\left(\delta^{13} C_{\text {V-PDB }} \%\right)\end{array}$ & Comments \\
\hline Petrovo graphite source, Kirovograd County & -34.232 & -34.17 & \\
Hayvoron graphite source, Kirovograd County & -27.768 & -28.94 & \\
Internally-thickened-rim dish, Test Pit 24/4 & -14.07 & -20.47 & $\begin{array}{l}\text { Closed tube } \\
\text { result suspect: } \\
\text { sample too } \\
\text { small }\end{array}$ \\
Internally-thickened-rim dish, Test Pit 24/4 & -24.249 & -24.38 & \\
Graphite-coated platform daub, Test Pit 18/2 & -30.9 & & \\
Graphite-coated platform daub, Test Pit 18/2 & -29.7 & & \\
Miniature Vessel A3290 & -30.7 & & \\
Miniature Vessel A3299 & -30.6 & & \\
Miniature Vessel A3289 & -30.2 & & \\
Miniature Vessel A3295 & -31.62 & -32.1 & \\
STANDARD IAEA-CH7 & -16.102 & -16.05 & \\
STANDARD USGS 24 & -16.102 & -16.05 & \\
\hline
\end{tabular}

In summary, insofar as any broader conclusions can be drawn from this preliminary study, it may be proposed that the differentiation between the ITR dish and the remaining Nebelivka objects matches the conclusions of the stylistic analysis of the vessels - namely that the ITR dish was probably an import from the East Balkans, while the miniature vessels and the decorated structural daub were probably locally produced.

\section{Oliver E. Craig, Harry K. Robson, Matthew von Tersch, Alexandre Lucquin \& John Chapman}

\subsubsection{The Interior of the Miniature Vessels}

An organic residue analysis of 45 vessels, the contents of two vessels and five soil samples was conducted in order to make sense of the use of pottery at Nebelivka. In addition to an intensive study of all 21 miniature vessels from the Mega-structure, we studied a variety of medium-sized bowls of differing shapes - open bowls, carinated bowls and an inverted-rim bowl - as well as rim sherds from vessels of unknown type $(n=15)$, and nine other miniature vessels from outside the main concentration 
in the Mega-structure, in order to provide a comparative picture of vessel use at the megasite.

\subsection{Materials and Methods}

Small samples (0.5-1.0 g) were removed from the interior walls of the miniature vessels with a scalpel so as to minimise any damage to these complete vessels. Lipids were extracted from three classes of vessel: 30 miniature vessels, nine fine wares and six coarse wares. The latter were taken from seven test pits made in one of the burnt houses $^{95}$. The soil samples were collected from the 2013 soil pit. Given the small quantity of material, lipid extraction and methylation were conducted in onestep according to an established method (Craig et al. 2013; Papakosta et al. 2015), which is known to maximise recovery, particularly of fatty acids (Correa-Ascencio and Evershed 2014). In short, methanol was added to the powdered samples (pottery sherd powder: $4 \mathrm{ml}$ to $1 \mathrm{~g}$; foodcrust: $1 \mathrm{ml}$ to $10-30 \mathrm{mg}$ ) and the mixture was sonicated for 15 minutes followed by acidification with concentrated sulphuric acid $(800 \mu \mathrm{l}$ and $200 \mu$ l, respectively). The sealed acidified samples were heated at $70^{\circ} \mathrm{C}$ for four hours, then cooled to room temperature. Lipids were extracted from centrifuged samples with $n$-hexane $(3 \times 2 \mathrm{ml})$ and directly analyzed by GC-FID and GC-MS.

GC-MS analysis was undertaken using an Agilent 7890A series chromatograph attached to an Agilent 5975C Inert XL mass-selective detector with a quadrupole mass analyser (Agilent technologies, Cheadle, Cheshire, UK). A splitless injector was used and kept at $300^{\circ} \mathrm{C}$. The GC column was inserted into the ion source of the mass spectrometer directly. Helium was used as the carrier gas and inlet/column headpressure was constant. The ionisation energy of the MS was $70 \mathrm{eV}$ and spectra were obtained by scanning between $\mathrm{m} / \mathrm{z} 50$ and 800 . Compounds were separated on a DB-5ms $(30 \mathrm{~m} \times 0.250 \mathrm{~mm} \times 0.25 \mu \mathrm{m}$; J\&W Scientific, Folsom, CA, USA). The temperature was $50^{\circ} \mathrm{C}$ for $2 \mathrm{~min}$ then $10^{\circ} \mathrm{C} / \mathrm{min}$ to $325^{\circ} \mathrm{C}$ and then held for $15 \mathrm{~min}$.

\subsection{Results}

Analysis of the miniature reveals an unusual distribution of fatty acids that is typical of a degraded plant oil. First, in all cases, the $\mathrm{C}_{16: 0}$ fatty acid is much more abundant than $\mathrm{C}_{18: 0}$. Also a range of unsaturated fatty acids are preserved, including $\mathrm{C}_{16: 1}, \mathrm{C}_{18: 1}$, $\mathrm{C}_{18: 2}, \mathrm{C}_{20: 1}$ and $\mathrm{C}_{22: 1}$ (Fig. 5.35). Of note is the particularly high abundance of $\mathrm{C}_{22: 1}$ a fatty acid (Erucic or Brassidic acid). This acid is rarely encountered in organic residues and is a major compound found in Brassicaceae seed oils. The oxidation products of this acid (vicinal dihydroxy acids and dicarboxylic acids) have been found in Ancient

95 Lipid samples were collected from the following Test Pits: 2012/Test Pit 1, 1/1, 1/4, 1/5, 24/3, 25/2, 25/3, 26/2, 26/6 and 33/1. 

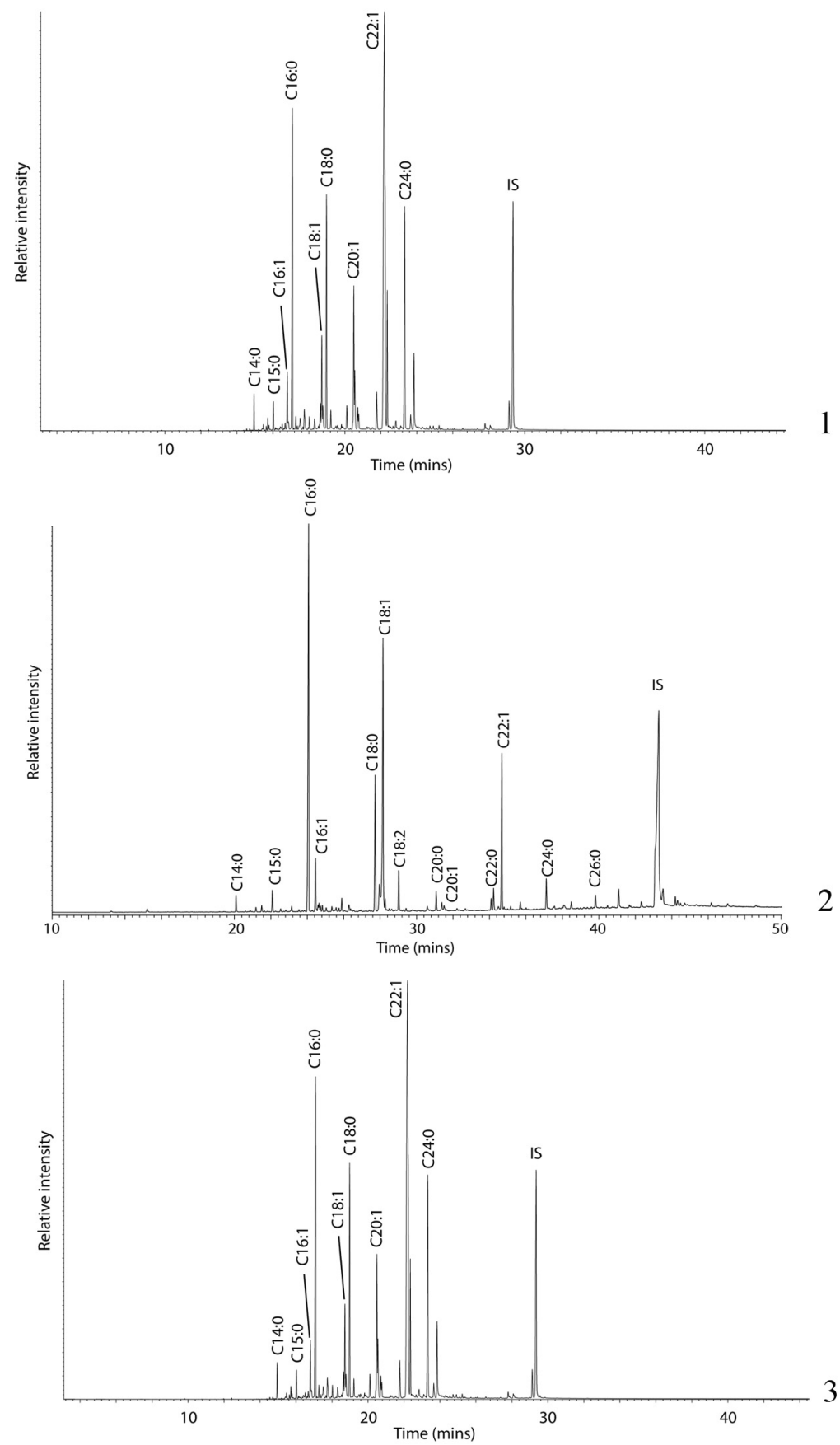

Figure 5.35: Gas chromatograms of lipid extracts from Nebelivka miniature vessels: (1) Test Pit 2012/3; (2) Mega-structure MP 16; and (3) Mega-structure MP 29 (by 0. Craig). 
Egyptian oil lamps (Copley et al. 2005), Islamic Egyptian shells, and Roman vessels (Colombini et al. 2005). In these cases, the oils were most likely used as an illuminant, which explains the presence of degradation products and the absence of the parent unsaturated acids, which would be readily oxidised during burning. The most likely oil for this purpose based on historic documents is radish oil.

However, in the case of the Trypillia miniature vessels, the original unsaturated acids are preserved, with little evidence of degradation products, including an absence of dicarboxylic acids, suggesting exceptional preservation and probably ruling out the use of the vessels as lamps. One concern, given the extremely well preserved nature of the lipid profiles, was to rule out contamination from modern vegetable oils or lipids present in the burial environment. To address this, we analysed a range of other ceramic samples from similar contexts and associated as well as background soil samples. The results showed that similar lipid profiles with a high relative abundance of $\mathrm{C}_{\text {22:1 }}$ were also found on three out of eight coarse ware bowls. The soil samples showed a profile atypically dominated by a range of saturated and unsaturated fatty acids, with $\mathrm{C}_{22: 1}$ representing one of the main fatty acids present.

A logical conclusion from the analytical work is that the soils and artifacts from Nebelivka are heavily contaminated with vegetable oil, possibly rapeseed oil, given that the fatty acid content of this source contains ca. 50\% erucic acid (cis-13docosenoic). Knowledge of the cultivation history of area would be useful to possibly confirm this source. How the lipids have migrated to a depth of ca. $50 \mathrm{~cm}$ from the modern land surface is not easily explained. Another possibility is contamination of the samples with vegetable oil during or after excavation. Laboratory contamination is less likely, considering that the blank controls analysed synchronously with the samples produced no lipids. Either way, the extensive testing of soils and controls makes it questionable that the organic residues found on the pots are from a endogenous and ancient origin.

\subsubsection{Summary}

Miniature vessels formed an important, if minor, part of everyday living at Nebelivka, with dishes and, less often, bowls deposited in burnt houses and pits, while a group of 21 flasks were found together as a special deposit in the Mega-structure. Organic residue analysis of the flasks and other miniature vessels showed that recent contamination was most probably responsible for the concentration of Brassica oils in most of the analysed vessels. Thus, the use of miniature vessels cannot yet be explained, with containers for specialised oils or pigments still a possible use. The Mega-structure group included six vessels with graphite wash and three or four with painted decoration. Additionally, graphite-painting occurred on an internallythickened-rim dish and fragment of platform daub, both from burnt houses. The results of stylistic and characterisation analyses of these vessels and daub matched 
well; there was good differentiation of the carbon isotopic profiles of the ITR dish, stylistically identified as an import from the East Balkans, from the remaining Nebelivka objects, which were stylistically identified as local products. However, no match has yet been found between any Nebelivka object and either of the two sources of Ukrainian graphite tested in this analysis.

\section{John Chapman, Marco Nebbia \& Bisserka Gaydarska}

\subsubsection{Other Miniature Vessels}

While the Mega-structure group comprises the most compelling find of all the miniature vessels, a further 63 such pots - almost all of them complete - have been found at Nebelivka. A total of 12 vessels was found in the Mega-structure outside of the main cluster, while 22 such pots were found in the Pit in Sondazh 1, together with smaller numbers in houses (six in House A9, and 23 more in nine different houses). A second major concentration of 20 such vessels was found in Quarters $\mathrm{G}-\mathrm{H}$ in six different houses, within 320m of each other. Three houses were located in the Inner Circuit and three in the Outer Circuit (including eight miniature vessels in Test Pit $23 / 2$ ), with $75 \%$ of vessels found along the long or short walls, $20 \%$ in the corners and only one in the middle Zone.

The miniature vessels were copies of larger pots of 'normal' size. Two principal shapes were found - dishes (in Ryzhov's system 'miski') (Fig. 5.36/1-2) and flasks ('kubki') (Fig. 5.36/3-6), with smaller numbers of bowls and plates. The majority of flasks was found in the Mega-structure, while dishes were more evenly distributed in houses and the Pit as well as the Mega-structure. One of the flasks found in House A9 (SF 17) (see https://doi.org/10.5284/1047599/ section 5.1.2.3.1) bore a striking resemblance to one flask in the main Mega-structure concentration (SF F5 MP17) (see https://doi.org/10.5284/1047599/ section 5.1.2.3.2). Dishes comprised the vast majority of miniature pots (75\%) in the Quarter $\mathrm{H}$ concentration. The form of the flasks in the Mega-structure group was relatively homogenous, with close shape parallels in only three other flasks at Nebelivka - all in Test Pit houses. Rarely, zoomorphic terminals were added to make these vessels even more special - as in the polypod plate from Test Pit 1/5 and a single dish from the Pit in Sondazh 1. An equally distinctive perforation just below the rim would have enabled the suspension of the vessel from the owner's neck or from a domestic fitting such as a shelf, chair or table (Fig. 5.36/2). 


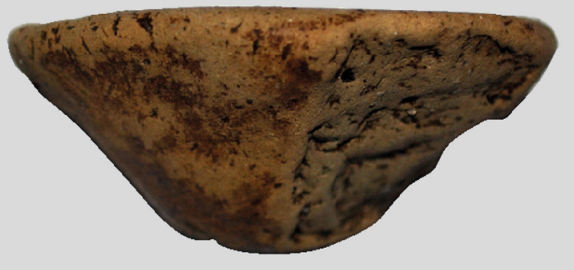

1

2

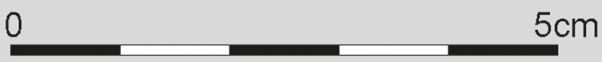

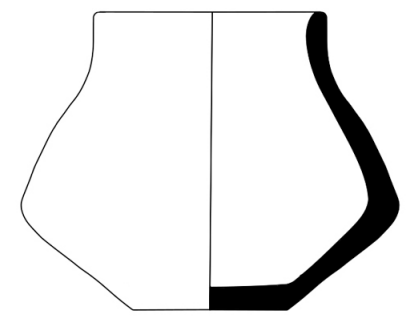

3
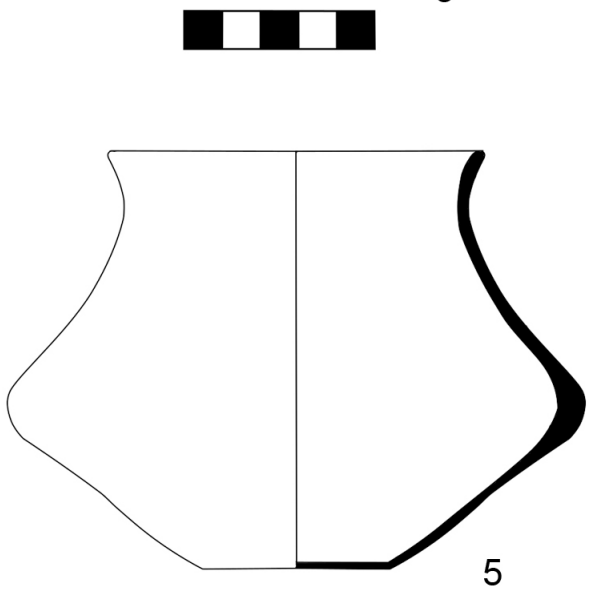

1日

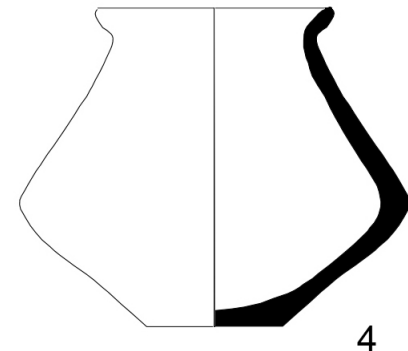

口ם

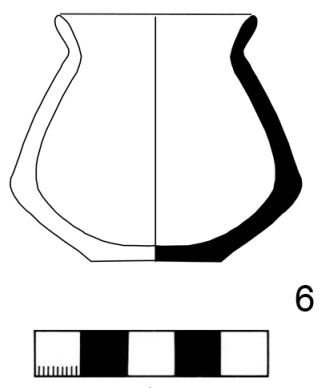

6

Figure 5.36: Types of miniature vessel from outside the Mega-structure cluster: dishes - (1) Test Pit 16/1; (2) Test Pit 31/2 (by K. Harding); flasks - (3) Test Pit 1/4; (4) 33/1; (5) Test Pit 1/4; and (6) 1/1 (by B. Gaydarska). 


\section{Dmytro Kiosak, Mykola M. Belenko \& John Chapman}

\subsubsection{Chipped Stone}

\subsubsection{Introduction}

While the lithic assemblages of Trypillia settlements have often been studied in detail (e.g., Bibikov 1953; Korobkova 1987; Sorokin 1991), few reports have as yet been published on assemblages from the largest megasites (for an exception, see Pichkur 2008). In this chapter, an analysis is offered of what should be considered as a small lithic assemblage. In view of the combined results of four seasons of excavation, including one Assembly House, two dwelling houses, three pits and 88 test pits sampling both Assembly and dwelling houses, there was a remarkably low total lithic discard rate, with just under 150 lithic items recovered. It should be noted that many lithic pieces were recovered from the dry-sieving and bucket flotation that was standard practice for all of the excavation units.

\subsubsection{Raw Materials}

Description of the raw material is based upon a code developed by Pawlikowski for Balkan sites (Pawlikowski 1992). The first part of code characterizes the country of samples origin (here ' $U A$ '), the second part is an abbreviation of site where samples were recovered from (Nebelivka is abbreviated to 'Neb'), the third part is a letter of the material denomination (flint $-\mathrm{F}$, chert - Ch) and finally an order number of a macroscopic group of raw material. The raw materials of the pieces recovered at Nebelivka in the 2012-2014 seasons are as follows:

- Ua-neb-f1 - grey and dark grey, plastic, high quality flint with some quite notable white inclusions. It is transparent when thin. It has a chalky primary cortex (abbreviated term - FUA-1)

- $\quad U a-n e b-f 2$ - honey-coloured and yellow flint with multiple white inclusions. It is transparent when thin. It has a reddish, smooth "pebble" cortex (abbreviated term - FUA-2).

- $\quad U a-n e b-f 3$ - grey, non-transparent flint with white inclusions (abbreviated term - FUA-3)

- $\quad U a-n e b-c h 1$ - greyish-red, large-grained siliceous rock (abbreviated term - CUA1).

- $\quad U A-N E B-R C 1$ - rock crystal (abbreviated term - RCUA-1)

The raw materials of lithics found in the 2009 season were identified using a different system, in which lithics from two known flint sources were identified - a flint quarry at Korobchino, Novomirgorodski region, with a production centre probably located at Korobchino - Rubanii mist (Tsvek \& Movchan 2005) - probably the same as type FUA-2. The second source concerns flint similar to that of Korobchino but more probably 
from Volhynia - i.e., type FUA-1. The other pieces cannot be precisely matched to the 2012-2014 raw material types.

\subsubsection{Technological Modes}

On the basis of Kiosak's analysis of the 2014 lithic assemblage, two modes of production sensu Domborócki et al. (2010) can be identified, which fit the whole assemblage:

- Mode No. 1 was is probably a result of expedient knapping done by member of a household for satisfying the immediate needs of the household itself. The raw material for mode No. 1 was mostly acquired by individual expeditions to nearby outcrops of moderately suitable flint and chert. The relevant raw material types are FUA-2, FUA-3, CUA-1 and RCUA-1.

- Mode No. 2 was based on raw material obtained and pre-prepared elsewhere, sometime in very distant locations, up to 300km away. Raw material type FUA-1 was turned into blades, which acted as universal blanks, bifacial points and partially polished flint axes by flint-knapping experts who may have been parttime specialists.

\subsubsection{The 2009 Assemblage}

The total number of lithic items found in the summer 2009 season was ca. 40. The majority of lithics was found in the excavation of House A9 (Figs. 5.39/13-15 \& $5.40 / 17-18)$, with the remainder $(n=17)$ deriving from the gridded surface collection of the 15-hectare geophysics grid (see Roe, Chapter 3.3.2; Roe, n.d., Fig. 24) (here Fig. 5.40/12-16).

House A9: five pieces are illustrated to represent the good-quality material of this assemblage: a projectile point (Fig. 5.39/13), a double end- and side-scraper (Fig. 5.39/14), a retouched blade which may have been a sickle insert (Fig. 5.39/15), a burin on a backed blade (Fig. 5.40/17) and a distal blade segment converted into a projectile point (Fig. 5.40/18).

Intra-site gridded surface material (see Chapter 3.2.2): this small group included a diverse collection - two complex scrapers on flakes: an end- and side-scraper (Fig. 5.40/12) and an end- and double side-scraper (Fig. 5.40/13); a secondary decortification flake with some cortex left remaining on the dorsal face (Fig. 5.40/14); a distal blade segment which may have been a sickle insert (Fig. 5.40/15) and another multiple scraper (Fig. 5.40/16). Two of the multiple scrapers seem to have been transformed from Volhynian flint core rejuvenation flakes (Figs. 5.40/12-13).

According to a preliminary classification, most of the material comprises retouched tools and their fragments. Some pieces have clear signs of wear-traces. There are no traces of local production. This suggests that the pieces arrived on the site as ready-made tools/tool blanks, mostly laminar and with some probable flake blanks. 
The surface flints were distributed across the entire gridded area, with no particular patterning and signs of only one minor cluster - four pieces in Square K13 (Roe, n.d., Fig. 24). Most lithics were discarded in grid squares also containing burnt daub - viz., the remains of burnt houses.

\subsubsection{The 2012 Assemblage (Table 5.9)}

A small sample of 25 pieces was recovered from the excavation of the Mega-structure - the largest Assembly House in Nebelivka - as well as two flints from the 2012 test pits. Since most of the Mega-structure pieces were recorded by Total Station, the possibility of spatial analysis of this sample is utilised.

The two most frequent raw materials represented in this small sample come from the FUA-1 and FUA-3 groups - both at one-third of the sample. FUA-1 is a highquality imported flint - well suited to the production of long regular blades. However, a similar number of pieces was discard from the much lower-quality local flint FUA-3. Some $20 \%$ of finds are so burnt that it was impossible to define their macroscopic raw material group. One other variety of lithic raw material is represented by a few pieces - the local chert CUA-1. An interesting single piece of greenstone - perhaps a volcanic tuff - shows that the re-sharpening of polished stone tools was practiced within the Mega-structure.

The finds deposited in the Mega-structure were used in different ways according to their different raw material groups. No formal cores were discarded in the Megastructure. Chunks were found as both retouched and unretouched forms in flint FUA-3 and chert CUA-1, as were primary decortification flakes. Cortex was found on the surface of many pieces - clearly not an impediment to their use; a good example is the end-scraper on a flake which retained cortex on $80 \%$ of the dorsal surface. It is important to note that core rejuvenation flakes, indicating local working, were made on imported flint FUA-1 as well as local chert CUA-1. Waste flakes showing local knapping were found in two flint types - the imported FUA-1 and the local FUA-3 (Fig. 5.37/11, 15) - as well as on burnt flint. Although flakes were occasionally produced and retouched (Fig. 5.37/7), the basic goal of the production sequence consisted of blades which were often snapped into blade segments - more often proximal than distal; there were no complete blades in the sample. Scrapers were made on both FUA-1 and FUA-2 flint, while two of the three projectile points were made on Volhynian flint. This low proportion of formal tools is not typical of Trypillia BII assemblages (Sorokin 1991). Although no formal tools were made on other raw materials, retouched edges were made on each raw material type, even the lowestquality chert CUA-1. Every piece of imported FUA-1 flint was retouched, while less than half of the FUA-3 flint pieces were retouched. Some flakes and chunks bore fine marginal retouch (Fig. 5.37/14). Blade segments showed semi-abrupt retouch along both edges or a single edge. Retouch is semi-abrupt and high, with long parallel facets (Fig. 5.37/5). 

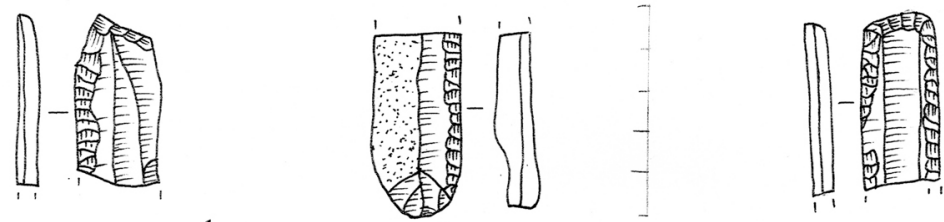

1
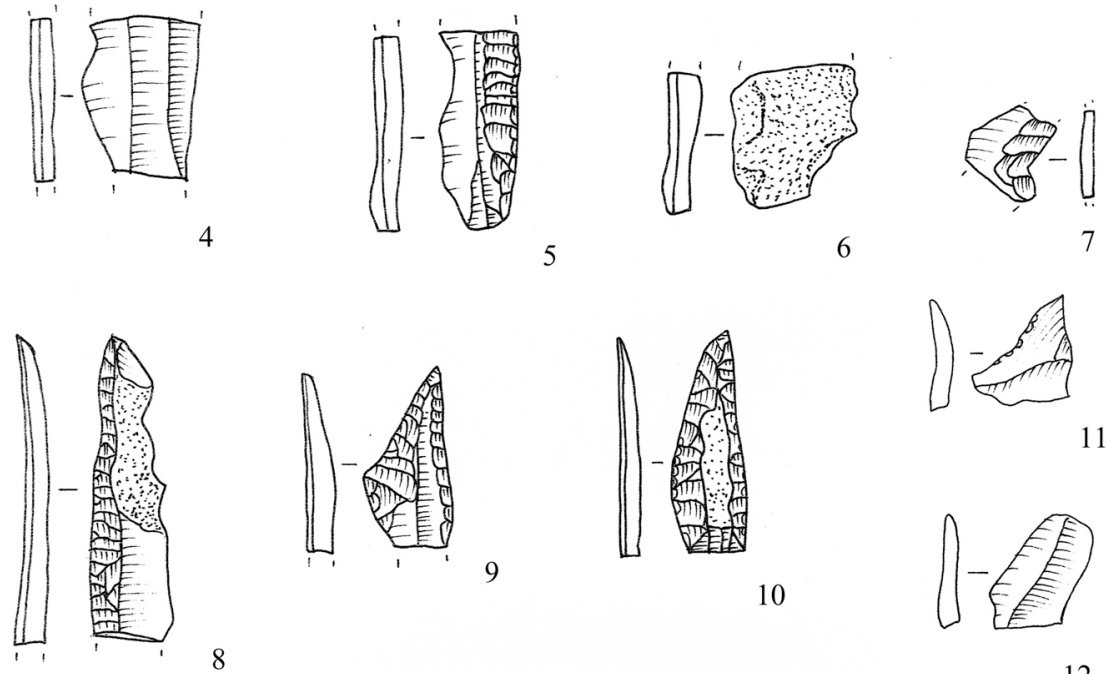

8

10

12

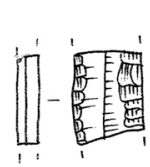

13
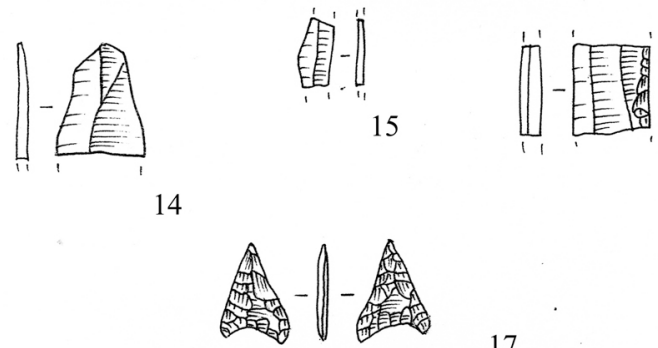

Figure 5.37: Lithics: Mega-structure: 5-7, 9-10, 14-15, 17; Pit, Sondazh 1: 2-4, 12-13; Test Pits: 1, 8, 11, 16 (by M. Gurova). 

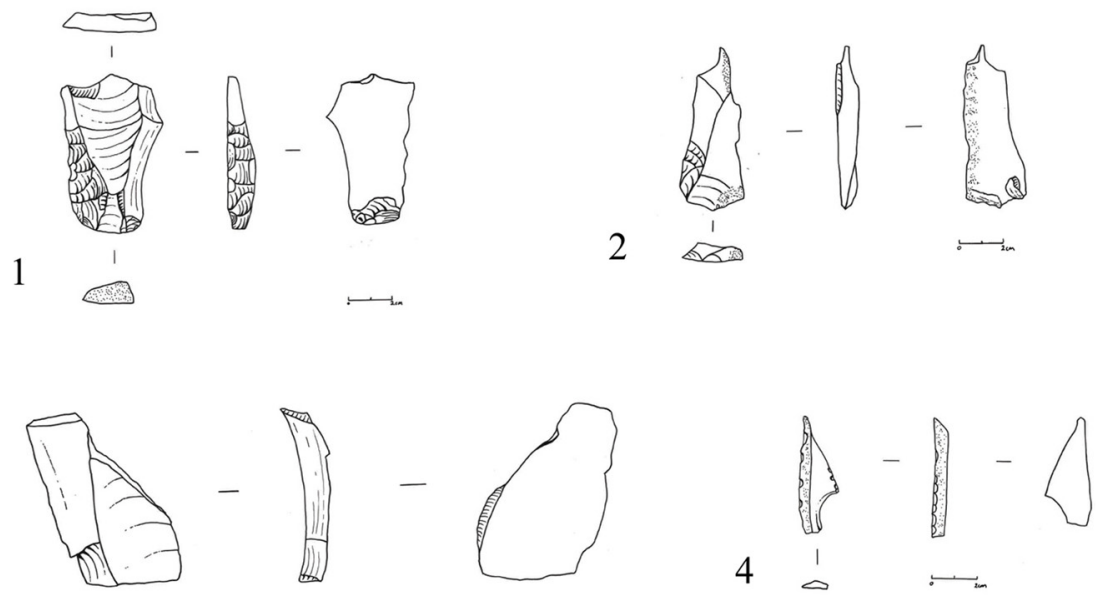

3
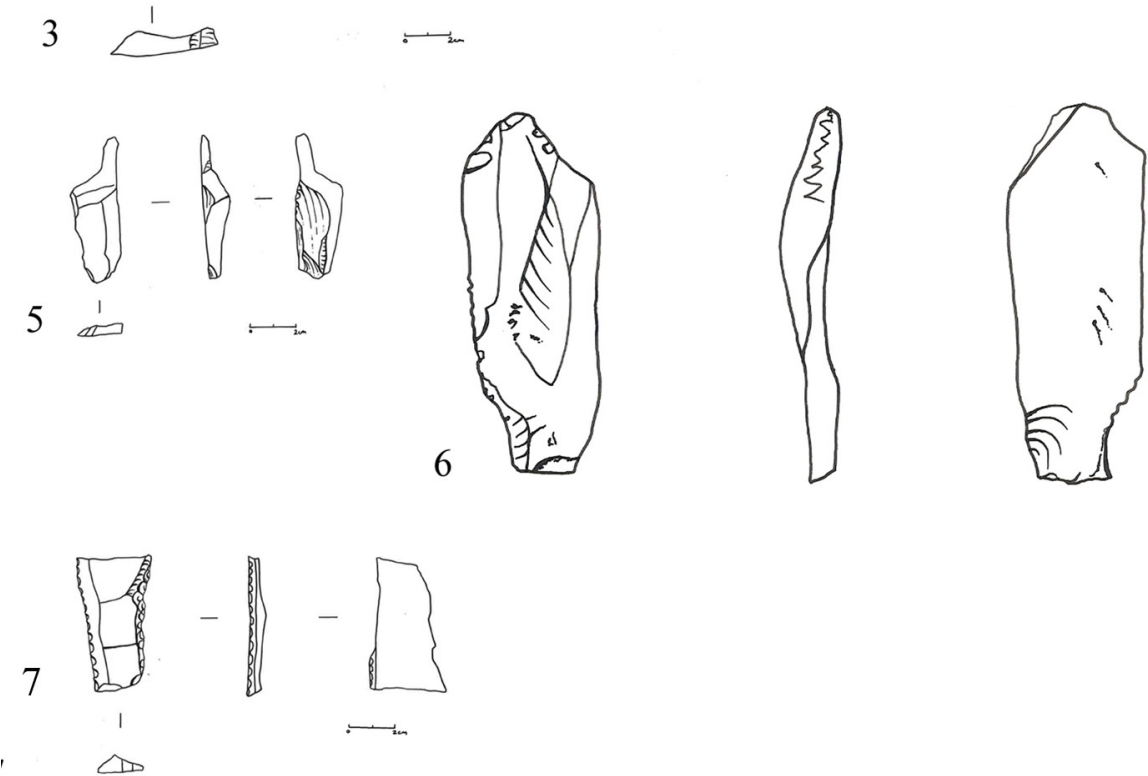

Figure 5.38: Lithics: Pit, Sondazh 1: 1-2, 4-5; Test Pits: 3, 7; Fieldwalking: 6; scale 1:1 (by L. Woodard). 

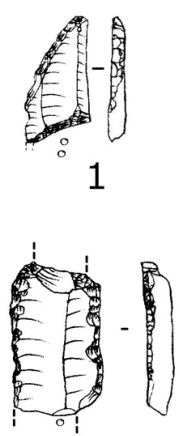

4

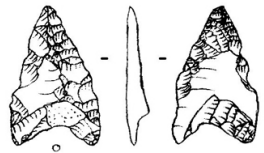

2

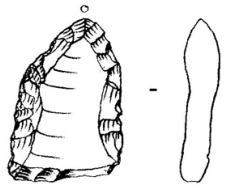

5

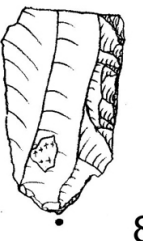

8

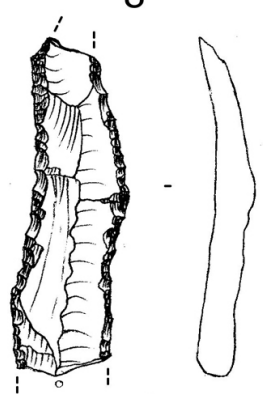

11

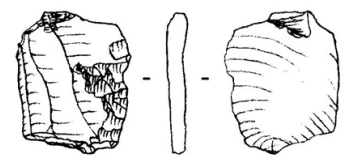

3

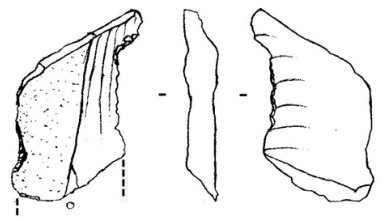

6

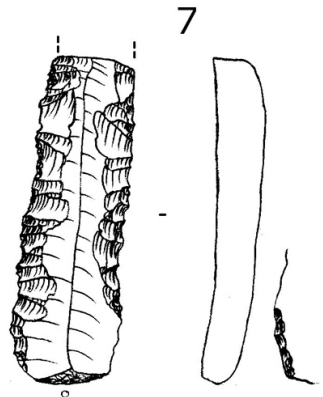

10
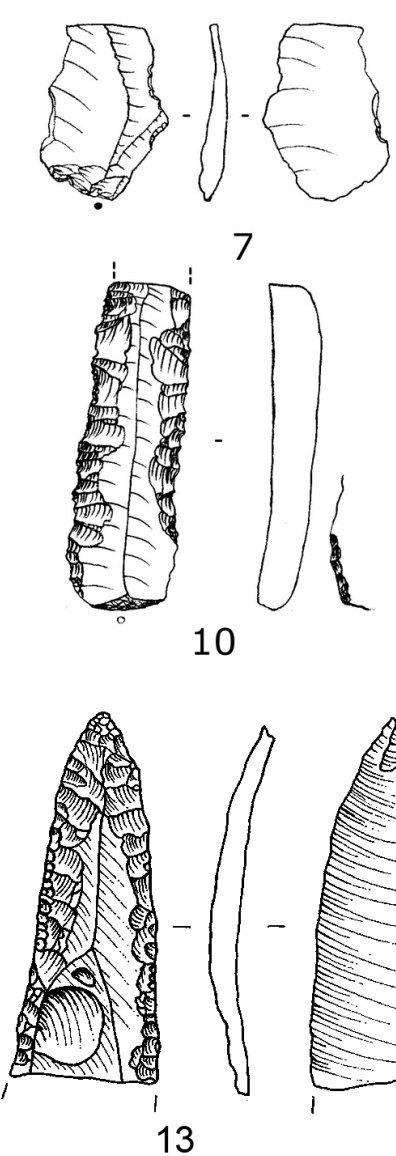

13

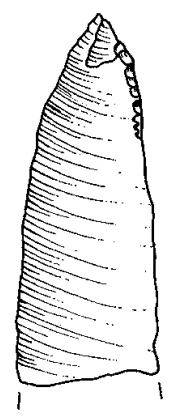

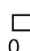

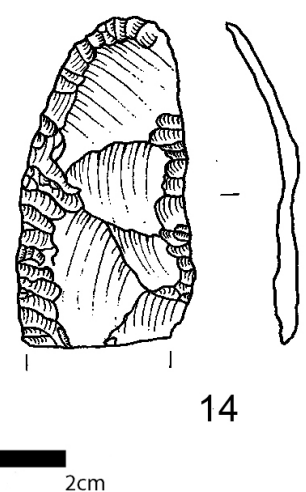

14
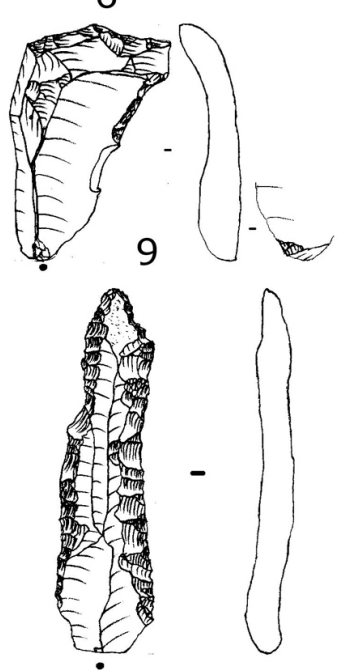

12

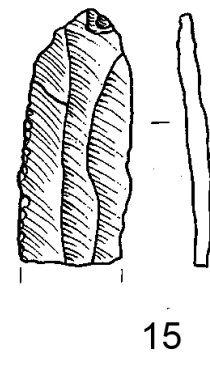

Figure 5.39: Lithics: 2014 season: 1-12 (by D. Kiosak); 2009 season: 13-15 (by L. Woodard). 
The three projectile points used different knapping strategies to reach the same end: abrupt retouch followed by parallel invasive retouch over all the cortex-free surface (Fig. 5.37/8), steep retouch on both edges to form the point, with thinning retouch on the ventral proximal side on both edges (Fig. 5.37/9) and fine retouch on both edges with thinning invasive retouch bifacially at the proximal end (Fig. 5.37/10). This suggests three different knappers were producing projectile points at Nebelivka.

While bulbs of percussion were removed on projectile points, striking platforms were retained in other pieces, such as the retouched flake (Fig. 5.37/6) as well as retouched and unretouched blade segments. Cortex was used as backing for blade segments and retouched flakes. Notches, both retouched and unretouched, were found on blade segments (Fig. 5.37/5) and retouched flakes (Fig. 5.37/7).

Table 5.9: Blanks and Tools, 2012 assemblage (by D. Kiosak).

\begin{tabular}{|c|c|c|c|c|c|c|c|}
\hline Type & CUA-1 chert & $\begin{array}{l}\text { FUA-1 } \\
\text { flint }\end{array}$ & $\begin{array}{l}\text { FUA-2 } \\
\text { flint }\end{array}$ & FUA-3 flint & Burnt flint & Total & $\%$ \\
\hline $\begin{array}{l}\text { Primary } \\
\text { decortification } \\
\text { flake }\end{array}$ & 1 retouched & - & - & 1 unretouched & 2 retouched & 4 & 16 \\
\hline Chunk & 1 retouched & - & - & $\begin{array}{l}3: 1 \text { retouched, } \\
2 \text { unretouched }\end{array}$ & 1 retouched & 5 & 20 \\
\hline $\begin{array}{l}\text { Core } \\
\text { rejuvenation } \\
\text { flake }\end{array}$ & 1 unretouched & - & - & - & - & 1 & 4 \\
\hline $\begin{array}{l}\text { CRF with } \\
\text { scraper } \\
\text { retouch }\end{array}$ & - & 1 & - & - & - & 1 & 4 \\
\hline Flake & - & 1 retouched & - & $\begin{array}{l}2: 1 \text { retouched, } \\
1 \text { unretouched }\end{array}$ & 1 unretouched & 4 & 16 \\
\hline Micro-blade & - & 1 retouched & - & - & - & 1 & 4 \\
\hline $\begin{array}{l}\text { Blade } \\
\text { segment }\end{array}$ & - & $\begin{array}{l}1 \\
\text { unretouched }\end{array}$ & - & $\begin{array}{l}\text { 2: } 1 \text { retouched, } \\
1 \text { unretouched }\end{array}$ & 1 unretouched & 4 & 16 \\
\hline $\begin{array}{l}\text { End-scraper } \\
\text { on blade } \\
\text { segment }\end{array}$ & - & 1 & - & - & - & 1 & 4 \\
\hline $\begin{array}{l}\text { End-scraper } \\
\text { on flake }\end{array}$ & - & - & 1 & - & - & 1 & 4 \\
\hline $\begin{array}{l}\text { Projectile } \\
\text { point }\end{array}$ & - & 3 & - & - & - & 3 & 12 \\
\hline Total & 3 & 8 & 1 & 8 & 5 & 25 & 100 \\
\hline
\end{tabular}




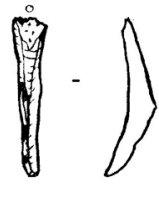

1

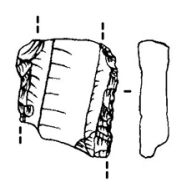

4
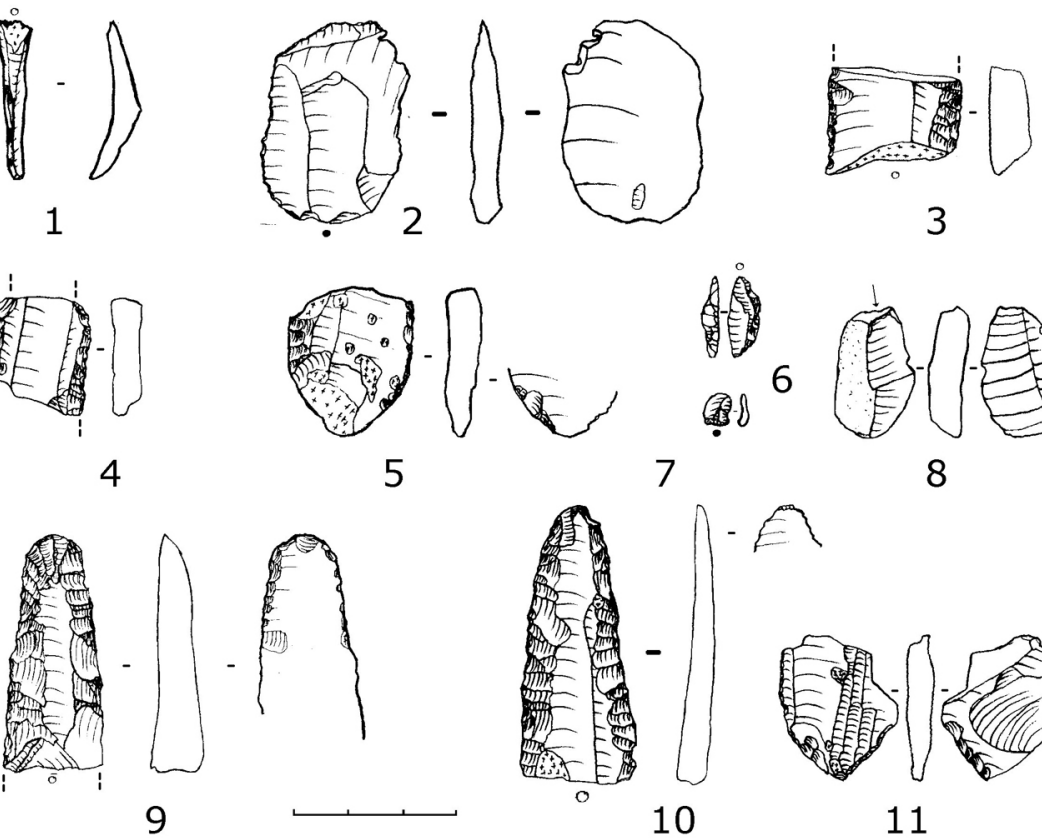

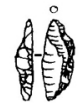
触 6

7

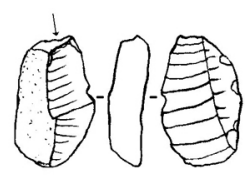

8

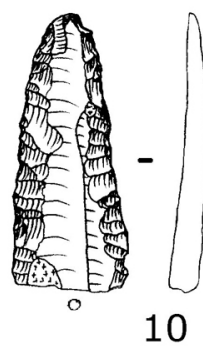

$-E$

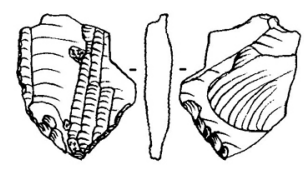

11

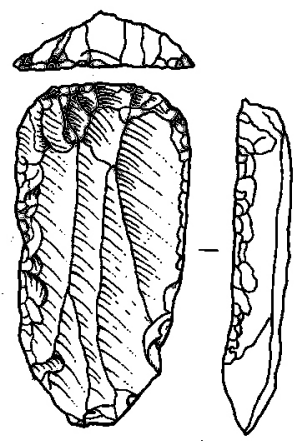

12

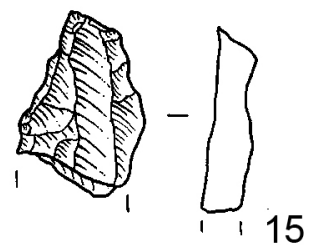

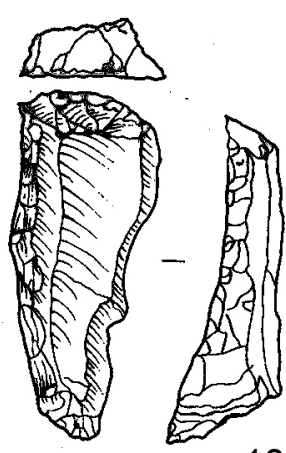

13

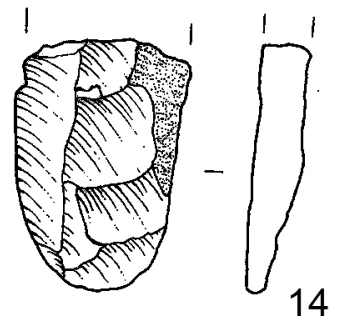

14
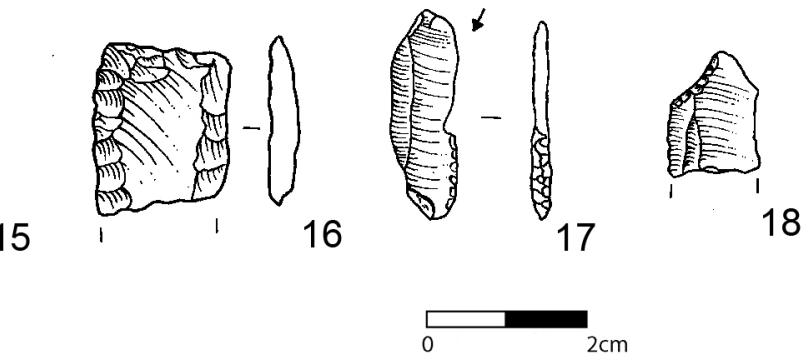

Figure 5.40: Lithics: 2014 season: 1-11 (by D. Kiosak); intra-site gridded fieldwalking: 12-16; House A9: 17-18 (by L. Woodard). 
The most interesting aspect of this small but varied assemblage is the way in which both production modes were deposited in the Mega-structure. The spatial patterning of this modal difference indicates a contrasting distribution of Modes No. 1 and 2 lithics. There were many more Mode No. 1 'local' flints discarded outside the Megastructure, while none was deposited in the central open area and some near the podium and in the Eastern rooms. Conversely, Mode No. 2 'imported' flint was rarely found outside the Mega-structure, with several in the open area and in the Eastern rooms.

Some local re-working of the imported flint shows that not all of the preparatory knapping was completed at some remote workshop. The tools made on the flint (projectile points, blades with semi-abrupt retouch, end-scrapers) were part of a Mode No. 2, curated tool-kit, whereas the local chert was deposited as a Mode No. 1, expedient tool-kit. We may perhaps be talking about people with different skill sets (e.g., experienced vs. novice knappers). But it is intriguing that the products of both modes were deposited in such a prestigious building as the largest Assembly House on the megasite.

\subsubsection{The 2013 Assemblage (Table 5.10)}

A small sample of 32 pieces was recovered from the excavation of a total of 41 test pits (only seven pieces) and the large Pit in Sondazh 1 (25 pieces, of which six came from flotation).

The two most frequent raw materials represented in this small sample come from the FUA-1 and FUA-3 groups, with half of the sample made of the much higher-quality imported FUA-1 and over a quarter of local FUA-3. Just over $10 \%$ of the sample was made on the local chert CUA-1, with two pieces burnt and a single piece made of rock crystal RCUA-1.

There is a contrast in scale between the finds deposited in the test pits and those in the large pit in Sondazh 1. Although a smaller assemblage $(n=7)$, the test pit finds comprised one example each of seven different techno-types, with FUA-1 flint twice as common as FUA-3 flint and the only example of rock crystal. However, it was only in the large Pit that CUA-1 chert and burnt flint was deposited, as well as the only examples of primary decortification flakes, débitage, a core rejuvenation flake with secondary scraper retouch, the only perforator and the sole burin. The principal contrast between the test pit houses and the large pit lay in the types discarded: six out of the seven pieces in or near the test pit houses were retouched examples of Mode No. 2 production, while the vast majority of production debris in Mode No. 1 was, as perhaps expected, placed in the large pit.

No formal cores were discarded in either type for context. Chunks were found as unretouched forms in flint FUA-3, although with one example of an unretouched notch. Primary decortification flakes were found in not only the local CUA-1 but also, importantly, in the Volhynian flint FUA-1 - clear evidence of on-site working of this 
imported material. This notion is supported by the two groups of FUA-1 débitage, one group with cortex and one group without, found during flotation. Cortex was found on the surface of a quarter of the pieces, not least on all three retouched projectile points (10\%, 30\% and 40\% cortex found) (Fig. 5.38/2, 4). Only one core rejuvenation flake was found in this assemblage, made on local FUA-3 flint and showing secondary use as a scraper. Although flakes were occasionally produced and retouched, the basic goal of the production sequence consisted of blades which were often snapped into blade segments - more often proximal than distal; there were no complete blades in the sample. Most scrapers (four out of five examples) were made on FUA-1 flint, with the other on FUA-3 flint, while projectile points were made on both Volhynian and local flint (Figs. 5.37/1 \& 5.38/4). The sole examples of a burin was made on FUA-1 flint, while the only perforator was made on FUA-3 flint (Fig. 5.38/5). The low proportion of formal tools (12 pieces, or 38\%) is not typical of Trypillia BII assemblages (Sorokin 1991).

Formal tools were made on either the imported FUA-1 flint or the local FUA-3 flint. However, only ten of the 16 pieces (or 63\%) of imported FUA-1 flint were retouched, with other pieces showing early stages of the production sequence - only slightly higher than the proportion of FUA-3 flint pieces with retouch (5 out of 9 pieces, or $55 \%$ ). Some pieces bore traces of a single form of retouch, whether fine marginal retouch on flakes or blade segments (Fig. 5.38/6), semi-abrupt retouch along both edges or a single edge of a blade segment (Fig. 5.37/13) or abrupt retouch on a flake. However, there were signs of intensive use of the flints, especially the imported FUA-1 material. One piece had scraper retouch at one end and notches on the right side, opposite an unretouched back, another scraper had fine retouch on one end as well as invasive retouch on the other edge (Fig. 5.37/16), while others had scraper retouch on one end and both sides in FUA-3 as well as FUA-1 material (Fig. 5.37/2, 3). Other pieces showed combinations of retouch, whether on a single side of a flake, or the fine retouch on two sides of a rock crystal flake and a notch on one side, or the invasive semi-abrupt retouch on one side of a thick flake with thinning retouch on the striking platform and a retouched notch on the other edge (Fig. 5.38/1). The intensity of usage is convincingly shown by the re-use of a FUA-3 core rejuvenation flake as a notched piece and as a scraper (Fig. 5.39/9).

Each of the three projectile points used different knapping strategies to reach the same end: abrupt retouch on one side and semi-abrupt retouch on the other (Fig. 5.37/1), fine retouch on one side and a notch on the other (Fig. 5.38/2) and a notch on one side and retouch across the cortex on the other (Fig. 5.38/1). It may be observed that the three projectile points retrieved from the Mega-structure (2012 season) were made in yet three more different ways (e.g., Fig. 5.37/17)! The working end of the perforator made in local FUA-3 flint was fashioned in yet another way - a retouched notch on one side and semi-abrupt retouch on the other. This reinforces the likelihood of several different knappers in action at Nebelivka. 
Table 5.10: Blanks and Tools, 2013 assemblage (italics - deposited in Test Pits: all others from Pit, Sondazh 1) (by D. Kiosak).

\begin{tabular}{|c|c|c|c|c|c|c|c|}
\hline Type & $\begin{array}{l}\text { CUA-1 } \\
\text { chert }\end{array}$ & $\begin{array}{l}\text { FUA-1 } \\
\text { flint }\end{array}$ & $\begin{array}{l}\text { FUA-3 } \\
\text { flint }\end{array}$ & $\begin{array}{l}\text { Rock } \\
\text { crystal } \\
\end{array}$ & $\begin{array}{l}\text { Burnt } \\
\text { flint }\end{array}$ & Total & $\%$ \\
\hline $\begin{array}{l}\text { Primary } \\
\text { decorti- } \\
\text { fication flake }\end{array}$ & 1 & 1 & - & - & - & 2 & 6 \\
\hline Chunk & 2 & - & $\begin{array}{l}3: 1 \\
\text { retouched, } \\
2 \\
\text { unretouched }\end{array}$ & - & - & 5 & 16 \\
\hline $\begin{array}{l}\text { CRF with } \\
\text { scraper } \\
\text { retouch }\end{array}$ & - & - & 1 & - & - & 1 & 3 \\
\hline Flake & $\begin{array}{l}1 \\
\text { unretouched }\end{array}$ & $\begin{array}{l}4: 2 \\
\text { retouched; } \\
2 \\
\text { unretouched }\end{array}$ & $\begin{array}{l}2 \\
\text { unretouched }\end{array}$ & $\begin{array}{l}1 \\
\text { retouched }\end{array}$ & - & 8 & 25 \\
\hline Débitage & - & $\begin{array}{l}\text { 2: } 1 \text { with } \\
\text { cortex; } 1 \\
\text { without } \\
\text { cortex }\end{array}$ & - & - & 1 & 3 & 9 \\
\hline $\begin{array}{l}\text { Blade } \\
\text { segment }\end{array}$ & - & 1 retouched & - & - & $\begin{array}{l}1 \\
\text { unretouched }\end{array}$ & 2 & 6 \\
\hline $\begin{array}{l}\text { End-scraper } \\
\text { on blade } \\
\text { segment }\end{array}$ & - & 1 & - & - & - & 1 & 3 \\
\hline $\begin{array}{l}\text { End-scraper } \\
\text { on flake }\end{array}$ & - & $2(1)$ & - & - & - & 2 & 6 \\
\hline $\begin{array}{l}\text { Side-scraper } \\
\text { on blade } \\
\text { segment }\end{array}$ & - & 1 & - & - & - & 1 & 3 \\
\hline $\begin{array}{l}\text { Side- and } \\
\text { end-scraper } \\
\text { on blade } \\
\text { segment }\end{array}$ & - & 1 & 1 & - & - & 2 & 6 \\
\hline $\begin{array}{l}\text { Projectile } \\
\text { point }\end{array}$ & - & $2(1)$ & 1 & - & - & 3 & 9 \\
\hline Perforator & - & - & 1 & - & - & 1 & 3 \\
\hline Burin & - & 1 & - & - & - & 1 & 3 \\
\hline Total & 4 & 16 & 9 & 1 & 2 & 32 & \\
\hline
\end{tabular}


While bulbs of percussion were thinned or removed on projectile points, striking platforms were retained in other pieces, such as on proximal blade segments (trapezoidal or sub-rectangular) (Fig. 37/2, 16) as well as unretouched (trapezoidal) and retouched (triangular) flakes (Fig. 5.37/12), chunks (semi-circular) and even one primary decortification flake (triangular). The variability in size and shape of surviving striking platforms suggests several hands at work in the knapping of these pieces.

This small but varied assemblage is convincing proof that not all of the preparatory knapping of the imported flint was necessarily completed at some remote workshop. Similarly, the collection and local working of CUA-1 chert and FUA-3 flint is attested. The contrast is still found between Modes No. 1 and No. 2, with Mode No. 2 intensively exploited, curated tools made on the high-quality flint (projectile points, blades with semi-abrupt retouch, four kinds of scrapers, burin) and the Mode No. 1 expedient tool-kit based upon lower-quality flint (FUA-3) and chert (CUA-1), although the FUA-3 perforator shows intensive usage of local flint as well. The pieces in the 2013 assemblage showed a greater intensity of use than in the 2012 or 2009 groups, while also indicating variability in knapping techniques that suggest several knappers were at work. This conclusion supports the notion of 'local' flint-knappers associated with different houses in the production of this assemblage.

\subsubsection{The 2014 Assemblage (Table 5.11)}

The collection consists of 49 chipped stone artefacts, originating from three sets of contexts. The first set is the most homogeneous, comprising pieces found in Pit 2 near the industrial feature. Sixteen items were found in the test pits scattered over the settlement area. This sample is not homogeneous and it cannot be treated as a single entity. In 2014, several contexts were sampled for water-sieving, producing 17 lithic items.

One flake was made on a small red "Carpathian pebble". The FUA-1 Volhynian flint was represented by $53 \%$ of all finds by number. Around a quarter of finds were so burnt or patinated that it was impossible to define their macroscopic raw material group. Other varieties of raw material were represented by only a few pieces.

Different raw material groups were put to various uses on the megasite. The majority of blade tools - perforators and end-scrapers - were made on FUA-1 flint, while all projectile points were produced from FUA-2 material. Both raw materials represent Mode No. 2 production. By contrast, other raw material groups yielded no formal retouched tools, conforming to Mode No. 1 production.

The only core found is a secondary core for flakes. It has a single platform and was made on a large, thick flake. It is not related to the usual chipped stone tool production at Nebelivka. The majority of the tools was made on FUA-1 raw material. Artefacts often bear some areas of primary cortex on their dorsal surface. It is unlikely that they were produced in the course of on-site decortification activities. It is more probable that the partially corticated dorsal surfaces were not treated as an obstacle 
for use of a tool. So, corticated blades could be brought as prepared blanks for tools on the site.

The debitage group consists of 10 flakelets and a chunk. Two flakelets have a morphology that is indicative of retouching chips: flat oblique butts, a visible ventral lip, a curved profile and "feather" end, and negative scars of the previous retouching rows in the proximal part of the flakelet's dorsal surface (Fig. 5.40/7). They can come

Table 5.11: Blanks and Tools, 2014 assemblage (by D. Kiosak).

\begin{tabular}{|c|c|c|c|c|c|}
\hline Description & Pit S1 & Trenches & Water-Sieving & Total & $\%$ \\
\hline secondary core on a flake & & 1 & & 1 & 2.04 \\
\hline flake & 2 & 3 & 2 & 7 & 14.29 \\
\hline corticated flake & & 2 & 1 & 3 & 6.12 \\
\hline blade & & 1 & 2 & 3 & 6.12 \\
\hline chip & & & 8 & 8 & 16.33 \\
\hline retouching flakelet & & & 2 & 2 & 4.08 \\
\hline chunk & 1 & & & 1 & 2.04 \\
\hline burin spall & & 1 & & 1 & 2.04 \\
\hline retouched flake & 2 & 2 & & 4 & 8.16 \\
\hline retouched blade & 3 & 4 & & 7 & 12.24 \\
\hline with semi-abrupt bilateral convergent & -1 & -3 & & & \\
\hline retouch & -1 & -1 & & & \\
\hline $\begin{array}{l}\text { with convergent semi-abrupt and fine } \\
\text { retouch } \\
\text { with semi-abrupt retouch on an edge }\end{array}$ & -1 & & & & \\
\hline splintered piece & 1 & 1 & & 2 & 4.08 \\
\hline end-scraper, & 2 & & & 2 & 6.12 \\
\hline on a retouched blade & -1 & & & & \\
\hline on a retouched flake & -1 & & & & \\
\hline tool with burin detachment & & & 1 & 1 & 2.04 \\
\hline perforators & 3 & 1 & & 4 & 8.16 \\
\hline geometric microliths & 1 & & 1 & 2 & 4.08 \\
\hline $\begin{array}{l}\text { lunate? } \\
\text { rhomboid point }\end{array}$ & -1 & & -1 & & \\
\hline bifacial arrowhead & 1 & & & 1 & 2.04 \\
\hline Total & 16 & 16 & 17 & 49 & 100.00 \\
\hline
\end{tabular}


from faceting of core's platform; however, both morphology and context are highly suggestive of their role in the knapping sequence as facconage debris.

Flakes outnumber non-retouched blades. But the inclusion of retouched items means an equal proportion of blades and flakes, with most tools made on blades. There are no complete blades in the collection. Some parts of blades can be analyzed from a technological viewpoint. Mostly they are fragments of not too wide and not too thin blades, with a pattern of dorsal negatives " 212 ", which is characteristic for serial detachment of blades from flat and wide fronts of cores (Léa 2003). The striking platforms (butts) were flat and elliptical, with an area of 9-12 $\mathrm{mm}^{2}$. Sometimes the detachment of a blade was prepared by reduction of overhang, done by means of abrasion "on the flaking surface". Dorsal negative ridges are wavy and uneven. Angles of detachment were recorded twice $-78^{\circ}$ and $85^{\circ}$. Consequently, the morphology of laminar products does not correspond to the use of the lever technique. We would hypothesize that a more widespread, less specialised technique was used for blade production, such as the punch technique or the soft organic percussion technique.

Defined types comprise almost a half of the collection, at 49\%. This high percentage of retouched items is typical for Trypillia Phase BII-C sites (Sorokin 1991). Some flakes bear fine marginal retouch (Figs. 5.39/6-7 \& 5.40/2, 5). One flake has flat alternative retouch (Fig. 5.39/3). Retouched blades are represented exclusively by medial parts of blades with semi-abrupt retouch along a single edge or both edges. Retouch is semi-abrupt and high, with long parallel facets (Figs. 5.39/8 \& 5.40/3-4). Several perforators are made on blades in a similar technique - by high, parallel, semi-abrupt retouch on both edges that converges to the end of a blank, becoming flat at the very tip. There are sectors with fine or flat ventral retouch, single flat detachments in the area near the pointed tip. Although the point is often broken, it is quite evident that the retouched blade was pointed by convergent semi-abrupt retouch (Figs. 5.39/10-12 \& 5.40/10). A blade was retouched along both edges with semi-abrupt retouch while its tip was rounded by flat retouch into a "scraper" front with an acute section (Fig. 5.40/9). There are small ventral facets opposite this working edge. They probably are macro-traces of use. This tool is close morphologically to the group of perforators which Telegin proposed to call "knives with scraper-like termination" (Telegin 1976, p. 27).

Medial parts of blades with semi-abrupt retouch could be fragments of perforators or "knives". End-scrapers are not really typical. An end-scraper on a flake has an angular front. The proximal end of an end-scraper on a retouched blade was destroyed by a facconage (façonnage) flake (Fig. 5.39/6).

Projectiles are made exclusively from honey-coloured or yellowish flint FUA-2.

A small $(2.5 \times 1.5 \mathrm{~cm})$ bifacial arrowhead bears a deep notch on its base and has isosceles straight edges (Fig. 5.39/2). It is produced by parallel flat retouch, which covered most of both dorsal and ventral surfaces. A rhomboid point was made on a blade by semi-abrupt and abrupt retouch. The distal truncation is acute $\left(40^{\circ}\right)$ while the proximal one is convex (Fig. 5.39/1). A "lunate"-like tool is a small $(1.4 \times 0.5 \mathrm{~cm})$ 
fragment of a blade with abrupt retouch, cutting an arched back in the blank (Fig. 5.40/6). Although it cannot be stated categorically that it is a fragment of a lunate, this fragment should belong to a tool of a similar type - for example to a point with an arched back, a traditional form of tool more typical of the Early Trypillia period.

Other tools are represented by two splintered pieces. One of them is made on a retouched blade (Fig. 5.40/11). One edge is retouched finely, while the other has semiabrupt retouch. There are several negatives of flat detachments on the dorsal surface, and a large flat negative on the ventral surface. There is also a corticated flake with large flat ventral negative of burin spall in the collection (Fig. 5.40/8).

\subsubsection{Discussion}

We suggest that the observed typological variability can be explained mainly through the use of two or three reduction sequences. The first one is related to the highquality "imported" Volhynian flint FUA-1. It arrived at the settlement in shape of blanks, maybe already retouched, that served as a universal tool, often re-sharpened or re-shaped. Similar items can have a multitude of functions defined by use-wear analysis (Korobkova 1987; Sorokin 1991). Re-sharpening is proved by retrieval of retouching flakelets from the water-sieving. This fact alone demonstrates the effectiveness of water-sieving in Trypillian site excavations. Such tools (perforators, blades with semi-abrupt retouch, end-scrapers, "knives") were part of a Mode No. 2, curated tool-kit. It is interesting that a majority of flint items in the Test Pits whose source could be identified were imports (Fig. 5.47).

The second context is related to the flint FUA-2 and is represented by projectiles of various shapes. In a local anomaly, this 'local' flint conforms to Mode No. 2 production. While the bifacial arrowhead with a convex base has numerous analogies on Late Trypillia sites, the rhomboid point made in local FUA-2 flint is rather related to the Early Trypillia technology of knapped stone. It is an obvious outsider in the Trypillia BII context. Its presence in the pit near the industrial feature needs an explanation. One suggestion is that the Phase A tradition of rhomboid arrowheads was retained locally as a connection to the ancestral roots of the Nebelivka settlement. A second idea is that visitors to the megasite brought this geometric form of arrowhead from an area in which this ancestral form was deliberately retained. A third, more straightforward idea is that the projectile point was found in the site area and re-utilised in a later arrow, in turn discarded in a BII megasite. Whichever reason is most plausible, the rhomboid projectile point touches on the interesting question of relations with ancestral Trypillia traditions. A similar link with the past is raised by the discard of an FUA-2 'lunate'.

The third context illustrates knapping procedures, represented first of all by a core and a thick flake made of a coarse-grained siliceous rock. This raw material was unusual in the tool-kit of a Late Trypillia site. Similar finds are usually interpreted as traces of children learning knapping skills (Shea 2006). 
The low discard of lithics, the high percentage of retouched tools - although reduced at Nebelivka - and their probable connection with short (viz., two- or three-stage) reduction sequences are quite characteristic for Late Trypillia sites. A similar model of chipped stone production and utilization is widespread in the Balkan Neolithic and Chalcolithic (Mateva 2011; Hansen et al. 2012; Sirakov 2002; Manolakakis 2005, 2008). It is probably connected with an established system of logistical supply of cores and blanks to Neolithic residents in order to sustain a settled way of life (Zimmermann 1995).

According to Bibikov (1970, pp. 3-6), there were two types of production in the Trypillia group - domestic and communal. Communal production was exemplified by pottery, flint-collection and - processing and metal production. The raw material was collected and the objects were produced for exchange, with the flint-knappers receiving some objects in return. If Bibikov's exchange model is correct, there should be central sources and centres of lithic production to serve a settlement as large as Nebelivka. However, no such centres have been as yet identified in the Nebelivka micro-region.

According to Tsvek, flint-extraction pits are considered to indicate flint sources. Such working pits have been found in the Novomirgorod region, near knapping sites. One such BII production site - Rubany Mist (Tsvek \& Movchan 2005; Tsvek et al. 2012) - may have been contemporary with Nebelivka. Given the relatively close distance of Nebelivka to the Korobchino quarry, and the overlap in date, it is possible that this quarry served the Nebelivka site. This notion is supported by the discovery of utilised Korobchino flint nodules at Nebelivka in the 2009 season. However, it is also possible that the Nebelivka people were using the lithic production centres near Volodymyrivka because this was their traditional flint source.

The results of these investigations raise questions about the procurement, distribution and further processing of lithics in the Eneolithic period. In the Early Trypillia period (phases A and BI), large lithic assemblages have been recovered, indicating large-scale deposition of mostly local flint with a few imported flint pieces from the Dobrogea and Volhynia, as at Bernishivka (Zbenovich 1989; cf. D. Chernovol's recent, still unpublished investigations which have yielded thousands of lithics: Shydlovsky \& Slesariev 2015).

It might be supposed that megasite populations would have needed large quantities of lithics for different purposes, whether scrapers or denticulate sickles and that, consequently, such procurement and processing could have been very important in the region. However, in phase BII, there was a dramatic, and as yet unexplained, decline in the discard practices of Trypillia settlers, with greatly reduced on-site lithic deposition. Despite their size, the megasites also conformed to this new model of minimal lithic deposition. An explanation for this major change in lithic discard is urgently required.

In the Late Trypillia phase, long-distance importing of flint was very important, even if not in great quantities. At the CI site of Dobrovodi (Pichkur 2005, p. 117), 
there were lithic imports of both light and dark brown varieties of Volhynian flint. Similarly, in the CI/phase 3 at Majdanetske, Volhynian flint imports were also found. According to Petrun (2001-02, p. 139), this flint derived from Turonian and Senonian (Cenomanian) epochs and bears a visual similarity to flint from outcrops in the Ternopil and Rivne regions. Characteristic examples of 'local' flint from the Synukha basin were not found in the lithic raw materials at Majdanetske. In the CI horizon at Taljanki, tools were made from imported Volhynian flint (Pichkur 2008, p. 158), although there are some 'local' tools made from the so-called Bug flint.

Thus, following the marked reduction in lithic discard, there is a change in the relationship of local and imported flint at the BII - CI transition, with imported flint outnumbering local flint at Taljanki, Dobrovodi and Majdanetske. This could show different traditions of lithic procurement, exchange networks and the types of tools used in the CI Tomashevka group. According to Skakun (2004, pp. 74-5 \& Fig. 14, 2012; Skakun et al. 2014), Trypillia society imported ready-made tools rather than raw materials of Volhynian flint. She draws parallels between lithics from the Bodaki flint-knapping workshop in the Ternopil region and those deposited at Majdanetske and Taljanki. The character of the Nebelivka lithics made of Volhynian flint suggests that this process of importing ready-made tools had already begun in the BII stage. This conclusion has implications for the dating of Volhynian flint exploitation and the use of the Bodaki workshop. In this way, this investigation of the materials from Nebelivka shed light on the local use of flint, the importing of flint and its processing.

\subsubsection{Conclusions}

Trypillian lithic collections shed light on the complex social organization of flintworking. On the level of empirical data, almost any Trypillian lithic collection is composed of two production modes: Mode No. 1, with sets of objects made from "local" flint, often of poor quality, knapped in basic ways, without complex preparations with extensive use of waste products as blanks for retouched tools; and Mode No. 2, with sets of objects produced from good-quality, often imported flint, with a notable input of expertise and skill, oriented towards blade production and their utilization as blanks for a wide variety of tools. Recent finds indicate that Mode No. 2 lithic production appeared as early as Trypillia A III (Precucuteni A3), first of all in the Dniester valley at rich flint outcrops (Kiosak 2016). Volhynian flint was utilized in such a way from the Trypillia BII stage onwards.

A small lithic assemblage, consisting of fewer than 150 pieces, has been retrieved from four seasons of excavations at the Nebelivka megasite. Approximately half of the lithics identified to raw material were imported, Volhynian flint (FUA-1). The megasite shares the dual system of lithic production in Modes No. 1 and 2 but with some exceptions. For example, the use of 'local' FUA-2 flint for projectile points combines a Mode No. 1 material with a Mode No. 2 technology. If the two modes reflect work by different flint-knappers, such an occurrence would betoken the sharing of knowledge 
between knappers. It is also noteworthy that five types - projectile points, three scraper types and perforators - were made from two raw materials, showing a crossover between Mode No. 1 and Mode No. 2 production, perhaps through imitation of FUA-1 products in local materials.

A high proportion of the Volhynian flint (FUA-1) which arrived at Nebelivka came in the form of blade blanks, most often to be converted into blade segments for multiple uses (scrapers, sickle inserts, projectile points and burins). A proportion of these blanks still contained cortex, especially the scrapers. Some of these pieces were repaired on site, leaving FUA-1 debitage. However, there is some evidence for local knapping of FUA-1 flint in the form of three primary decortification flakes and a core rejuvenation flake. Local Mode No. 1 production is more widely attested, whether by primary or secondary decortification flakes, waste flakes, retouched and unretouched chunks and the sole core found at Nebelivka - a CUA-1 secondary flake core on chert. The overall structure of the Nebelivka assemblage indicates a lower proportion of formal tools than in other Late Trypillia lithic groups. While this could indicate a stronger focus on production at Nebelivka, the use of flotation and sieving in excavation recovery may also lead to a higher proportion of production debris than in trench hand-recovery.

Finally, Bibikov's exchange model is not the only possible explanation for such supra-communal production efforts. Some authors link early forms of craft specialization to elite political development (Brumfiel \& Earle 1987). However, others believe that the Neolithic-Eneolithic craftsmen acted within a complex kinship-based systems providing access to specialised products to any member of large, kinshiprelated groups of people (Kienlin 2012). The lithic assemblage at Nebelivka shows the typical combination of Mode No. 1 and Mode No. 2 production, with cross-overs between the two modes. Since the greater part of the megasite has not been excavated, one can never rule out the existence of specialist lithic production zones. However, the current evidence suggests import of a small number of exotic lithics from Volhynia and local, small-scale production on a household level. The picture is more or less the same for most Trypillian settlements from the BI period onwards. Flint-knapping is conducted in very limited parts of sites and, quite often, almost all flint items enter the settlement as ready to use and are only rejuvenated and re-sharpened on site. Moreover, the working areas seem to be located away from the dwellings - in particular the activity of working fresh hides. The scrapers required in this practice constitute up to $60 \%$ of retouched tools in "rich" lithic assemblages of Trypillian sites and are less numerous in "poor" lithic complexes recovered from most Phase BI-CII sites.

One author (John Chapman) concludes that this scale of production is hardly consistent with the 'maximalist' position of large-scale, long-term permanent occupation of the megasite. Instead, the lithic results support the use of Nebelivka on a lower-intensity, shorter, perhaps seasonal occupation. The alternative is that the scale of production contradicts the concept of megasites as "large villages", since at least some of the typical site activities, including flint-knapping, took place outside the foci of megasite social space. 


\section{John Chapman}

\subsubsection{Ground Stone}

The study of the Nebelivka ground and polished stonework was undertaken by Mr. Tom Bergquist as an undergraduate dissertation in the University of Durham (Bergquist n.d.).

\section{Zsuzsanna Tóth \& Alice Choyke}

\subsubsection{Worked Bone}

\subsubsection{Introduction}

There are only a very few pieces of worked osseous material available for study from the megasite at Nebelivka. In fact, there are only eight objects made from bone, antler and tooth coming from four seasons of excavations that took place at this site. Due to the small size of the assemblage, it is difficult to draw any far-reaching conclusions. Despite the small number of pieces, however, rich information can be achieved by careful and detailed examination of the individual ornaments and tools. Optical microscopic study of the manufacturing and use wear was carried out on the objects to exploit the maximum information from them.

The site itself was largely explored through various kinds of remote sensing techniques and these artefacts come from excavation work on selected house features. Still, despite the limited nature of the excavation, the numbers of bone tools seem very low (cf. almost 150 lithic items), given that the soil was subjected to careful screening. Prehistoric sites of this period and even later in the Bronze Age usually have a greater density of worked osseous materials on them connected to the detritus of everyday life and activities.

\subsubsection{Description}

Three of the objects belong to the group of tooth pendants. One of the objects is a bead/pendant made from a red deer (Cervus elaphus L. 1758) mandibular incisor (Fig. 5.41/1). This pendant is barely modified. The tip of the root is smoothed down, probably with abrasion, although marks of this activity are almost completely obliterated by use-wear. The root is also covered with intense scraping made by a flint tool (Fig. $5.41 / 1 \mathrm{~b})$. The first step in manufacturing was probably to create a nice and even-looking surface. Approximately $5 \mathrm{~mm}$ from the end, there is a notch created by sawing which could have served for attachment (Fig. 5.41/1c). Otherwise, there are none of the other modifications typical for tooth pendant/beads. The dental crown was left in its natural state, although intense use formed moderate rounding and polish can be observed on it. Similar use-wear, rounding and polish could be observed at the tip of the root as well. The walls of the notch are rounded. The degree of use wear and rounding of edges suggests that this object was used for an extended period spanning years of use. 


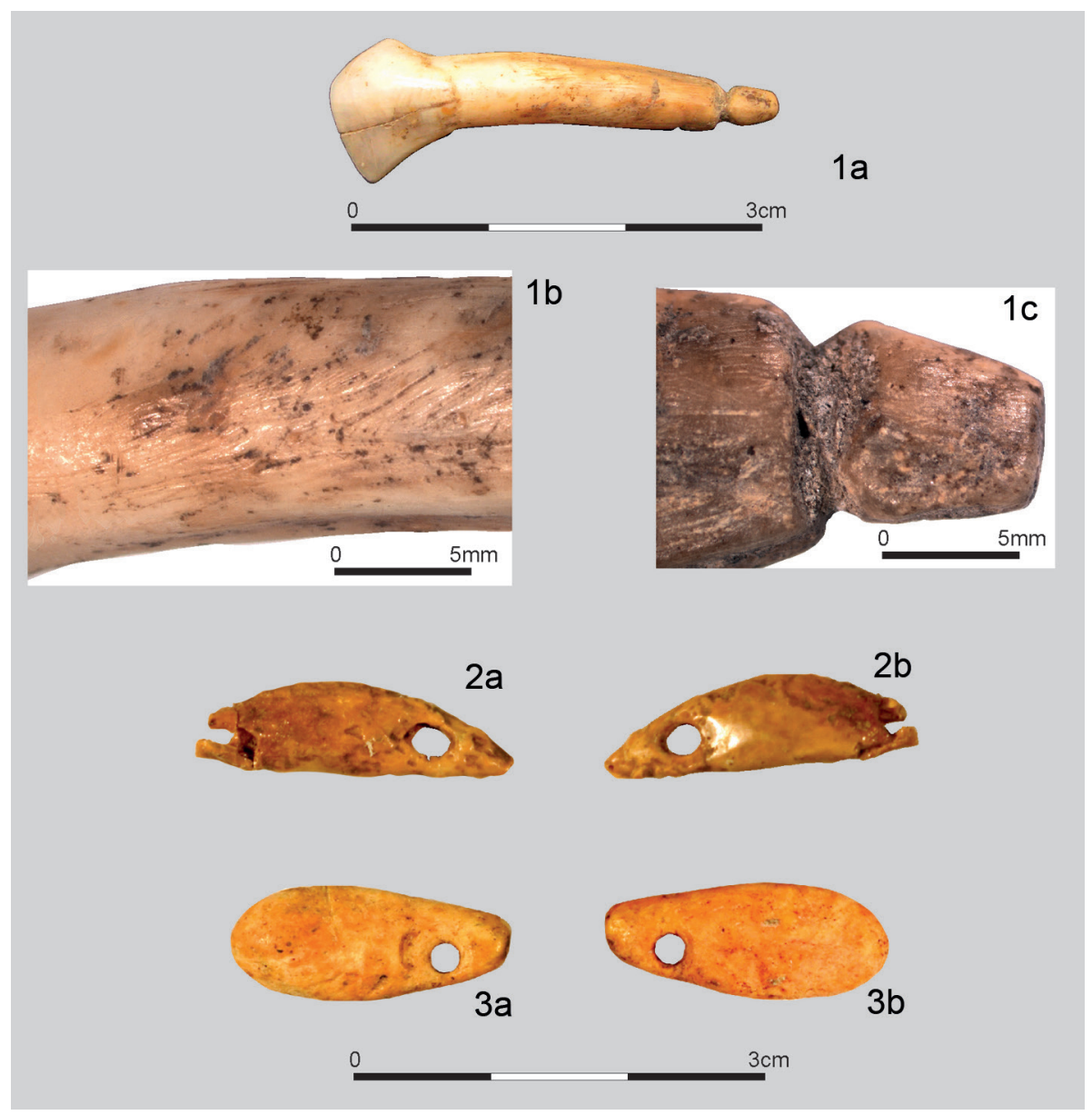

Figure 5.41: Worked bone tools: (1) tooth bead-pendant, Pit, S. 1 SF 47, with close-ups (b) and (c); (2) tooth bead-pendant, Mega-structure TsT 1461, Context 64; (3) bone imitation of tooth pendant, Mega-structure TsT 1827, Context 142 (by K. Harding based on photographs by Zs. Tóth).

Two other tooth pendants were found on the surface. One of them was probably made from an actual red deer canine (Fig. 5.41/2). The root, typically, was perforated and served to fix or suspend the ornament. It seems to have been damaged in ancient times since another perforation was made at the other end. This secondary hole looks quite worn as well, indicating that the pendant was used over a rather long period. The other pendant bead (Fig. 5.41/3) appears to be a bone imitation of a red deer canine bead/pendant closely following the form and size of actual red deer canines (for example see Spatz 1999). This bead was made from cortical bone taken near an epiphysis of a horse-cattle size animal long bone diaphysis and later perforated at the narrower end, although the perforation itself lies outside the central long axis 
of the object. The positioning of the hole may be connected with the way the object was meant to hang. The cortical bone around the hole was first scraped away in a disk shape before the hole was actually drilled. Although the NISP for red deer bone was very low, the incisor and true canine bead still could easily have been taken from locally killed game.

The fourth object is a slender point made of fishbone (Fig. 5.42/1). Unfortunately, the object is broken, with only the active end and middle section remaining intact. It has a delicate point shaped with longitudinal flint scraping. The surface is entirely covered with intense manufacturing (scraping) marks. Only the rounding and polish of use obscures them slightly (Fig. 5.42/1b). There are multiple impact fractures at the tip (Fig. 5.42/1c). Thus, it appears the tool continued to be used even after the tip became slightly damaged. A fragile tool made of a relatively easily chipped raw material, this object must have been used in a task not requiring much force, probably connected to processing soft materials such as thin hide and/or textiles but, in any case, a task that required only light force or pressure but a fine sharp point.

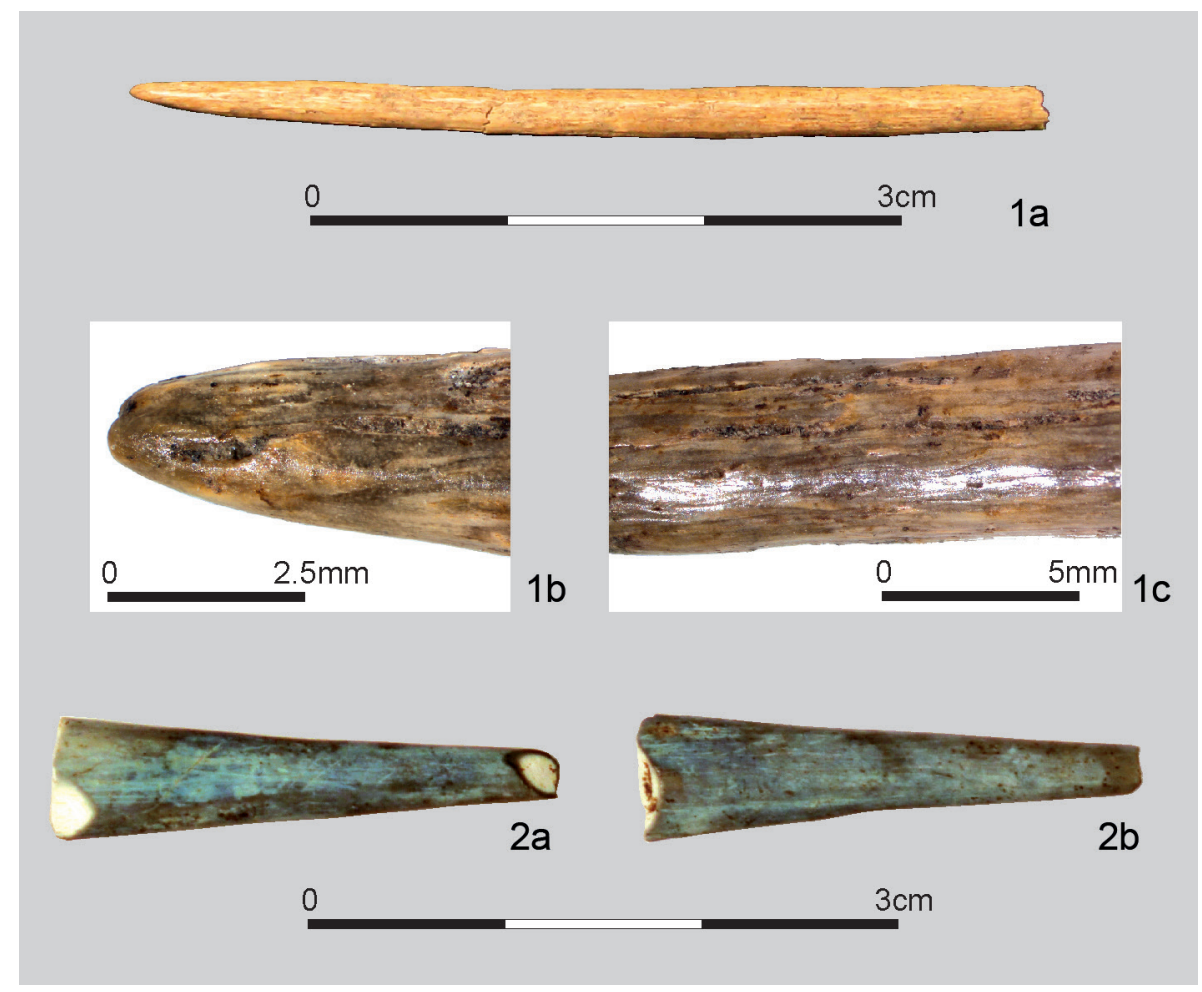

Figure 5.42: Worked bone tools: (1) fishbone point, Pit, S. 1, SF 48, with close-ups in (b) and (c); (2) broken bone awl with copper staining, Mega-structure, Grid Square D10 (by K. Harding based on photographs by Zs. Tóth). 
The fifth artefact is a tiny ad hoc point made of small ungulate long bone shaft splinter (Fig. 5.43/1). The bone is barely modified at all although some scraping can be observed towards the active tip. However, besides this, the craftsperson took advantage of the bone splinter's natural shape with only the most necessary modification at the active end. This is the only tool which displays clear traces of taphonomic changes in the form of root etching at several spots over the whole surface. All the edges and especially the tip show traces of use wear including rounding and polish (Fig. 5.43/1b).

The sixth object is part of a broken awl made from a long splinter of small ungulate (caprine) long bone diaphysis, most probably a metapodial (Fig. 5.42/2). Unfortunately, it is broken and neither the active end (tip) nor the base remain, preventing identification of the exact typological group. However, it very much looks like the remains of one of the finely made small metapodial points so often found on Late Neolithic and Chalcolithic sites. The final shape was produced with scraping with a chipped stone tool. The traces are still visible on the tool's surface, along with a green staining which may be from contact with a copper object.

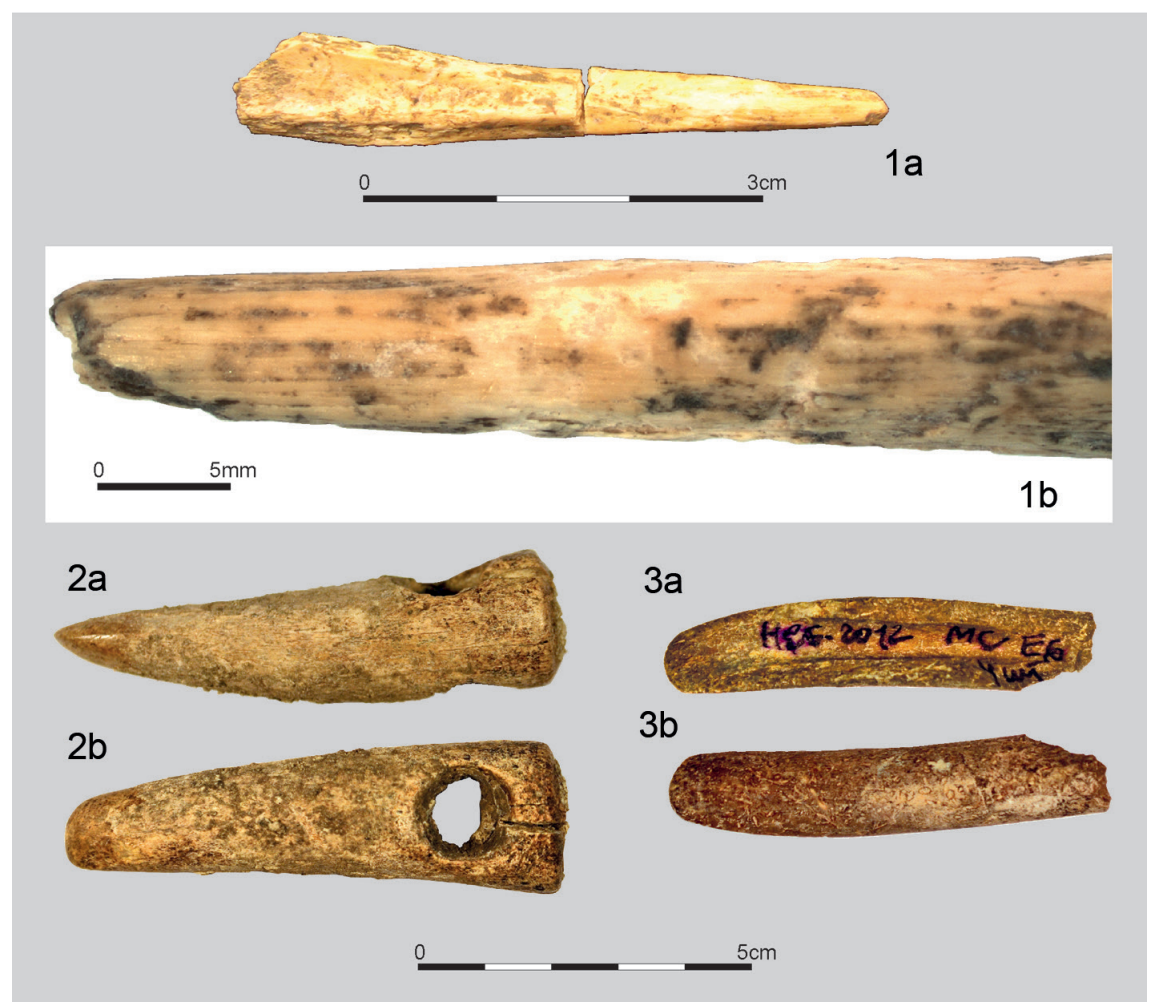

Figure 5.43: Worked bone tools: (1) ad hoc bone point, Test Pit 19/2, Context 3, SF 6, with close-up in (b); (2) red deer antler hoe model, Pit, S. 1 SF 71; (3) possible bone tool, Mega-structure Grid Square E6 (by K. Harding based on photographs by Zs. Tóth). 
Only one worked osseous object from the site was made from red deer antler. The tool, made from a tine tip, is a small bevel-ended 'pick' with a small hafting hole at one end (Fig. 5.43/2). The sharp lateral edges and even polish of the bevelling at the active end strongly suggest that this bevelling is artificial and not a natural shape caused by the buck rubbing his antlers against trees as the velvet is being shed. The tine was cut half way up its length. The compact tissue at the wider end was thinned on both sides of the tool before boring the round hole from both sides. Meanwhile, the tine tip was lightly worked into a narrow, delicate bevel-form. Otherwise, the ridges of the natural surface were left intact. The active end reveals signs of use in the form of rounding and polish. Thus, the tool was surely used in a light activity such as bark-removal or wood-working (where the wood interior is burned first before removal) which did not result in serious, marked damage(s) to the active end. There is no apparent evidence of any curation work on the active end.

Finally, there is an object which may or may not be an actual tool (Fig. 5.43/3). If indeed it is a tool, then it was produced on a longitudinal long bone fragment from a pig-caprine - size animal. It appears to have a bevelled active end but the surface is much eroded, making it impossible to determine whether it was worked or simply used.

\subsubsection{The Manufacturing Continuum}

These few objects cover the whole range of planning and intensity of modification along the manufacturing continuum (Choyke 1997). There are three planned utensils (Class I): a lightly worked pointed tool with carefully chosen but unusual raw material (fish bone), a typical utensil of the Late Neolithic toolkit made from an intensely modified small ungulate metapodial bone and an antler tine hafted 'pick' that has been moderately worked. A fourth specimen represents an object made from a piece of refuse bone that broke accidently into a useful shape and was used with a minimum of alteration. If this latter object is indeed a tool, then it would fall into the ad hoc, barely modified Class II end of the manufacturing continuum. This final possible object may be a badly eroded bevel-ended, ad hoc tool made from the longitudinal splinter of a pig-caprine size animal. However, due to the poor surface preservation it is impossible to say whether the shape was produced naturally or was the result of manufacturing activity.

The three pendants made from a red deer incisor, an actual red deer canine and the bone imitation of a red deer canine, as well as the small ungulate awl, all belong at the Class I end of the manufacturing continuum because of the distinctive choice of the skeletal element mostly derived from species not as readily available as local domesticates to local craftspeople. The manufacturing chain for the real tooth pendant beads is not very complicated: the shaping was done by relative simple techniques requiring a few steps. The imitation red deer bead required more knowhow to produce. The small fishbone point falls rather in the Class I-II category in the 
middle of the manufacturing continuum. We suggest that the rules for raw material choice for tools was not very strict and the natural slenderness of the fishbone made it a good candidate for producing a slender, sharp point. Since the object is broken, only the final steps of shaping are apparent, that is, the scraping marks on the surface, but it seems the manufacturing sequence was not particularly complicated. The third object is a real Class II tool, a small ad hoc point. Neither its raw material or skeletal element was strictly chosen and the manufacturing process is simple. If the final bevel-ended tool based on a long bone diaphysis fragment is really a tool, then it too would fall in the Class II ( $a d$ hoc) end of the manufacturing continuum.

\subsubsection{Evaluation}

Personal adornments, like pendants or beads forming part of complex, composite ornaments such as necklaces, hair pieces or girdles occur regularly in many different periods. Objects made of animal teeth, possibly from animals that possessed a special iconographic or symbolic meaning for the wearer or receiver of the ornament, are very common in site assemblages throughout prehistory and even in later time periods as well. Teeth are objects of display for both the animals they come from as well as the humans who take up their use later. Wearing these objects may be strongly connected to gender as with perforated and shaped boar tusks or perforated red deer canines (both tusks and red deer canines derive from male animals). These teeth may have come from species that have special symbolic significance to the audience for whom they are displayed. Thus, there is also an amuletic, apotropaic aspect to their use, so that the bead comes to represent the way the animal species eats and protects itself (Choyke 2010) - as well as the power(s) ascribed to the living animal in particular cultural contexts.

More typical red deer tooth beads from the final Neolithic and Early Chalcolithic in this region are perforated red deer canines, mostly coming from male deer (canine teeth in does are smaller if they are even present), found collected in hoards or as parts of necklaces and scattered finds on sites. The final Neolithic in Hungary and Germany (Spatz 1999) is also represented by imitations of red deer canines that either take the form of nested hour-glass beads that fit into each other cross-wise leaving only the rounded ends exposed. These imitation necklaces and ornaments often contain a single genuine red deer canine. Given the differential wear on the beads, it has been suggested that such composite, fractal ornaments were produced at the time of burial and given to females as grave goods at the site of Polgár 6 (Choyke 2001; Siklósi 2013) and may well represent a kind of materialized social enchainment between the living members of a family group and the dead. Further to the West, in Germany, there are burials in cemeteries, more or less contemporary with Polgár 6, with imitation red deer canine beads, closely following the biological form of the teeth but these are given to men in burials (Spatz 1999). In any case, it seems clear that red deer had a special ideological meaning connected at the very least to gender identity for various 
groups of people living across a broad swathe of Central and Eastern Europe. In this sense, their relative abundance in the worked sample compared to the presence of hunted animals in the faunal assemblage is at least worthy of note.

Pendants made of perforated or notched animal teeth can be found in the territory of the Trypillia Culture as well. Unlike this specimen, the other known examples are usually made either from predators, mainly canid (wolf/dog/fox) canines such as the pieces from the cemetery at Vinogradnyj (Rassamakin 2004, Abb. 52:18, Abb. 72:10) or Ol’šanka Kurgan 3 (Rassamakin 2004, Abb. 109:5). Red deer canine pendants came to light in Tudorovo 1 Kurgan 1 (Dergačev 1991, Taf. 59), while a perforated elk (Alces alces L. 1758) tooth was used at Luka Vrublevetskaya (Zbenović 1996, Taf. 10:17). Imitations made of animal bones are common as well, such as at the cemetery of Vinogradnyj (Rassamakin 2004, Abb. 52: 16-17) or Giurgiuleşti (Rassamakin 2004, Abb. 72:11). The incisor from Nebelivka is not perforated nor is it a canine, but it was fixed with the help of a notch. Nevertheless, it clearly belongs to the category of pendant/beads within personal ornaments made of animal teeth. The choice of deer canine as a bead is surprising considering the scarcity of red deer in the environs of the site. However, since these beads were used over a very long period, probably involving multiple generations, it may be equally likely they were produced in an area with plenty of red deer and the raw material choice and form was related to other, currently unknowable parts of the Trypillia period belief system. It seems reasonable to suggest that the tooth was chosen because the animal it came from - red deer - was a generally iconic, special animal in the region and for this period.

The three small perforators made from small ruminant metapodial, bone shaft and a fishbone are extremely common prehistoric types. Awls made from a variety of skeletal elements from many different species usually represent the most numerous tool type at most prehistoric sites although fish bone is not such a common raw material for producing bone tools of any kind, including points. Slender points made from a variety of osseous raw materials can be found both at settlements, such as the megasite at Taljanki (Kruts et al. 2008, Fig. 22: 6-8) or Bernashivka (Zbenović 1996, Taf. 10: 1-3, Taf. 11: 1-2, 9), Luka Vrublevetskaya (Zbenović 1996, Taf. 11: 6-7), or Okopy (Zbenović 1996, Taf. 10:5, Taf. 11: 10) as well as in burials in cemeteries such as Nikol'skoe, Kurgan 1, Grave 7; Staronižesteblivskaja, Grave 30; Aleksandrija, Grave 22 and Vinogradnyj, Grave 44 (Rassamakin 2004, p. 90). While Late Neolithic-Early Chalcolithic hafted antler tine picks tend to be cut from the beam and used intact, such small pick-like tools are much less common.

\subsubsection{Conclusions}

The seven (possibly eight) bone, tooth and antler objects found during excavations at the megasite of Nebelivka are too few to draw any far-reaching conclusions although their unexpected paucity raises interesting ideas about the way these dwellings were lived in and abandoned. Such small sample sizes can result in extremely biased 
results. Nevertheless, the unusual circumstance that three out of seven (eight) objects were red deer tooth beads or their imitation certainly raises questions about activities at the settlement and/or the people dwelling in the structures.

The objects themselves span the entire manufacturing continuum: the relatively well worn and intensely used red deer incisor bead which can be considered a Class I planned object; the fishbone point where the raw material choice seems unplanned but where the manufacturing activity is relatively intense that occupies the Class I-II part of the continuum; and the point made from randomly produced scrap bone and barely modified at the Class II end of the manufacturing spectrum.

Use wear studies suggest that that the red deer incisor bead was used over a prolonged period of several generations and is connected to other red deer tooth beads, although these beads overwhelmingly come from the canines of bucks. The fish bone point was used in a delicate activity on a contact material that was soft and did not offer much resistance. It was used even after small chips were accidently removed from the tip during use. The small ad hoc point was affected by root etching, precluding the possibility of identifying use wear.

The objects themselves do not stand out from the kind of objects generally found at other Trypillia sites in the region. It is hoped that an accumulation of detailed studies will lead to a more comprehensive picture of modified osseous materials at megasites of this period. Based on the faunal evidence, there seems to be some focus on raw material from red deer including antler and teeth. This focus was not reflected in the animal bone material and one cannot discount the possibility that these objects (the beads and the pick) were brought to the site as finished objects.

\section{John Chapman, Marco Nebbia \& Bisserka Gaydarska}

\subsubsection{Other Special Finds}

The following Special Finds constitute a diverse collection of rare forms, in all cases but one made of fired clay. This amounts to a total of 29 special finds, with a majority found in the Mega-structure and very few in House A9 (DOI: https://doi. org/10.5284/1047599 Section 5).

- Zoomorphic vessel

Three fine ware legs of (?) zoomorphic vessels were found in the Pit in Sondazh 1. Blurred painted motifs were found on SF 16.

- Vessel with zoomorphic terminal

Two such vessels were found in the Mega-structure - both with triangular animal heads attached to wall sherds (MS F19 \& F20). The heads resemble the heads of zoomorphic figurines found on the megasite (DOI: https://doi.org/10.5284/1047599 Section 5). 
- Polypod vessel

A single largely complete dish with four worn feet was found in Test Pit $1 / 5$. The interior of the dish had badly worn fine painted lines in a criss-cross pattern, while the slightly thickened rim had oblique parallel lines, as was found in graphite painting on one of the miniature vessels from the Mega-structure.

- Strainer

A single basal fragment of a strainer was found in the Pit in Sondazh 1; six perforations, ca. $5 \mathrm{~mm}$ in diameter, had been made in the base.

- House model fragments

Eight small fragments are known - four from each of the Mega-structure and the Pit in Sondazh 1. While small, each fragment is identifiable as to its part of the house - a trait typical for the fragmentation practices of significant objects (cf. Chapman 2000 for Adriatic salt pots). The most striking fragment is a painted roof and upper wall fragment (Pit SF 5727), with the parallel painted lines on the flat roof evoking roof timbers (Fig. 5.44/1). The closest parallel comes from the Voroshilivka roof fragment (No. 17 in Shatilo's (2005) thorough catalogue) and also dating to Phase BII. Other structural parts include three angles of the ground floor and wall, one angle of the upper floor and wall, two wall fragments and the corner of two walls. The concentration of house model fragments in an Assembly House and a pit shows the importance of these places for deposits embodying a key aspect of the Trypillia Big Other - the house itself.

- Sledge model

One fired clay fragment showing the angle of a vertical and a horizontal edge has a narrower cross-section than the house model fragments. It may have been a fragmentary sledge model (cf. the many examples found at Majdanetske and Taljanki: Müller \& Pollock 2016, p. 284).

- Incised sign

The only sign found at Nebelivka was incised on the exterior of a single greybrown medium coarse ware body sherd. There are no close parallels for this incised sign in the corpus of painted Trypillia signs (Tkachuk 2005).

- Gaming board

Two fragments of a fired clay plate decorated with incised concentric circles and with semi-perforations in two circles were deposited in the Mega-structure (Fig. 5.44/2-3). The concentric incisions are reminiscent of the fine incised decoration of platform daub. The small diameter of the semi-perforations (up to $10 \mathrm{~mm}$.) make them too small for the insertion of any of the Nebelivka tokens but other sticks or plant stems could have been inserted (cf. Shatilo 2015). A general parallel for such 'gaming boards' was found at Taljanki (Shatilo 2015, Fig. 2). 


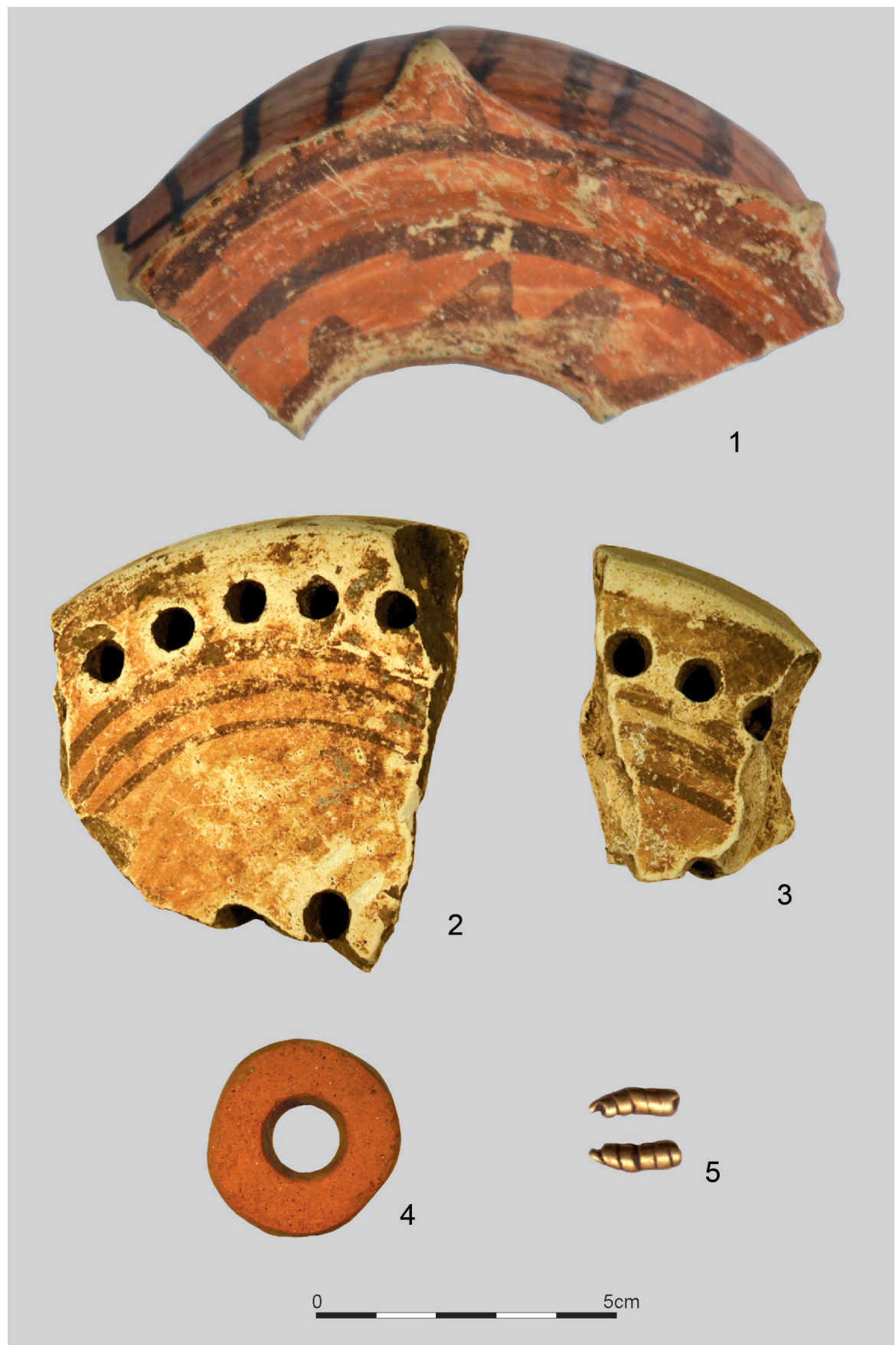

Figure 5.44: Special Finds: (1) fragment of house model, Pit, Sondazh 1, SF 5727; (2)-(3) two fragments of (?) fired clay gaming board, unstratified; (4) fired clay ring, House A9; and (5) gold hair ornament, SF 1181, Mega-structure (by K. Harding). 
- Spindle-whorl

Two fired clay spindle-whorls were found at Nebelivka - one in House A9 and one in the Mega-structure. The A9 item was larger $(4 \mathrm{~cm}$ diameter, with perforation diameter of $1.1 \mathrm{~cm}$ ), of coarser clay and chipped, while the whorl from the Megastructure was in mint condition, of finer clay and smaller $(2.5 \mathrm{~cm}$ diameter, with perforation diameter of $0.4 \mathrm{~cm}$ ). Spindle-whorls were rarely discarded in the houses at Majdanetske and Taljanki.

- Clay ring

A simple fired clay ring, of outer diameter $3.2 \mathrm{~cm}$ and inner diameter $1.35 \mathrm{~cm}$ was found in House A9 (Fig. 5.44/4). The red clay surface was smoothed but undecorated.

- Perforated fired clay object

A fragment of a crudely shaped, oval clay object with a partially surviving perforation was found in Test Pit 24/3. Its function remains unknown.

- Clay ball

Three examples of fired clay balls have been found at Nebelivka - two in Test Pits and one in the Mega-structure. All objects share a similar coarse fabric with the majority of tokens (see above, pp. 336-337), with one ball being spherical (diameter $3.5 \mathrm{~cm})$ and two being oval and with similar dimensions $(2.8 \times 2.5 \mathrm{~cm} ; 3 \times$ $2.6 \mathrm{~cm}$ ). The spherical ball was burnt on one face; none had any sign of decoration. It is possible that they could have been used as sling bullets or for throwing at stray animals to bring them back into line.

- Unidentifiable fired clay lump

Three unidentifiable fired clay lumps were found at Nebelivka - one in the Megastructure, one in House A9 and one in Test Pit 25/3. Minor shaping, such as a groove or a pinched area, give these irregular items more shape. However, their function remains unknown.

- Gold spiral ornament

The first gold ornament known from the Trypillia group was deposited in one of the East rooms of the Mega-structure. The item is $15 \mathrm{~mm}$ in length and $4.5 \mathrm{~mm}$ in diameter and consists of a thin gold rod which has been heated to allow the wrapping of the rod around a solid (? timber) core six times (cf. Leusch et al. 2014, Fig. 9a) to produce a bead or a small hair ornament (Fig. 5.44/5). Leusch et al. (2014, p. 183) consider two possible uses for such a spiral bead - as an ornament in its own right or as a semi-finished product in the preparation of gold disc beads. The find is so precious that no analysis of the gold has yet taken place; the possibilities include the Caucasus Mountains, the alluvial gold sources of Eastern Bulgaria or the rich gold sources of the Munţii Metaliferici of Central Transylvania. Whichever was the source of the Nebelivka gold ornament, the implication is some form of long-distance exchange into the heartland of a loessbased, gold-free landscape. 
The closest parallels to such a gold ornament derives from the Varna I cemetery, which dates 500-600 years earlier than Nebelivka (e.g., the gold spiral ornament from Grave 97: Leusch et al. 2014, Figs. 3b \& 9b). Similar dates apply to the sheet copper spiral ornament from the Chapli cemetery (Chernyh 2010, Ris 3/19), as well as the copper spiral bead with six twists from the Cucuteni site of Traian (Mareş 2002, Pl. 59/14). This ornament was the only example of a undoubted prestige good found so far at Nebelivka. Its deposition in the Mega-structure underlines the significance of that building to the entire megasite.

\section{John Chapman}

\subsubsection{Summary}

These Special Finds can shed light on five closely interlinked aspects of the Trypillia world: the all-encompassing Big Other, inter-regional and regional exchange networks, local production practices, deposition and, fifthly, personhood.

The pattern of material engagement described above is a clear indication of the way that those dwelling in, or visiting, the megasite resisted, for the most part, the deposition of polished stone and metal objects in favour of the key element of the Trypillian Big Other - clay. The discard of two polished stone axe fragments (DOI: https://doi.org/10.5284/1047599 Section 5) and one gold spiral ornament, in addition to the green (? copper) staining of a single bone awl, indicates the limitations of stone and metal deposition at the megasite. The exception to the discard of stone objects concerns the chipped and ground stone fragments which were part and parcel of daily lifeways. This is not to claim that Trypillia farmers did not fell trees with stone axes or that Trypillia leaders did not wear costume enriched with copper or gold ornaments - only that such items were as a rule excluded from settlement deposition. The positive side of this coin is that a great variety of fired clay objects discarded on site materialised the Big Other, as they did at countless other Trypillia sites, big or small.

The raw materials and objects flowing across the networks which sustained the Big Other indicate inter-regional exchange and use of local resources for Nebelivka. While none of the Nebelivka metal or pigments has been located to a single source, the gold spiral ornament, the copper that produced the green stain on the bone awl and the manganese pigment used on painted pottery must have come from an exotic source several hundred kms from the megasite, while it is very probable that the graphite-painted dish was a direct import from the East Balkans. The same is true of the high-quality Volhynian flint whose sources lay more than 200km to the West. Local resources included lower-quality flint, sandstone for grindstones and possibly graphite for the decoration of miniature vessels and house platforms. However, with the exception of salt exchange (pp. 471-472), most of this exchange and procurement was low-bulk and probably episodic and/or seasonal, integrated with the Nebelivka 
calendar of ceremonies and house-burning. The persons engaged most directly in such exchanges - especially if going on long-distance voyages (Helms 1988) - would have become different kinds of persons, respected but also feared for their contact with the 'Other'.

The small scale of lithic and worked bone discard and prestige goods deposition was a source of surprise to the Nebelivka team, who were expecting major depositional practices consonant with a long-term, socially-differentiated urban site with a large population. Instead, painted fine wares, whether as complete vessels or in fragments, comprised by far the greatest bulk of discard in all excavation units (see Chapter 5.1). This scale of production of chipped and ground stone tools is consonant with household production - even the Volhynian flint, which did not always come in ready-for-use forms. There is also a wide range of quality of products, expressed for worked bone as the 'manufacturing continuum' (Choyke 1997) and also found in chipped stone (Modes 1 and 2). While high-quality objects produced by skilled practitioners (? specialists) were found (e.g., the gold spiral ornament, the miniature vessels, the imitation in bone of a red deer canine bead/ pendant), most of the clay figurines and tokens showed simple shaping skills, no decoration and low firing temperatures. These findings, again, suggest household production and local use until the objects were worn, followed by fragmentation and local deposition of parts and wholes.

There are two clear patterns of deposition of Special Finds at Nebelivka: a concentration of most categories of special find in the Mega-structure (the obvious example being the group of 21 miniature vessels) (Fig. 5.48 lower), with dispersed distribution in the Test Pits (Fig. 5.45) and a generalised distribution within the Megastructure with a notable lack of finds concentrations (Fig. 5.48 upper). The former underlines the significance of the Mega-structure to the entire megasite. There was also greater diversity of Special Finds in the Southern part of the megasite (Quarters L and M) (Fig. 5.45). The latter suggests episodic deposition of figurines, tokens (and gaming boards), Mode 1 and 2 lithics and ground stone. Those participating in the exchanges and ceremonies would have extended and differentiated their personhood over and above those remaining on the social periphery. The Special Finds distribution in Neighbourhoods showed great variability, with only one case of two houses with identical Special Finds - both in Neighbourhood 13. There were no Neighbourhoods where figurines were found in more than a single house - perhaps a hint of ritual variability within Neighbourhoods? It was also in Neighbourhood 13 that we found the only instance of a house with deposition of both exotic and local flint. 


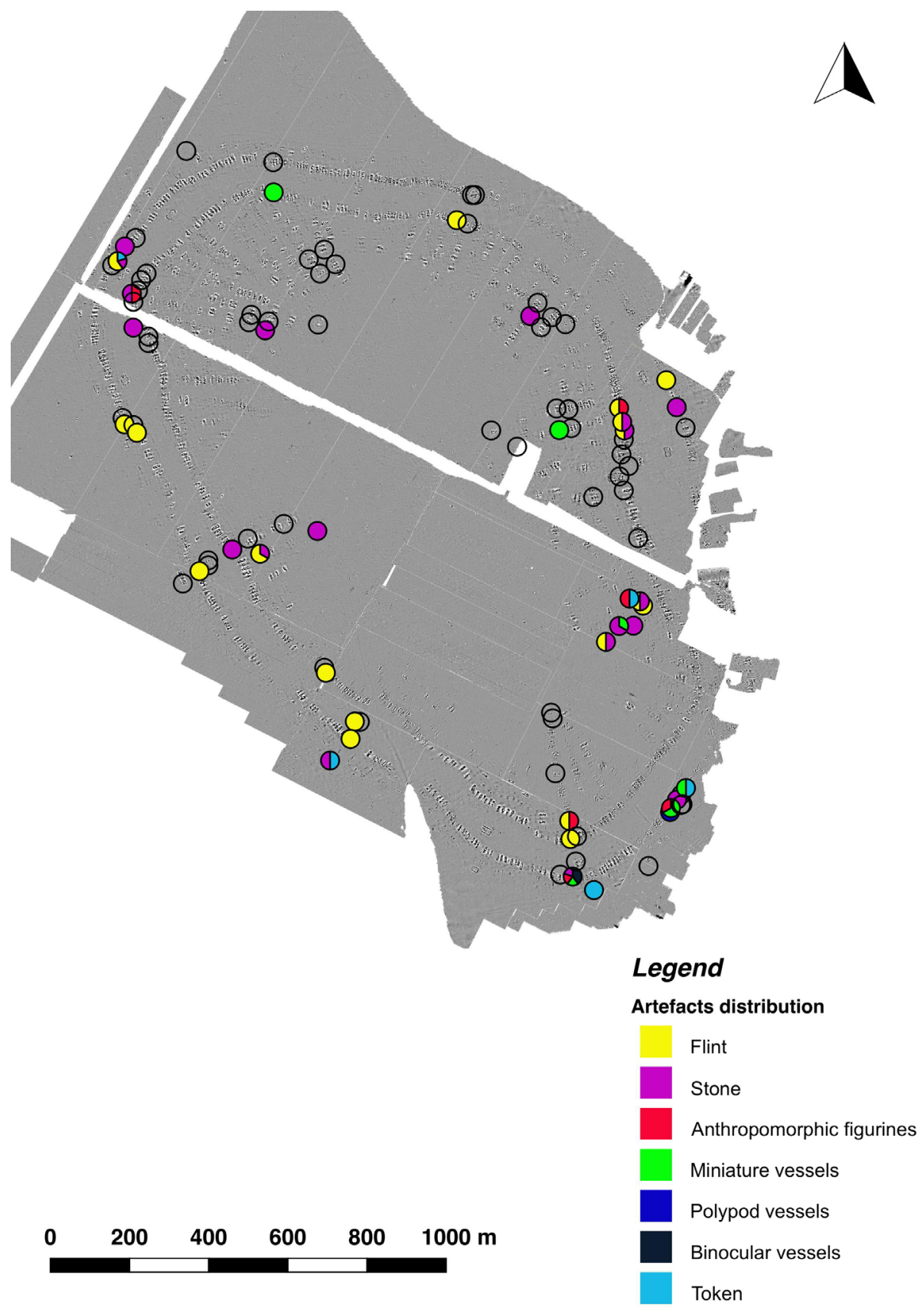

Figure 5.45: Special Finds distribution, megasite (by M. Nebbia). 


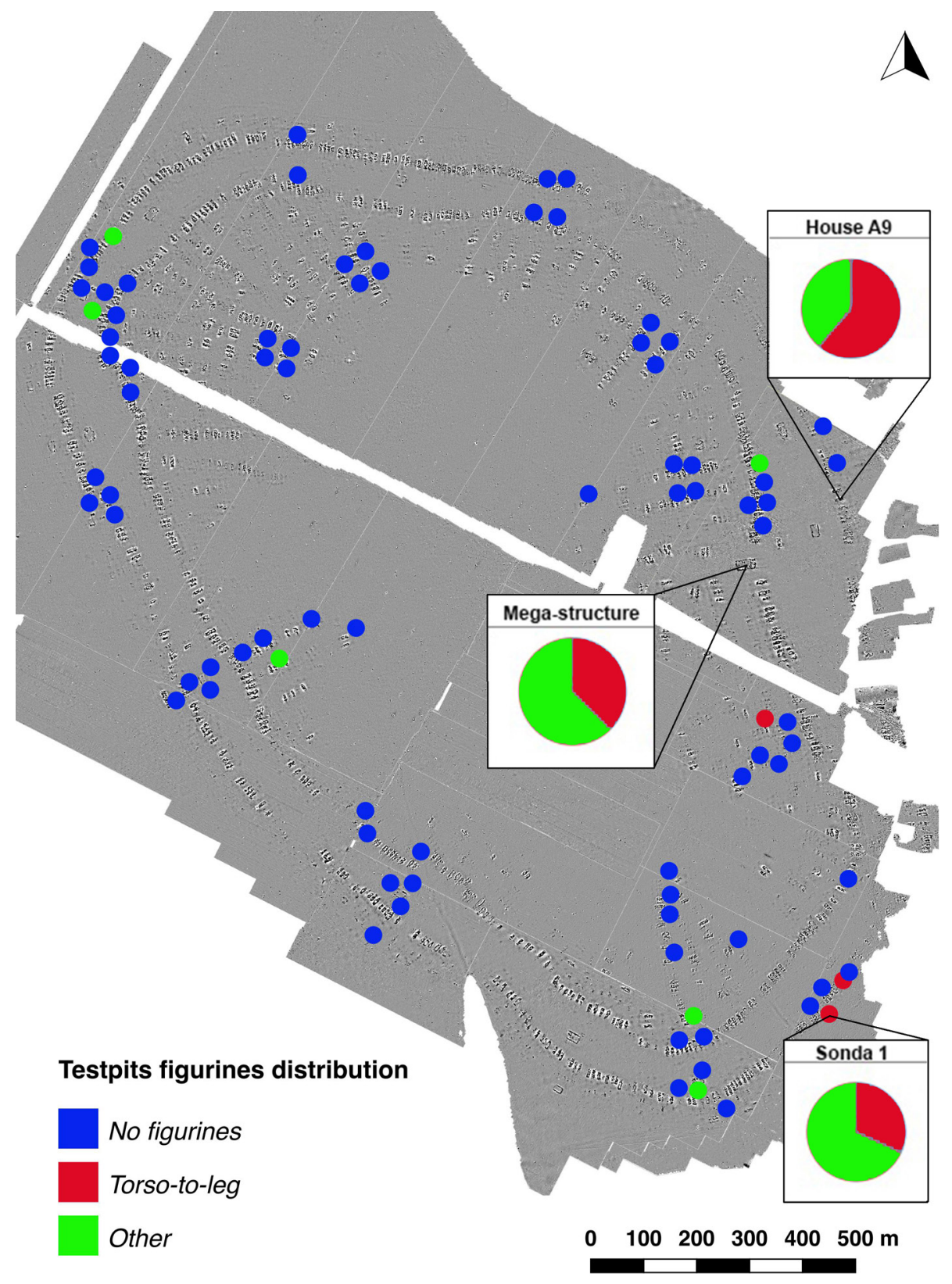

Figure 5.46: Distribution of figurines, megasite (by M. Nebbia). 


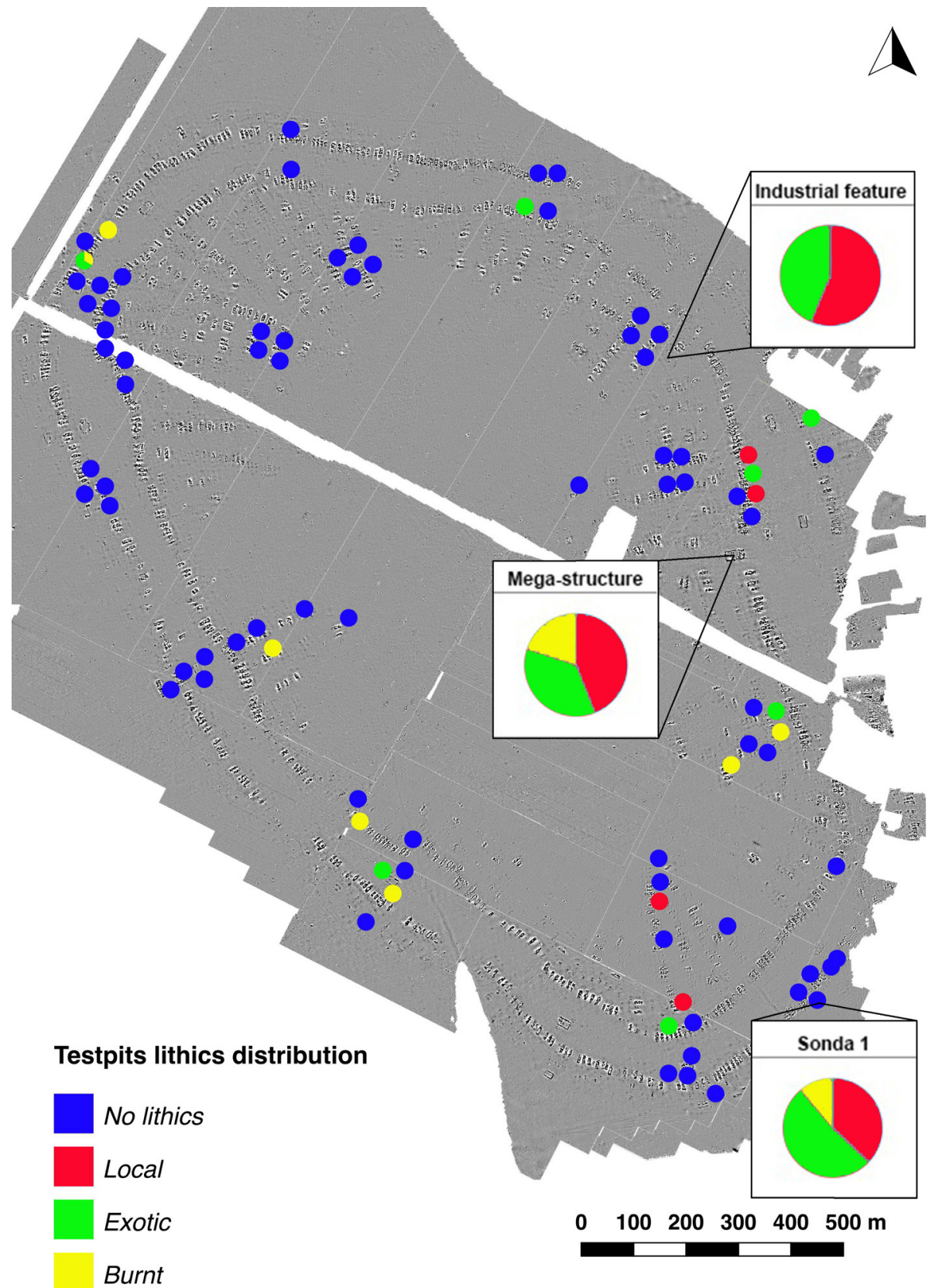

Figure 5.47: Distribution of lithics, megasite (by M. Nebbia). 


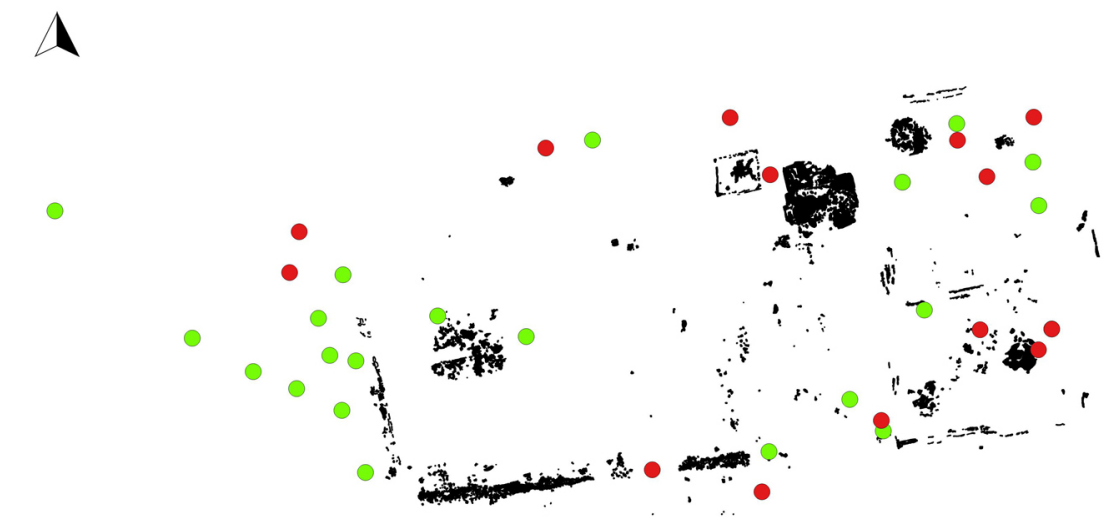

Mega-structure finds distribution

- Figurines

Tokens

$\begin{array}{lllll}0 & 5 & 10 & 15 & 20 \mathrm{~m}\end{array}$

Construction features

$\Lambda$

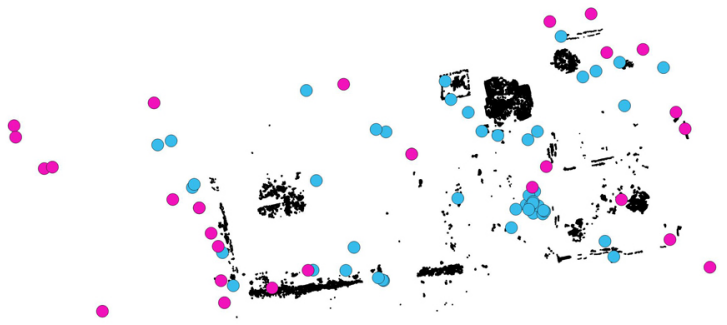

Mega-structure finds distribution

- Lithics

- Other finds

$\begin{array}{lllll}0 & 5 & 10 & 15 & 20 \\ & & & \end{array}$

Construction features

Figure 5.48: Special Finds distribution: (upper) figurines and tokens; (lower) lithics and Other finds, Mega-structure (by M. Nebbia). 
There are many aspects of the Nebelivka Special Finds that shed light on personhood - the way that persons developed an (in)dividual identity through their lives. Engagement in exotic voyages and participation in ceremonial life have already been mentioned. Two other ways of producing personhood were through the development of productive skills and the representation of the human form. Many household members would have possessed skills sufficient to make tools from local flint or sandstone, spin yarn or make ad hoc bone tools (Chapman \& Gaydarska 2011). However, the skill of carving a red deer canine into a fine ring/pendant would have marked out the craftsperson as someone special, whose identity may have become as extended in time as the highly curated ring/pendant itself - on the basis of experimental work estimated to be two or three generations. Equally, the use of an 'archaic' style for a rhomboid point and a lunate suggests a form of lithic curation linking the persons dwelling at Nebelivka with persons and their skills from times past. Contemporary individualised production and perhaps use are suggested by the six flint projectile points, each made in a different way into varied, visually distinctive forms and perhaps with different hunting results (cf. Wiessner 1983).

The only representation of the human form at Nebelivka - the fired clay figurines and statuettes - emphasised that individual and dividual aspects of personhood were often in tension. While image fragmentation focussed on the dividual aspect of personhood, with heads frequently missing, the rare use of statuette heads to define 'realistic' persons reminded users of the individual side of personhood. In parallel to such representation, the visual aspects of costume were important for personhood. Whoever wore the Nebelivka gold spiral ring must have had a special identity, even if only for annual ceremonies, and perhaps different from the identity of the wearer of the fired clay ring.

The persons dwelling in, or visiting, Nebelivka created a visually differentiated, colourful world of houses, pottery, figurines and Special Finds, all of which related to the Trypillia Big Other. To the extent that persons, households, Neighbourhoods, Quarters and the entire megasite were engaged with Special Finds, these objects contributed to the formation of new and continuing identities that, in turn, helped to shape their own social world. This section is a testimony to the diversity of the objects produced in, or for, Nebelivka. 


\section{David Orton, James Nottingham, Giselle Rainsford-Betts, Kim Hosking \& Andrew Millard}

\subsection{Animal Bones}

This report is dedicated to the memory of Charles Schwartz, who contributed a significant portion of the primary research on which it is based, and who very sadly died a few weeks before it was completed.

\subsubsection{Introduction}

Over the four joint Kyiv-Durham field seasons at Nebelivka (2009, 2012-2014) a large quantity of animal bones was recovered from many of the excavated features. These were recorded and analysed variously by Olena Sekerskaya (Archaeological Museum, Odessa), Charles Schwartz (independent consultant, Los Angeles), Zsuzsanna Tóth (Eötvös Loránd University, Budapest), Carrie Armstrong and Louisa Gidney (both Durham University), but only the first-named's work has resulted in a published report (Sekerskaya 2017). Accordingly, the present chapter aims to draw together the work produced by these analysts, along with a last few bones analysed in York by the authors, in order to give an overview of the animal bone assemblages from the site. An additional comment by Andrew Millard refers to the isotopic dietary information for the animals as derived from the AMS dating procedure. Apart from broad questions of subsistence, set in the wider context of Trypillia economy, particular attention will be paid to differences in faunal composition between different features and feature types, and especially to understanding the nature of bone deposition in the Megastructure. Necessarily given the history of study, we shall also assess potential interobserver bias. Some key questions for this report are as follows:

- What was the relative contribution of hunted vs. herded animals at Nebelivka, and how does this fit into wider trends noted for the Trypillia period?

- Are there any detectable differences in animal use (or at least bone deposition) between areas of the site and/or between different context types, e.g., houses and their associated pits?

- What was the nature of bone deposition in the Mega-structure?

\subsubsection{Areas and Assemblages}

Table 5.12 shows the total counts of bones included in this chapter, by site area and analyst. 
Table 5.12: Counts of diagnostic and non-diagnostic bones by excavation area/feature and analyst (by D. Orton).

\begin{tabular}{|c|c|c|c|}
\hline Area & Analyst(s) & Diagnostic & Non-diagnostic \\
\hline \multirow[t]{3}{*}{ Sondazh 1 - Pit } & Louisa Gidney and Carrie Armstrong & 25 & 77 \\
\hline & Olena Sekerskaya & 345 & 489 \\
\hline & Present authors (wet sieved) & & 6 \\
\hline \multirow[t]{2}{*}{ Ditches } & Louisa Gidney and Carrie Armstrong & 1 & 2 \\
\hline & Present authors (wet sieved) & 3 & 134 \\
\hline House A9 & Olena Sekerskaya & 179 & 277 \\
\hline \multirow[t]{2}{*}{ House B17 } & Louisa Gidney and Carrie Armstrong & 2 & 3 \\
\hline & Olena Sekerskaya & 201 & 283 \\
\hline \multirow[t]{3}{*}{ House B17 - Pit } & Louisa Gidney and Carrie Armstrong & 4 & 2 \\
\hline & Olena Sekerskaya & 416 & 519 \\
\hline & Present authors (wet sieved) & & 42 \\
\hline \multirow[t]{2}{*}{ House B18 } & Louisa Gidney and Carrie Armstrong & 1 & 3 \\
\hline & Olena Sekerskaya & 14 & 5 \\
\hline \multirow[t]{2}{*}{ House B18 - Pit } & Olena Sekerskaya & 15 & 34 \\
\hline & Present authors (wet sieved) & 5 & 96 \\
\hline \multirow[t]{2}{*}{ Kiln } & Louisa Gidney and Carrie Armstrong & 4 & 9 \\
\hline & Present authors (wet sieved) & 5 & 72 \\
\hline \multirow[t]{2}{*}{ Kiln - Pit } & Louisa Gidney and Carrie Armstrong & 5 & 1 \\
\hline & Present authors (wet sieved) & 9 & 43 \\
\hline \multirow[t]{2}{*}{ Barrow } & Olena Sekerskaya & 2 & 7 \\
\hline & Present authors (wet sieved) & & 4 \\
\hline \multirow[t]{2}{*}{ Mega-structure } & Charles Schwartz \& Zsuzsanna Tóth & 220 & 1570 \\
\hline & Olena Sekerskaya & 132 & 216 \\
\hline \multirow[t]{3}{*}{ Test pits } & Louisa Gidney and Carrie Armstrong & 106 & 551 \\
\hline & Olena Sekerskaya & 11 & 12 \\
\hline & Present authors (wet sieved) & 16 & 167 \\
\hline Grand Total & & 1721 & 4624 \\
\hline
\end{tabular}


- House A9

Excavated in 2009 by the Ukrainian team, with the UK team conducting dry sieving, flotation and environmental sampling. All of the bones from this burnt structure were studied and published by Olena Sekerskaya (2017).

- Mega-structure

This building was excavated over an eight-week period in 2012, the first and the last weeks by the Ukrainian side alone and weeks $2-7$ by the joint Kyiv-Durham team. Bones from the joint excavations were recorded by Charles Schwartz and Zsuzsanna Tóth; those from the final week subsequently by Olga Sekerskaya. A 10-litre earth sample from each Context was subject to dry-sieving and flotation. This material forms the largest single bone assemblage from Nebelivka, at 2,138 fragments, though not the largest identified sample $(n=352)$.

- Houses B17 and B18

These two burnt houses were excavated in 2013 by the Kyiv team, along with adjacent pits interpreted as being associated with the respective houses. House B17 and its pit, in particular, produced significant bone assemblages of 203 and 430 diagnostic specimens respectively (489 and 983 fragments in total). Only small parts of House B18 and the adjacent pit were excavated. This sample was recovered by hand-excavation with no dry-sieving or flotation.

- Sondazh 1 - Pit

This was a similar feature to the B17 and B18 pits, but in this case the pit was excavated by the Durham team and the associated house was not excavated. A sample of 20 litres from each level (2013 excavations) and each context (2014 excavations) was subject to dry-sieving and flotation.

- Test pits

A total of 82 small test pits was excavated in 2013 and 2014 across numerous sectors of the site, primarily in order to obtain samples for AMS radiocarbon dating. The majority of bones from these test pits were studied by Gidney and Armstrong with a view to identifying suitable radiocarbon samples, hence only diagnostic specimens were consistently recorded, although total bone counts were also available. The present authors revisited this material and confirmed that, with the exception of some small mammal and fish bones that have been updated accordingly in the database, the unrecorded specimens are indeed nondiagnostic. For simplicity, all this material is nonetheless listed under Gidney in Table 5.12. A 10\% sample of each test pit deposit was also subject to dry-sieving and flotation.

- Barrow

This sample derived from the 2013 cleaning of a robber trench within a barrow located in the Northern part of the megasite. None of the deposits was subject to dry-sieving or flotation. 
- Kiln/Cooking feature

This feature and its associated pit were excavated in 2014 by the Kyiv team, and have been described in detail by Burdo \& Videiko (2016). The nature of the feature remains contentious, with the Kyiv team interpreting it as a kiln and the Durham team as a communal cooking feature. A small number of bones was recovered by hand and recorded by Louisa Gidney.

- Ditches

Three trenches (Sondazh 2, 4 and 10) were dug to investigate the perimeter ditch in various parts of the site. Very few bones were recorded from these, by Louisa Gidney, and they are subsumed together here and included in Table 5.12 for completeness.

- Flotation residues (various areas)

A final batch of bones from flotation during the 2014 season was recorded in York in 2017 by the present authors. These derive mainly from the test pits, the kiln/ cooking feature, and its associated pit.

\subsubsection{Methodology}

Given that the underlying data was produced by multiple analysts with differing methodologies, it was necessary to adopt what may be termed a 'lowest common denominator' approach, limiting the detail that can be presented here. Pre-existing data from ten separate data sheets were combined into a single master-database, decoded as far as possible - using keys provided by the analysts where available plus-cross referencing with Sekerskaya (2017) - and the terminology standardised. Inevitably, there were details that were either incommensurate or could not be decoded.

\subsubsection{Diagnostic and Non-Diagnostic Specimens}

Ideally, a consistent approach to defining 'diagnostic' specimens would be applied, based on objective criteria regarding elements and portions present, in order to minimise identification biases between taxa and between analysts (see e.g., Russell \& Martin 2005). Since this is not possible when working with existing data, our primary criterion for a specimen to be 'diagnostic' is simply whether or not it was identified to a particular taxon (usually genus-level or below). It was evident, however, that major differences in identification protocol between analysts needed to be addressed: most notably, Olena Sekerskaya routinely identified ribs and vertebrae to genus or species level - not the practice of the other analysts. To avoid introducing a substantial interanalyst bias, it was thus necessary to treat all of these elements (excluding atlas, axis, and sacrum) as 'non-diagnostic'. This should be borne in mind when reviewing Table 
5.12: many of the specimens listed as 'non-diagnostic' were originally identified to taxon by Olena Sekerskaya, hence the discrepancy between the numbers presented here and those in the original report (Sekerskaya 2017, p. 18).

Despite this adjustment, it is apparent from Table 5.12 that the ratio of diagnostic to non-diagnostic bones varies considerably across the overall assemblage. This could relate to any combination of three explanations: (a) differing levels of fragmentation, (b) differing approaches to identification and particularly recording of small, indeterminate fragments, or (c) differential recovery linked to excavation strategies. To explore this, Table 5.13 compares identification rates by excavation team, area, and faunal analyst, for all subdivisions with greater than 300 fragments recorded. The results suggest that inter-analyst differences are the primary factor in identification rates at Nebelivka, with Sekerskaya consistently recording ca. $40 \%$ of specimens to taxon (excluding ribs and vertebrae) regardless of excavation team or site area, while the other analysts reported a significantly higher proportion of nondiagnostic specimens - albeit without a comparison from the solely Kyiv-excavated areas.

Table 5.13: Identification rates by excavation area and analyst. Numbers represent proportion of bones identified to taxon, out of 1 . NB this excludes wet-sieved material (by D. Orton).

\begin{tabular}{|c|c|c|c|c|}
\hline Team & Area/Feature & $\begin{array}{l}\text { Charles Schwartz \& } \\
\text { Zsuzsanna Tóth }\end{array}$ & $\begin{array}{l}\text { Louisa } \\
\text { Gidney }\end{array}$ & Olena Sekerskaya \\
\hline \multirow[t]{2}{*}{ Joint } & House A9 & & & 0.39 \\
\hline & Mega-structure (wks 2-7) & 0.13 & & \\
\hline \multirow[t]{2}{*}{ Durham } & Sondazh 1 - Pit & & & 0.41 \\
\hline & Test pits & & 0.16 & \\
\hline \multirow[t]{3}{*}{ Kyiv } & House B17 & & & 0.41 \\
\hline & House B17 - Pit & & & 0.45 \\
\hline & Mega-Structure (wks 1 \& 8) & & & 0.38 \\
\hline $\begin{array}{l}\text { NB this } \\
\text { excludes } \\
\text { wet-sieved } \\
\text { material }\end{array}$ & & & & \\
\hline
\end{tabular}




\subsubsection{Quantification}

The sole quantification method used here is Number of Identified Specimens (NISP, aka fragment count), since reliable calculations were not possible for Minimum Numbers of Individuals (MNI) and related measures when working from previously recorded data. MNI is, in our view, of limited use at a settlement scale in any case, but its impossibility here is regrettable from the point of view of comparisons with other sites in the region (see below). The inability to calculate minimum numbers for specific elements, meanwhile, severely limits the potential to examine anatomical representation.

\subsubsection{Burning and Taphonomic Modification}

Different analysts used slightly different terminology for burning and other surface modifications, making it difficult to compare results. In order to track frequencies of burning across certain areas of the site, we therefore simply collapsed the range of descriptions to 'burnt' or 'unburnt'.

\subsubsection{Measurements}

Few metrical data are available for the Nebelivka fauna. Only Gidney provided metrics along with standard von den Driesch (1976) codes, but this amounted to just fifteen specimens, the majority of which are cattle. Sekerskaya (2017) reports a further small number of cattle measurements, with generic descriptions, that can probably be equated with von den Driesch codes. No key was available for the coding system used by Schwartz and Tóth. Log Size Index (LSI) values were calculated for cattle following Meadow (1981), using the Ullerslev Cow (Degerbøl \& Fredskild 1970) as the standard.

\subsubsection{Age Data}

While Gidney provided information on proximal and distal fusion explicitly, Sekerskaya and Schwartz and Tóth only gave relative age classes ('juvenile', 'subadult', etc.). Coupled with portions present, it was often possible to reconstruct fusion data from these relative ages, but this was not consistent and hence the results are not deemed systematic enough to be reliable. Only Gidney provided details of dental wear stages, resulting in samples of fewer than ten mandibles per species that could be assigned to mandibular age stages following Payne (1973). Accordingly, no analysis of age-at-death is conducted here, although the results reported by Sekerskaya (2017) can be consulted. 


\subsubsection{Taxonomic Frequencies}

Table 5.14 shows taxonomic frequencies by excavation area, with the overall assemblage summarised in Figure 5.49/upper. The vast majority of specimens identified were large mammals, dominated by the main Neolithic domesticates (cattle, pig, sheep, goat, and dog - collectively making up 93.8\% of identified fragments) and especially cattle (62.0\% alone). The range of presumably hunted taxa is rather small, including red and roe deer, aurochs, equids, hare, turtle but no wild carnivores with the possible exception of wolf and apparently no wild pigs (see below). Fish and bird bones were very rarely recovered, even in wet-sieved material, while the small number of rodent specimens recorded by the present authors includes at least one vole, hamster (Cricetus cricetus) and ground squirrel (Spermophilus sp.) - the latter identified with the aid of images in L. Popova (2016). Hamsters and ground squirrels are burrowing taxa that are likely to be intrusive, though not necessarily significantly post-dating occupation.

\subsubsection{Identification Issues}

In general, the shared use of Linnaean taxonomy makes comparison of different analysts' taxonomic identifications straightforward. Potential complications arise, however, with (a) sheep versus goat identification; (b) the potential presence of wild and domestic forms of cattle (Bos), pigs (Sus), and Canis; and (c) equids.

Sheep and goat identifications are reported as given in the first instance, but are combined into a general 'Ovis/Capra' category for subsequent analysis due to widely differing identification rates and likely asymmetry in the identifiability of sheep and of goat depending on criteria used (Zeder \& Lapham 2010; see also reasoning in Orton, D. et al. 2016, p. 5).

The separation of wild and domestic specimens is also problematic. While Schwartz and Tóth explicitly recorded all Bos and Sus specimens as belonging to the domestic form (with the sole exception of a vertebra recorded only as 'cattle', which is in any case treated here as non-diagnostic-see above), Gidney and Armstrong recorded specimens simply as 'Bos' or 'Sus'. Sekerskaya, meanwhile, recorded the vast majority of cattle, and all pigs, as 'domestic', with only a handful of aurochs separated out. No analyst definitively identified any pig specimen as wild.

Cattle from Nebelivka were probably overwhelmingly domestic, given the Sekerskaya and Schwartz and Tóth results and the generally low contribution of aurochs at Trypillia sites (see e.g., Zhuravlev 2008). Further limited support for this is provided by the small number of available LSI measurements for cattle (Fig. 5.49/ lower): the majority of measured specimens are clearly smaller than the standard - a small Danish female aurochs - with two only slightly larger. Some additional 


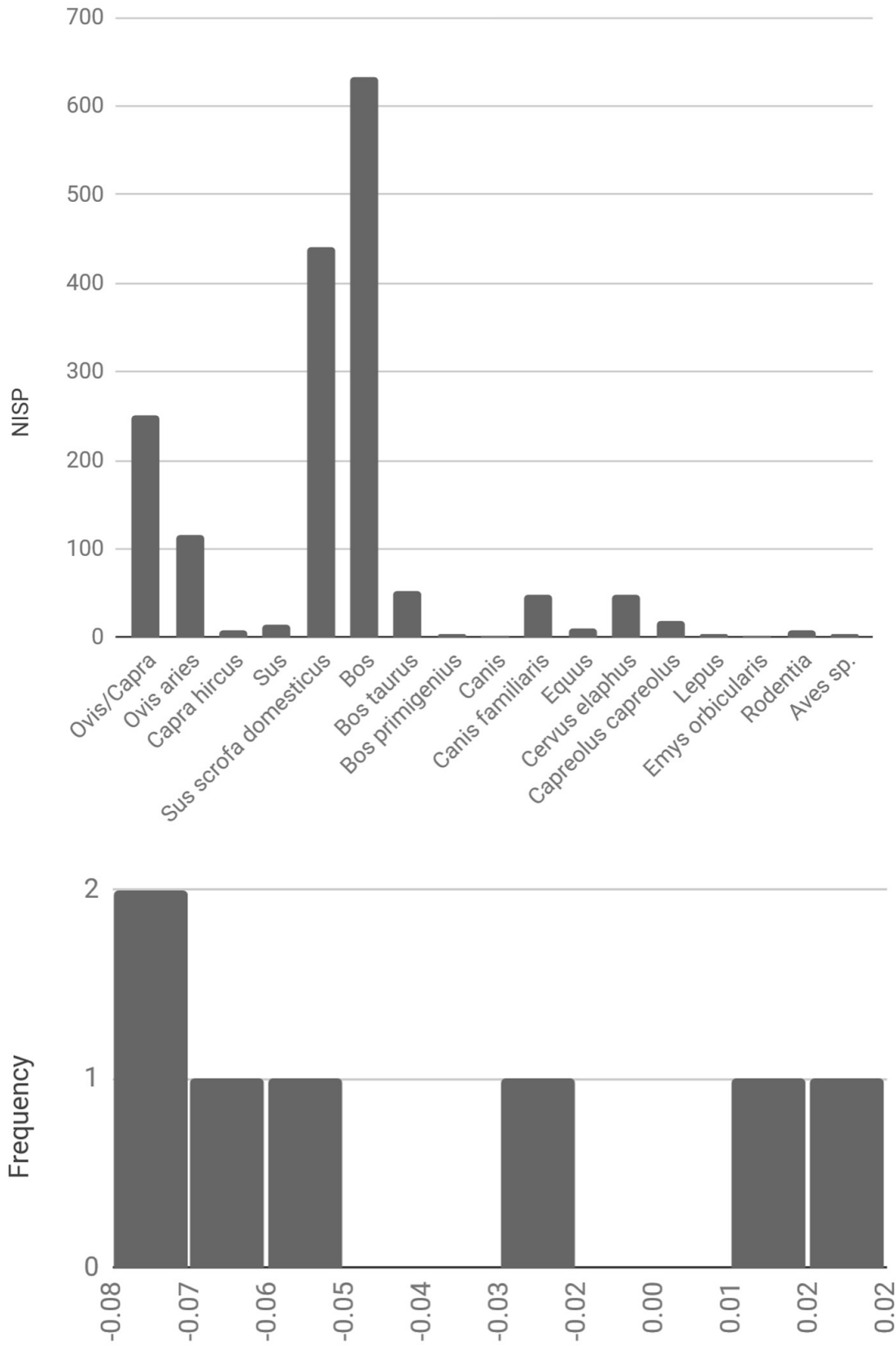

LSI

Figure 5.49: Upper: overall taxonomic distribution of faunal remains (NISP); lower: Distribution of Log Standard Index (LSI) values for measurements on cattle bones (by D. Orton). 


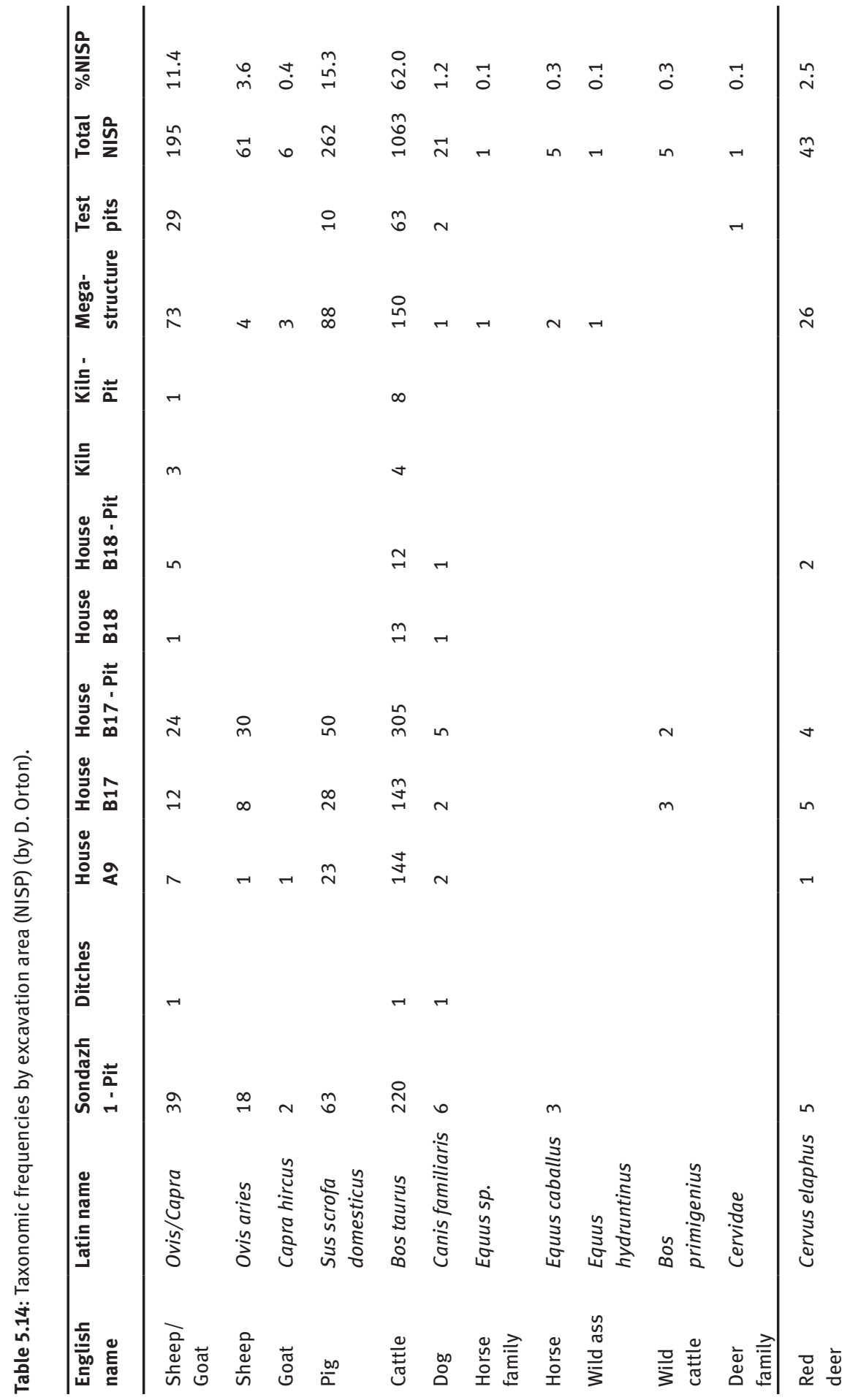




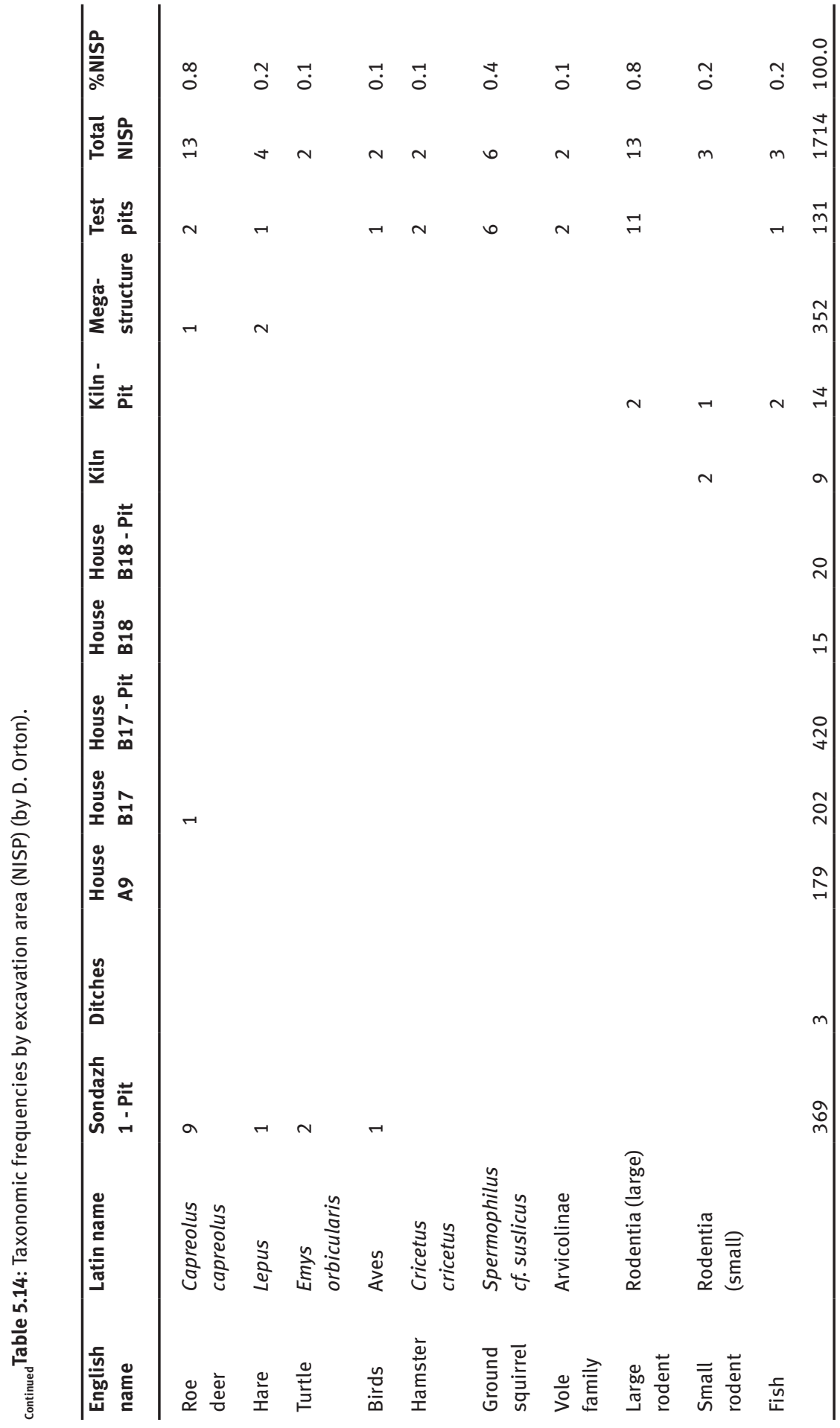


aurochsen may be hidden within the indeterminate 'Bos' specimens, but these are unlikely to change the overall picture considerably. The same case can be made for pigs, which were overwhelmingly recorded as definitively domestic, but here the absence of definitive wild specimens is more surprising since they are present in almost all comparable assemblages, often in greater numbers than their domestic counterparts.

The majority of Canis specimens was recorded by Sekerskaya, who identified them as domestic dog, Canis familiaris. Schwartz and Tóth, and Gidney, recorded one Canis specimen each, without indicating domestication status. In the absence of any positive identifications of wolf, it seems reasonable to assume that all, or nearly all, canid specimens represent domestic dog.

Finally, equids were recorded variously as horse (Equus caballus), wild ass (Equus hydruntinus), and indeterminate equid. Given the recent demonstration that even experienced researchers cannot reliably distinguish these taxa, even using teeth (Twiss et al. 2017), they are all treated as Equus sp. from here on. The domestication status of horses at Nebelivka is unclear (Sekerskaya 2017, p. 21).

\subsubsection{Regional Comparisons}

Zooarchaeological data from Ukrainian Trypillia sites have previously been collated by Zbenović (1996), Kruts (2002), Videiko \& Burdo (2004), and Zhuravlev (2008). Of these, only the last-named lists raw data in NISP form that be used for direct comparison with the Nebelivka results. Additional data for Romanian Cucuteni sites come from Bejenaru and colleagues (Bejenaru \& Stanc 2011, 2012; Bejenaru et al. 2011; Oleniuc \& Bejenaru 2011). Figure 5.50/upper shows the sites used for comparison here, after applying a minimum NISP cut-off of 300, while Figure 5.51 summarises these data by broad chronological phases: (1-2) Trypillia A and BI (3-4) Trypillia BII-CI (i.e. the period of the megasites), and (5-6) Trypillia CII, including sites listed as "CI-CII".

A trend from hunted taxa to the major domesticates over the course of the Trypillia period has been previously noted (Kruts 2002; Kirleis \& Dal Corso 2016) but is not clearly apparent in this dataset, with variation in the wild:domestic ratio appearing to be geographical as much as temporal (NB equids have been separated here due to ambiguities over their domestication status: see also Sekerskaya 2017, pp. 20-21). Hunting generally seems to play a bigger role in Western areas than in the East, with domesticates particularly dominant in the core megasite region around Uman, where Nebelivka's ca. 94\% domestic fauna is consistent with neighbouring sites. ${ }^{96}$ A low relative contribution of wild meat might be expected at such large sites a priori, simply

96 Dal Corso et al. (2019, p. 7) report 98\% domestic species, with ten times the bone weight of cattle in comparison to either caprines or pigs, in a sample of 1,334 bone fragments from Majdanetske. 

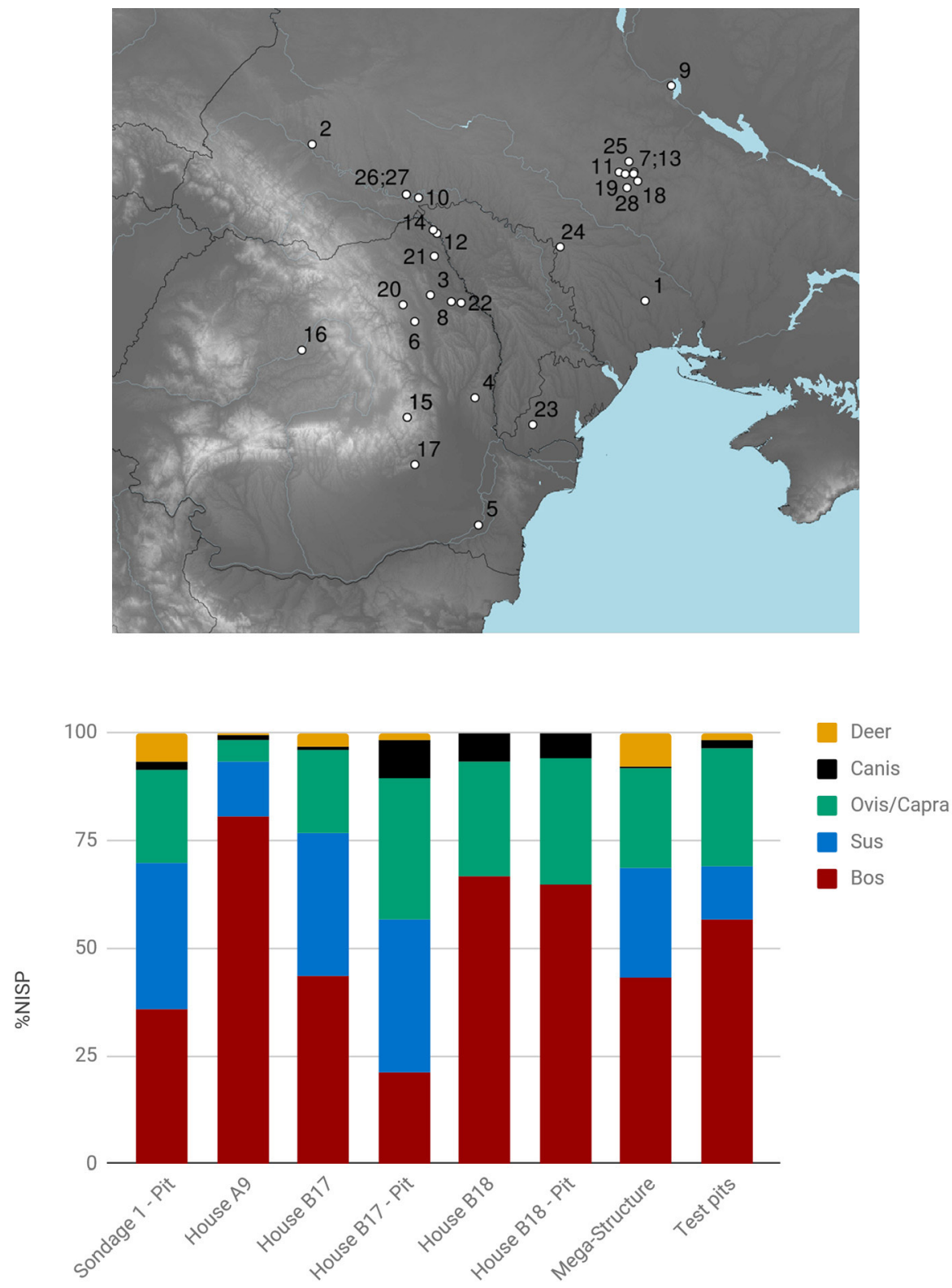

Figure 5.50: Upper: Trypillia and Cucuteni sites with raw NISP available and used for comparison here. 1. Berezivka, 2. Bilshivtsi, 3. Cucuteni, 4. Draguşeni, 5. Feteşti, 6. Ghelăieşti, 7. Maidanetske, 8. Hoiseşti, 9. Ignatenkova Gora, 10. Konovka, 11. Kosenivka, 12. Liveni, 13. Grebenyukov Yar, 14. Mitoc, 15. Poduri-Dealul Ghindaru, 16. Santana de Mureş B, 17. Sarata-Monteoru, 18. Sverdlikove, 19. Taljanki, 20. Târpeşti, 21. Truşeşti, 22. Valea Lupului, 23. Vasylivka, 24. Velyka Slobidka, 25. Vesely Kut, 26. Zhvanets-Shovb, 27. Zhvanets, 28. Nebelivka; lower: main taxa identified at Nebelivka by excavation area (\%NISP) (by D. Orton). 

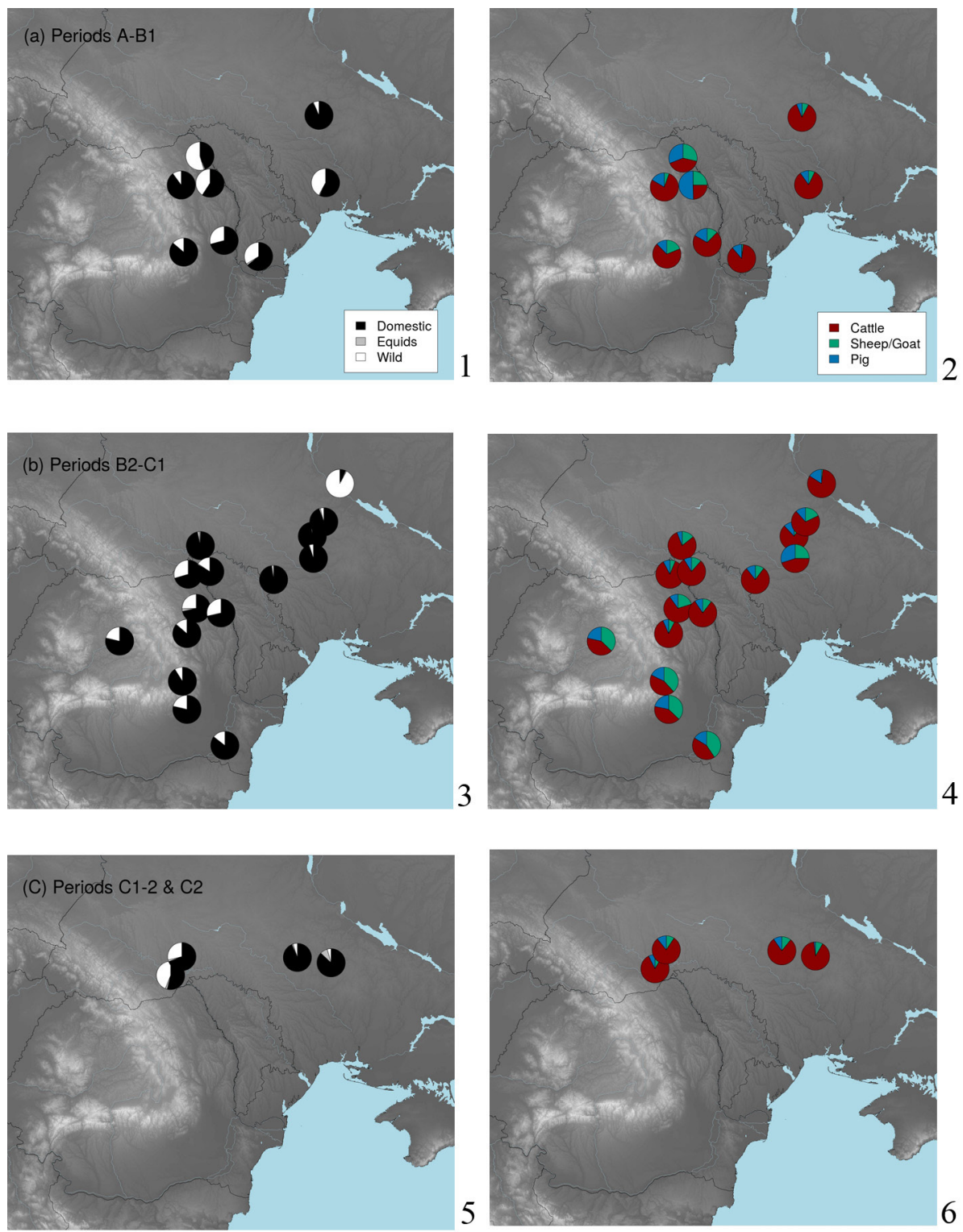

Figure 5.51: Contributions of wild versus domestic taxa $(1,3 \& 5)$ and breakdown of the main domesticates (2, 4 \& 6) for Trypillia and Cucuteni sites in the Early (1-2), Middle (3-4), and Late (5-6) Phases as defined in the text (by D. Orton). 
due to limits on the amount of game that could be caught within a practical distance from the site. That said, this broad regional pattern appears to hold both before the megasites and in the period of their decline, albeit based on limited data.

Breaking the domestic component down into the three main taxa (cattle, pigs, and sheep/goat), regional trends again appear at least as prominent as temporal ones. Cattle are the dominant taxon at most sites in all periods. The exceptions in the early period are two sites in North-Eastern Romania, Hoiseşti and Truşeşti, which have - respectively - a dominance of pig and a fairly even split in the domestic fauna (although this would still mean that cattle provided the most meat in all cases). In the middle period, the four South-Westernmost Cucuteni sites in the dataset stand out as having similar numbers of sheep and of cattle specimens, while sites across the rest of the region have fairly uniform cattle-dominated assemblages. The few assemblages in the dataset from the late period are uniformly cattle-dominated, with no sign of the shift towards sheep and goats observed elsewhere (e.g., Kruts 2002) and argued to represent the development of more extensive pastoralism (Diachenko 2016a).

To summarise, the overall results from Nebelivka are consistent with the broader regional picture in terms of both the wild:domestic ratios and of the balance of domestic taxa.

\subsubsection{Intra-Site Comparisons}

Figure 5.50/lower plots the main taxa identified at Nebelivka by excavation area, excluding wet-sieved material and the smallest samples. Some variation is seen across the site, with some areas - notably House A9 - being heavily dominated by cattle, and others - particularly the Mega-structure and some of the pits - having much higher percentages of the smaller domesticates. The assemblages from House B17 and its associated pit are very similar, perhaps confirming the association between these two features, although the route by which bones became included in the burnt house remains is unclear - particularly in the absence of data on burning - so this conclusion remains tentative. The samples from House B18 and its pit are really too small to be reliable, but are included for comparison. Even given the small sample sizes, the absence of pigs (which make up $15.3 \%$ of the overall site assemblage) in both features is notable.

Given the variable identification rates noted above, it is necessary to assess possible inter-analyst and inter-excavation-team differences. To this end, Table 5.15 compares (a) two assemblages from the Mega-structure, excavated by different teams and recorded by different analysts; and (b) Sondazh 1 and the House B17 pit - two similar features excavated by different teams but both recorded by Sekerskaya. Figure 5.52/1 presents the same comparisons visually, for the main taxa only. Unfortunately, there was no case in which excavation team could be held constant across large samples recorded by different analysts. 
Table 5.15: Comparison of taxonomic frequencies between areas and analysts (NISP) (by D. Orton).

\begin{tabular}{|c|c|c|c|c|c|}
\hline (a). & Mega-structure & & (b). & Sondazh 1 - Pit & House B17 - Pit \\
\hline Team & Joint & Kyiv & & Durham & Kyiv \\
\hline Analyst(s) & Schwartz \& Tóth & Sekerskaya & & Sekerskaya & Sekerskaya \\
\hline Ovis/Capra & 66 & 7 & & 31 & 24 \\
\hline Ovis aries & 1 & 3 & & 18 & 30 \\
\hline Capra hircus & 3 & & & 2 & \\
\hline Sus scrofa dom. & 65 & 23 & & 61 & 49 \\
\hline Bos taurus & 53 & 97 & & 205 & 302 \\
\hline Canis familiaris & 1 & & & 6 & 5 \\
\hline Bos primigenius & & & & & 2 \\
\hline Equus sp. & 4 & & & 3 & \\
\hline Cervus elaphus & 24 & 2 & & 5 & 4 \\
\hline Capreolus capreolus & 1 & & & 9 & \\
\hline Lepus europaeus & 2 & & & 1 & \\
\hline Emys orbicularis & & & & 2 & \\
\hline Aves & & & & 1 & \\
\hline Total & 220 & 132 & & 344 & 416 \\
\hline
\end{tabular}

Two main observations can be made here: first, the number of taxa reported from the jointly or Durham-excavated areas is considerably higher than from the Kyivexcavated areas, even where the analyst is the same and the Kyiv sample is larger. Since the additional taxa are mostly fairly small, this might reflect differences in bone recovery. Secondly, there is a marked difference in taxonomic composition between the two samples from the Mega-structure, with cattle dominating in the Kyiv (week 8) portion studied by Sekerskaya, but trailing pigs and caprines in the jointly excavated portion (weeks 2-7) studied by Schwartz and Tóth. It is impossible to say for sure to what extent this relates to excavation methodology or to recording protocols and inter-analyst variation, but the similarity in results obtained by Sekerskaya for the two pits points to the importance of the latter.

In order to remove this inter-observer effect, Figure 5.52/2 compares excavation areas using only data recorded by Sekerskaya. The immediate impression is of similarity, with cattle dominating across the board, though in fact the contribution of caprines ranges widely, from $5 \%$ in House A9 to $15 \%$ in the Sondazh 1 Pit. This variation might point to functional differentiation, spatial variation in preferences for or access to resources, or perhaps temporal changes within the period of occupation. 

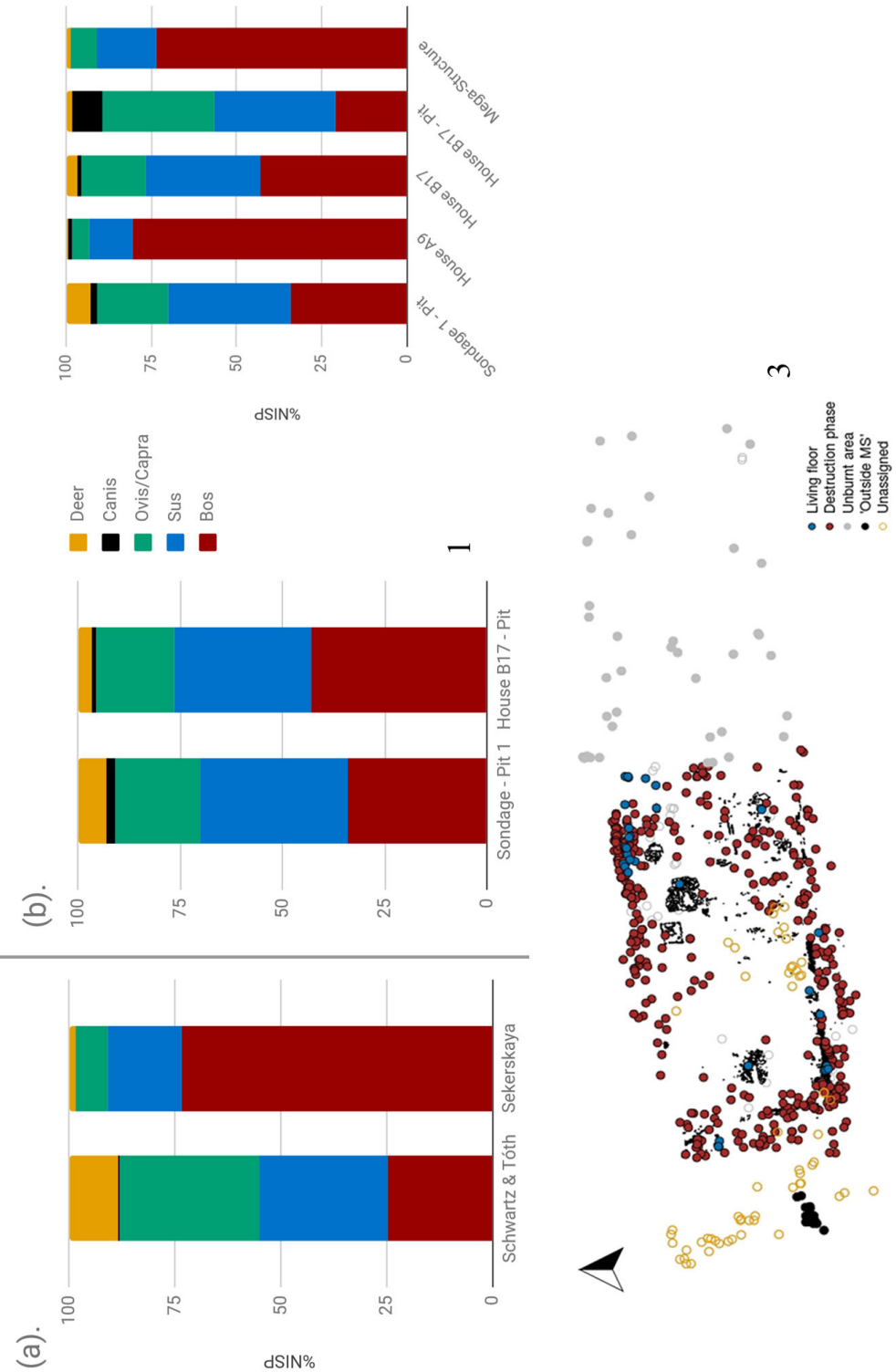

Figure 5.52: (1) comparison of frequencies of major taxa between (a) analysts for the Mega-structure and (b) areas recorded by Sekerskaya (\%NISP); (2) comparison of frequencies of major taxa in areas studied by Sekerskaya (\%NISP); (3) findspots of bones assigned to different phases within the Mega-structure. NB. Each dot shows a total station record that can represent a single or multiple bone fragments (by D. Orton). 
However, any such interpretation must be tempered by the possibility of taphonomic differences, especially between house and pit contexts. In particular, it is not clear how bones found within building remains relate to the use and/or abandonment of those buildings - a topic that is explored below in the context of the Mega-structure - particularly since Sekerskaya did not record evidence for burning. Without more taphonomic data, we cannot rule out, for example, the possibility that some of the bones recovered from the rubble of houses had actually been spread from the associated pits by ploughing or other disturbance.

Whether due to spatial differences in the deposition of animal remains or to inter-observer factors, the amount of variation seen within the recorded assemblage from Nebelivka should be taken as a cautionary tale when comparing data between similar sites. Had only the Mega-structure been excavated, for example, Nebelivka would have stood out from neighbouring sites in terms of the balance of domesticated species (Fig. 5.51/4).

\subsubsection{The Mega-Structure}

During the excavation of the Mega-structure, considerable effort was dedicated to understanding the building's abandonment and eventual destruction by fire, and the relationship of finds to this process. Importantly, there was probably a period of abandonment prior to the final burning and collapse, as indicated by the formation of a thin chernozem between the living surface and the burnt building debris in a number of different areas within the Mega-structure (Chapman et al. 2014). Bones beneath this layer are assumed to represent activity within the building at or immediately after the point of abandonment (Phase 2); those within the burnt debris, or at the interface between chernozem and debris, are assigned to the destruction event (Phase 3). The authors also suggest a final phase (4) of post-destruction deposition.

Table 5.16 shows counts of bone fragments assigned to each of these phases, with findspot locations plotted visually in Figure 5.52/3. The number of bones assigned to the destruction phase is somewhat surprising, but at face value might be taken to indicate significant deposition within the abandoned structure shortly before the burning event. Alternatively, some of these bones may belong to phase 4, perhaps becoming mixed into the destruction debris by subsequent disturbance and recent ploughing.

Bones beneath the chernozem may have been protected from burning to some extent, especially in less intensely burnt parts of the structure, but those that were on the surface within the building at the point of destruction can reasonably be expected mostly to be visibly burnt. Where burning is not evident, bones are likely to represent subsequent activity, i.e. Phase 4. To this end, Table 5.17 compares burning rates and 
Table 5.16: Frequencies of diagnostic and non-diagnostic bone fragments assigned to each phase of the Mega-structure (by D. Orton).

\begin{tabular}{llll}
\hline & Diagnostic & Non-diagnostic & Total \\
\hline Destruction & 123 & 844 & 967 \\
Living Floor & 24 & 423 & 447 \\
Pre-Mega-structure & 2 & 2 & 4 \\
Unattributable & 71 & 296 & 367 \\
Total & $\mathbf{2 2 0}$ & $\mathbf{1 5 6 5}$ & $\mathbf{1 7 8 5}$ \\
\hline
\end{tabular}

distributions between phases of the Mega-structure (excluding bone recorded by Sekerskaya, who did not report burning), and other site areas with reasonable sample sizes. Burning rates are low throughout the structure: 4\% amongst unattributed specimens (mostly from the unburnt portion of the structure); $2 \%$ on the living floor; and $14 \%$ even in the destruction phase. Much higher rates are seen elsewhere on the site, though this comparison should be treated with caution due to differences in recovery strategy and analyst. The low burning rate within the building suggests either that a substantial portion of the bone was deposited after the burning event or, perhaps more likely, that bones within the building were somehow protected from the effects of the fire. Within the burnt portion of the building, burnt fragments are generally present in proportion to the total density of bones, with the surprising exception of the South-West corner (Fig. 5.53/1). This matches the distribution of hightemperature vitrified daub as measured by Shevchenko (see above, Chapter 4.9 and Fig. 4.41).

Table 5.17: Comparison of burning rates within the Mega-structure and with other areas (by D. Orton).

\begin{tabular}{clll}
\hline & Burnt & Unburnt & Burning rate \\
\hline Mega-structure & 146 & 1643 & 0.09 \\
Living Floor & 9 & 438 & 0.02 \\
Destruction & 121 & 845 & 0.14 \\
Unattributable & 13 & 354 & 0.04 \\
Sondazh 1 - Pit & 6 & 96 & 0.06 \\
Test pits & 120 & 537 & 0.22 \\
\hline
\end{tabular}



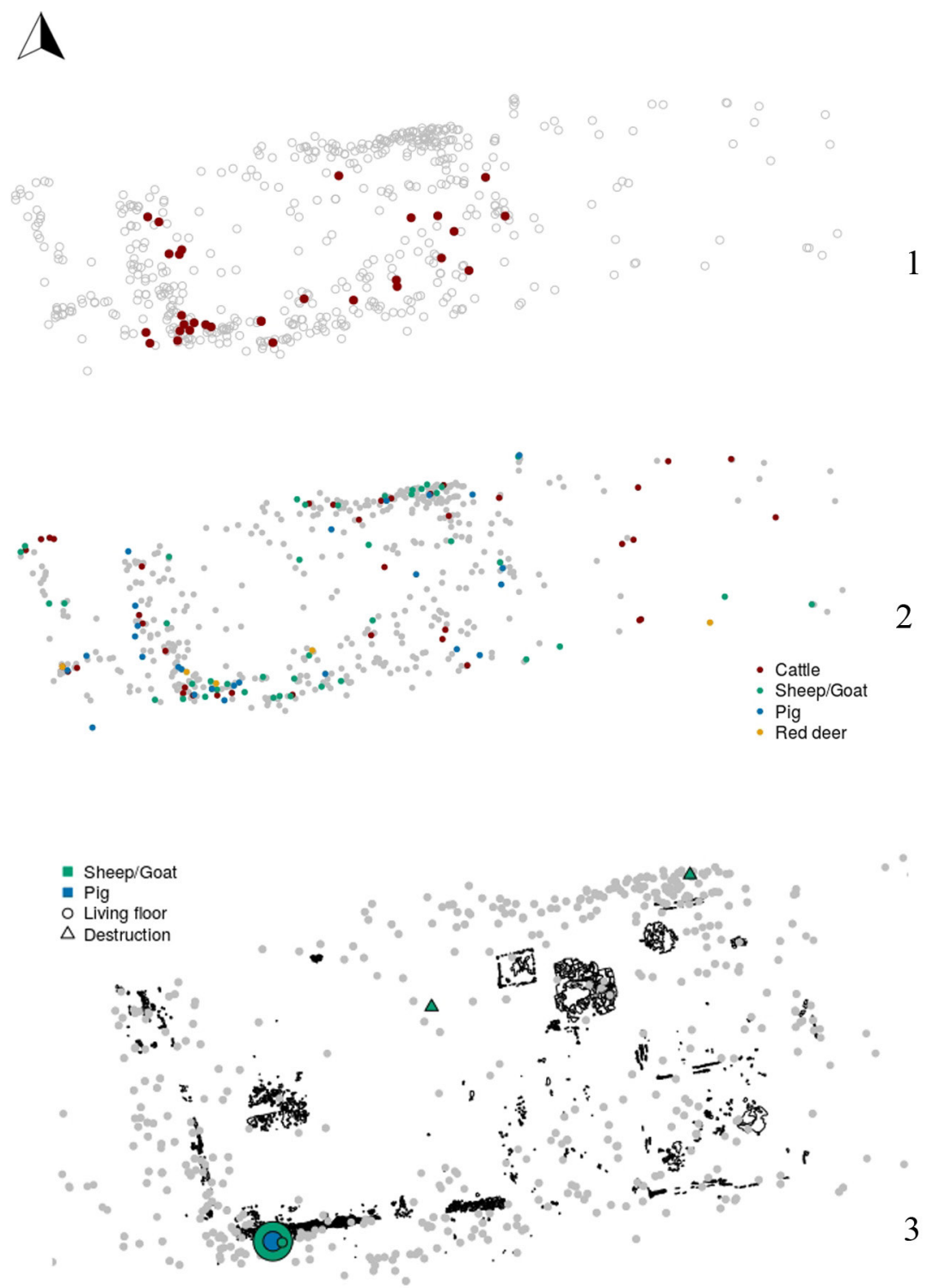

Figure 5.53: (1) findspots of burnt bone within the Mega-structure. As above, single dots may represent multiple specimens; (2) spatial distribution of major taxa within the Mega-structure; (3) foetal/neonatal bones recovered from the living floor and destruction phases of the Mega-structure. Diameter of markers is proportional to number of specimens. Length of burnt part of Mega-structure $-36 \mathrm{~m}$. (by D. Orton). 
The spatial distribution of taxa within the Mega-structure remains does not show any obvious patterning (Fig. 5.53/2); cattle are possibly over-represented within the unburnt area, but this is based on a small sample size. Nor is there any discernible pattern of body part representation. There is an interesting concentration of foetal/ neonatal bones in the South-West corner of the building, however, including remains from at least one pig and at least two sheep or goats - all unburnt and associated with the living floor (Fig. 5.53/3). All diagnostic perinatal bones within the structure are mandibles, apart from an isolated sheep/goat maxilla in the destruction phase and a distal pig humerus within the cluster - a pattern that may simply reflect limited preservation since these are some of the most robust bone portions in the body. Without more detailed information on the taphonomy, treatment, and precise situation of these bones, it is hard to suggest a firm explanation, though the presence of two different species of perinatal bones in the same exact location is unlikely to be coincidental, and may point to deliberate deposition associated with the abandonment of the structure.

\section{Andrew Millard}

\subsubsection{Isotopic Dietary Information}

Supplementary dietary information produced through AMS dating of over 80 animal bone samples led to the plotting of carbon and nitrogen isotopic values (Fig. 5.54). These data indicate that the animal fodder for the domestic suite of caprines, cattle and pigs primarily consisted of a range of $\mathrm{C}_{3}$ plants, which include most naturallyoccurring plants in the region as well as domesticates such as wheat and barley. The $3.5 \%$ orange of $\delta^{13} \mathrm{C}$ suggests variability in fodder plants consumed, including some $\mathrm{C}_{4}$ plant consumption, which might include naturally occurring $\mathrm{C}_{4}$ grasses. This contrasts with the Early Neolithic South Romanian site of Măgura-Boldul lui Moş Ivănuş, where $\delta^{13} \mathrm{C}$ values did not exceed - 19.9\%o (Balasse et al. 2013). As many bones from Nebelivka were not identifiable to species, both wild and domestic animals may be included. The one outlier is a cattle bone clearly indicating maize consumption, that was dated to the 1950s or 1970s AD (OxA-31730). 


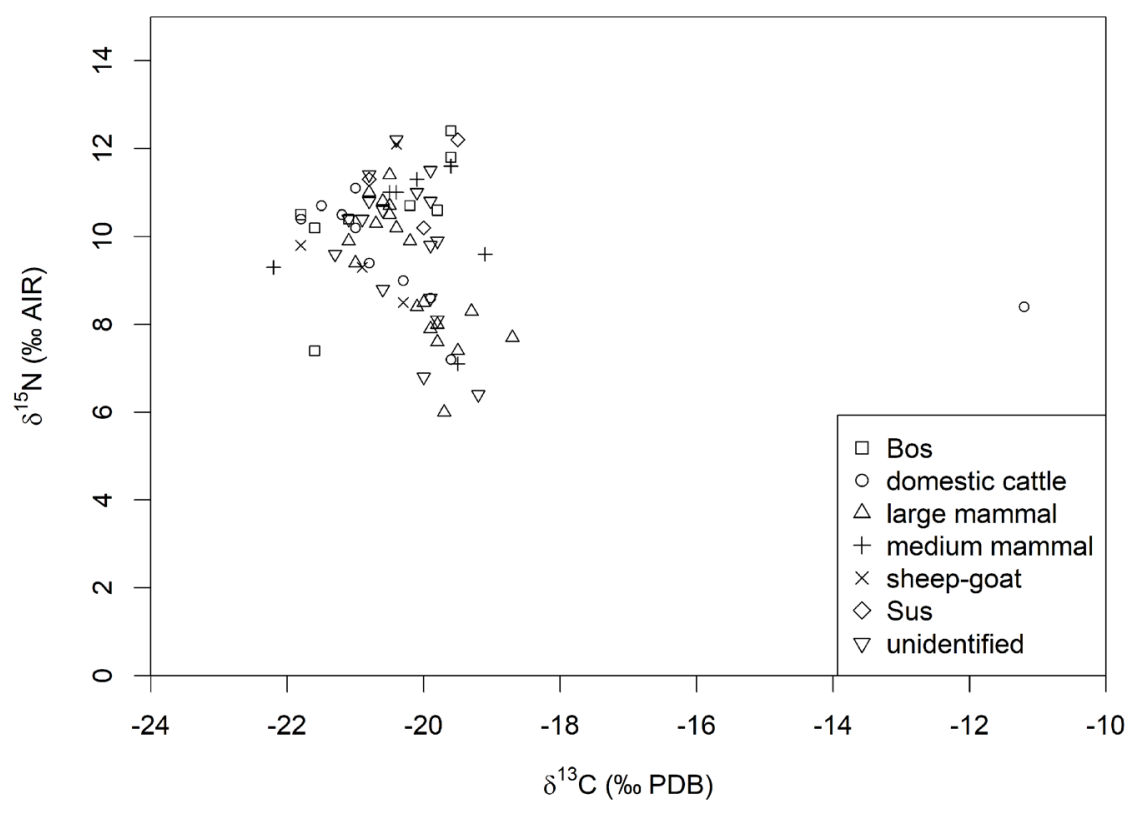

Figure 5.54: Isotopic collagen values, Nebelivka mammals (by A. Millard).

\section{David Orton}

\subsubsection{Summary}

The various zooarchaeological datasets from Nebelivka have been combined, though the secondary nature of this report inevitably limits the depth of conclusions. Nonetheless, some general observations can be made.

First, while differences both in excavation strategy and in analytical protocols appear to have had an effect upon the results, there do also appear to be genuine differences in bone deposition between areas. Cattle remains are extremely abundant in the remains of House A9, for example, while the pit in Sondage 1 contained more of the smaller domestic taxa. These intra-site differences have obvious implications for inter-site comparisons, highlighting the risks in assuming that bones recovered from large and complex settlements, especially from small-scale excavation, are necessarily representative of those sites as a whole. Likewise, the results from the Mega-structure highlight the dangers of variation between analysts and excavation teams.

The processes by which the bone assemblage from the Mega-structure formed remain enigmatic, with the low rate of burning being particularly hard to explain. 
While the small number of bones found on the living floor - including a curious cluster of perinatal lamb and piglet bones - may have been protected from fire by accumulation of sediment during the period between abandonment and destruction, the large number of unburnt bones found within the destruction layer is harder to explain. One possibility is that a significant quantity of these bones was actually deposited on the house after the destruction event, becoming included in the daub layer by subsequent disturbance. This would be a very interesting phenomenon, if correct, but does not accord well with stratigraphic observations in the field.

If the combined recorded fauna from Nebelivka are taken at face value, they indicate that the settlement relied heavily on domestic animals and particularly cattle, in keeping with other nearby Trypillia sites.

\section{John Chapman, Galyna Pashkevych \& Dan Miller}

\subsection{Plant Remains}

\section{John Chapman}

\subsubsection{The 2009 Season}

A wet-sieving operation led by Mr. Ronan O'Donnell was able to process key deposits from House A9. The method used has been developed as a standard for the water-sieving of Ukrainian samples for archaeo-botanical research by Dr. Galyna Pashkevych: a sample of one bucket of standard size was divided into six parts, with each part washed in another bucket five or six times and the light fraction collected before the heavy fraction was retained. For time reasons, some of the samples were washed only three or four times. A total of 11 samples was processed from sealed contexts inside the daub layers and the remains were air-dried in the field base. With the exception of one small grain of Triticum sp., no plant remains were identified. This charred seed was AMS-dated in Poznan (Poz-32552), with the date of $5030 \pm 40 \mathrm{BP}$ showing that it was indeed coeval with the house. This indicates that at least House A9 was kept extremely clean during their occupation. There are two principal candidates for the disposal of the plant remains: (a) the pits which were often dug within $5 \mathrm{~m}$ of the house; and (b) the incorporation of plant remains into the house daub during its manufacture.

\section{Galyna Pashkevych}

\subsubsection{The Mega-Structure (2012)}

The palaeo-ethnobotanical analysis was conducted on soil samples collected during the field season 2012. Wet sieving was carried out on the soil systematically selected from a range of different site contexts. Botanical macro-remains, charcoal 
and different organic materials were separated from soil using the flotation tank constructed by Mr. Mykhailo Videiko Jnr. The samples contained rootlets of modern plants, pieces of charcoal, small fragments of ceramics and daub and rare carbonized grains of cultivated plants. The analysis of samples, identification and measurement of grains was carried out according to a standard laboratory procedure based on the use of a standard lab. microscope (Pashkevych 2014).

The composition of the samples was very diverse. In the course of the microscope study, it was revealed that grains of cultivated plants comprised a very small quantity. The majority of the samples contained practically no grains of cultivated plants. In most cases, the plant remains have been destroyed or damaged during flotation. Sometimes this damage was so serious that there was no possibility of identifying the samples to either species or genus. Individual grains of cultivated plants were found in the samples. Several samples contained only a number of small fragments of grains which cannot be identified.

Grains and seeds of the following cultivated plants were discovered:

- Cereals: emmer (Triticum dicoccon), einkorn (Triticum monococcum), hulled barley (Hordeum vulgare)

- Pulses: lentil (Lens culinaris), pea (Pisum sativum), bitter vetch (Vicia ervilia). Grains of emmer and einkorn are the most frequent among the finds.

Palaeoethnobotanical materials from more than a hundred Trypillia sites have yielded thousands of pottery fragments with impressions of plant remains, hundreds of $\mathrm{kg}$ of clay daub with similar impressions and carbonized grains and seeds. This large data set makes it possible to determine the assortment of plants cultivated by the Trypillia groups (Yanushevich 1989; Pashkevitch \& Videiko 2006; Kirleis \& Dal Corso 2016; Dal Corso et al. 2019). This assortment consisted of hulled wheat: emmer, einkorn and spelt, as well as pulses - pea, lentil, bitter vetch. Thus, the assortment of cultivated plants revealed in the samples from Nebelivka is typical for Trypillia cultivation practices.

In contrast to the restricted finding of grains and pulses, the seeds of weeds and wild plants were present in many samples and in a well-preserved condition. The seeds of white goosefoot (Chenopodium album) and yellow foxtail (Setaria glauca) prevail among the weeds. Other weed species also discovered included: fumitory (Fumaria sp.), lady's bedstraw (Galium aparine), and small seeds of Cruciferae and Brassicaceae of indeterminable genus. Since the good preservation of these seeds suggested recent deposition in the soil, a group of weed seeds was AMS-dated in Oxford, with the result that they were indeed modern in date.

The abundant impressions of plant remains on daub were more informative than the weed seeds. The impressions included the grains of emmer wheat, einkorn wheat and hulled barley, with occasional impressions of well-preserved ears. 
Thus, all these data show that, included in the crops grown by the inhabitants of the settlement of Nebelivka, there was hulled wheat, barley and pulses - peas, lentil and bitter vetch.

\section{Dan Miller}

\subsubsection{The 2013 and 2014 Seasons}

The 2014 season included an extensive palaeo-environmental testing program, with over 285 samples collected and ca. 4,050 litres of deposit processed in the field. This produced a very limited archaeo-botanical (charcoal) assemblage, and the first molluscan (shell) evidence from the site. The extremely low levels of wood charcoal across all features except pits raises a number of unanswered questions about the total amount, life-use, destruction, and taphonomy of charred timber on the site.

In 2014, the author's own version of bucket-flotation/sieving was used, derived from North-West European traditions of wet-sieving and screen-processing. These techniques are especially suited to deposits with low charcoal content, often wet or moist. The method can be extremely efficient, with very high recovery rates, especially of semi-buoyant items, such as sediment-infiltrated charcoal and shells.

It can therefore be stated with certainty that many of the Nebelivka deposits, especially those associated directly with houses, are virtually charcoal-free, including micro-charcoal in silt/clay fractions. Isolated fragments (eg < $1 \mathrm{~mm}$ to $4 \mathrm{~mm}$ ) and sparse wood charcoal only is the norm when charcoal is present. This also applies to the variously charcoal-rich pit layers, where wood-only charcoal accounts for $99.99 \%+$ of all charcoal, and frequently is the only charcoal observed. The extent of timber use, and supply, is an interesting issue, as the molluscan evidence indicates that developed Holocene woodland was never present at the site.

Evidence of cereals and other plants from the 2013 and 2014 seasons at Nebelivka is extremely limited, in line with the paucity of the charcoal assemblage in most features. Similar conclusions were reached in the 2009 and 2012 seasons. Non-wood charred plant remains are remarkably rare - only a single cereal glume-base and no more than 10 scattered possible Trypillia cereal grains were recovered in total between 2013 and 2014. Five charred Rumex sp. and four Atriplex sp. seeds are potentially not introduced from modern burning of fields, and may be archaeological 'weeds'. Additionally, no unambiguous cereal or cereal chaff has been observed in the various impressions, phytolith sheets and 'charcoal skins' in multiple baked daub samples at Nebelivka. Although not fully studied at present and in contrast to Pashkevych's findings, the daub does seem to have contained many small leaf fragments of noncereal grasses, consistent with herbivore dung. No archaeological features or finds can be directly linked to crop processing, and 'off-site' processing must remain purely conjectural as there are no known contemporary 'crop processing' sites or areas for the local region around Nebelivka. Conceptually, the absence of large-scale 
crop processing evidence, with unknown disposal patterns of the products and by-products, is hard to distinguish from a situation where cereal production in total was never very high, or never very large in scale.

\subsubsection{Summary}

The use of wet-sieving, bucket flotation as well as the sectioning of daub to recover plant impressions, led to the discovery of a very modest archaeo-botanical assemblage from a wide range of archaeological contexts - burnt House A9, the Megastructure and Pits in Sondazh 1, near House B17 and near the 'industrial feature'. This assemblage consisted of hulled wheat - emmer, einkorn and spelt - as well as pulses - pea, lentil, bitter vetch. Thus, the assortment of cultivated plants revealed in the samples from Nebelivka is typical for Trypillia cultivation practices. A total of five charred Rumex sp. and four Atriplex sp. seeds may well be Trypillia-age weed seeds. An even smaller charcoal assemblage was also recovered. The paucity of botanical remains is surprising in view of the scale of the investigations and the varied nature of recovery techniques.

\section{John Chapman}

\subsection{Summary}

one damn thing after another ${ }^{97}$

The Nebelivka finds assemblage is at once an utterly typical Trypillia assemblage replete with (in order of frequency) painted pottery, animal bones, grindstones, lithics, figurines/statuettes and a handful of other special finds - yet also a mysterious bricolage of (in)dividual acts of deposition and discard, which raises more questions than it answers. Consider, if you will, the following eight statements:

- a Trypillia board game, played with tokens on a decorated clay board, needs several tokens to play. But a find of more than one token together has yet to be made at Nebelivka. Perhaps the players brought their own tokens, played the game, won or lost, and went away with their own tokens, ready to fight another day?;

- despite the absence of large-scale sherd re-fitting, there remains a stubborn conviction that many of the deposits made in houses-to-be-burnt were sherds -

97 The full quote "Life is just one damn thing after another" is variously attributed to Mark Twain, the aphorist Elbert Hubbard and the journalist Frank Ward O’Malley. 
synecdoches for whole pots, part of which were perhaps placed in another houseto-be-burnt;

- the imbalance of figurine heads at Nebelivka - only three out of a total of 78 fragments - demonstrates the enchainment of person parts with other (not yet excavated) contexts on the megasite or perhaps outside it;

- the fragmentary nature of the faunal remains, with hardly any articulated bones, let alone a complete carcase;

- the absence of a single functionally coherent 'living assemblage' of vessels in any deposit made in the Mega-structure or either totally excavated house;

- the scarcity of burnt animal bones in a so-called Destruction Phase of the Megastructure which was clearly destroyed by burning;

- the discovery of only a handful of charred cereal remains in four seasons of excavations which prioritised flotation;

- the almost complete absence of prestige good deposition in the Mega-structure the largest building known as yet in the Trypillia world.

We cannot, as yet, combine these inter-related sentences about finds classes to make a general narrative of the megasite. What we can suggest is that 'what you see is not what you get' - there are vanishingly few examples of the survival of 'living assemblages' (primary refuse sensu Schiffer 1976). Instead, the archaeology of Nebelivka is an archaeology of selective fragmentation and episodic discard/depositional practices, mediated by principles which we can glimpse but which are rarely in clear focus (e.g., the 'Trypillia Big Other', the rules of ceramic deposition following collective or personal consumption, gender negotiation). We are better placed to identify the scale of these practices from the finds at Nebelivka, which ranges from (in)dividual acts to large-group events.

The individual act is exemplified by the placing of perinatal bones of pigs and caprines in the South-West corner of the Mega-structure, the discard of a red deer incisor bead-pendant already a century old in Mega-structure destruction daub or the deposition of fragments of binocular vessels in House A9. We may not know the identity of the person making the deposits but these were single acts set in the context of multiple other discard acts - "one damn thing after another". At the other end of the scale were the big event of deposition at the base of the Pit in Sondazh 1, the Episodes in the same Pit with fragments of over 40 different vessels and the collapse of a shelf in one of the Eastern rooms of the Mega-structure which led to the group of 21 miniature vessels. While remaining anonymous, the Pit deposits betoken collective action between more than one household and perhaps as large a social group as a Neighbourhood. Key ceramic ratios (open forms: closed forms; plates: dishes) can be used to prioritise discard after collective or (in)dividual consumption acts. The largest collective event concerned the destruction by fire of the biggest building - the Megastructure - with an estimated minimum number of 332 vessels placed in the building before burning over an unclear period of time. The cumulative effect of all of these 
forms of discard and deposition, in all their diversity of (in)dividual and collective agencies, was the 'final assemblage' that is available in the 21st century AD to posthoc comparative analysis.

We can also begin to identify usually ignored linkages between different data sets, as in the discovery of the leaf fragments of non-cereal grasses in house daub, consistent with the making of daub with herbivore dung. It has long been known that cereal remains were incorporated into house daub (Yanushevich 1989) but now we can link herbivores, as well as lithic, bone, shell and ceramic fragments, to the making of Trypillia houses. We can extend the link between pottery and house wall decoration to include the use of graphite. And we can show that both finely-made imported (Volhynian) flint and carelessly knapped local flint were both deposited in the biggest building on Nebelivka. These enchainment practices are best exemplified by the distribution of pottery decorative motifs, which criss-crossed the megasite, mimicking the movement of people and the selective deposition that lies at the heart of Nebelivka, while at the same time - slowly, cumulatively - creating the social environment of the megasite itself. 